\title{
Electrical remodeling and management of atrial fibrillation : experimental studies in the chronically instrumented goat
}

Citation for published version (APA):

Duytschaever, M. (2002). Electrical remodeling and management of atrial fibrillation : experimental studies in the chronically instrumented goat. [Doctoral Thesis, Maastricht University]. Universiteit Maastricht. https://doi.org/10.26481/dis.20021213md

Document status and date:

Published: 01/01/2002

DOI:

10.26481/dis.20021213md

Document Version:

Publisher's PDF, also known as Version of record

Please check the document version of this publication:

- A submitted manuscript is the version of the article upon submission and before peer-review. There can be important differences between the submitted version and the official published version of record.

People interested in the research are advised to contact the author for the final version of the publication, or visit the DOI to the publisher's website.

- The final author version and the galley proof are versions of the publication after peer review.

- The final published version features the final layout of the paper including the volume, issue and page numbers.

Link to publication

\footnotetext{
General rights rights.

- You may freely distribute the URL identifying the publication in the public portal. please follow below link for the End User Agreement:

www.umlib.nl/taverne-license

Take down policy

If you believe that this document breaches copyright please contact us at:

repository@maastrichtuniversity.nl

providing details and we will investigate your claim.
}

Copyright and moral rights for the publications made accessible in the public portal are retained by the authors and/or other copyright owners and it is a condition of accessing publications that users recognise and abide by the legal requirements associated with these

- Users may download and print one copy of any publication from the public portal for the purpose of private study or research.

- You may not further distribute the material or use it for any profit-making activity or commercial gain

If the publication is distributed under the terms of Article $25 \mathrm{fa}$ of the Dutch Copyright Act, indicated by the "Taverne" license above, 
Electrical Remodeling and Management of Atrial Fibrillation 
(1) Mattias Duytschaever. Maastricht 2002

vormgeving en druk: Leieland / Sint-Martens-Latem 


\title{
Electrical Remodeling and Management of Atrial Fibrillation
}

\author{
Experimental Studies \\ in the Chronically Instrumented Goat
}

\author{
Proefschrift
}

ter verkrijging van de graad van doctor

aan de Universiteit Maastricht,

op gezag van de Rector Magnificus, Prof. dr. A.C. Nieuwenhuijzen Kruseman,

volgens het besluit van het College van Dekanen,

in het openbaar te verdedigen

op vrijdag 13 december 2002 om 14.00 uur

door

Mattias Duytschaever

Geboren te Gent op 31 december 1970 


\section{Promotor:}

Prof. dr. M.A. Allessie

Beoordelingscommissie:

Prof. dr. H.J.G.M. Crijns

Prof. dr. H.J.J. Wellens

Prof. dr. M.J. Janse

Prof. dr. L. Jordaens

Prof. dr. H.A.J. Struijker Boudier

This study was supported by a grant of the Belgian Organization for Scientific Research (F.W.O).

Financial support by Medtronic and Guidant for the publication of this thesis is gratefully acknowledged. 


\section{Dankzij mijn Ouders}

Voor Belleke en Charles 



\section{Contents}

CHAPTER 1 Introduction: 9

Atrial Fibrillation: The Oldest Arrhythmia-The Newest Disease

Atrial Fibrillation: The Otden Armythmia-The Newest Disease

CHAPTER 2 Repetitive Atrial Electrical Remodeling:

No Cumulative effect of Repeated paroxysms of AF.

J Cardionase Electnophysiol, 1999;10:1101-1108.

CHAPTER 3 Widening of the Window of Inducibility of AF by Electrical

Remodeling: Time course and Mechanisms.

Pacing Clin Electrophysiol, 2000:23: 730 (ahstrua).

CHAPTER 4 A Supervulnerable Period after Termination of Atrial Fibrillation.

$J$ Candiovase Electrophysiol. 2002:13:267-275.

ChAPTER 5 Is there an Optimal Pacing site to Prevent Atrial Fibrillation?

An experimental study in the chronically instrumented goat.

J Candiowasc Electmphysiol, 2002; 13:(december issue).

CHAPTER 6 Pro-fibrillatory effects of Verapamil but not of Digoxin in the Goat Model of Atrial Fibrillation.

$J$ Candiovase Electrophysiol, 2000:11:1375-1385.

CHAPTER 7 Methods for Determining the Refractory period and Excitable Gap during Persistent Atrial Fibrillation in the Goat.

Circulation. 2001:104:957-962.

ChAPTER 8 General Discussion:

New Perspectives for Atrial Fibrillation.

NAWOORD 

Chapter 1

\section{Introduction}

\section{Atrial Fibrillation:}

The Oldest Arrhythmia - The Newest Disease. 
"The notion of a patient continuing to live with an auricle incapable of contraction is a somewhat novel idea...it seems necessary to devote a little study to the condition

Thomas Lewis (1902). 


\section{Natural History of Atrial Fibrillation}

\section{THE OLDEST ARRHYTHMIA}

Atrial fibrillation was a cause of speculation by physicians since early times. Initially it was referred to as rebellious palpitations, delirium cordis and pulsus irregularis pepetuus.' In 1902, James MacKenzie provided the first insight into the mechanism of the pulsus irregularis perpetuus. In the "Study of the Pulse", he published a report showing that during the irregular heart rhythm the jugular "A wave" was lost. This provided the first insight into the mechanism of auricular fibrillation. Similar venous and arterial pulse recordings were made by Cushny. Edmunds and Lewis in directly observed auricular fibrillation." In 1909. Thomas Lewis, taking advantage of Einthoven's newly developed galvanometer, was the first to establish electrocardiographically that auricular fibrillation was the cause of pulsus irregularis perpetuus (Fig. 1).' As for auricular fibrillation, along the way it became "atrial fibrillation" or "atrial fib" and sometimes it is respectfully referred to as the grandfather of arrhythmias.
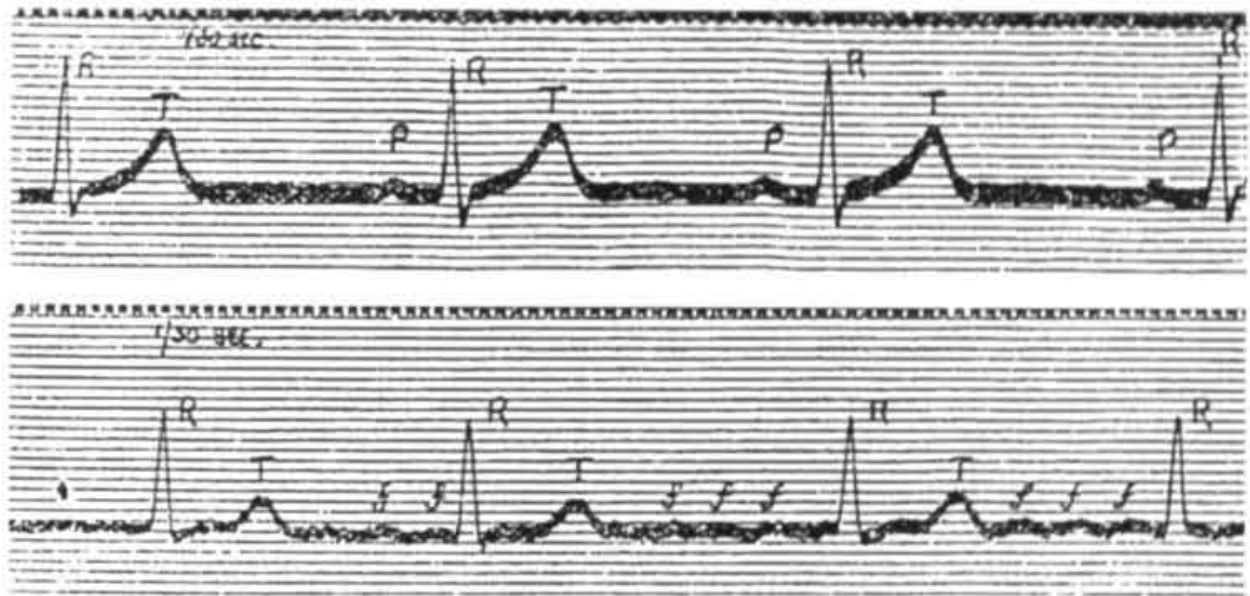

Figare I. Electros andiogrums reconted by Thomas Lewis showing sinus thvthm in a normal patient (upper panel) and auricular fibrillation in another patient (lower panel). Fibrillating (f) waves are demonstruted

\section{THE MOST COMMON ARRHYTHMIA}

With 500 million people in the European Union, and a prevalence rate approaching $2 \%$, the number of people with AF can be estimated to be around 10 million." The median age of patients is 75 years with $84 \%$ are older than 65 years. The incidence and 
prevalence of AF is expected to increase as the global demographic tide will result in a marked increase of the elderly population.' Indeed, Braunwald, in his Shattuck lecture, referred to the growing "epidemic" of AF." The genesis of this epidemic is not only due to changes in the age-distribution of the population. The Framingham study found an increasing prevalence of $\mathrm{AF}$ even after adjusting for age. ${ }^{10}$ Underlying explanations remain speculative and may be multi-factorial. Since 10 to $35 \%$ of patients with $\mathrm{CHF}$ develop $\mathrm{AF}$, the increasing number of patients with $\mathrm{CHF}$ may play an important role." Indeed, atrial fibrillation and heart failure represent the intersection of two common diseases, both of which have been labeled "new epidemics". .12 Notwithstanding the increasing numbers of patients with $\mathrm{AF}$, there is a strong likelihood that the incidence and prevalence of $\mathrm{AF}$ are even substantially underestimated. In the Stroke Prevention in Atrial Fibrillation study (SPAF-III) approximately $45 \%$ of patients had AF detected incidentally when electrocardiography was performed for an unrelated reason." In patients with symptomatic paroxysmal $\mathrm{AF}$, there is a $12: 1$ ratio of asymptomatic versus symptomatic episodes." Indeed, Camm referred to silent atrial fibrillation as being another Pandora's box. ${ }^{15}$

\section{A TROUBLESOME ARRHYTHMIA}

Atrial fibrillation has a marked effect on morbidity and mortality. Also its socioeconomic consequences due to hospital admissions, chronic disease management and disabilities are substantial. Atrial fibrillation is known to be an independent risk factor for stroke. in is Overall, it is associated with a 4- to 5-fold higher risk of stroke," and the major cause of embolic stroke. Besides major thromboembolism. AF is also associated with intermittent ischemic attacks or even silent cerebral infarcts. According to magnetic resonance images, $40 \%$ of AF patients have one or more cerebral infarcts. ${ }^{193}$ These may cause develop apparently unaccountable neurological symptoms, ranging from forgetfulness to frank dementia. The impact of AF on mortality was less clear. However, recently the Framingham study showed that the presence of AF independently increased the risk for death in men (Odds ratio:1.5) and women (Odds ratio:1.9). Especially in patients with LV dysfunction. AF was found to have a detrimental role. In the Studies Of Left Ventricular Dysfunction (SOLVD) trials, the presence of AF was a powerful independent predictor of death due to pump failure and re-hospitalization for $\mathrm{CHF}^{21}$

\section{THE NEWEST DISEASE}

Although the oldest arrhythmia, for some reasons atrial fibrillation seems the newest disease. The degree of interest in AF, as distinct from other forms of arrhythmias, has 
increased significantly in recent years. This is illustrated in Fig.2, in which we plotted the number of full papers on AF published in Cinculation from 1950-2000. It is clear that especially during the last decade, research was performed on atrial fibrillation. It is difficult to say what caught the attention of the cardiologist, arrhythmologist or physiologist. One explanation for this may be the fact that the successful treatment of ventricular arrhythmia and other forms of supraventricular tachycardia turned the attention of cardiologists to the remaining challenges in arrhythmia management. More likely however is the increased awareness of the considerable prevalence and morbidity of AF and that $\mathrm{AF}$ is just not an acceptable alternative to normal sinus rhythm.

Nunber of papers in

Circulation

30

20

10

0

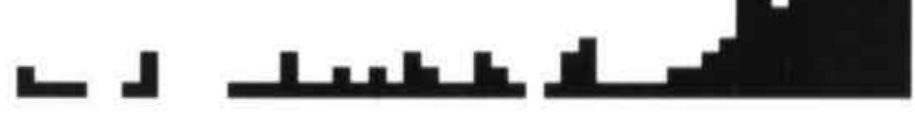

1950

1960

1970

1980

1990

2000

Year of Publication

Figure 2. Number of papers on atrial fibrillation published in Cirrulation between 1950 and 2000. Only during the last decade, the degree of interest in AF has increased significantly.

\section{Treatment Options in Atrial Fibrillation: From Drugs to Devices}

The evolution of treatment strategies in atrial fibrillation is summarized in Fig. 3. Clearly, with time there is a gradual shift towards rhythm control with non-pharmacological means to treat atrial fibrillation. 


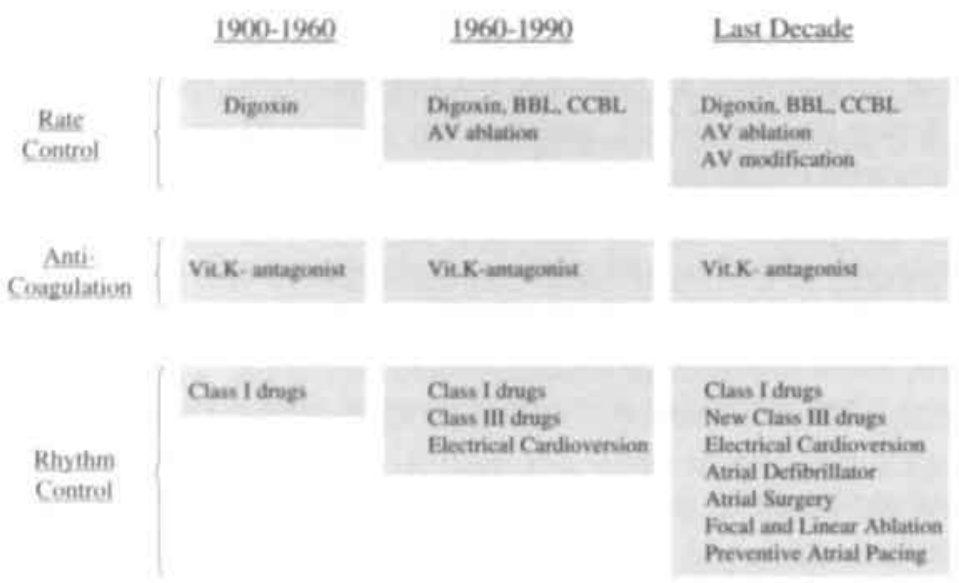

Figure 3. Evolution of therapeutic opfioms in atrial fibrillation. With time there is a grad. ual shift tonsands restonation of sinus rhythm (rhythm control) and non-pharmacological means to treat atrial fibrillation.

\section{0-1960}

In the first half of the previous century the comerstones for pharmacological treatment of AF were digoxin, anticoagulation and quinidine. In "the management of acute cardiac emergencies" De La Chapelle et al. give a point of view on the treatment of auricular fibrillation in 1951." Most clinicians digitalized patients "who show signs of heart failure or who have a rapid ventricular rate as result of auricular fibrillation". In addition. anticoagulation was administered "since, with this treatment the tendency for the deposition of mural thrombi and therefore of embolism can probably be diminished." To restore sinus rhythm "the initial treatment should include physical and mental rest obtained by means of a sedative (preferably a barbituratic acid derative). Quinidine is usually effective in converting paroxysmal auricular fibrillation to normal sinus rhythm and is considered by most clinicians to be the drug of choice for this purpose, regardless of the underlying type of heart disease."

So at the end of the first half of the previous century, treatment of AF seemed strikingly similar to actual treatment currently applied in the majority of patients with AF. Also the incremental benefit of rhythm control was acknowledged. ${ }^{\text {ए }}$ This was beautifully illustrated by Sokolow et al. who showed that cardioversion of AF resulted in marked clinical improvement. as expressed by a decrease in body weight and circulation time (Fig. 4. left panel). ${ }^{4}$ On the other hand. Sokolow et al already documented the pitfalls of rhythm control of AF (Fig.4, right panel). They showed that the efficacy of cardioversion by quinidine was limited by the duration of the preceding AF duration and that a high rate of recurrences of AF occurred during the first week after successful restoration of sinus rhythm." 

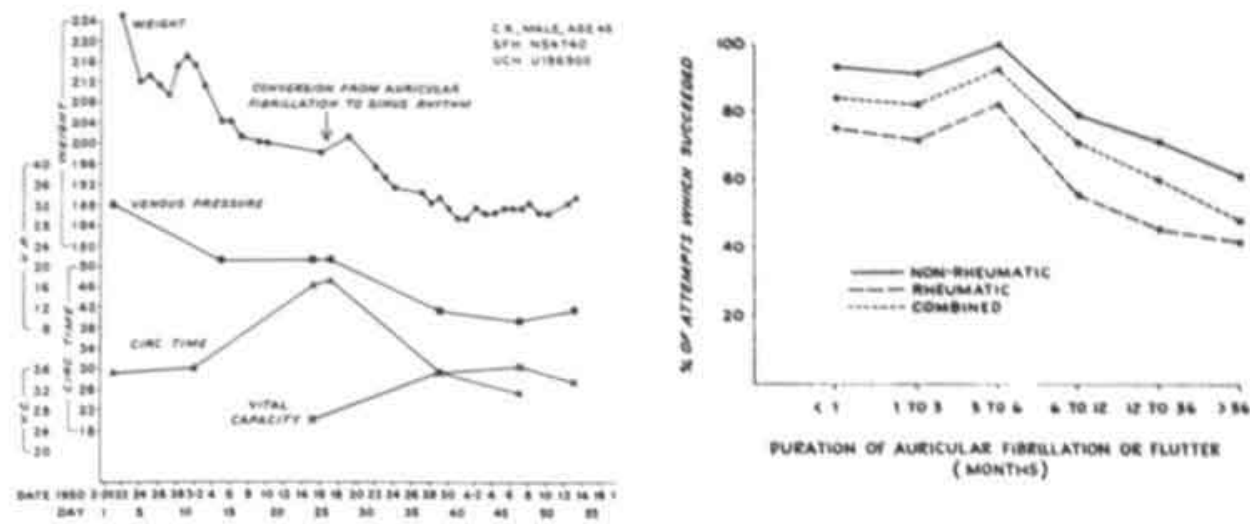

Figure 4, Chemical cardioversion of atrial fibrillation by quimidine at the end of the first half of the previous century. Restoration of sinus rhythm resulted in marked clinical improvement, as exprssed by a decrose in body ueight and circulation time (left panel). Efficacy of candioversion by quintine depended on the preceding duration of $A F$ ( $r i g h t$ panell.

\section{0-1990}

A main change in the treatment of atrial fibrillation was the introduction of electrical cardioversion of cardiac arrhythmias in 1962." This non-pharmacological approach markedly improved the efficacy of cardioversion of long lasting AF up to $90 \%{ }^{\text {* }}$ However, its long-term efficacy seemed to be limited by a high rate of recurrences of AF with only $20-40 \%$ of patients maintaining sinus rhythm during the first year. ${ }^{27 \%}$ Both class IA, IC and III drugs (quinidine, flecainide, propafenone, sotalol, amiodarone) were found to prevent recurrences of atrial fibrillation after cardioversion of $\mathrm{AF}^{\mathrm{wi}}$ However, despite the use of antiarrhythmic drugs, the recurrence rate of AF remained as high as 25 to $50 \%$ after I year (Fig.5)."

\begin{tabular}{|c|c|c|c|}
\hline & \multicolumn{2}{|c|}{ Low Efficacy } & Low Safety \\
\hline & $\begin{array}{l}\% \text { of SR } \\
\text { after I year }\end{array}$ & $\begin{array}{c}5 \text { of } S R \\
\text { after } 5 \text { years }\end{array}$ & $\begin{array}{l}\text { Mortality compared } \\
\text { to Placebo }\end{array}$ \\
\hline Quinidine & $50 \%$ & & $2.9 \%$ vs $0.8 \%$ \\
\hline Flecainide & $50 \%$ & $18 \%$ & $7,7 \%$ vs $3.0 \%$ \\
\hline Sotalol & $77 \%$ & & $5.0 \%$ vs $3.1 \%$ \\
\hline Amiodarone & $53.87 \%$ & & \\
\hline
\end{tabular}

Figure 5. Limited efficacy and pm-arrhythmic risks of various class $I$ and III antiar. hythmic drug therapies for atrial fibrillation. Despite antiarriythmic drugs, after I year onls $50-759$ of patients are still in sinus rhythm. Moreover, antuarrhythmic drags are associated with a higher morialiry compared to placebo. 
Moreover, when patients were followed beyond the standard of 1 year, only $18 \%$ of patients were still in sinus rhythm 5 years after cardioversion. ${ }^{*}$ More frightening was the observation that the use of antiarnhythmic drugs was associated with a higher mortality. In 1989, the CAST investigators reported an increased mortality in patients treated with class I drugs to suppress arrhythmias after myocardial infarction. ${ }^{n: m}$ Also the class III drugs (d-sotalol) were found to found to carry an increased risk in patients with heart failure, ${ }^{10}$ In patients with congestive heart failure and atrial fibrillation, the use of antiarrhythmic drugs was associated with a higher mortality compared to placebo, ${ }^{\text {ple }}$ As a result, antiarrhythmic drugs seemed to have both a low efficacy and safety for treatment of atrial fibrillation (Fig.5).

\section{THE LAST DECADE}

The limited efficacy and pro-arrhythmic risks of antiarrhythmic drug therapies for atrial fibrillation resulted in a growing interest in non-pharmacological options in the treatment of $\mathrm{AF}$. Current therapeutic developments encompass new antiarrhythmic drugs, the atrial defibrillator, atrial surgery. linear and focal ablation and preventive atrial pacing (Fig.6). "All of these interventional options are directed either at prevention or termination of atrial fibrillation. Clinical investigation of the new class III agents (dofetilide, azimilide, ibutilide, tedisamil, etc...) have shown them to offer incremental benefit over existing agents. However, the major shortfall remains the potential to cause pro-arrhythmias." The internal atrial defibrillator in theory is an excellent modality for rapid conversion of $\mathrm{AF}^{+1}$ Limited data suggest that early cardioversion prolongs the interval between recurrent episodes of AF." However, the drawbacks include discomfort from the shocks and immediate recurrence of AF," Surgical therapy for AF (maze procedure) is highly successful in patients who require open-heart surgery for another indication. ${ }^{4.47}$ In patients with lone AF or no other indication for surgery, an intra-operative approach for the treatment of AF seems unattractive due to potential risks, discomfort and prolonged convalescence. Linear catheter ablation is still hampered by technical problems and serious complications such as cerebrovascular accidents, cardiac tamponade and loss of atrial function." Focal catheter ablation has been shown to be effective in drug-refractory patients with symptomatic paroxysmal AF" $*$ However, after the initial experience, it became clear that focal ablation within pulmonary veins. pulmonary vein isolation or segmental isolation of pulmonary veins are long-lasting procedures with serious complications (pulmonary vein stenosis, thromboembolism, hemopericardium,...). Moreover, uncertainty exists about long-term results with regard to AF recurrence and PV stenosis." Preventive atrial pacing was shown to decrease the likelihood of AF in patients with vagotonic AF or sinus node disease. ${ }^{\text {st }}$ However, atrial pacing can not be justified in patients without sinus node disease."

Although the wide spectrum of new approaches seems promising, they can be applied in 
only a minority of patients with AF. In fact, the variety in treatment options may reflect confusion, similar to the variety of names given to AF in the beginning of the previous century (Fig.6). Despite all efforts, with a few exceptions, present-day treatment of AF can still be characterized as 'doing our best without knowing what is wrong'. To develop a more effective strategy for treatment of atrial fibrillation, one needs to further investigate the pathophysiological mechanisms underlying initiation and perpetuation of atrial fibrillation. As Thomas Lewis suggested in 1902: "The notion of a patient continuing to live with an auricle incapable of contraction is a somewhat novel idea... it seems necessary to devote a little study to the condition."

$1900-1920 \ldots$

- Atrial Paralysis

- Delirium Cordis

- Pulsus Irregularis Perpetuus

- Pulsus Arrhythmicus

- Auricular Fbrillation ...last decade

- New Antiarrhythmic Drugs

- Atrial Defibrillator

- Atrial Surgery

- Focal and Linear Ablation

- Preventive Atrial Pacing

Figur 6. New treatment options for AF encompass new antiarthythmic drugs, the atrial defibrillator, atrial surgery, focal and linear ablation and preventive atrial pacing. Although the wide spectrum seems promising, the variety in treatment options probably reflects confusion. similar to the variefy of names given to AF in the begin. ning of the provious centur: 


\section{References}

1. Silverman ME. From rebellious palpitations to the discovery of auricular fibrillation: contribution of Mackenzie, Lewis and Einthoven. Am J Cardiol. 1994:73:384-389.

2. MacKenzie J, Observations on the process which results in auricular fibrillation. Br Med J, 1922 2: 71.73

3. Cushny AR, Edmunds CW, Paroxysmal irregularity of the heart and auricular fibrillation Am J Med Sci. 1907:133:66-77.

4. Lewis T. Auricular fibrillation: a common clinical condition. Br Med J, 1909:2:1528.

5. Benjamin EJ. Levy D, Vaziri SM, D'Agostino RB. Belanger AJ. Wolf PA. Independent risk facton for atrial fibrillation in a population-based cohort: the Framingham Heart study. J Am Med IAssec. 1994:271:840-844.

6. Benjamin EJ. Wolf PA, D'Agostino RB, Silbershatz H. Kannel WB. Levy D. Impact of atrial fibrillation on the risk of death: the Framingham Heart study. Circulation, 1998:98:946-952.

7. Feinberg WM. Blackshear J., Laupacis A. Kronmal R, Hart RG. Prevalence, age distribution and gender of patients with atrial fibrillation: analysis and implications. Arch Intern Med. 1995:155:469-473

8. Caselli G. Loper AD. Health and mortality among elderly populations. New York. NY Clarendon Press, 1996.

9. Braunwald E. Shattuck lecture-cardiovascular medicine at the turn of the millenium: triumphs, concerns and opportunities. N Engl J Med, 1997:337:1360-1369.

10. Wolf PA, Benjamin EJ, Belanger AJ, Kannel WB, Levy D, D'Agostino RB. Secular trends in the prevalence of atrial fibrillation: the Framingham study. Am Heart J. 1996:131:790-795.

II. Carson PE, Johnson GR. Dunkman WB. Fletcher RD. Farrell L, Cohn JN. The influence of atrial fibrillation on prognosis in mild to moderate heart failure: the V-HeFT Studies. Circulation. 1993:87:Suppl 6, V1102-110.

12. Scheinman MM. Atrial fibrillation and congestive heart failure: the intersection of two common diseases (editorial). Cinculation, 1998:98:941-942.

13. Blackshear JL. Kopecky SL. Litin SC. Safford RE. Hammill SC. Management of atrial fibrillation in adults: prevention of thromboembolism and symptomatic treatment. Mayo Clin Proc, 1996;71: 150-160.

14. Page RL. Wilkinson WE. Clair WK. McCarthy EA, Pritchett EL. Asymptomatic arthythmias in patients with symptomatic paroxysmal atrial fibrillation and paroxysmal supraventricular tachycardia. Cinculation, 1994:89:224-227.

15. Savelieva I. Camm JA Silent atrial fibrillation - another Pandora's box. PACE. 2000:23:145-148.

16. Wolf PA. Dawher TR. Thomas HE. Kannel WB. Epidemiologic assessment of chronic atrial fibrillation and risk of stroke: the Framingham study. Neurology, 1978:28:973-977.

17. Hart RG. Pearce L.A. Rothbart RM. McAnulty JH. Asinger RW. Halperin JL Stroke with intermittent atrial fibrillation: incidence and predictors during aspirin therapy. Stroke Prevention in Atrial Fibrillation Investigaton. I Am Coll Candiol, 2000;35: 183-187. 
18. Wolf PA. Abbott RD, Kannel WB. Atrial fibrillation as an independent risk factor for stroke; the Framingham study. Stroke. 1991:22:983-988.

19. Ezekowitz MD, James KE, Nazarian SM et al. Silent cenebral infarction in paticnts with non-rheu matic atrial fibrillation. Cinculation. 1995:92:2178-2182.

20. Feinberg WM. Seeger JF, Carmody RF et al. Asymptomatic cerebral infaretion in patients with atri al fibrillation. Cinculation. 1988:19:955-957.

21. Dries DL. Exner DV, Gersh BJ. Domanski MJ. Waclawiw MA. Stevenson LW. Atrial fibrillation is associated with an increased risk for mortality and heart failure progression in patients with asymp tomatic and symptomatic left ventricular systolic dysfunction: a retrospective analysis of the SOLVD trials. J Am Coll Cardiol, 1998,32:695-703.

22. De La Chapelle CE. Rose $\mathrm{OA}$. The management of acute cardiac emergencies, Cinculation, 1951;:IV:764-774.

23. McCord MC, Taguchi JT. A study of the effect of procaine amide hydrochlonide in supraventricu lar anthythmias. Circulation. 1951:IV:387-393.

24. Sokolow M. Ball RE. Factors influencing conversion of chronic atrial fibrillation with special reference to serum quinidine concentration. Cinzulation. 1956:XIV:568-583.

25. Lown B, Amarasingham R. Neuman 3. New method for terminating cardiac arrhythmias: use of synchronized capacitator discharge, JAMA, 1962:182:548-555,

26. Lown B. Electrical cardioversion of cardiac armythmias. Br Heart J. 1967:29:469-487.

27. Nattel S. Newer development in the management of atrial fibrillation. Am Heart J, 1995;130: $1094-1096$.

28. Sopher SM, Camm AJ. Atrial fibrillation: maintenance of sinus thythm versus rate control. Am J Candiol, 1996:77:24A-37A.

29. Prystowski EN. Benson DW, Fuster V. et al. Management of patients with atrial fibrillation. Cinculation, 1996:93:1262-1277.

30. Coplen SE. Antman EM. Berlin AJ. et al. Efficacy and safety of quinidine therapy for maintenance of sinus thythm after cardioversion. A meta-analysis of randomized control trials. Circulation, 1990:82:1106-1116.

31. Antman EM, Beamer AD, Cantillon C. et al. Long-term oral propafenone therapy for suppression of refractory symptomatic atrial fibrillation and atrial flutter. J Am Coll Candiol, 1988:I2:1005-1011.

32. Hohnloser SH, van de Loo A, Baedeker F. Efficacy and proarrhythmic hazards of pharmacological cardioversion of atrial fibrillation: prospective comparison of sotalol versus quinidine. J Am Coll Cardiol, 1995:26:852-858.

33. Duytschaever M. Haerynck F. Tavernier R. Jordaens L. Factors influencing long term persistence of sinus thythm after a first electrical cardioversion for atrial fibrillation. PACE. 1998:21 (II);284-287.

34. Chun SH, Sager PT. Stevenson WG, et al. Long-term efficacy of amiodarone for the maintenance of normal sinus rhythm in patients with refractory atrial fibrillation or flutter. Am J Candiol. 1995;76:47-50.

35. Hohnloser SH, Yi-Gang Li. Drug treatment of atrial fibrillation: what have we learned ? Current Opinion Cardiol, 1997:12:24-32.

36. Zehender M. Faber T. Jeron A et al. Is conversion of atrial fibrillation the ultimate long-term goal? Cinculation, 1995:92 (Suppl D):755. 
37. Cardiac Arrhythmia Suppression Trial (CAST) Investigators. Preliminary report: Effect of encainide and flecainide on mortaility in a randomized trial of arrhythmia suppression after myocardial infarction. N Engl J Med, 1989;321:406-412.

38. Echt DS. Liebson PR. Mitchell LB et al. Mortality and morbidity in patients receiving encainide. flecainide or placebo: the Cardiac Arthythmia Suppression Trial (CAST). N Engl J Med, 1991: 324:781-788.

39. Waldo AL. Camm AJ, deRuyter $\mathrm{H}$ et al. for the SWORD investigators. Effect of d-sotalol on mortality in patients with left ventricular dysfunction after recent and remote myocardial infarction. Lancet, 1996;348:7-12.

40. Flaker GC, Blackshear JL, McBride R, Kronmal RA, Halperin JL. Hart RG. Antiarthythmic drug therapy and cardiac mortality in atrial fibrillation. The Stroke Prevention in Atrial Fibrillation Investigators, J Am Coll Cardiol. 1992;20:527-532.

41. Scheinman M. Morady F. Nonpharmacological approaches to atrial fibrillation. Circulation, 2001:103:2120-2125.

42. Camm AJ. Clinical differences between the newer antiarrhythmic agents. Europace Supplements, 2000; 1:C16-C22.

43. Wellens HJJ, Lau CP. Luderizz B. Akhtar M. Waldo AL. Camm AJ. Timmermans C, Tse HF. Jung W. Jordaens L. Ayers G, for the METRIX Investigators. Atrioverter: an implantable device for the treatment of atrial fibrillation. Cinculation. 1998:98:1651-1656.

44. Timmermans C. Levy S. Ayers GM et al. Spontaneous episodes of atrial fibrillation after implantation of the Metrix Atrioverter: observations on treated and nontreated episodes. J Am Coll Candiol, 2000:35:1428-1433.

45. Timmermans C. Rodriguez LM. Smeets JLRM, Wellens HJJ. Immediate reinitiation of atrial fibrillation following internal atrial defibrillation. J Cardiovasc Electrophysiol, 1998;9:122-128.

46. Cox J. Boineau J. Schuessler R, et al. A review of surgery for atrial fibrillation. J Cardiovasc Electmphvsiol. 1991:2:541-561.

47. Schaff HV, Dearani JA, Daly RC. Orszulak TA. Danielson GK. Cox-Maze procedure for atrial fibrillation: Mayo Clinic experience. Semin Thorac Candiovasc Surg, 2000;12:30-37.

48. Haissaguerre M, Jais P. Shah DC, et al. Right and left atrial radiofrequency catheter ablation the rapy of paroxysmal atrial fibrillation. J Candiovasc Electrophysiol. 1996:7: 1132-1144.

49. Ernst S, Schlutter M. Ouyang F. et al. Modification of the substrate for maintenance of idiopathic human atrial fibrillation: efficacy of radiofrequency ablation using nonfluoroscopic catheter guidance. Circulation, 1999:100:2085-2092,

50. Thomas SP. Nunn GR. Nicholson IA. et al. Mechanism, localization, and cure of atrial arrhythmias occurring after a new intraoperative endocardial radiofrequency ablation procedure for atrial fibrillation. J Am Coll Candiol, 2000:35:442-450.

51. Haissaguerre M. Jais P. Shah DC. Takahashi A. Hocini M. Quiniou G. Garrigue S. Mouroux AL. Metayer PL. Clementy J, Spontaneous initiation of atrial fibrillation by ectopic beats originating in the pulmonary veins. $N$ Eng $J$ Med. 1998:339:659-666,

52. Jais P, Haissaguerre M, Shah DC, Chouairi S, Gencel L. Hocini M, Clementy J. A focal source of atrial fihrillation treated by discrete radiofrequency ablation. Cinculation. 1997:95:572-576.

53. Chen $\mathrm{SA}$. Hsich MH. Ta TC et al. Initiation of atrial fibrillation by ectopic beats originating from 
the pulmonary veins: electophysiological characteristics, pharmacological responses, and effects of radiofrequency ablation. Circulation, 1999:100:1879-1886.

54. Pappone C, Oreto G, Rosiano S. et al. Atrial electroanatomic remodeling after circumferential radiofrequency pulmonary vein ablation: efficacy of an anatomic approach in a large cohort of patients with atrial fibrillation. Circulation. 2001:104:2539-2544.

55. Wellens HJJ. Pulmonary vein ablation in atrial fibrillation: Hype or Hope? Circulation, 2000; 102:2562-2564.

56. Coumel P. Friocourt P. Mugica J et al. Long-term prevention of vagal arrhythmias by atrial pacing at 90/minute: experience with 6 cases. Pacing Clin Electrophysiol, 1983;6:552-560.

57. Andersen HR, Nielsen JC. Thomsen PEB et al. Long-term follow-up of patients from a randomized trial of atrial versus ventricular pacing for sick sinus syndrome. Lancet. 1997:350:1210-1216.

58. Gillis AM, Wyse DG, Connolly SJ, et al. Atrial pacing periablation for prevention of paroxysmal atrial fibrillation. Cinculation, 1999;99:2553-2558. 



\section{Chapter 2}

\section{Repetitive Electrical Remodeling by Paroxysms of Atrial Fibrillation in the Goat:}

No cumulative effect on inducibility or stability of atrial fibrillation.

Clifford J. Garratt, MD; Mattias Duytschaever, MD; Matthijs Killian, PhD; Rick Dorland, BS: Frans Mast, PhD: Maurits A. Allessie, MD PhD. 


\section{Abstract}

Background: Episodes of atrial fibrillation (AF) are known to cause both a rapid reduction in atrial refractoriness (atrial electrical remodeling) and a more delayed increase in AF stability in the chronic goat model. The aims of this study were to examine I) the hypothesis that an AF-induced increase in AF stability might be due to a mechanism with a longer onset and offset than that of changes in refractoriness and 2) the possibility that repeated paroxysms of maintained $\mathrm{AF}$ might cause a cumulative increase in $\mathrm{AF}$ stability independent of changes in atrial refractoriness.

Methods and Results: AF was maintained by rapid atrial pacing in 7 goats for three consecutive 5 day periods, each separated from each other by 48 hours of sinus rhythm. Assessments of atrial refractory periods, conduction velocity, AF inducibility, and duration of individual episodes of AF were attempted at intervals throughout the protocol. Forty-eight hours of sinus rhythm was just sufficient for refractoriness changes to fully reverse in all goats, with no evidence of any "residual" increase in AF inducibility. There was no significant difference between any of the 3 periods of pacing-maintained AF with regard to time to develop episodes of $\mathrm{AF}$ of 60 seconds duration $(22.1 \pm 13$ hours, $23.8 \pm 16$ hours, $30.3 \pm 29$ hours). I hour duration ( $56.6 \pm 28$ hours, $61.3 \pm 31$ hours, $60.1 \pm 32$ hours) or 24 hours duration ( $84.0 \pm 3$ I hours, $87.0 \pm 33$ hours, $83.5 \pm 32$ hours).

Conclusion: There is no evidence for a cumulative effect of AF paroxysms on AF inducibility or stability independent of changes in refractoriness. These findings highlight the importance of atrial refractoriness as a potential target for antiarrhythmic strategies aimed at inhibiting the self-perpetuation of $\mathrm{AF}$. 


\section{Introduction}

Atrial fibrillation (AF) has a tendency to become more persistent with time, a large percentage of patients with paroxysmal $\mathrm{AF}$ eventually developing chronic $\mathrm{AF}^{1,2}$ Although progression of an underlying cause is one explanation for this phenomenon. in a significant proportion of cases no underlying cardiovascular disease is evident.' Recently Wijffels and coworkers' have demonstrated, in a chronically instrumented conscious goat model, that episodes of $\mathrm{AF}$ are self-perpetuating ("AF begets $\mathrm{AF}^{\prime}$ ). Induction of $\mathrm{AF}$ in this model is accompanied by a marked shortening of atrial refractory periods and loss of the normal rate-adaptation of refractoriness (termed atrial electrical remodeling). It is postulated that these effects increase AF stability by shortening atrial wavelength and increasing the potential number of reentrant wavelets in the atria." * These electrophysiological changes have a relatively rapid time course, most of the effects occurring within 48 hours of the onset of $\mathrm{AF}^{4}$ In contrast, the time required for induced $\mathrm{AF}$ to become stable is significantly longer and more variable (from 3 to 20 days). ${ }^{*}$ This time delay between postulated cause and effect has led to the suggestion that additional factors with a longer time course than the shortening of atrial refractoriness may play a role in the self-perpetuation of AF. There are a number of potential candidates, including atrial dilatation and changes in atrial structure, which are likely to take more than 48 hours to develop or resolve.

The primary aim of this study was to examine the hypothesis that an AF-induced increase in AF stability might be due to a mechanism (a so-called second factor) with a longer time course than that of change in atrial refractoriness. If this were the case then it would be expected that the increase in AF vulnerability and stability that is evident following a prolonged paroxysm of AF would remain for a longer period than that required for atrial refractoriness to return to normal. A second aim of the study was to examine the possibility that repeated paroxysms of AF result in a cumulative increase in AF inducibility or stability independent of changes in atrial refractoriness. This would provide a potential means whereby recurrent paroxysms of AF might progress to persistent AF despite full reversal of refractoriness changes between successive paroxysms.

\section{Methods}

\section{CHRONIC GOAT MODEL OF ATRIAL FIBRILLATION}

Seven female goats were used for this study. Animal handling was performed according to the Dutch Law on Animal Experimentation and approved by the Animal Investigation 
Committee of the University of Maastricht. The goats were anaesthetised with Thiopental (15 mg/kg) and ventilated with halothane (1-2\%) and a 1:2 mixture of $\mathrm{O} 2$ and $\mathrm{N} 2 \mathrm{O}$. A left intercostal thoracotomy was made and the pericardium was opened to expose the heart. A silicon strip of $10 \times 1.2 \mathrm{~cm}$, containing 23 unipolar platinum electrodes (diameter $1.5 \mathrm{~mm}$, interelectrode distance $6-10 \mathrm{~mm}$ ) was guided through the anterior transverse sinus between the atria and the aortic root and sutured to the tips of both atrial appendages. In addition, two smaller silicon plaques, each containing 30 electrodes, were sutured to the lateral walls of the right and left atria (interelectrode distance $5 \mathrm{~mm}$ ). After approximation of the pericardium and closure of the thorax, the electrode leads were tunnelled subcutaneously to the neck and exteriorised by three 30 -pin connectors. Three silver plates (diameter $25 \mathrm{~mm}$ ) were left subcutaneously to serve as grounding and indifferent electrodes and to record a precordial electrocardiogram. Post-operatively the animals received buphrenorphine (Temgesic) for 1-3 days. Ampicillin (1000mg) was given prophylactically both before and after surgery.

Approximately 2 weeks after surgery the goats were connected to an external automatic atrial fibrillator. The external automatic fibrillator consisted of a personal computer connected to a stimulator (Medtronic SP3084). The software continuously analysed one of the atrial electrograms and as soon as sinus rhythm was detected, a I-second burst of biphasic stimuli (duration $2 \mathrm{~ms}$, interval $20 \mathrm{~ms}$, strength 4 times diastolic threshold) was delivered to a pair of atrial electrodes. By these automatic bursts of stimuli, atrial fibrillation could be maintained continuously 24 hours a day as has been previously described. ${ }^{*}$

\section{STUDY PROTOCOL}

The protocol for the study consisted of the maintenance of AF for three consecutive 5 day periods, each separated from each other by a weekend (48 hours) of sinus rhythm. Pilot studies had indicated that after 5-days of maintained AF, a period of 36-48 hours of sinus rhythm was required for refractoriness to return to control. Assessment of the atrial refractory period, conduction velocity, AF cycle length, and AF inducibility (right and left atria). was attempted during baseline and after 6. 12, 24, 48, 72, 96 and I20 hours of maintained AF (Figure 1). The duration of individual episodes of AF (the time between 2 atrial pacing bursts) was recorded automatically on a personal computer. If AF did not terminate spontaneously within 6 hours at the end of 5 days, sinus rhythm was established by external DC cardioversion. Following return to sinus rhythm, the refractory period and AF inducibility were measured 24 and 48 hours post-cardioversion. 


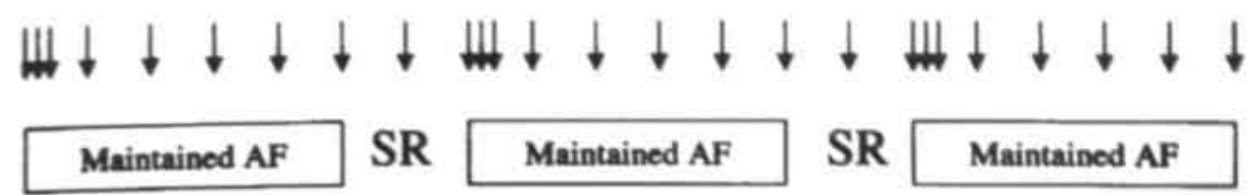

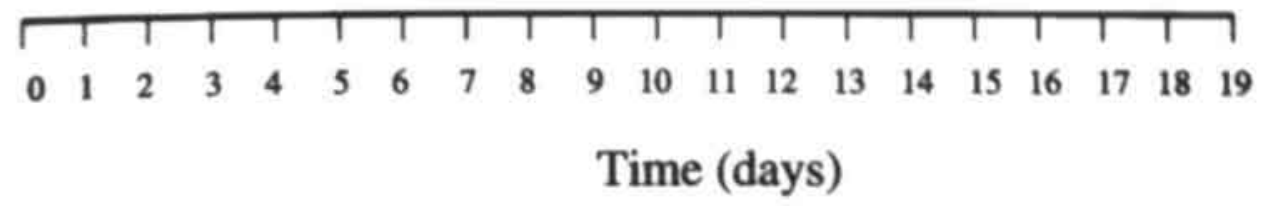

Figurr I. The shaty profocol. Arnows indicate times at which measurements of atrial refractory period, condaction velacify, Af ogrle length and AF inducibility are attempted.

\section{MEASUREMENTS}

The atrial effective refractory period (AERP) was measured at sites on the left and right atria (selected on the basis of good signal recording and low stimulation thresholds) during a basic pacing drive of $400 \mathrm{~ms}$. A single premature stimulus ( 4 times threshold) was interpolated at every fifth basic interval and, starting from well within the refractory period, the S1-S2 coupling interval was incremented in steps of $1 \mathrm{~ms}$. The shortest S1-S2 interval resulting in a propagated atrial response was taken as the AERP. Intra-atrial conduction velocity was calculated from conduction times recorded at the atrial free wall during regular pacing $(400 \mathrm{~ms}$ drive) from the left or right atrial appendage, the interelectrode distances calculated from the known interelectrode dimensions of the silicon electrode plaques. Mean atrial fibrillation cycle length (AFCL) was determined during induced AF from a sample of 300 cycles using an automatic detection algorithm which was validated by periodic manual confirmation and continuous display of AF interval histograms.

The inducibility of AF was assessed by the response to single premature stimuli delivered during a $400 \mathrm{~ms}$ drive at the AERP. Atrial fibrillation was considered to be induced if the single premature stimulus was followed by rapid irregular atrial activity lasting for more than one second on at least 2 of 3 attempts.

\section{DATA ANALYSIS}

Data are presented as mean \pm standard deviation. Statistical analysis of the paired data was performed using the Student's t-test and in the case of multiple statistical comparisons the $\mathrm{p}$ value was corrected by multiplying it with the number of comparisons. $\mathrm{A}$ corrected $\mathrm{p}$ value of less than 0.05 was considered to be statistically significant. 


\section{Results}

\section{ATRIAL REFRACTORINESS}

Atrial electrical remodeling (defined in this study as a reduction in atrial refractoriness measured during a $400 \mathrm{~ms}$ drive) occurred in all 7 goats in the study, the greatest reduction in refractoriness occurring within the first $\mathbf{2 4}$ hours. Measurements of refractory periods were possible in all goats for the first 24 hours of maintained AF. Because the duration of AF episodes became more sustained after this time, the opportunities to measure refractory periods became less. As a result, in only 4 of 7 goats could atrial refractory periods be measured at 48 and 72 hours, in 2 of 7 at 96 hours and in only one goat at the end of the 5 day period of AF. In Figure 2 refractory period measurements at the right and left atria (mean values all goats) are plotted during the 3 successive 5-day periods of $\mathrm{AF}$. Following both the first and second periods of $\mathrm{AF}$, atrial refractoriness had returned to baseline values $(+5 \%)$ after 48 hours of sinus rhythm in all 7 goats. No significant differences were seen either in the degree (absolute values achieved) or the rate of remodeling between the 3 successive periods of $\mathrm{AF}$. In other words no evidence could be found of any preconditioning by previous episodes of AF on the process of atrial electrical remodeling.

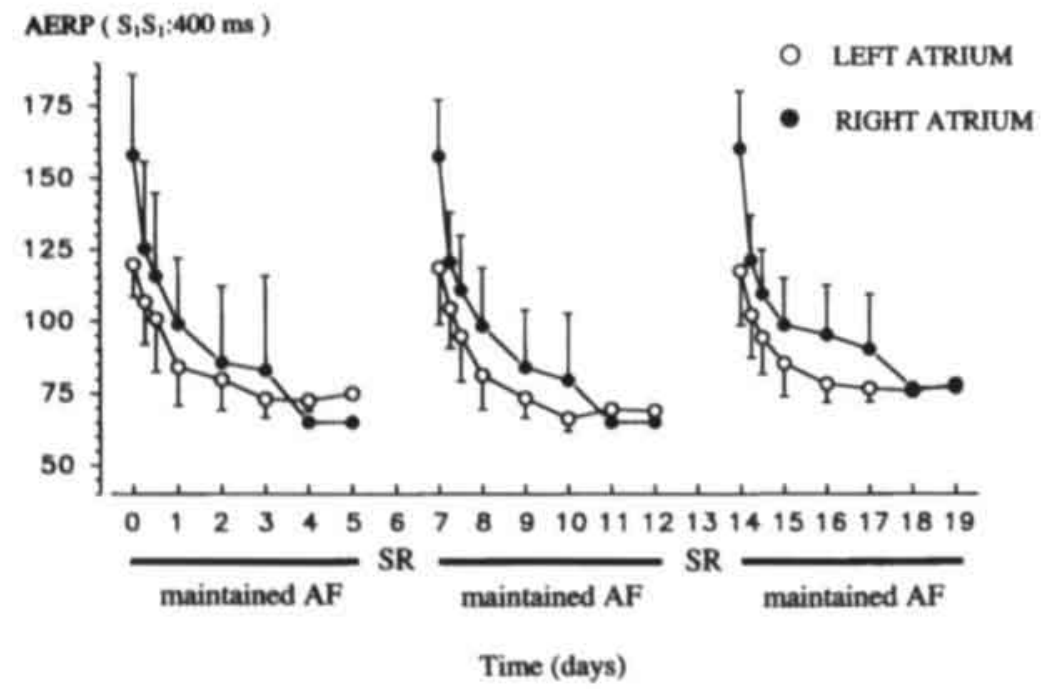

Figur 2. Changes in right and left atrial refractoriness. Results are eypressed as means and standand drvations of whiues obtained in all goats. 


\section{CONDUCTION VELOCITY}

Measurements of atrial conduction velocity were limited to 4 of the 7 goats (left atrial free wall only), because of lack of high quality recordings from chronic electrodes perpendicular to the activation wave during pacing. As with measurement of atrial refractory periods, conduction velocity measurements could always be made for the first 24 hours of maintained AF (each of the 3 episodes) but thereafter, because of the high inducibility of prolonged episodes of AF, measurements became more sparse. There was no evidence of a cumulative effect of episodes of pacing maintained AF on conduction velocity in the left atrium (Figure 3 ). Mean conduction velocity at the start of each of the 3 periods of maintained AF was $132 \pm 29 \mathrm{~cm} / \mathrm{s}, 122 \pm 29 \mathrm{~cm} / \mathrm{s}$ and $121 \pm 50 \mathrm{~cm} / \mathrm{s}$ (no significant difference). The corresponding values after 24 hours of each of the 3 periods were $134 \pm 23,136 \pm 26$ and $115 \pm 36$ (no significant difference).

1st paroxysm

\section{Baseline}

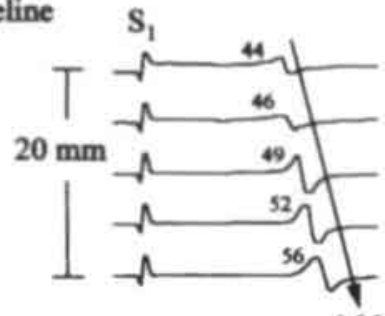

24h of AF

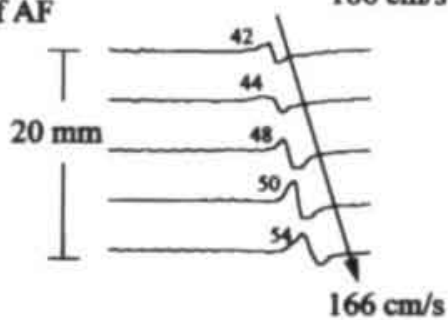

2nd paroxysm

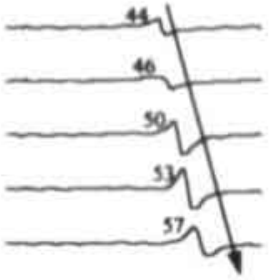

$154 \mathrm{~cm} / \mathrm{s}$

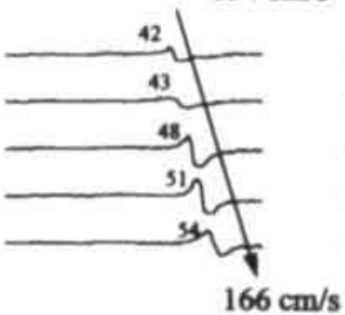

3rd paroxysm

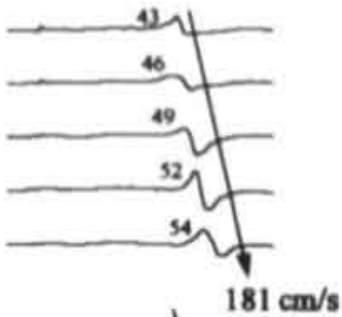

Figure 3. Example of conduction velocity measurements over the left atrium in a single goat. Ther is no consistent change in conduction velocirv measured prior to the start of the 3 episodes of maintained AF or after 24 hours of each of these periods.

\section{CYCLE LENGTH OF INDUCED AF}

The shortening of atrial refractoriness was associated with a concomitant shortening of mean AF cycle length (Figure 4) in all goats. There was no evidence of a cumulative effect of episodes of pacing maintained AF on the cycle length of the induced episodes. either in terms of absolute changes or their rate of development. 


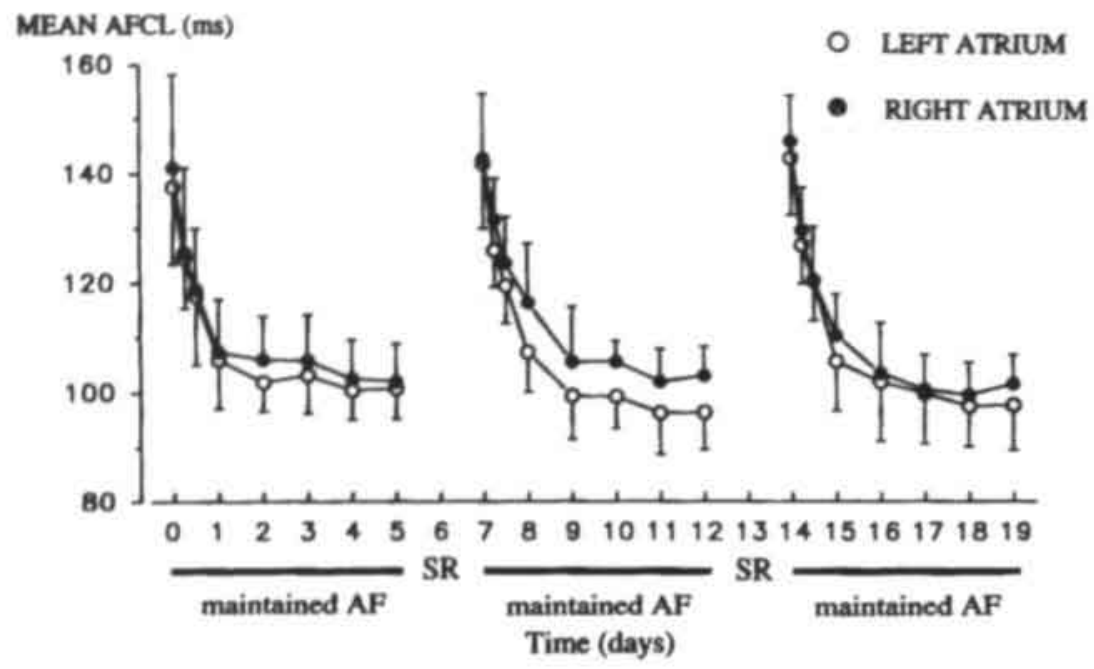

Figure 4. Changes in right and left AF cycle length of induced episodes of AE. Results are expressed as means and standant devianons of values obtained in all goats.

\section{INDUCIBILITY OF AF}

The effects of the 3 periods of maintained AF on AF inducibility with single premature stimuli are detailed in the table. Inducibility at the beginning of the first, second and third periods was $36 \%, 21 \%$ and $43 \%$ respectively. The corresponding values after 12 hours of pacing were $86 \%, 86 \%$ and $86 \%$, and after 24 hours of pacing were $100 \%, 100 \%$ and $93 \%$. Beyond 24 hours, inducibility of AF was universally $100 \%$ whenever it could be tested. This increase in inducibility with duration of maintained AF was evident in all 3 periods of $\mathrm{AF}$ and there was no evidence of any "residual" increased inducibility after return of atrial refractoriness to baseline values. There was no evidence of a cumulative effect of repeated episodes of maintained AF on AF inducibility.

\section{STABILITY OF AF}

The stability of AF, as measured by the mean duration of individual episodes of induced AF, increased over each 5-day period of maintained AF in all goats, but in no goat was there evidence of a cumulative effect of repeated episodes of maintained AF. There was a wide variation in AF stability between individual goats (Figure 5). In terms of the pooled results (Figure 6) there was no significant difference between any of the 3 periods of maintained AF with regard to time to develop episodes of AF of 10 seconds duration ( $6.8 \pm 12$ hours. $10.3 \pm 14$ hours, $8.8 \pm 11$ hours), 60 seconds duration ( $22.1 \pm 13$ hours. 
$23.8 \pm 16$ hours, $30.3 \pm 29$ hours), I hour duration $(56.6 \pm 28$ hours . $61.3 \pm 31$ hours, $60.1 \pm 32$ hours) or 24 hours duration ( $84.0 \pm 31$ hours, $87.0 \pm 33$ hours, $83.5 \pm 32$ hours). AF stability returned to baseline values within the two 48 hour periods of sinus rhythm in all goats, with mean durations of individual episodes of induced AF being $12.6 \pm 10 \mathrm{~s}$, $10.4 \pm 8.5 \mathrm{~s}$, and $14.2 \pm 15 \mathrm{~s}$ (not significantly different) at the beginning of each of the 3 periods of pacing-maintained $\mathrm{AF}$.

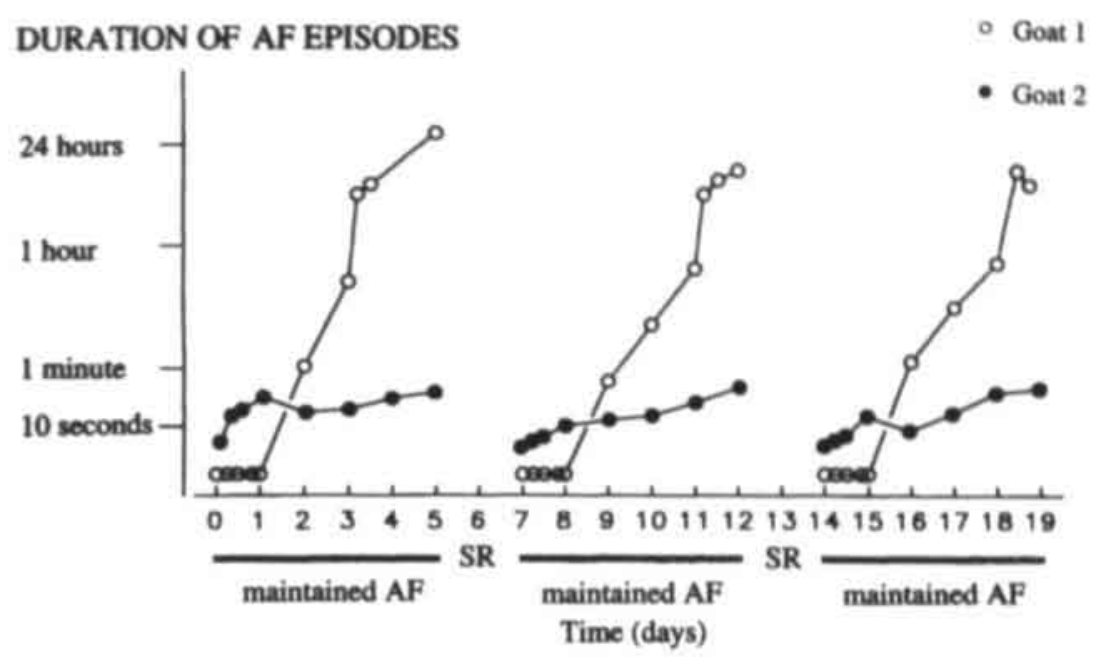

Figure 5, Changes in mean duration of induced AF episodes in 2 individual goats ilog scale) There is a large difference in the rate of increase in AF stability with time between the 2 goats, but then is no cumulative effect of periods of maintained AF in either individual.

\section{DURATION OF AF EPISODES}

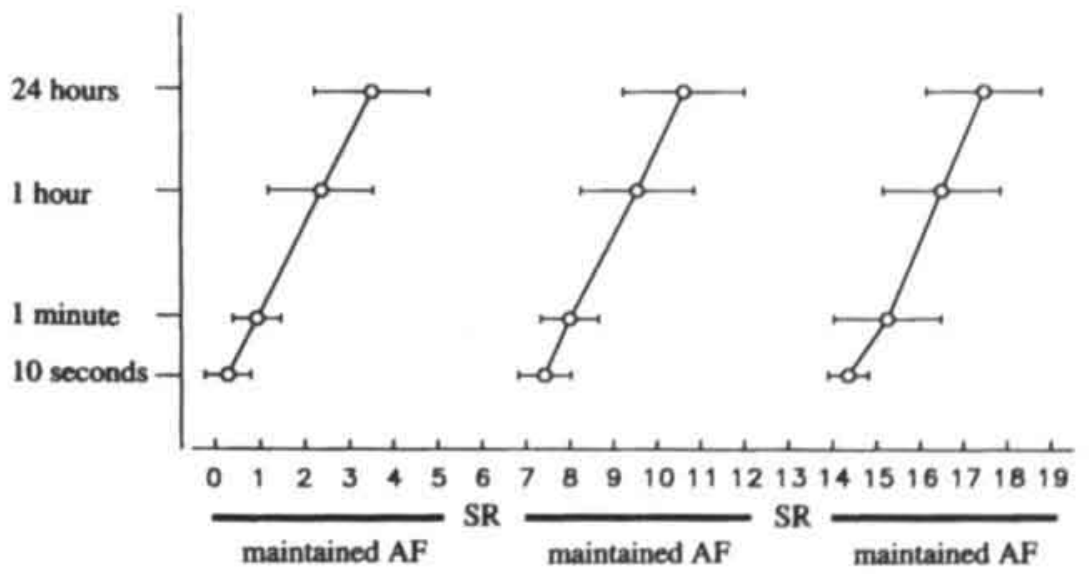

Time (days)

Figure 6. Mean times to development of Af of 10 seconds, I minute. I hour and 24 hour durations (means and standard deviations of all goats). 


\section{Discussion}

\section{THE MAIN FINDINGS}

The principal findings of this study are 1) electrical remodeling and its reversal is a rapid and reproducible process in goat atria, 2) recovery of post-AF atrial vulnerability does not have a longer time course than the time course of reversed electrical remodeling, 3) recurrent episodes of atrial remodeling do not have a cumulative effect on AF stability or inducibility independent of changes in refractoriness.

\section{IS THERE A SECOND FACTOR?}

One of the aims of this study was to examine the hypothesis that a so-called second factor with a longer time course (with respect to both onset and offset) than atrial electrical remodeling has an important role in the self-perpetuating nature of $\mathrm{AF}$. If this were the case, then the increase in AF vulnerability and stability following a prolonged paroxysm of AF should endure for a longer period of time than required for reversal of atrial refractoriness. This turned out not to be the case. After a 5-day period of maintained AF, 2 days of sinus rhythm were not only sufficient for reversal of atrial refractoriness but also for full normalisation of both vulnerability and stability of AF. In other words no evidence was found for a second factor with offset kinetics slower than those of AF-induced changes in atrial refractoriness. This suggests that either 1) small progressive changes in atrial refractoriness occurring after the first 48 hours of AF are responsible for further increases in $\mathrm{AF}$ stability or 2) there is a second factor with slow onset but rapid offset kinetics.

The possible candidates for a second factor include atrial dilatation. increased spatial dispersion of refractoriness and changes in conduction properties of the atria. Patients with longstanding lone AF usually have dilated left atria' and an increase in atrial "area" would be expected to increase AF stability according to Moe's multiple wavelet hypothesis. However patients with brief $(<2$ weeks) or moderate $(2-6$ weeks) duration of AF do not have a measureable increase in atrial size.' In contrast to atrial size, atrial mechanical systolic function is affected by short episodes of AF: Even brief ( $<2$ weeks) episodes of AF result in depressed peak $A$ wave velocity and percent $A$-wave velocity. these changes being largely reversible within 24 hours of restoration of sinus rhythm. Longer episodes of AF result in depression of atrial systolic function that is more persistent, indicating that it is the AF rather than the DC shock that is the important factor in terms of altered systolic function. Animal studies have indicated that AF-induced atrial dysfunction has both a rapid onset and offset and is inhibited by calcium channel blockade. "implicating cytosolic calcium overload as the cause. Atrial electrical remodeling is also inhibited by 
calcium channel blockade, 10, 11 and it is Fikely that AF-induced atrial systolic dysfunction and electrical remodeling are expressions of the same phenomenon. rather than systolic dysfunction being a "second factor" with a different time course.

An increase in dispersion of atrial refractoriness might be expected to be a good candidate for a "second factor" but previous work with the goat model of AF has indicated that dispersion decreases rather than increases during pacing-maintained AF: Nevertheless refractoriness was measured in only a few sites and in theory it would only require a single site to fail to remodel (or remodel to a lesser degree) for dispersion of refractoriness to increase as AF became more prolonged. For dispersion of refractoriness to increase beyond the initial $24-48$ hour period one would have to hypothesise that a) refractoriness is actually continuing to fall in some areas (i.e. not a second factor at all) or b) refractoriness increases in some cells after this period, a phenomenon that has yet to be demonstrated convincingly in the first few days of AF. Finally, one can speculate that changes in conduction properties of atrial tissue might take several days to develop and provide a means whereby AF might become increasingly stable. Studies in dog models of atrial fibrillation have shown decreasing conduction velocity in the atria ${ }^{12}$ and prolonged surface P wave duration" after prolonged periods of high rate atrial pacing. Gaspo and coworkers ${ }^{12}$ have demonstrated that this atrial pacing-induced conduction slowing in dogs has a slower time course than that of atrial refractoriness change and suggest that this effect may constitute a "second factor". This reduction in conduction velocity is associated with a decrease in sodium current ( $\mathrm{INa}$ ) density in dog atrial myocytes, AF duration being related to INa density in each dog. ${ }^{4}$ Interestingly, no changes in atrial conduction velocity have been seen after episodes of pacing-maintained AF in goats. Wijffels and coworkers 4 found no depressive effect of $1-4$ days of AF on intra-atrial conduction velocity measured along a row of electrodes sutured onto Bachman's bundle. In the current study relatively limited measurements of left atrial conduction velocity were made but there was no evidence of a cumulative effect of AF paroxysms on this parameter. This apparent lack of effect of AF on atrial conduction characteristics may represent a real species difference in atrial electrophysiology between dogs and goats.

This study does not give information on potential contributors to AF stability for episodes of AF lasting longer than 5 days. Prolonged episodes (several weeks) of high rate atrial pacing in both dogs ${ }^{13}$ and goats ${ }^{13}$ have been shown to cause marked changes in atrial myocyte structure and significant increases in atrial diameter. Preliminary results of ultrastructural studies of fibrillating goat atria have indicated that it may take over one week of maintained AF before morphological changes occur. ${ }^{16}$ It would not be surprising if such changes had an additional influence on atrial electrophysiology over and above that of electrical remodeling which might contribute to the perpetuation of AF. The 5-day period was chosen because in previous experiments an increase in AF stability was clearly demonstrable after this period of maintained AF. Indeed, in 5 of the 7 goats in this study the individual episodes of induced AF were lasting longer than 24 hours by this time. So although a contribution from structural factors is likely in longer lasting $\mathrm{AF}$. it is clear that such factors are not necessary for AF to become stable in the goat model. 


\section{CELLULAR MECHANISMS OF ATRIAL ELECTRICAL REMODELLING}

In the original study of Wijffels et al. ${ }^{4}$ atrial electrical remodeling induced by maintaining AF for long periods was shown to have a rapid onset (most of the effect occurring in the first 2 days) and be completely reversible within less than one week of resumption of sinus rhythm. The current study has demonstrated that, for episodes of AF maintained for 5 days, electrical remodeling is fully reversible within 48 hours. This time course of onset and offset of electrical remodeling has implications for the underlying cellular mechanisms involved. Very short-term metabolic changes, such as changes in ionic pump activity or phosphorylation of ion channels, are unlikely to be the underlying mechanism. Similarly, long term structural changes are not likely to be implicated. In contrast. processes leading to altered gene expression of ion channel proteins would be expected to have a time course of onset and offset similar to that of electrical remodeling demonstrated in this study. This would be consistent with studies in human and dog atrial myocardium that have shown changes in ion channel expression occur in chronic AF (associated with reduced expression of Kv1.5 alpha subunit proteins and a decreased outward potassium current density) ${ }^{17}$ and after prolonged rapid atrial pacing (results in a reduction of densities of the transient outward current [Ito] and L-Iype calcium current [ICa] )."

\section{RELEVANCE TO CARDIAC MEMORY}

The term "cardiac memory" has been used to describe the persistence of T wave changes after termination of ventricular pacing. left bundle branch block or ventricular preexcitation ${ }^{19}$ and it has been suggested that an atrial equivalent of this phenomenon may have relevance to the mechanism of atrial electrical remodeling and its reversal following termination of atrial fibrillation. Certainly the development and persistence of altered repolarisation in response to increased rate and/or changed electrical activation sequence is a shared feature. In a canine heart model of cardiac memory such changes are abolished by pretreatment with 4-aminopyridine, a blocker of the transient outward current (Ito), ${ }^{3}$ consistent with the participation of specific potassium channels in the development of the memory phenomenon. Katz ${ }^{21}$ discussed the modification of potassium channels as a basis for cardiac memory and summarised evidence for altered gene expression determining the structure and function of ion channels as an important mechanism for changes in cardiac repolarisation. Supporting this view are the observations that alterations of the activation sequence can lead to altered wall motion and stretch and that cell deformation can modify protein synthesis by stimulation of stretch-activated channels. ${ }^{2}$ A key aspect of the original observations of cardiac memory was the increased magnitude and slower regression of $\mathrm{T}$ wave changes when the heart was exposed repeatedly to the changes in ventricular activation sequence ("accumulation")." Del Balzo and Rosen 
20 demonstrated accumulation in the open-chest anaesthetised dog subjected to 3 discontinuous 20-minute periods of right ventricular pacing, each separated by a period of normal conduction sufficient for $T$ wave changes to return to control values. They noted that the magnitude and duration of the post-pacing $T$ wave changes increased with each successive pacing period. These findings are clearly in contrast to those of the current study, in which there was no evidence of accumulation of either the remodeling process itself (refractoriness changes) or the rate of development of stable AF. Clinical studies also indicate that cardiac memory has a much slower offset than atrial remodeling, with $\mathrm{T}$ wave changes remaining weeks or months after cessation of pacing. This difference in time course argues against a common mechanism.

\section{ABSENCE OF A CUMULATIVE EFFECT OF AF PAROXYSMS}

The absence of any demonstrabie cumulative effect of short AF paroxysms independent of atrial electrical remodeling in the goat has significant implications. As long as there is sufficient time between paroxysms of AF to allow atrial refractoriness to return to normal, the substrate for $\mathrm{AF}$ is not altered and paroxysmal AF would not be expected to progress to chronic AF. In addition to the possible clinical importance of these observations (see below), this high degree of reproducibility of the remodeling process and lack of cumulative effects indicates that the model is suitable for experimental study of potential inhibitors of the process.

\section{CLINICAL IMPLICATIONS AND LIMITATIONS}

The current study has demonstrated that the general concept of "AF begets $\mathrm{AF}^{\text {" is only }}$ likely to apply to recurrent paroxysmal AF if there is insufficient time between paroxysms to allow for full reversal of atrial electrical remodeling. This would imply that the development of chronic or permanent AF might be prevented by aggressive treatment of patients with very frequent paroxysms of AF with therapies aimed at either increasing the time between episodes or accelerating recovery from electrical remodeling. Of course the extent to which the remodeling process, as demonstrated in the goat, applies to the clinical situation is unknown and the results of the current study (particularly in terms of time required for recovery of remodeling) cannot be extrapolated directly to humans without further clinical studies.

This study was not designed to examine the question of why some individuals (goats or humans) are more susceptible to AF-induced electrophysiological changes than others and this aspect of the process remains to be investigated. 
Table 1. Effects of Maintained Atrial Fibrillation on Inducibility of Atrial Fibrillation With Single Premature Stimuli.

\begin{tabular}{|c|c|c|c|c|c|c|c|c|c|c|}
\hline Goats & $\begin{array}{l}\text { Pacing } \\
\text { Site }\end{array}$ & $S R$ & $\begin{array}{c}\text { After } 12 \\
\text { Hours }\end{array}$ & $\begin{array}{c}\text { After } 24 \\
\text { Hours }\end{array}$ & SR & $\begin{array}{c}\text { After } 12 \\
\text { Hours }\end{array}$ & $\begin{array}{c}\text { After } 24 \\
\text { Hours }\end{array}$ & SR & $\begin{array}{c}\text { After } 12 \\
\text { Hours }\end{array}$ & $\begin{array}{c}\text { After } 24 \\
\text { Hours }\end{array}$ \\
\hline \multirow[t]{2}{*}{1} & RA & - & + & + & - & $\div$ & + & - & + & + \\
\hline & LA & + & + & + & + & + & + & + & + & + \\
\hline 2 & LA & + & + & + & + & + & + & + & + & + \\
\hline \multirow[t]{2}{*}{3} & RA & - & + & + & - & + & + & - & + & + \\
\hline & LA & - & + & + & - & + & + & - & + & + \\
\hline \multirow[t]{2}{*}{4} & $\mathrm{RA}$ & - & $=$ & + & - & - & + & - & - & - \\
\hline & LA & - & + & + & - & + & + & - & + & + \\
\hline 6 & LA & - & + & + & - & + & + & + & + & + \\
\hline \multirow[t]{2}{*}{7} & RA & - & - & + & - & - & + & - & - & + \\
\hline & L.A & + & + & + & - & + & + & - & + & + \\
\hline \multicolumn{2}{|c|}{ All Goats } & $\begin{array}{c}5 / 14 \\
(36 \%)\end{array}$ & $\begin{array}{c}12 / 14 \\
(86 \%)\end{array}$ & $\begin{array}{c}14 / 14 \\
(100 \%)\end{array}$ & $\begin{array}{c}3 / 14 \\
(21 \%)\end{array}$ & $\begin{array}{l}12 / 14 \\
(86 \%)\end{array}$ & $\begin{array}{c}14 / 14 \\
(100 \%)\end{array}$ & $\begin{array}{c}6 / 14 \\
(43 \%)\end{array}$ & $\begin{array}{c}12 / 14 \\
(86 \%)\end{array}$ & $\begin{array}{c}13 / 14 \\
(93 \%)\end{array}$ \\
\hline
\end{tabular}




\section{References}

1. Godtfredsen J. Atrial fibrillation: etiology, course and prognosis. A follow-up study of 1212 cases. Copenhagen, Munksgaard, 1975.

2. Petersen P. Godtfredsen J. Atrial fibrillation: a review of course and prognosis. Acta Med Scund. 1984:216:5-9.

3. Kopecky St. Gersh BJ, McGoon MD, Whisnant JP, Holmes DR, Ilstrup DM, Frye RL. The natural history of lone atrial fibrillation: a population based study over three decades. $N$ Eng $J$ Med. 1987:317:669-674.

4. Wijffels MCEF, Kirchof CJHJ. Dorland R. Allessie MA. Atrial fibrillation begets atrial fibrillation. A study in awake chronically instrumented goats. Circulation 1995:92:1954-1968.

5. Moe GK. On the multiple wavelet hypothesis of Af. Anch Int Pharmacodyn Ther. 1962; 140:183-188.

6. Moe GK. Rheinboldt WC. Abildskov JA. A computer model of atrial fibrillation. Am Heart J. 1964:67:200-220.

7. Van Gelder IC. Crijns HJ, Van Gilst WH. Hamer HPM. Lie KI. Decrease of right and left atrial sizes after direct current electrical cardioversion in chronic atrial fibrillation. Am J Candiol. 1991:67:93-95.

8. Manning WJ, Silverman DI, Katz SE, Riley MF. Come PC. Doheny RM. Munson IT. Douglas PS Impaired left atrial mechanical function after cardioversion: relation to the duration of atrial fibrillation. J Am Coll Candiol, 1994:23:1535-1540.

9. Leistad E, Aksnes G, Verburg E. Christensen G. Atrial contractile dysfunction after short-term atrial fibrillation is reduced by verapamil but increased by BAY K8644.

10. Tieleman RG, de Langen CDJ, Van Gelder IC, de Kam PJ, Grandjean J, Bel KJ. Wijffels MC, Allessic MA. Crijns HJ. Verapamil reduces tachycardia induced electrical remodeling of the atria. Cinculation 1997:95:1945-1953.

11. Goette A. Honeycun C. Langberg JJ. Electrical remodeling in atrial fibrillation: time course and mechanisms, Circulation 1996:94:2968-2974.

12. Gaspo R. Bosch RF. Talajic M. Nattel S. Functional mechanisms underlying tachycardia-induced sustained atrial fibrillation in a chronic dog model. Circulation 1997:96:4027-4035.

13. Morillo CA, Klein GJ, Jones DL. Guiraudon CM. Chronic rapid atrial pacing: structural. functional and electrophysiologic characteristics of a new model of sustained AF. Cinculatiom 1995:91:1588-1595,

14. Gaspo R. Bosch RF. Bou-Abboud E. Nattel S. Tachycardia-induced changes in Na+ current in a chronic dog model of atrial fibrillation. Cin Res 1997:81:1045-1052.

15. Ausma J, Wijffels M. van Eys G. Koide M. Ramaekers F. Allessie M. Borgers M. Dedifferentiation of atrial cardiomyocytes as a result of chronic atrial fibrillation. Am J Pathol. 1997:151:985-997.

16. Ausma J. Lenders MH. Mast F, Allessie MA. Ramaekers F. Wouters L. Thone F, Borgen M. Time course of structural changes due to atrial fibrillation in the goat (abst.). Cinculation 1998;98: 1-683,

17. Van Wagoner DRV. Pond AL. McCarthy PM. Trimmer JS. Nerbonne JM. Outward K+ current densities and Kv1.5 expression are reduced in chronic human atrial fibrillation. Circ Res. 1997;80:772-781. 
18. Yue L, Feng J, Gaspo R, Li G-R, Wang Z, Nattel S. Ionic remodeling underlying action potential changes in a canine model of atrial fibrillation. Circ Res. 1997:81:512-525.

19. Rosenbaum MB, Blanco HH, Elizari MV, Lazari JO, Davidenko JM. Electrotonic modulation of the T wave and cardiac memory. Am J Cantiol. 1982;50:213-222.

20. Del Balzo U, Rosen MR. T wave changes persisting after ventricular pacing in canine heart are altered by 4-aminopyridine but not by lignocaine. Circulation, 1992:85:1464-1472.

21. Katz AM. T wave "memory": possible causal relationship to stress-induced changes in cardiac ion channels? J Cardiovase Electrophysiol. 1992:3:150-159.

22. Sadoshima JI. Izumo S. Mechanical stretch rapidly activates multiple signal transduction pathways in cardiac myocytes: Potential involvement of an autocrine/ paracrine mechanism. EMBO 1993:12:1681-1692. 


\section{Chapter 3}

\section{Widening of the Window of Inducibility of AF by Electrical Remodeling:}

\section{Time course and Mechanisms.}

Mattias Duytschaever, MD: Peter Danse, MD; Maurits Allessie, MD, PhD

This study was presented in part at the 2 Ist Annual Scientific Sessions of The North American Society of Pacing and Electrophysiology. May 17-20, 2000, Washington. 


\section{Abstract}

Background: Electrical remodeling of the atria due to fibrillation (AF) creates a substrate for perpetuation of AF. In the present study we evaluated the effect of electrical remodeling on the window of inducibility (WI-AF) and the substrate of initiation of AF by single premature beats.

Methods: In 7 goats AF was maintained for 2 days by burst pacing. After 24 and $48 \mathrm{~h}$ of electrical remodeling WI-AF was determined at 7 atrial sites at the right (RA) and left atrium (LA) and Bachmann's bundle (BB). During regular pacing (S1-S1:400ms), the upper and lower limit of inducibility of AF (ULI-AF, LLI-AF) by a single premature stimulus (S1-S2) were determined. Dispersion in atrial refractoriness (DISP-AERP) was defined by the difference between the shortest and longest AERP. The zone of conduction delay (CDZ) of premature beats was determined by mapping of RA, LA and BB.

Results: In all goats, 2 days of AF resulted in a marked ( 3 to 15-fold) widening of WIAF. Due to AF-induced shortening of refractoriness, LLI-AF decreased at all sites whereas ULI-AF remained constant $( \pm 150 \mathrm{~ms})$. Widening of WI-AF was not due to an increase in DISP-AERP $(66 \pm 21 \mathrm{~ms}$ vs $76 \pm 16 \mathrm{~ms}, \mathrm{p}=0.37)$ or CDZ $(73 \pm 25 \mathrm{~ms}$ vs $88 \pm 26 \mathrm{~ms}, \mathrm{p}=0,38$ ). Both in normal and remodeled atria, premature beats were associated with a similar zone of critical conduction at the mid-portion of BB. However only after $48 \mathrm{~h}$ of $\mathrm{AF}$, due to the short AERP, the presence of critical conduction at BB resulted in reentry and initiation of AF.

Conclusions: In the goat, electrical remodeling by two days of AF is associated with a marked widening of the window of inducibility of AF by premature beats. AF paroxysms could now be initiated by both short and late coupled premature beats. Widening of the window of inducibility was not related to an increase in dispersion of refractoriness or the zone of conduction delay/block of premature beats. Instead, enhanced vulnerability to AF could be explained by the higher likelihood of uni-directional block and reentry in remodeled atria.

Key-words: Fibrillation-Electrophysiology-Vulnerability. 


\section{Introduction}

New approaches to treat human atrial fibrillation are evolving rapidly.' Part of these strategies (preventive atrial pacing, surgical maze, linear ablation, pulmonary vein ablation, antiarrhythmic drugs) is directed at the prevention of the initiation of atrial fibrillation (AF). However, despite a significant reduction of paroxysms of AF, in many cases recurrences still frequently occur. Gaining more insights into the pathophysiological mechanisms of the initiation of AF might help to increase the efficacy of prevention of AF, In humans paroxysms of AF are elicited by atrial premature beats or by a repetitively discharging focus. ${ }^{2-}$ The actual mechanism of initiation of AF by these "triggers" is still unclear. Also little is known to what extent AF-induced electrical remodeling plays a role in the development of a substrate for initiation of AF."

In the present study, we determined the effects of AF-induced electrical remodeling in the goat on the initiating mechanisms of AF by single premature beats. Both for right and left atrial premature beats, we determined the window of inducibility of AF before and after 1-2 days of atrial fibrillation. Programmed electrical stimulation was used to measure dispersion in atrial refractoriness and the zone of conduction delay of premature beats. The mechanism of initiation of AF was evaluated by mapping.

\section{Methods}

\section{THE GOAT MODEL OF AF}

Seven goats weighing between 42 and $58 \mathrm{~kg}(50 \pm 6)$ were used for this study. Animal handling was carried out according to the European Directive for animal research. The study was approved by the ethical committee of the university of Maastricht. After sedation with Nesdonal ( $15 \mathrm{mg} / \mathrm{kg} \mathrm{I.V.)} \mathrm{the} \mathrm{animals} \mathrm{were} \mathrm{anaesthetized} \mathrm{by} \mathrm{halothane} \mathrm{(I} \mathrm{to}$ $2 \%$ ) and a mixture of $\mathrm{O}_{2}$ and $\mathrm{N}_{2} \mathrm{O}$. The chest was opened through a left intercostal thoracotomy and three teflon felt plaques. each containing 23-30 silver electrodes, were sutured to the atria (Fig.1). A rectangular plaque $(3 \times 2.5 \mathrm{~cm}$, 30 electrodes, inter-electrode distance $4 \mathrm{~mm}$ ) was sutured on the free wall of the right (RA) and left atrium (LA). A strip of $6 \times 1 \mathrm{~cm}$. containing 23 electrodes (inter-electrode distance 6-10 mm) was pulled through the space between the aortic root and Bachmann's bundle (BB) and sutured to the tips of the atrial appendages. A silver plate was sutured subcutaneously to serve as indifferent electrode. The electrode leads were tunneled to the neck and exteriorized by three 30-pin connectors (Lemosa®). Post-operatively the animals received 
buprenorfine (Temgesic®) for 1-3 days. Ampicilline (1000mg) was given prophylactically once before and after surgery. The experiments were started 3-4 weeks after surgery. A fibrillation pacemaker was used to maintain atrial fibrillation for 48 hours.' A custom made computer program automatically delivered 1-second bursts of stimuli (50$\mathrm{Hz}$ ) to a pair of atrial electrodes as soon as sinus rhythm was detected.

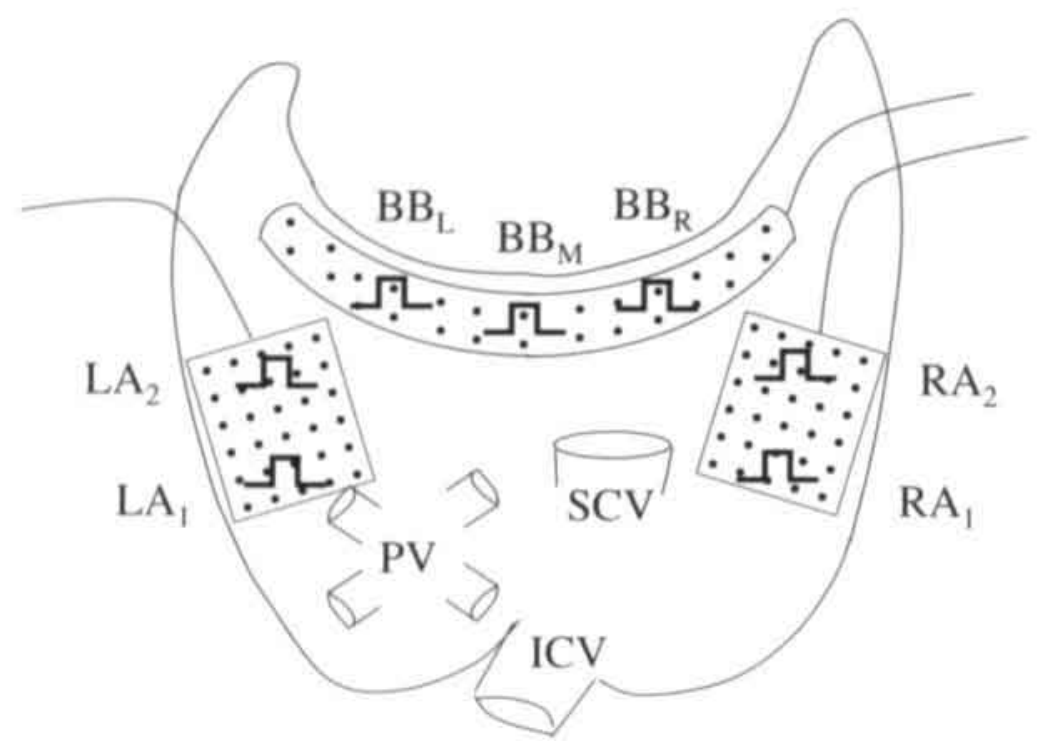

Figure I. Lscalization of the epicardial electrodes. Stimulation was performed at 7 atrial sites at the right atrium (RA) and RA2) and left atrium (LA) and LA2) and the right (BBR). mid (BBM) and leff (BBL.) parts of Bachmann's' bunalle.

\section{DATA ACQUISITION}

After amplification $(500 \mathrm{x})$ and filtering $(1-500 \mathrm{~Hz})$ all unipolar atrial electrograms were stored on tape. The spatial propagation of depolarization waves was reconstructed by custom made mapping software. Local activation times were determined automatically by an algorithm detecting the maximal negative slope of the electrograms. Isochrones were drawn manually at 5 or $10 \mathrm{~ms}$ intervals.

\section{EXPERIMENTAL PROTOCOL}

In each animal, the protocol was performed before and after 24 and 48 hours of AFinduced electrical remodeling. Measurements were performed at least 10 minutes after spontaneous termination of a paroxysm of AF. The atria were paced by biphasic stimuli 
of $2 \mathrm{~ms}$ duration generated by a constant current stimulator (Medtronic SP3111). The minimal current intensity required for capture during slow pacing was taken as the stimulation threshold.

The window of inducibility of AF by single premature beats (WI-AF) was determined at 7 atrial sites ( $\mathrm{RA}_{1}: \mathrm{RA}_{2}: \mathrm{LA}_{1}: \mathrm{LA}_{2} ; \mathrm{BB}_{\mathrm{k}}: \mathrm{BB}_{\mathrm{M}} ; \mathrm{BB}_{1}$ ) (see Fig.1). During regular pacing with an interval of $400 \mathrm{~ms}$, premature stimuli ( $\mathrm{S} 1-\mathrm{S} 2,4 \mathrm{x}$ threshold) were applied, starting with a coupling interval of $250 \mathrm{~ms}$. Each coupling interval was repeated 3 times and then decremented in steps of $5 \mathrm{~ms}$. Induction of AF by a single premature stimulus was defined as a rapid irregular atrial activity lasting for more than 2 seconds. The upper limit of the window of inducibility (ULI-AF) was determined as the longest S1-S2 coupling interval resulting in AF. The lower limit (LLI-AF) was defined by the shortest S1-S2 interval that induced AF.

The atrial effective refractory period (AERP) was determined during regular pacing with an S1-S1 interval of $400 \mathrm{~ms}$. After every $8^{\text {"t }}$ basic stimulus, premature stimuli (S1-S2, 4x threshold) were interpolated, starting with a coupling interval well within the refractory period. Incrementing the coupling interval in steps of $2 \mathrm{~ms}$, the shortest S1-S2 interval resulting in a propagated atrial response was taken as the AERP. Spatial dispersion in AERP (DISP-AERP) was defined as the difference between the longest and shortest AERP measured at the 7 pacing sites.

The zone of conduction delay of premature beats (CDZ) was determined during premature stimulation at $\mathrm{RA}_{1}$ and $\mathrm{LA}_{1}$. The longest $\mathrm{S} 1-\mathrm{S} 2$ interval associated with an intra-atrial conduction delay of $>10 \mathrm{~ms}$, was taken as limit for conduction delay. Mapping of RA, LA and BB was used to partly reconstruct the activation pattern of the premature beats and initiation of $\mathrm{AF}$.

\section{STATISTICAL ANALYSIS}

Data are presented as mean \pm SD. Statistical analysis was performed by the paired Student's t test. A p-value of less than 0.05 was considered as statistically significant. 


\section{Results}

\section{WIDENING OF THE WINDOW OF INDUCIBILITY DURING 48 HOURS OF AF}

During the first $48 \mathrm{~h}$ of $\mathrm{AF}$, we observed a marked widening of the window of inducibility of $\mathrm{AF}$ by single premature beats. A representative example during premature stimulation at $\mathrm{RA}_{1}$ is shown in Fig.2. Due to the AF-induced shortening of atrial refractoriness, after 24 and $48 \mathrm{~h}$ of AF paroxysms could be initiated by earlier premature beats (lowering of LLI-AF from $126 \mathrm{~ms}$ to $96 \mathrm{~ms}$ to $68 \mathrm{~ms}$ ). On the other hand the longest SI $\mathrm{S} 2$ interval that could induce AF was not changed during the 2 days of electrical

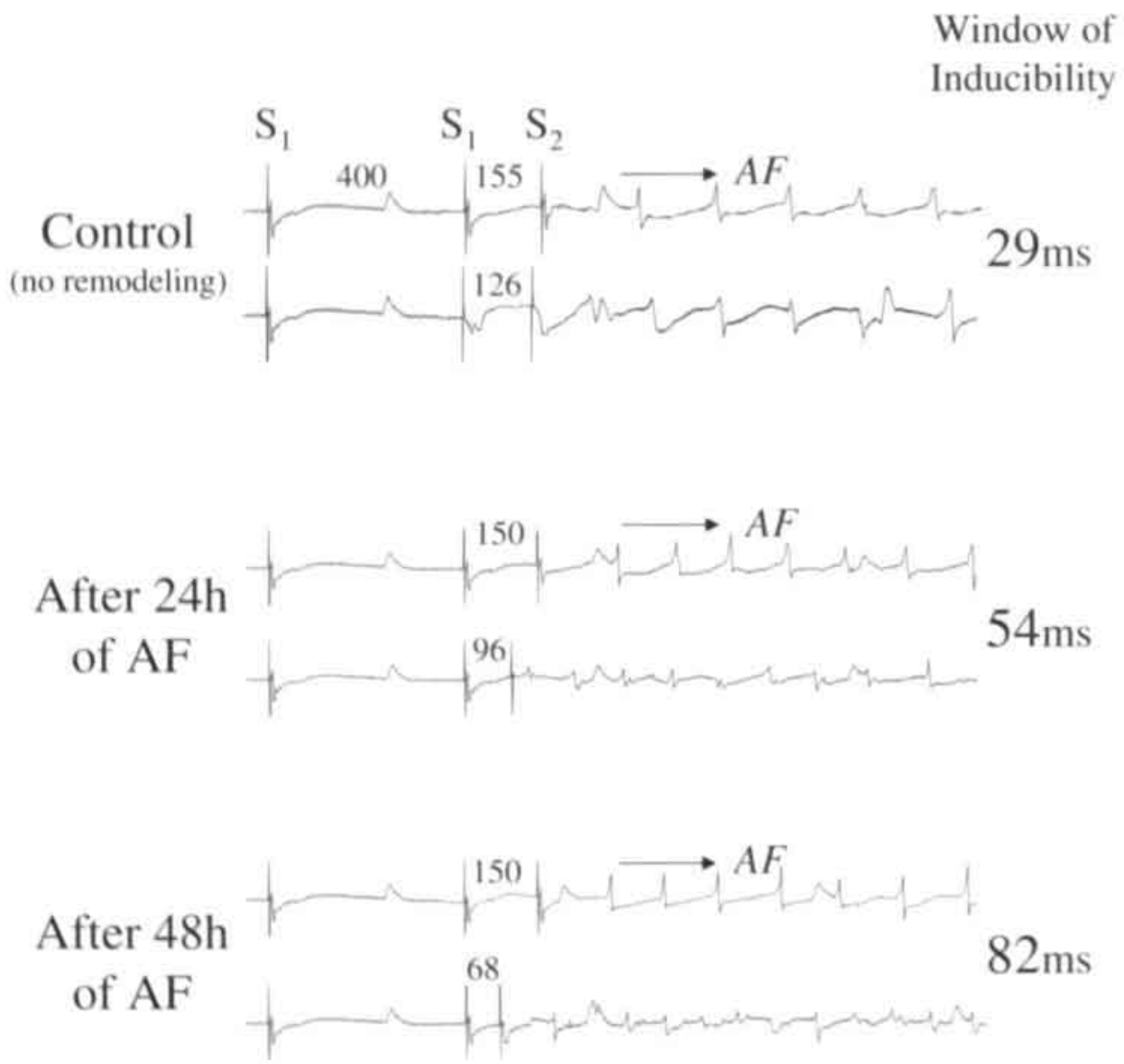


remodeling (ULI-AF: from $155 \mathrm{~ms}$ to $150 \mathrm{~ms}$ to $150 \mathrm{~ms}$ ). As a result. the window of inducibility widened from $29 \mathrm{~ms}$ during control to $54 \mathrm{~ms}$ and $82 \mathrm{~ms}$ after 1 and 2 days of AF. In Fig.3, the window of inducibility of AF of the right and left atrium is plotted for all goats. At the right atrium (left panel). WI-AF widened from $20 \pm 14 \mathrm{~ms}$ to $45 \pm 9 \mathrm{~ms}$ after $24 \mathrm{~h}$ of $\mathrm{AF}(\mathrm{p}<0.01)$ and $73 \pm 15$ after $48 \mathrm{~h}$ of $\mathrm{AF}(\mathrm{p}<0.01)$. At the left atrium (right panel), WI-AF widened from $8 \pm 15 \mathrm{~ms}$ to $41 \pm 18 \mathrm{~ms}(\mathrm{p}<0.01$ ) and $62 \pm 15(\mathrm{p}<0.01)$. In both cases, widening of WI-AF was due to a significant shortening of LLI-AF $(p<0.01)$ while ULIAF remained constant ( $\mathrm{p}$-value ranging from 0.30 to 0.87 ). In Table 1, the mean LLI-AF, ULL-AF and WI-AF are given for all 7 atrial sites. Two days of AF resulted in a 3 to more than 15-fold widening of WI-AF. In all cases widening of WI-AF was due to shortening of LLI-AF ( $<<0.01)$ whereas ULI-AF remained constant. The LLI-AF was determined by the local AERP, whereas ULI-AF was independent of the site of premature stimulation. At the mid-portion of Bachmann's bundle $\left(\mathrm{BB}_{\mathrm{M}}\right)$ premature stimuli never elicited a paroxysm of AF.

Right Atrium

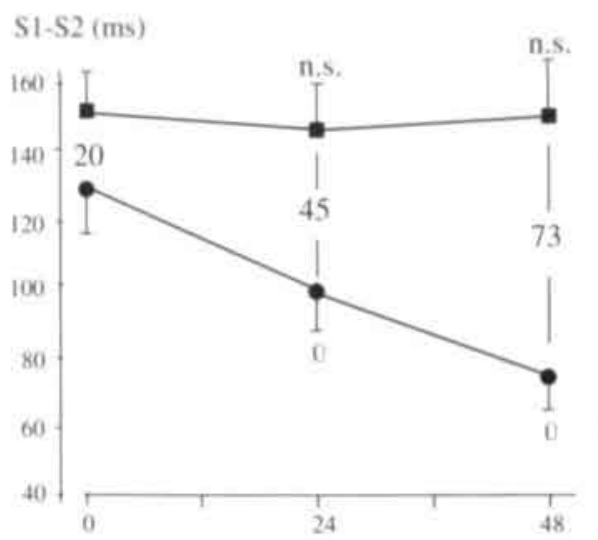

Hours of AF

\section{Left Atrium}

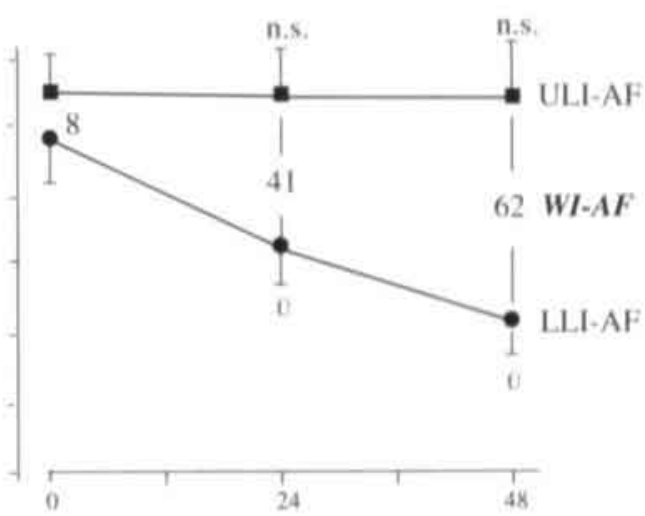

Hours of AF

Figure 3. Progressive widening of the window of inducibility of AF (7 goats) by single premature stimuli applied at the right and left atrium. 


\section{SPATIAL DISPERSION OF REFRACTORINESS BEFORE AND AFTER REMODELING}

We hypothesized that the upper limit of inducibility was determined by the longest refractory period present somewhere in the atria. In Fig. 4 we plotted the mean AERP at 7 atrial sites before and after remodeling ( 7 goats). During control (left panel), AERP at $\mathrm{BB}_{\mathrm{M}}(186 \pm 9 \mathrm{~ms})$ was significantly longer $(\mathrm{p}<0.01)$ than the AERP at $\mathrm{RA}_{1}(130 \pm 14 \mathrm{~ms})$, $\mathrm{RA}_{2}(146 \pm 18 \mathrm{~ms}), \mathrm{BB}_{\mathrm{k}}(148 \pm 18 \mathrm{~ms}), \mathrm{BB}_{\mathrm{L}}(136 \pm 24 \mathrm{~ms}), \mathrm{LA}_{2}(140 \pm 14 \mathrm{~ms})$ and LA, $(138 \pm 18 \mathrm{~ms})$. There was no significant difference between the other 6 sites. The spatial dispersion in AERP was $66 \pm 21 \mathrm{~ms}$. After electrical remodeling by $48 \mathrm{~h}$ of $\mathrm{AF}$ (right panel) the AERP was (equally) shortened at all sites. As a result, the AERP at the middle portion of $\mathrm{BB}(146 \pm 16 \mathrm{~ms})$ was still significantly longer $(\mathrm{p}<0.01)$ than at each of the other 6 atrial sites $\left(\mathrm{RA}_{1}: 74 \pm 14 \mathrm{~ms} ; \quad \mathrm{RA}_{2}: 83 \pm 17 \mathrm{~ms} ; \mathrm{BB}_{\mathrm{k}}: 85 \pm 16 \mathrm{~ms} ; \mathrm{BB}_{1}: 98 \pm 33 \mathrm{~ms}\right.$; $\mathrm{LA}_{2}: 84 \pm 15 \mathrm{~ms}: \mathrm{LA}_{1}: 83 \pm 11 \mathrm{~ms}$ ). The spatial dispersion in AERP in the remodeled atria was not significantly different from control $(76 \pm 16 \mathrm{~ms}, \mathrm{p}=0.37)$.

\section{Control (no Remodeling)}

\section{After $48 \mathrm{~h}$ of $\mathrm{AF}$}

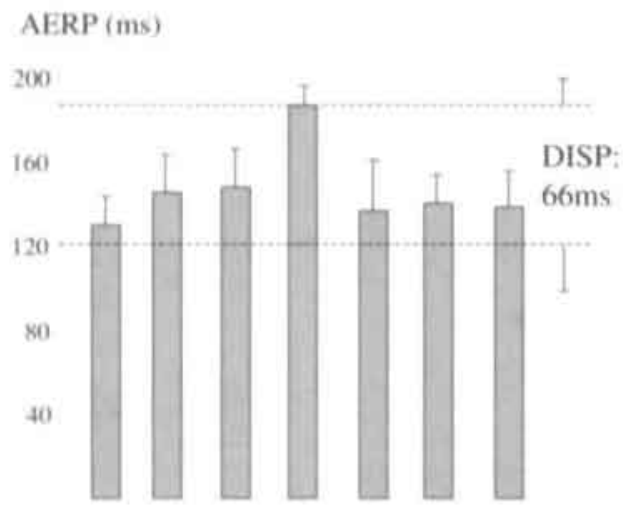

$\begin{array}{lllllll}R A_{1} & R A_{3} & B B_{k} & B B_{M} & B B_{L} & L A_{2} & L A_{1}\end{array}$
$\operatorname{AERP}(m s)$

200

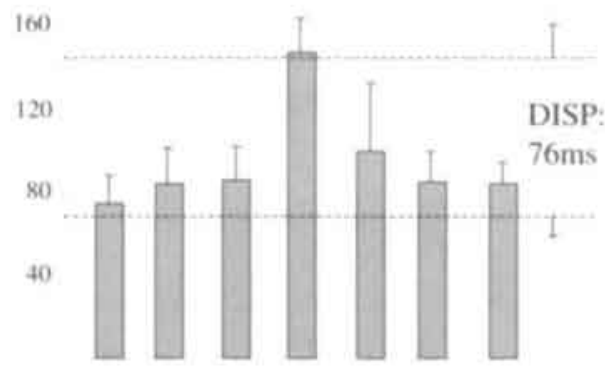

$\begin{array}{lllllll}R A_{1} & R A_{2} & B B_{R} & B B_{M} & B B_{1} & L A_{2} & L A_{1}\end{array}$

Figure 4. Sparial distribution of atrial nefroctoriness before and after $48 \mathrm{~h}$ of AF 77 goats). The spatial dispersion in AERP was net significantly altered after $48 \mathrm{~h}$ of $A F, 76 \pm 10 \mathrm{~ms}$ vs $00 \pm 2, p=0.37$. The exact location of atrial sites is illustrated in Fig. $l$. 


\section{CONDUCTION DELAY OF PREMATURE BEATS BEFORE AND AFTER REMODELING}

In all goats, single premature beats elicited in the right and left atrium were associated with preferential conduction delay at the mid-portion of Bachmann's bundle. In the left panel of Fig.5 the A1-A2 intervals along $B B\left(B_{k}\right.$ and $\left.B B_{L}\right)$ in response to $S 1-S 2$ stimulation at $\mathrm{RA}_{1}$ are plotted. Due to AF-induced electrical remodeling. AERP had shortened from $120 \mathrm{~ms}$ during control to $82 \mathrm{~ms}$ after $48 \mathrm{~h}$ of $\mathrm{AF}$. Both in normal and remodeled atria, at long coupling intervals $(>200 \mathrm{~ms})$ premature beats conducted without conduction delay along $\mathrm{BB}\left(\mathrm{A} 1-\mathrm{A} 2_{\text {ван }}=\mathrm{A} 1-\mathrm{A} 2_{\text {ввк }}\right)$. However, whereas during control progressive conduction delay ( $\mathrm{A} 1-\mathrm{A} 2_{\mathrm{Ba}}>\mathrm{A} 1-\mathrm{A} 2_{\text {Bar }}$ ) became apparent at $\mathrm{S} 1-\mathrm{S} 2$ intervals $<200 \mathrm{~ms}$, in remodeled atria conduction delay occurred only at $\mathrm{S} 1-\mathrm{S} 2$ intervals $<160 \mathrm{~ms}$.

In the right panel of Fig.5, the conduction time along BB in response to SI-S2 stimulation at RA is plotted for 7 goats. The relative prematurity of the $\mathrm{S} 1-\mathrm{S} 2$ interval is defined as the degree of prematurity relative to the AERP (S1-S2 interval - AERP). Both during control and after $48 \mathrm{~h}$ of $\mathrm{AF}$, premature beats were associated with similar intra-atrial conduction delay. In both cases, with increasing degree of prematurity a progressive increase in conduction time from $30 \mathrm{~ms}$ to $85 \mathrm{~ms}$ became apparent. In normal atria, the zone of conduction delay of RA premature beats was $73 \pm 25 \mathrm{~ms}$ compared to $88 \pm 26 \mathrm{~ms}$ after $48 \mathrm{~h}$ of $\mathrm{AF}(\mathrm{p}=0.38$ ). Also for LA premature beats CDZ had not changed after $48 \mathrm{~h}$ of $\mathrm{AF}(62 \pm 14 \mathrm{~ms}$ vs $74 \pm 18 \mathrm{~ms}, \mathrm{p}=0.36)$.
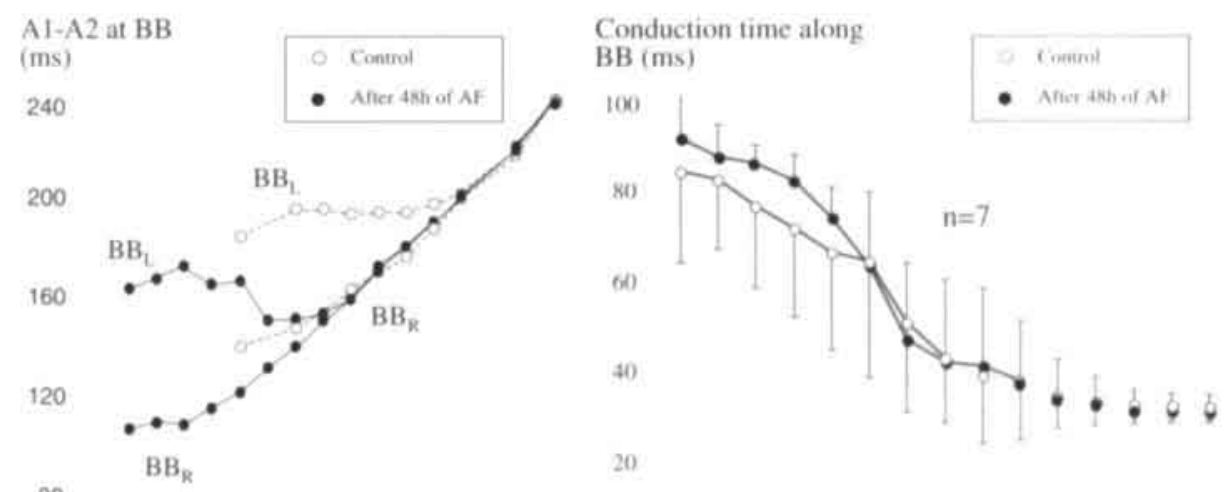

80

$$
\begin{array}{lll}
120 & 160 & 200 \\
& & \mathrm{~S} 1-\mathrm{S} 2(\mathrm{~ms})
\end{array}
$$$$
\begin{gathered}
\text { AERP }+20+40+60++80+1(x)+120+140 \\
\text { Relative S1-S2 (ms) }
\end{gathered}
$$

Figure 5. Left panel: representative A1.A2 curves along BB during S1-52 pacing at RA. See test for explanation. Right panel: mean conduction time along BB for 7 goats. The prematurity of the $51-S 2$ interval is presented as the degree of prematurity relative to the AERP (S)-S2 interval-AERP). Both during contml and after $48 h$ of AF, premuture beats were associated with similar intra-atrial conduction delay. 


\section{CRITICAL CONDUCTION AND REENTRY BEFORE AND AFTER REMODELING}

In all goats we observed that due to AF-induced shortening of atrial refractoriness, in remodeled atria critical conduction at $\mathrm{BB}_{\mathrm{M}}$ resulted more readily in reentry of the premature beat and initiation of AF. A representative example is shown in Fig.6. The unipolar electrograms were recorded at $\mathrm{RA}, \mathrm{BB}_{\mathrm{k}}, \mathrm{BB}_{\mathrm{M}}, \mathrm{BB}_{\mathrm{L}}$ and $\mathrm{LA}$. In normal atria (left panel), a premature beat with a relative coupling interval of $50 \mathrm{~ms}$ was associated with preferential conduction delay at $\mathrm{BB}_{\mathrm{M}}$, as evidenced by an increase in conduction time

\section{Control (no Remodeling)}

After 48 h of AF
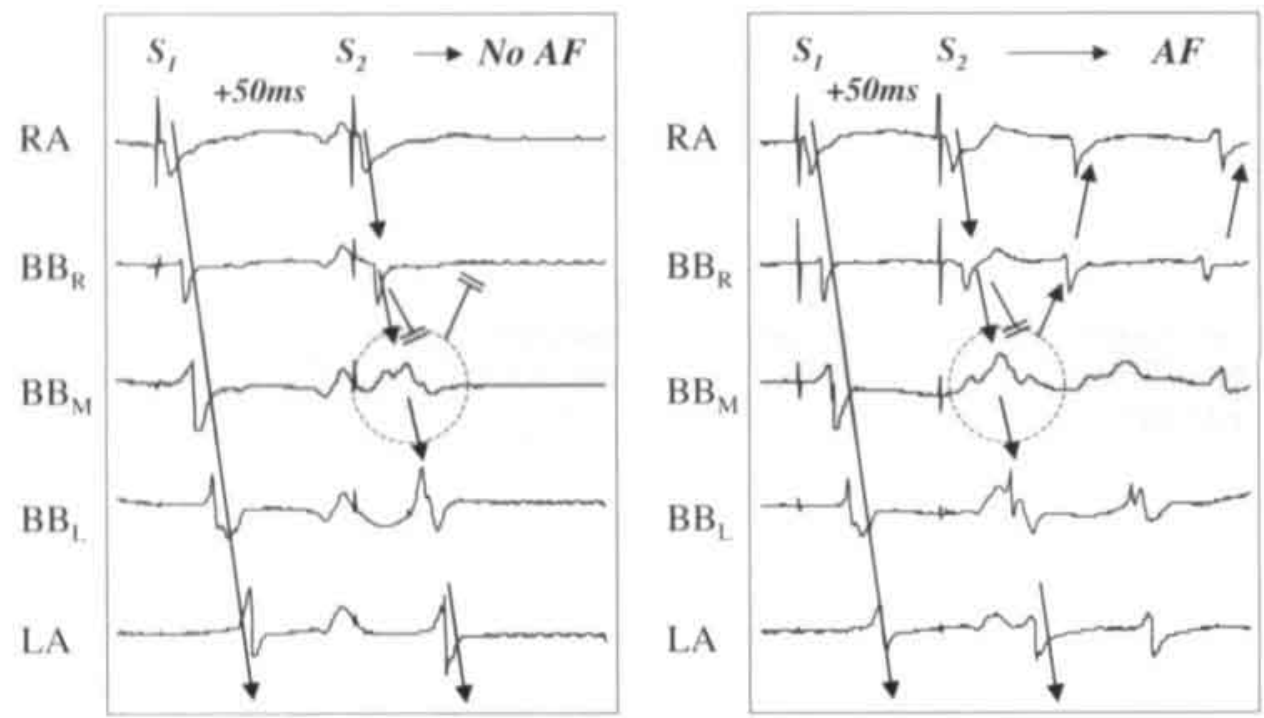

Pisure 6. Uinipolar rlectmegrams reconded at RA. BBR. BBM. BBL. and LA. In normal atria, critical conduction at BBM deses not result in initiation of AF. wherras in remodeled atria fragmentation at BBM is associated with proximal mentry and initiation of $\mathrm{AF}$.

along $\mathrm{BB}$ and fragmented, low amplitude electrograms recorded at $\mathrm{BB}_{\mathrm{M}}$. However. despite the presence of critical conduction and fragmentation at the mid-portion of BB. this premature beat did not evoke AF. After $48 \mathrm{~h}$ of AF (right panel), a premature beat (relative S1-S2: $50 \mathrm{~ms}$ ) was associated with similar conduction delay and fragmentation at $\mathrm{BB}_{\mathrm{M}}$. However, now critical conduction at $\mathrm{BB}_{\mathrm{M}}$ resulted in reentry and initiation of $\mathrm{AF}$ proximal to the area of fragmentation at $\mathrm{BB}_{\mathrm{M}}$. In Fig.7, the corresponding activation maps of RA, BB and LA are shown. During regular pacing ( $\mathrm{S} 1-\mathrm{S} 1: 400 \mathrm{~ms}$ ) the wavefront propagated uniformly from RA along BB to LA. The premature beats, both in normal and remodeled atria, were associated with preferential conduction delay at the mid-portion of BBM (grey area). In both cases, the left side of BB was activated after a considerable conduction delay of $>40 \mathrm{~ms}$. However, only in remodeled atria. critical conduction 
at $\mathrm{BB}_{\mathrm{M}}$ was associated with initiation of $\mathrm{AF}$. From the activation map it can be seen that during the first beat of $\mathrm{AF}$, the earliest activation occurred at $\mathrm{BB}_{\mathrm{K}}$ proximal to area of fragmented potentials. The combination of low-voltage potentials at $\mathrm{BB}_{M}$ and early re-excitation of $\mathrm{BB}_{\mathrm{k}}$ strongly suggests that $\mathrm{AF}$ was initiated by block and reentry in Bachmann's bundle. However. the activation maps can not distinguish between microreentry within BB and macro-reentry involving the inter-atrial septum.

The higher likelihood of reentry of premature beats in remodeled atria was observed in all goats, both during RA and LA premature stimulation. Reentry of the premature beat could be explained by the short AERP present in remodeled atria $(<100 \mathrm{~ms})$. In the presence of critical conduction, a short AERP will allow more readily reentry of the premature beat proximal to the zone of critical conduction (uni-directional block). On the other hand, in non-remodeled atria, despite the presence of critical conduction, a long AERP $(>130 \mathrm{~ms})$ will prevent reentry of the premature beat and initiation of AF (bi-directional block).

\section{Control (no Remodeling)}

\section{After 48 h of AF}
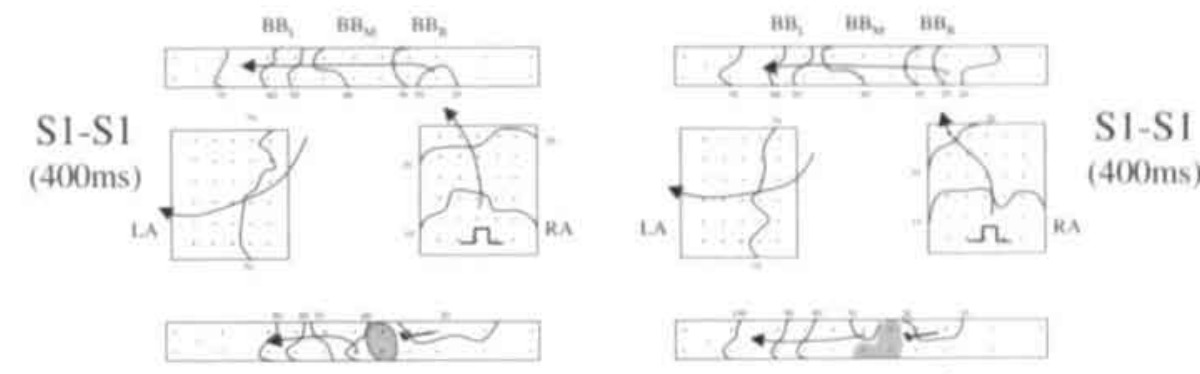

$(400 \mathrm{~ms})$
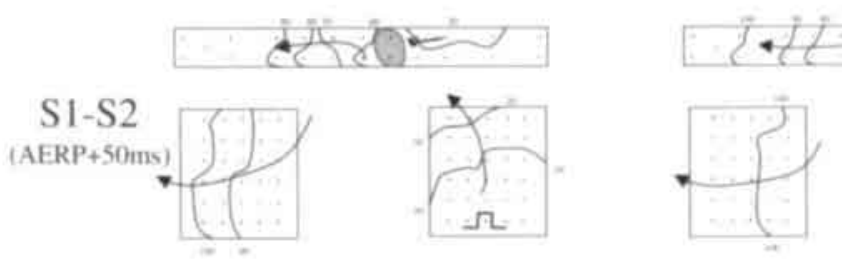

S1-S2
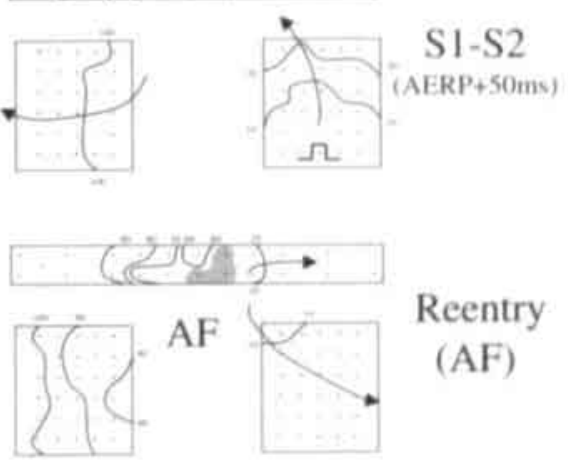

Reentry

(AF)

\section{No} Reentry
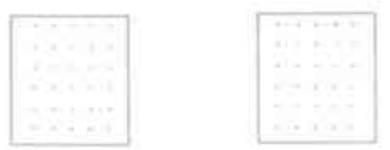

Figure 7. Representative activation maps of RA premature beats before and after remodeling. Both in normat and remodeled arria, premature heats were associated with critical comduction at the mid-portion of BB (grry arra). In remodeled atria. during the first beas of AF. the earliest actwation occurred at BBR pmimal to area of fragmented potentials. 


\section{Discussion}

\section{MAIN FINDINGS}

In the present study we determined in the caprine model, the effect of 2 days of maintained atrial fibrillation on the substrate of initiation of AF by single premature beats. The main results were as follows. (1) In the goat, electrical remodeling by 2 days of $\mathrm{AF}$ is associated with a marked ( 3 to 15 -fold) widening of the window of inducibility of AF by premature beats. Due to AF-induced shortening of atrial refractoriness. AF paroxysms could be initiated by shorter coupled premature beats (shortening of the lower limit of inducibility). However, electrical remodeling did not shorten the upper limit of inducibility which remained constant $( \pm 150 \mathrm{~ms})$. (2) In the goat, the mid-portion of Bachmann's bundle is an area of preferential conduction delay of premature beats. Critical conduction at the center of BB was associated with fragmented low-voltage potentials at Bachmann's bundle. The combination of low-voltage potentials together with early re-excitation proximal to this area strongly suggest that initiation of AF was due to conduction block and reentry at Bachmann's bundle. Critical conduction along Bachmann's bundle could be explained by a considerable longer refractory period at its mid-portion. (3) In the goat, electrical remodeling by 2 days of AF had no effect on the spatial dispersion of atrial refractoriness or the zone of conduction delay of premature beats. As a result, both in normal and remodeled atria, premature beats were associated with a similar zone of critical conduction at the mid-portion of BB. (4) Enhanced vulnerability to initiation of AF by "late" premature beats was due to AF-induced shortening of atrial refractoriness itself. Due to the short AERP, in remodeled atria critical conduction of premature beats resulted more readily in reentry and initiation of AF (uni-directional block).

\section{WIDENING OF THE WINDOW OF INDUCIBILITY OF AF}

Previous studies on the window of inducibility of AF by single premature beats were performed only in non-remodeled atria. In canine hearts, the window of inducibility of AF was $22 \pm 9 \mathrm{~ms}$, In patients, the "zone of induction of repetitive atrial firing" by applying single premature stimuli was $23 \pm 5 \mathrm{~ms}$. Widening of the window of inducibility due to atrial fibrillation implies a highly vulnerable substrate for (re-)initiation of $\mathrm{AF}$ in electrically remodeled atria. After cardioversion of human AF. atrial premature beats both early and late in diastole are expected to re-initiate paroxysms of AF. This might explain the high incidence of recurrences of atrial fibrillation during the first days after restoration of sinus rhythm. 
Although our caprine model of AF can not emulate the more complex substrate in human atrial fibrillation, the present findings may help to guide and optimise treatment of atrial fibrillation in patints. The window of inducibility of AF seems a useful tool to quantify atrial vulnerability for AF by single ectopic beats. The lower limit of inducibility is determined by the local AERP, whereas the upper limit of inducibility was independent of the site of premature stimulation. Treatment strategies aimed at shortening of WI-AF are expected to reduce the statistical likelihood of recurrence of AF. However, it remains to be seen whether antiarrhythmic drugs, linear ablation or preventive pacing can effectively reduce the window of inducibility of human $\mathrm{AF}^{12}$ On the other, in patients with a large window of inducibility, the beneficial effect of a treatment shortening WI-AF might be negligible and useless. Evaluation of the window of inducibility in patients would imply Holter monitoring. body surface mapping or programmed electrical stimulation.

\section{BACHMANN'S BUNDLE: THE "INITIATOR" OF AF}

In the present study we observed preferential conduction delay at the center of Bachmann's bundle. The fragmented low-voltage potentials recorded at Bachmann's bundle could be the result of non-uniform anisotropy, slow discontinuous conduction. longitudinal dissociation or conduction block. "' Critical conduction along Bachmann's bundle could be explained by a considerable longer refractory period at its mid-portion. These findings imply a critical role of the mid-portion of Bachmann's bundle (roof of the inter-atrial septum) in the genesis of human atrial fibrillation. Also in human atria, the inter-atrial septum seems to play a critical role in the genesis of AF. The inter-atrial septum was found to have the longest atrial refractory period and also to be the area of preferential conduction delay of premature beats. ${ }^{16.12}$ More recently, it was shown that in patients with theumatic heart disease, earliest activity during induced $\mathrm{AF}$ was located near the inter-atrial septum (ostium of the coronary sinus)." Treatment strategies aimed at de-activation of this initiator are expected to prevent recurrences of $\mathrm{AF}$. In a recent study in the goat. we showed that pacing at the mid-portion of Bachmann's bundle effectively reduced the propensity of right or left atrial premature beats to induce AF : Also in patients preventive pacing at BB seems to have incremental benefit over pacing at RA. ${ }^{140}$ Likewise, ablation of the mid-part of the inter-atrial septum was shown to reduce the likelihood of initiation of $\mathrm{AF}^{21}$ However we want to emphasize that due to age, dilatation, fibrosis, etc... in patients with $\mathrm{AF}$ other areas than the inter-atrial septum may become the "initiator" of $\mathrm{AF}^{2221}$ Identification of the "initiator" in patients would imply an electrophysiological study to localize the areas of critical conduction and fragmentation and the site(s) of earliest re-activation during AF. 


\section{EFFECT OF ELECTRICAL REMODELING ON THE SUBSTRATE OF INITIATION OF AF}

In the present study we observed no change in spatial dispersion of refractoriness or zone of conduction delay of premature beats after 2 days of maintained atrial fibrillation. Investigators have observed varying alterations in dispersion of AERP after maintained episodes of high atrial rates. ${ }^{6,34}$ Our data are in agreement with previous studies in the goat reporting that the difference between RA and LA refractory period was not altered during remodeling. ${ }^{67}$ On the other hand, Nattel et al. showed that enhanced vulnerability due to rapid atrial pacing was due to an increase in refractoriness heterogeneity. ${ }^{34}$ Also in patients with atrial fibrillation, the increase in atrial vulnerability is often ascribed to an increase in dispersion in atrial refractoriness or a widening of the zone of conduction delay of premature beats. ${ }^{3 *}$

In the present study we showed that enhanced atrial vulnerability might be due to shortening of AERP alone. Due to AF-induced shortening of AERP, critical conduction resulted more readily in reentry (uni-directional block). These findings imply that already in normal human atria (no ageing, no remodeling, ...). due to functional properties of the atrial tissue, a marked substrate for initiation of AF may already exist. However, this substrate of initiation may remain concealed until either shortening of atrial refractoriness (metabolic changes, dilatation,....) or additional changes in the substrate (cardiac disease, fibrosis. ...) will result in reentry and initiation of $\mathrm{AF}$.

\section{LIMITATIONS}

In the present study, atrial vulnerability and the substrate for reentry were measured by applying external extrastimuli during sinus rhythm. Since in the goat, spontaneous atrial premature beats are virtually absent, we could not study the effect of remodeling on the initiation of AF by spontaneous ectopic beats. Also we do not know whether the substrate for initiation of AF would be the same after AF of $>48$ hours of duration. During chronic AF other changes (like a decrease of connexin 40 , an increase in size of the atrial myocytes, loss of sarcomeres, dedifferentiation. atrial dilatation etc.) might alter the substrate for initiation of AF.

The limited epicardial mapping. does not allow complete reconstruction of all the complex interactions between ectopic premature beats and the different pacing modes to prevent initiation of AF. Since no endocardial recordings were made, the three-dimensional structure of the atrial wall, which might play a role in the activation during AF. was not taken into account. 
Table 1. Window of Inducibility of AF by Single Premature Stimuli.

\begin{tabular}{|c|c|c|c|c|c|c|c|c|c|}
\hline \multirow[b]{2}{*}{$\begin{array}{l}\text { Pacing } \\
\text { Sites }\end{array}$} & \multicolumn{3}{|c|}{ CONTROL (NO REMODELING) } & \multicolumn{3}{|c|}{ ATTER $24 \mathrm{H}$ OF AF } & \multicolumn{3}{|c|}{ ATTER $48 \mathrm{H}$ OF AF } \\
\hline & $\begin{array}{c}\text { LLI-AF } \\
\text { (ms) }\end{array}$ & $\begin{array}{c}\text { ULI-AF } \\
\text { (ms) }\end{array}$ & $\begin{array}{c}\text { WI-AF } \\
(\mathrm{ms})\end{array}$ & $\begin{array}{c}\text { LLI-AF } \\
\text { (ms) }\end{array}$ & $\begin{array}{c}\text { ULI-AF } \\
\text { (ms) }\end{array}$ & $\begin{array}{c}\text { WI-AF } \\
\text { (ms) }\end{array}$ & $\begin{array}{c}\text { LLI-AF } \\
\text { (ms) }\end{array}$ & $\begin{array}{c}\text { ULI-AF } \\
\text { (ms) }\end{array}$ & $\begin{array}{c}\text { WI-AF } \\
\text { (ms) }\end{array}$ \\
\hline RAI & $130 \pm 14$ & $\mid 51 \pm 4$ & $20 \pm 14$ & $97 \pm 11 \div$ & $145 \pm 14$ & $45 \pm 9+$ & $74 \pm 14 \%$ & $151 \pm 7$ & $73 \pm 15$ \\
\hline RA2 & $146 \pm 18$ & $152 \pm 11$ & $10 \pm 13$ & $107 \pm 18 \div$ & $144 \pm 16$ & $39 \pm 16 \div$ & $83 \pm 17 \div$ & $158 \pm 20$ & $76 \pm 22 \div$ \\
\hline$B B R$ & $148 \pm 18$ & $147 \pm 16$ & $4 \pm 7$ & $1.12 \pm 19 \div$ & $145 \pm 15$ & $31 \pm 20+$ & $85 \pm 16 \div$ & $151 \pm 11$ & $66 \pm 134$ \\
\hline BBM & No AF & No AF & - & No $A F$ & No $A F$ & - & No $A F$ & No AF & - \\
\hline $\mathrm{LA} 2$ & $140 \pm 14$ & $140 \pm 6$ & $4 \pm 10$ & $108 \pm 12 \div$ & $147 \pm 13$ & $52 \pm 40+$ & $84 \pm 15 \div$ & $143 \pm 18$ & $59 \pm 16+$ \\
\hline LAI & $138 \pm 18$ & $143 \pm 18$ & $8 \pm 15$ & $104 \pm 12 \div$ & $146 \pm 20$ & $41 \pm 18 \div$ & $83 \pm 11 \div$ & $145 \pm 19$ & $62 \pm 15 \div$ \\
\hline
\end{tabular}

Mean values $( \pm$ SD) for 6 goats: LLI-AF: lower limit of inducibility of AF: ULI-AF: upper limit of inducibility of AF: WI-AF: window of inducibility of $\mathrm{AF}: \uparrow: \mathrm{p}<0.01$ compared to control. 


\section{References}

1. Scheinman M. Morady F. Nonpharmacological approaches to atrial fibrillation. Circulation, 2001: 103:2120-2125.

2. Bennet MA, Pentecost BL. The pattern of onset and the spontaneous cessation of atrial fibrillation in man. Circulation, 1970:41:981-988.

3. Hoffmann E, Janko S, Steinbeck G, Edvardsson N, Camm J, for the AFT study group. Onset scenarios of paroxysmal atrial fibrillation using new diagnostic pacemaker functions (abstract). Pacing Clin Electmphysiol, 2000, 23(partII);656.

4. Waktare J, Hnatkova K. Sopher S, Murgatroyd F, Guo X, Camm A, Malik M. The role of atrial ectopics in initiating paroxysmal atrial fibrillation. Eur Heart J, 2001:22:333-339.

5. Haissaguerre M, Jais P. Shah DC. Takahashi A. Hocini M, Quiniou G. Garrigue S. Mouroux AL. Metayer PL. Clementy J. Spontaneous initiation of atrial fibrillation by ectopic beats originating in the pulmonary veins. $N$ Eng J Med, 1998:339:659-666.

6. Wijffels MCEF, Kirchoff CJHJ. Dorland R. Allessie MA. Atrial fibrillation begets atrial fibrillation: a study in awake chronically instrumented goats. Circulation, 1995;92:1954-1968.

7. Garratt CJ, Duytschaever M, Killian M. Dorland R, Mast F, Allessie MA. Repetitive electrical remodeling by paroxysms of atrial fibrillation in the goat: no cumulative effect on inducibility or stability of atral tibnillation. I Candiovasc Electrophys, 1999:10:1101-1108.

8. Friedman HS, Sinha B. Tung A. Pasha R. Sharafkhaneh A. Bharadwaj A. Zones of atrial vulnera bility. Relationships to basic cycle length. Circulation. 1996;94;1456-1464.

9. Wyndham C. Amat-Y-Leon F, Wu D. Denes P. Dhingra R. Simpson R. Rosen K. Effect of cycle length on atrial vulnerability. Cinculation, 1977:55:261-267.

10. Pandozi C, Bianconi L. Villani M. Gentilucci G, Castro A. Altamura G, Jesi A. Lamberti F. Ammirati F. Santini M. Electrophysiological characteristics of the human atria after cardioversion of persistent atrial fibrillation. Circulation, 1998:98:2860-2865.

11. Tieleman RG. Van Gelder IC. Crijns HJ. de Kam PJ, van den Berg MP. Haaksma J, Van der Woude HJ, Allessic MA. Early recurrences of atrial fibrillation after electrical cardioversion: a result of fibrillation-induced electrical remodeling of the atria? J Am Coll Cardiol. 1998:31:167-173.

12. Duytschaever M. Danse P. Allessie MA. Is there an optimal atrial pacing site to prevent atrial fibrillation? PACE. 1999: 22:777 (abstract).

13. Ogawa S, Dreifus L. Osmick M. Longitudinal dissociation of Bachmann's bundle as a mechanism of paroxysmal supraventricular tachycardia. Am J Candiol. 1977:40:915-922.

14. Dolter P. Spach M. Structure of canine Bachmann's bundle related to propagation of excitation. Am J Physiel, 1989;257:HI446-H1457.

15. Wang J. Liu L. Feng J. Nattel S. Regional and functional factors determining induction and maintenance of atrial fibrillation in dogs. Am J Physiol, 1996:273:H148-H158.

16. Chen SA, Hsich MH. Tai CT. Tsai CF. Prakash VS, Yu WC. Hsu TL. Ding YA. Chang MS. Initiation of atrial fibrillation by ectopic beats originating from the pulmonary veins. Electrophysiological characteristics. pharmacological responses and effects of radiofrequency ablation. Cinculation. 1999:100:1879-1886. 
17. Papageorgiou P. Monahan K. Boyle NG. Seifert MJ. Beswick P. Zebede J. Epstein LM, Josephson ME. Site-dependent intra-atrial conduction delay: relationship to initiation of atrial fibrillation. Cinculation, 1996:94:384-389.

18. Nair M. Shah P. Batra R. Kumar M. Mohan J. Kaul U, Arora R. Chronic atrial fibrillation in patients with rheumatic heart disease. Mapping and radiofrequency ablation of flutter eircuits seen at initiation after cardioversion. Circulation, 2001:104:802-809.

19. Papageorgiou P. Anselme F. Kirchoff CJHJ, Monahan K. Rasmussen CAF, Epstein LM, Josephson ME. Coronary sinus pacing prevents induction of atrial fibrillation. Circulation. 1997:96:1893-1898.

20. Bailin SJ, Adler SW. Giudici MC. Prevention of chronic atrial fibrillation by pacing in the region of Bachmann's bundle: results of a multicenter randomized trial. I Cardiovesc Electrophys, 2001:12:912-917.

21. Tondo C, Scherlag BJ, Otomo K. Antz M, Patterson E, Arruda M, Jackman WM, Lazzara R. Critical atrial site for ablation of pacing-induced atrial fibrillation in the normal dog heart. $J$ Candiovasc Electrophysiol. 1997:8:1255-1265.

22. Davies MJ. Pomerance A. Pathology of atrial fibrillation in man. Br Heart J, 1972;34:520-525.

23. Thijssen VL. Ausma J. Liu GS et al. Structural changes of atrial myocardium during chronic atrial fibrillation. Candiovase Pathol, 2000;9:17-28.

24. Fareh S. Villemaire C. Nattel S. Importance of refractoriness heterogeneity in the enhanced vulnerability to atrial fibrillation induction caused by tachycardia-induced atrial electrical remodeling. Circulation, 1998:98:2202-2209.

25. Ramdat Misier A. Opthof T, Van Hemel N. Defauw JJ, de Bakker JM, Janse MJ, van Capelle FJ. Increased dispersion of "refractoriness" in patients with idiopathic paroxysmal atrial fibrillation. J Am Coll Cardiol, 1992:19:1531-1535.

26. Ramanna H, Hauer R. Wittkampf F, de Bakker J, Wever E. Elvan A, Robles de Medina E. Identification of the substrate of atrial vulnerability in patients with idiopathic atrial fibrillation. Circulation, 2000;101:995-1001.

27. Cosio FG. Palacios J. Vidal JM. Cocina EG. Gomez-Sanchez MA. Electrophysiologic studies in atrial fibrillation: slow conduction of premature impulses: a possible manifestation of the background for reentry. Am J Cardiol, 1983;51:122-128.

28. Buxton AE, Waxman HL, Marchlinski FE, Josephson ME. Atrial conduction: effects of extrastimuli with and without atrial dysthythmias. Am J Cardiol, 1984:54:755-761. 



\section{Chapter 4}

The Supervulnerable Phase Immediately after Termination of Atrial Fibrillation.

Mattias Duytschaever, MD, Peter Danse, MD, Maurits Allessic, MD, PhD

J Cardiovasc Electrophysiol, 2002;13:267-275. 


\section{Abstract}

Background: Recent studies with the implantable atrial cardioverter have shown that in about $27 \%$ of the cases AF recurs almost immediately after successful cardioversion. In the present study we determined the electrophysiological properties of the caprine atrium immediately after spontaneous termination of AF both before and after $48 \mathrm{~h}$ of AF-induced electrical remodeling.

Methods: In 8 goats, atrial effective refractory period (AERP), intra-atrial conduction velocity (CV) and atrial wavelength (WL) were measured during sinus rhythm, both before $(t=0)$ and after 48 hours $(t=48)$ of electrically maintained AF (baseline). After baseline, a 5-min paroxysm of $A F$ was induced during which refractory period $\left(\mathrm{RP}_{\mathrm{AH}}\right)$ was determined. AERP. CV and WL were also measured immediately after spontaneous restoration of sinus rhythm (post-AF values).

Results: Both in normal and remodeled atria, immediately after AF, AERP and CV were markedly decreased compared to baseline $(\mathrm{p}<0.01)$. In normal atria, post-AF AERP

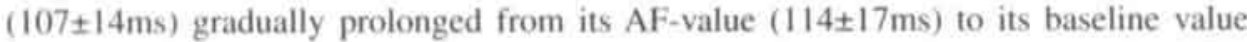
(f $38 \pm f 5 \mathrm{~ms}$ ). CV decreased from $130 \pm 9 \mathrm{~cm} / \mathrm{s}$ to $117 \pm 9 \mathrm{~cm} / \mathrm{s}$. After 48 hours of AF. AERP had shortened to $74 \pm 8 \mathrm{~ms}$. RPAF was $89 \pm 9 \mathrm{~ms}$. Surprisingly. immediately after termination of AF. AERP was further shortened to $58 \pm 6 \mathrm{~ms}(\mathrm{p}<0.01)$. Post-AF CV decreased from $136 \pm 11 \mathrm{~cm} / \mathrm{s}$ to $122 \pm 10 \mathrm{~cm} / \mathrm{s}(\mathrm{p}<0.01)$. As a result, the post-AF WL became as short as $7.1 \pm 1 \mathrm{~cm}$. These changes were transient and all parameters gradually returned to baseline within 1-2 minutes after conversion of AF.

Conclusions: Due to a combined decrease in AERP and CV, a marked shortening of the atrial wavelength occurs during the first minutes after conversion of AF. In electrically remodeled atria. this results in a transient ultra-short value of AERP $(<60 \mathrm{~ms})$ and atrial wavelength $(\mathrm{WL}: 7.1 \mathrm{~cm})$. These observations imply a highly vulnerable substrate for reentry immediately after termination of atrial fibrillation. During this supervulnerable phase, both early and later premature beats re-initiated immediate recurrences of $\mathrm{AF}$.

Key Words: Electrophysiology-Atrium-Atrial fibrillation. 


\section{Introduction}

Clinical studies with the implantable atrial defibrillator have reported a high incidence of immediate recurrences of AF (IRAF) within 1 minute after successful electrical cardioversion (27\%). ${ }^{13}$ Mapping of immediate recurrence demonstrated that all IRAF's were triggered by premature ectopic beats, mostly originating from atrial foci in the pulmonary veins or crista terminalis. ${ }^{* 5}$ Also after spontaneous restoration of sinus rhythm, a high incidence of immediate AF recurrences has been reported. Immediate recurrences of AF after electrical or spontaneous cardioversion of $\mathrm{AF}$ may be due to increased atrial ectopy during the first minutes of sinus rhythm and/or to a higher vulnerability for the initiation of reentry.

It is not clear to what extent AF-induced electrical remodeling plays a role in the occurrence of IRAF. A progressive shortening of the atrial action potential and refractory period during the first 1-2 days of AF has been shown to increase both inducibility and persistence of AF. An additional post-cardioversion shortening of atrial refractoriness and slowing of conduction may further enhance the vulnerability of the atria. The aim of the present study was to evaluate the electrophysiological substrate for reentry during the first 5 minutes after spontaneous termination of AF, both in remodeled and non-remodeled atria.

\section{Methods}

Eight goats weighing between 40 and $58 \mathrm{~kg}(50 \pm 6)$ were used for this study. The study was approved by the ethical committee of the university of Maastricht and animal handling was carried out according to the European Directive for animal research. After sedation with Nesdonal $(15 \mathrm{mg} / \mathrm{kg} \mathrm{I.V.)} \mathrm{the} \mathrm{animals} \mathrm{were} \mathrm{anaesthetized} \mathrm{by} \mathrm{halothane}$ (1-2\%) and a mixture of $\mathrm{O}_{2}$ and $\mathrm{N}_{2} \mathrm{O}$. The chest was opened through a left intercostal thoracotomy and three teflon-felt plaque electrodes were sutured to the atria (Fig1). Two oval-shaped plaques $(3.5 \times 2.5 \mathrm{~cm}, 30$ electrodes, inter-electrode distance $4 \mathrm{~mm})$ were sutured to the free walls of the right (RA) and left atrium (LA). A strip of $6 \times 1 \mathrm{~cm}$. containing 23 electrodes (inter-electrode distance $6-10 \mathrm{~mm}$ ) was pulled through the space between the aortic root and Bachmann's bundle and sutured to the tips of the atrial appendages. A small plaque containing 4 electrodes was sutured to the free wall of the left ventricle (LV). A silver plate was implanted under the skin of the thorax to serve as indifferent electrode. The electrode leads were tunnelled subcutaneously to the neck and exteriorized by three 30-pin connectors (Lemosa®). Post-operatively the animals received buprenorfine (Temgesic $\otimes)$ for 1-3 days. Ampicilline $(1000 \mathrm{mg}$ ) was given prophylactically both before and after surgery. 

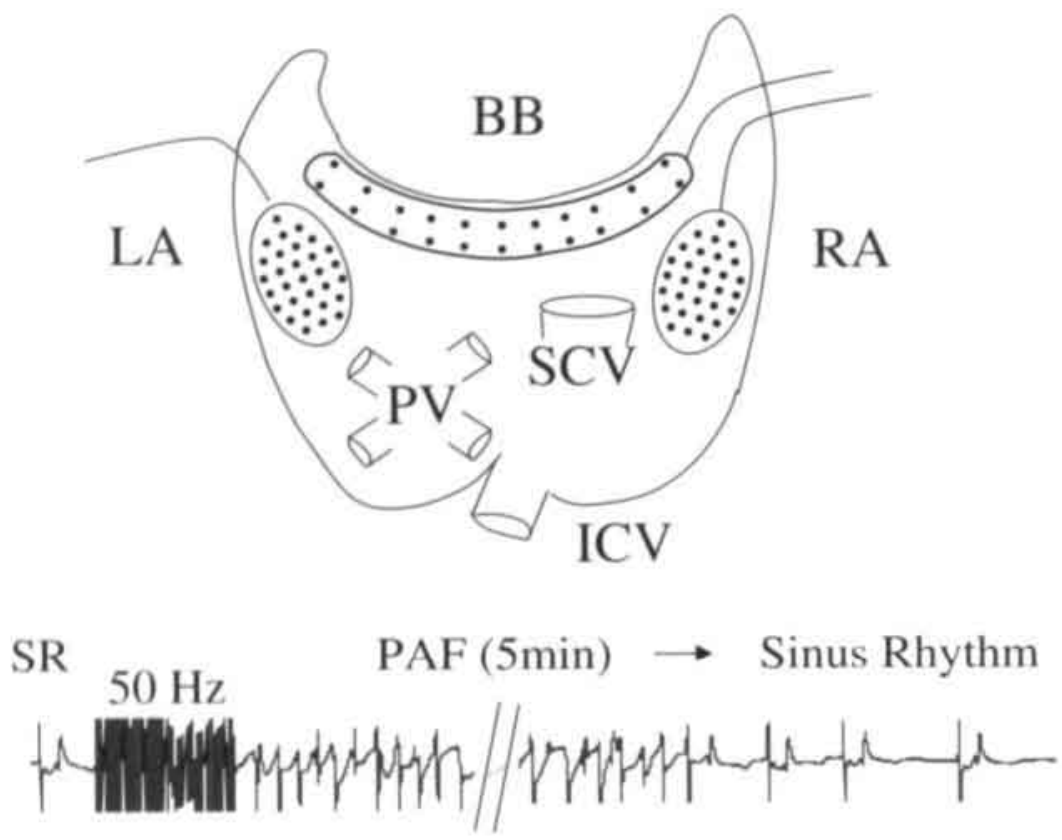

Figure 1. Localization of the chmonically implanted epirandial electrodes (upper panel). Tuo aval plaques, each containing 30 electrodes, were sutured to the free wall of the $R A$ and $L A$. One strip with 23 electrsies was positioned on Bachmann's bundle, In the lower panel the fianction of the fitrillation pacemaker is illustrated. As soon as simus rhvthm is deterted, a I secand burst of stimuli ( $50 \mathrm{H}$; ) was delivered to induce AF. BB: Bachmann's bandle: RA: right atrium: 1A. Ieft atrium; PV: mulmenary veins; SCV: superior caval vein: ICV inferior caval sein; PAF; panowsmal arriat fibrillation.

\section{DATA ACQUISITION}

After the goats recovered from surgery (2-3 weeks) they were connected to a data acquisition system recording all unipolar atrial electrograms simultaneously (gain 300; bandwidth $1-500 \mathrm{~Hz}$ ). Atrial conduction velocity was measured during sinus rhythm from the conduction time between two electrodes on Bachmann's bundle (inter-electrode distance $4-6.6 \mathrm{~cm}$ ). Local activation times were determined by a custom made algorithm for automatic detection of the intrinsic negative deflection of the electrogram. The maximal negative slope of the unipolar electrogram was taken as the local activation time. Uniform propagation along Bachmann's bundle was verified by mapping. It was defined as homogeneous propagation with synchronous activation of the two rows of electrodes. Atrial fibrillation cycle length (AFCL) was determined from a unipolar atrial electrogram from the right or left atrium by an algorithm detecting the maximal negative slope of the fibrillation electrogram. The median and $5^{\circ}$ percentile of the AFCL. were calculated from 100 consecutive AF cycles. 


\section{ELECTRICAL STIMULATION}

A pair of electrodes in the center of the electrode-array at the free wall of the right $(n=5)$ or left atrium ( $\mathrm{n}=3$ ) was used for stimulation. Biphasic stimuli of $2 \mathrm{~ms}$ duration were applied by a constant current stimulator (Medtronic SP3111), equipped with an amplifier recording a bipolar electrogram from the pacing electrodes. The stimulation threshold (mA) was determined during slow pacing. Atrial fibrillation was maintained by a fibrillation pacemaker delivering a 1 -second burst of stimuli $(50 \mathrm{~Hz}, 4$ xdiastolic threshold) as soon as sinus rhythm recurred." The atrial effective refractory period (AERP) was determined during sinus rhythm. during incremental pacing and during regional entrainment of AF. During sinus rhythm, the premature stimuli were synchronized to the bipolar electrogram recorded from the pacing electrodes. After 8 sinus beats, a single stimulus (4xthreshold) was delivered and the coupling interval was incremented in steps of $2 \mathrm{~ms}$. The shortest coupling interval resulting in a propagated early response $4 \mathrm{~mm}$ from the pacing site was taken as the AERP. During incremental pacing (SI-S1: 400-160ms) the AERP was determined by interpolated premature stimuli ( 4 xthreshold). Starting well within the refractory period, after every $8^{\mathrm{m}}$ basic stimulus, the coupling interval was incremented in steps of $2 \mathrm{~ms}$. The shortest $\mathrm{S} 1-\mathrm{S} 2$ interval resulting in a propagated response was taken as the $\mathrm{AERP}$. The refractory period during $\mathrm{AF}\left(\mathrm{RP}_{\mathrm{Al}}\right)$ was measured during regional entrainment of AF, as recently described." The right or left atrium was paced with an interval equal to the median AFCL (4xdiastolic threshold). Capture during AF could be differentiated from fibrillatory activity by the latency and morphology of an electrogram recorded $4 \mathrm{~mm}$ from the pacing site, In case of capture, the electrograms show a constant morphology (low amplitude $\mathrm{S}$-wave) together with a short and constant interval between stimulus and response. In addition, mapping was used to verify a radial spread of activation from the pacing site. After 8 entrained beats, a single premature stimulus was applied with a coupling interval starting well within the refractory period. The S1-S2 interval was changed in steps of $2 \mathrm{~ms}$. In case of capture, the premature electrogram showed a similar morphology and latency as during entrainment. The longest SIS2 interval that failed to capture the atria was taken as the RP during entrainment of $\mathrm{AF}^{4}$ Atrial vulnerability was measured by the incidence of AF during measurement of the AERP. In electrically remodeled atria ( $100 \%$ induction of AF), the window of inducibility (WI-AF) was used to quantify the vulnerability of the atria. The lower limit of the W1-AF was given by the AERP at the site of pacing, whereas the upper limit of inducibility was determined by the longest S1-S2 interval still inducing AF.

\section{EXPERIMENTAL PROTOCOL}

In each animal, the same protocol was executed twice, once before and once after electrical remodeling ( 48 hours of AF). Both in non-remodeled and remodeled atria. first a 
baseline study was performed to determine the AERP and conduction velocity during steady-state sinus rhythm and the rate adaptation of the AERP during incremental pacing. In case of electrical remodeling, these measurements were performed at least 10 minutes after a 48 hours period of AF maintained by a fibrillation pacemaker. After the baseline study, a paroxysm of 5 minutes of AF was induced during which the AFCL and $\mathrm{RP}_{\mathrm{AI}}$ were determined. In normal atria, switching off the fibrillation pacemaker resulted in prompt restoration of sinus rhythm (13 \pm 14 seconds, range:4-46). In electrically remodeled atria, AF persisted some what longer (119 127 seconds, range:54-320) before sinus rhythm resumed.

Immediately after spontaneous termination of AF, we determined the time course of changes in $\mathrm{CV}$ and AERP during the first 5 minutes of sinus rhythm (post-AF values). After restoration of sinus rhythm, $\mathrm{CV}$ was measured continuously from the conduction times along Bachmann's bundle. The change in AERP was measured 10 times during the first 5 minutes of sinus rhythm. Single extrastimuli were introduced starting with a coupling interval slightly shorter than the expected refractory period and incremented after every 4 sinus beats in steps of $2 \mathrm{~ms}$. For statistical analysis the exact moments of measurement of the AERP were divided in 5 classes: $10 \mathrm{sec}$ (range 0-20): 30 sec (range 20-40); I min (range 40-1:20): $2 \mathrm{~min}$ (range 1:20-2:40): $5 \mathrm{~min}$ (4-6min). If during measurement of the post-AF AERP AF of $>8 \mathrm{sec}$ was induced, the measurements were interrupted and the heart was kept in sinus rhythm for 10 minutes. During this period the AERP returned to its baseline sinus rhythm value. Then, a new paroxysm of AF ( 5 minutes) was induced and measurement of the post-AF AERP was continued. For each experiment, about 3 to 5 paroxysms were needed to collect at least 10 data points during the first 5 minutes after a paroxysm of AF. No cumulative effect of repetitive AF inductions on AERP was observed.

\section{STATISTICAL ANALYSIS}

Data are presented as mean \pm SD. Statistical analysis was performed by the paired Student's t-test. A p-value of less than 0.05 was considered as statistically significant.

\section{Results}

In Fig 2 the rate adaptation of the atrial refractory period before and after 48 hours of AF is plotted for all goats. In normal atria, the AERP during baseline sinus rhythm was $138 \pm 13 \mathrm{~ms}$. Due to the physiological rate adaptation the refractory period shortened to 
$128 \pm 8 \mathrm{~ms}$ during rapid pacing ( $\mathrm{p}<0.05, \mathrm{~S} 1-\mathrm{S} 1: 180 \mathrm{~ms}$ ). During entrainment of $\mathrm{AF}$ ( $\mathrm{S} 1$ $S 1: 145 \pm 12 \mathrm{~ms})$ the AERP was $114 \pm 17 \mathrm{~ms}(-17 \%, \mathrm{p}<0.01$. Table 1). After 48 hours of AFinduced electrical remodeling, the AERP during sinus thythm was shortened to $74 \pm 8 \mathrm{~ms}$ and the physiological rate adaptation was lost. Since in some goats an inversed rate adaptation was present, the average AERP slightly prolonged from $74 \pm 12 \mathrm{~ms}$ during slow pacing $(400 \mathrm{~ms})$ to $84 \pm 12 \mathrm{~ms}$ during rapid pacing $(\mathrm{p}<0.05, \mathrm{~S} 1-\mathrm{S} 1: 170 \mathrm{~ms})$. During entrainment of AF (S1-S1: $108 \pm 10 \mathrm{~ms}$ ) the AERP was $89 \pm 9 \mathrm{~ms}(+21 \%, \mathrm{p}<0.01$, Table 1$)$. There were no differences between RA and LA.

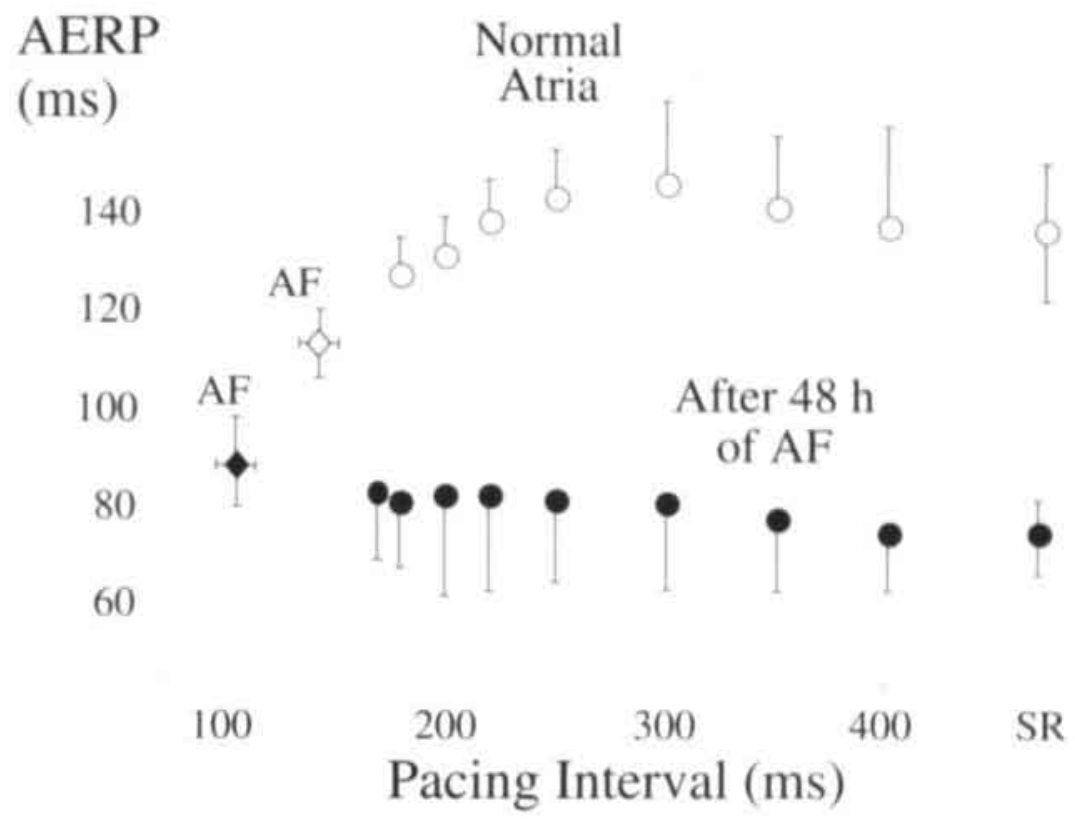

\footnotetext{
Figure 2, Rate adaptation of atrial refractoriness in normal atria topen svmbols) and after tK hours of $A F$ (filled symbols). The leftmost data points (diamonds) were obtained diring regiomal entrainment of AF Due to AF-induced electrical remodeling, the AERP was markedly shortened and its normal physiological rate adaptation was lost or became even slightly imersed. As a result, the AERP during entrainment of AF was tonger than during sinus rhythm. AERP. atrial effective refractory period: $S R$ : simus rate; $A F$ : entrainment of atrial fibrillution.
}

\section{ATRIAL WAVELENGTH IMMEDIATELY AFTER CONVERSION OF ATRIAL FIBRILLATION}

Both in normal and remodeled atria, atrial refractoriness was transiently shortened immediately after termination of AF. A representative example is given in Fig 3. In the absence of electrical remodeling. immediately after termination of AF. AERP during sinus rhythm gradually prolonged from its $\mathrm{AF}$ value $(124 \mathrm{~ms})$ to baseline $(155 \mathrm{~ms})$. In electrically remodeled atria, the AERP during baseline sinus rhythm (at least 10 minutes 
Normal Atria

(No Remodeling)
After 48 h of $\mathrm{AF}$

(Electrical Remodeling)
Baseline SR

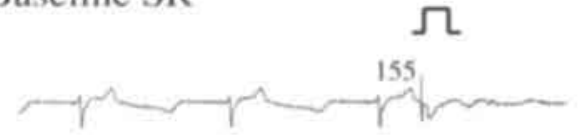

$\mathrm{AF}$ (Entrainment: $150 \mathrm{~ms}$ )

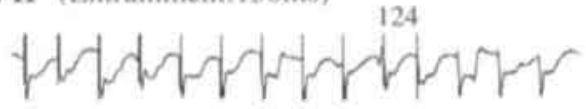

Post-AF SR

10 seconds

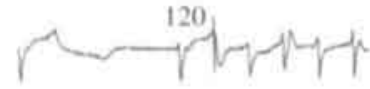

1 minule

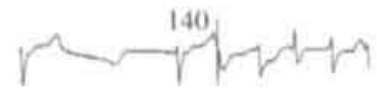

2 minutes

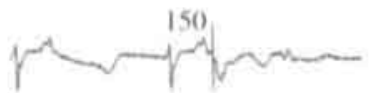

Baseline SR

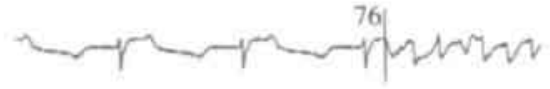

AF (Entrainment: 108ms)

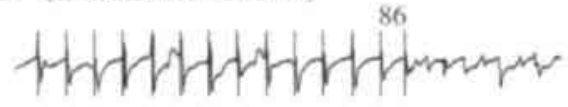

Post-AF SR

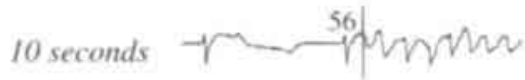

1 minute

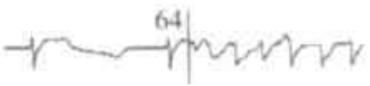

2 minules

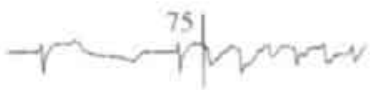

Figure 3. After restoration of simus rhsthm, in normal atria the AERP gnadually prolongs from its AF value to the baseline sulue during sinus rivath. In contrast, ufter 48 hours of electrical remodeling, immediately after candioversion of AF the AFRP shartenci markrdly from \$6ms diring AF to $56 \mathrm{~ms}$ after 10 seconds of sinus rhvthm. As a result, both in normal and remodeled atria, after termination of a 5 -min panoxysm of AF, the AERP was approximately $20 \%$ short. er than during baseline simes rhythm.

after spontaneous cardioversion of a 48-hours period of AF) was as short as $76 \mathrm{~ms}$. During entrainment of AF. the refractory period was $86 \mathrm{~ms}$. Immediately after termination of a new paroxysm of AF ( $5 \mathrm{~min}$ ), the AERP was extremely shortened to a value of $56 \mathrm{~ms}$. Also intra-atrial conduction was temporarily depressed immediately after termination of AF. A representative example is shown in Fig 4 . Both in normal and remodeled atria, the conduction velocity of the first sinus beats after termination of a $5 \mathrm{~min}$ paroxysm of AF was significantly decreased ( 110 and $116 \mathrm{~cm} / \mathrm{s}$ respectively). Normal atrial conduction velocity was restored rapidly within one minute of sinus thythm (not shown). 


\section{Baseline SR}
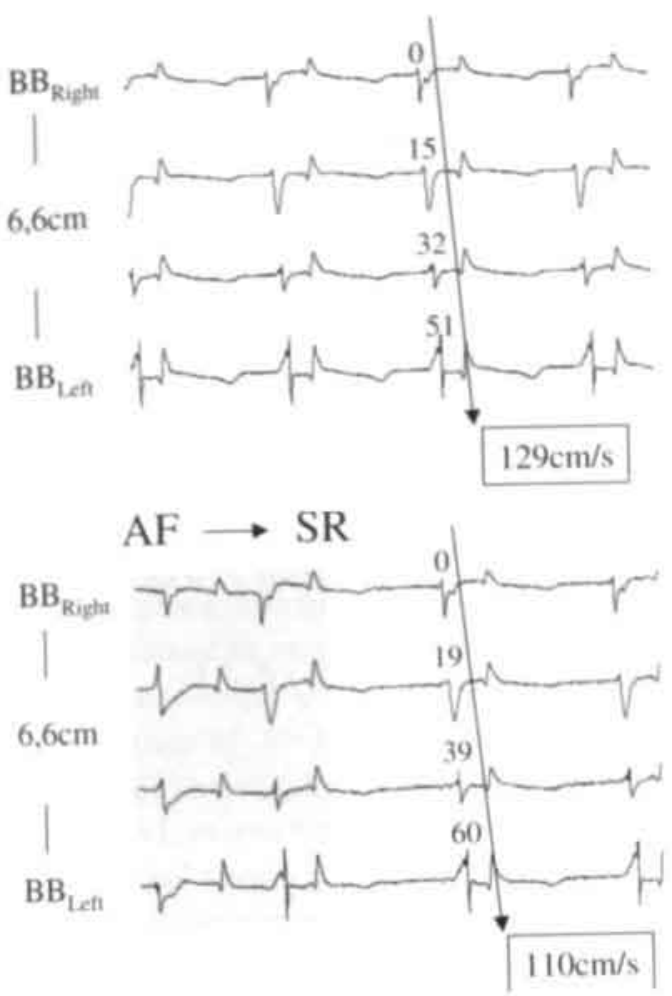

\section{Baseline SR}
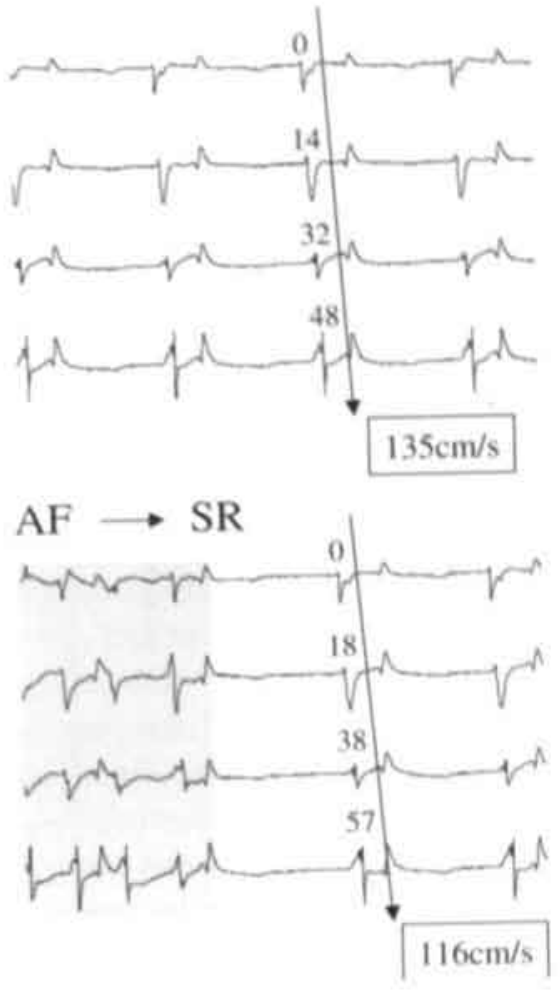

Figure 4. Slowing of atrial conduction velocity along Bachmann's bundle immediately after termination of a 5 min panoxysm of AF Conduction velocity during sinus rhythm was calculated fom the relative ac tivation times of $n$ o elec. trodes on the right and left part of Bachmann's bundle (interelectrode distance $6.6 \mathrm{~cm}$ ). Both in normal atria $(\mathrm{CV} \cdot 129 \mathrm{~cm} / \mathrm{s})$ and after 48 hours of AF (CV.135 cm/s). atrial conduction velecity during the first simus beats after spontancous conversion of $A F$ was depressed by about $14^{5}$. 


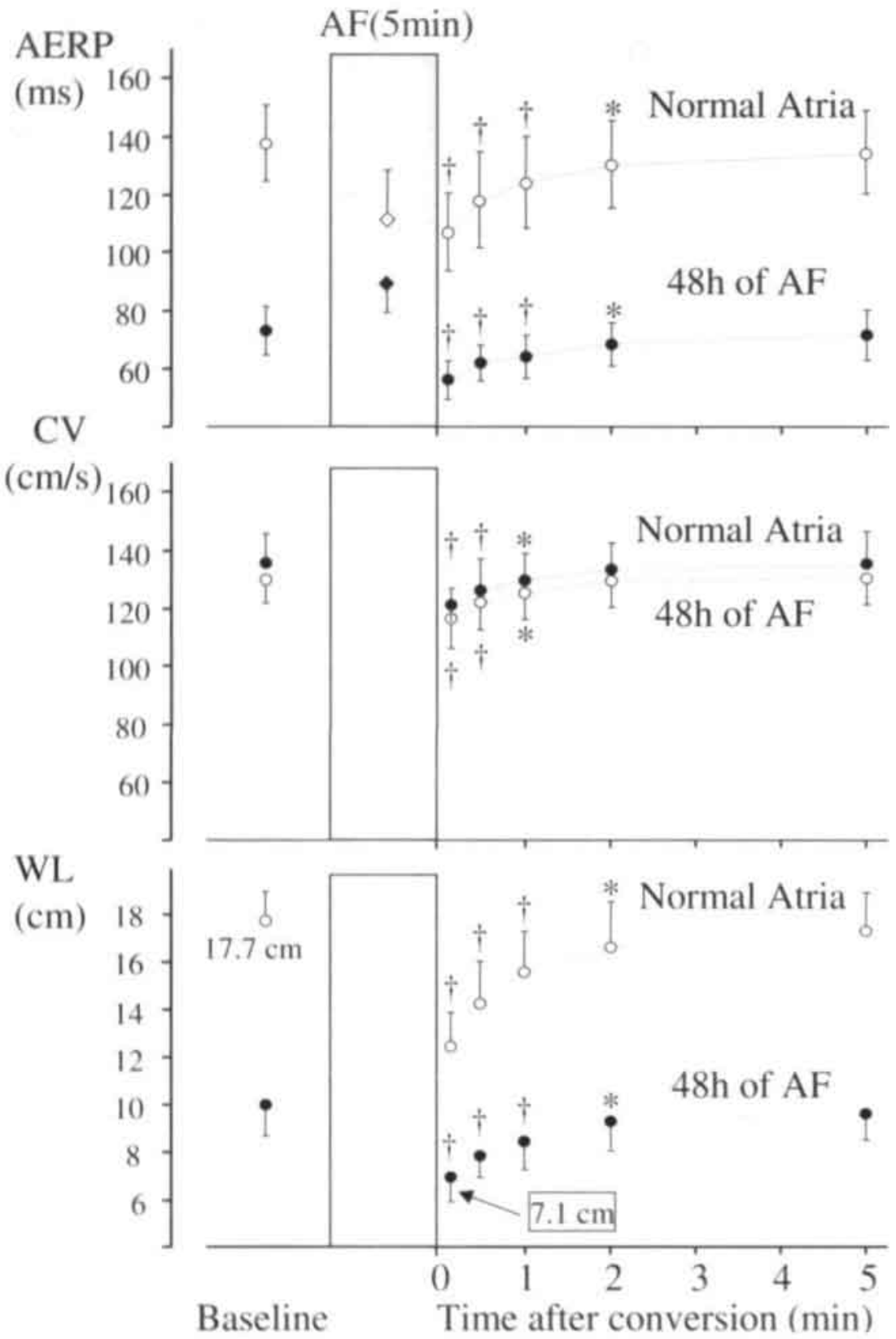

Figure 5. Mean and sfandand deviation (S gesats) of AERP. CV and WL during sinus rhythm both before (open symbols) and after $4.8 h$ of AF (filled symbelsi. After $4.8 h$ of AF the baseline measurements were

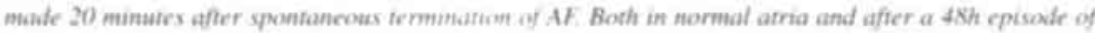

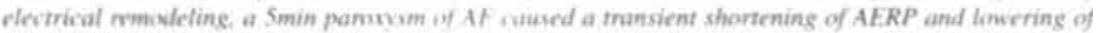
CV: As a result, immediately after comersion tor $S R$, the W $L$ was temporarily shortened by approximately 305. Diee to the cumulative effects of clerthest remodeling and imumctiate post-AF changes in AERP

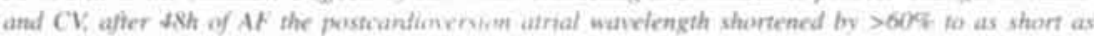

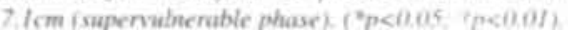


In Fig 5 and Table 1 the AERP, CV and WL are given for all goats $(n=8)$. Whereas in normal atria the AERP shortened from $138 \pm 13 \mathrm{~ms}$ during sinus rhythm to $114 \pm 17 \mathrm{~ms}$ during $\mathrm{AF}$, in remodeled atria (48h of AF) the AERP actually slightly prolonged from $74 \pm 8 \mathrm{~ms}$ to $89 \pm 9 \mathrm{~ms}$. After restoration of sinus rhythm, in normal atria the AERP gradually prolonged from its AF value to the baseline value during sinus rhythm. In contrast, after 48 hours of electrical remodeling, immediately after cardioversion of AF the AERP shortened markedly from $89 \pm 9 \mathrm{~ms}$ during AF to $58 \pm 6 \mathrm{~ms}$ after 10 seconds of sinus rhythm. As a result, after termination of a 5-min paroxysm of AF, the AERP was respectively 22 and $21 \%$ shorter than during baseline sinus rhythm $(\mathrm{p}<0.01)$. Both in remodeled and non-remodeled atria, this post-AF shortening of the AERP lasted only for a few minutes and after 5 minutes of sinus rhythm the AERP had already returned to its baseline value. Atrial conduction velocity directly after termination of AF was slightly decreased $(-10 \%, p<0.01)$ both in normal and remodeled atria. Normal atrial conduction velocity was restored within 2 minutes of sinus rhythm ( $p=0.32$ and $p=0.13$ ). Due to the post-AF changes in AERP and CV, immediately after cardioversion the atrial wavelength was shortened by respectively $30 \%$ and $29 \%$ ( $<<0.01$ ). Due to the combination of electrical remodeling and the immediate post-AF changes in AERP and $\mathrm{CV}$, after conversion of 48 hours of AF the atrial wavelength became temporarily as short as $7.1 \pm 1 \mathrm{~cm}$. Compared to a wavelength of $17.7 \mathrm{~cm}$ in normal atria, immediately after cardioversion of AF the WL in remodeled atria was shortened by more than $60 \%$. These immediate postAF changes were not associated with alterations in sinus rate. Three to five sinus beats after cardioversion, sinus rate was equal to the rate before the paroxysm of AF.

\section{VULNERABILITY TO ATRIAL FIBRILLATION IMMEDIATELY AFTER TERMINATION OF AF}

Both in normal and remodeled atria. the vulnerability for initiation of $\mathrm{AF}$ was higher immediately after termination of $\mathrm{AF}$. In normal atria a single early premature beat evoked a short paroxysm of AF in only 2 of 8 goats. Immediately after a 5 -min paroxysm of AF, an early premature beat reinduced AF in 7 of 8 goats. In electrically remodeled atria, already during baseline, AF was induced in $8 / 8$ goats (Table 1). To assess the difference in post-cardioversion vulnerability, the window of inducibility by single premature beats was determined within 30 seconds after termination of AF. An example is shown in Fig 6. Immediately after termination of AF the window of inducibility was widened from 74 to $94 \mathrm{~ms}$. In Table 2 the data are given for all 8 goats. In remodeled atria ( $48 \mathrm{~h}$ of AF) the window of inducibility was $90 \pm 15 \mathrm{~ms}$ (lower limit: $74 \pm 8 \mathrm{~ms}$; upper limit: $167 \pm 11 \mathrm{~ms}$ ). Immediately after spontaneous conversion of $5 \mathrm{~min}$ of $\mathrm{AF}$, the window of inducibility was increased by $20 \%$ to $109 \pm 22 \mathrm{~ms}$ ( $\mathrm{p}<0.05$ ). This was due to shortening of the refractory period from $74 \pm 8 \mathrm{~ms}$ to $57 \pm 10 \mathrm{~ms}(\mathrm{p}<0.01)$ without a concomitant change in the latest premature beat that induced $A F(168 \pm 19$ versus $167 \pm 11, p=0.8$ ). 


\section{Electrical Remodeling}

Window of Inducibility: $74 \mathrm{~ms}$
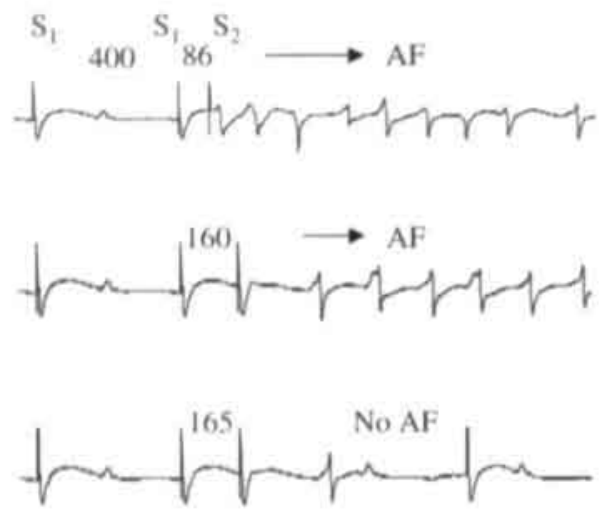

\section{Immediate Post-AF}

Window of Inducibility: $94 \mathrm{~ms}$
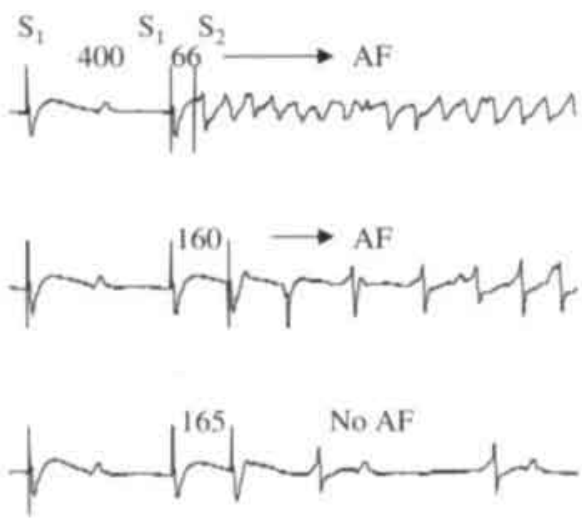

Figure 6 . Wideninx of the window of inducibility immediately after termination of AF. The earliest and latest premature beat (SI - S2) that induced AF were taken as the lower and upper limit of the window of inducibilin: After 48 hours of AF the WI.AF was $74 \mathrm{~m}$ s (left panel). Immediately after termination of a new 5 min panoxysm of $A F$ this window of inducibility was widened to $94 \mathrm{~ms}$ (right panel). New: shorter coupled premature beats also induced AF (LLIAf: $60 \mathrm{~ms}$ ) whereas the upper limit of inducibility remained unchanged (100ms).

\section{CHARACTERISTICS OF IMMEDIATE RECURRENCES OF ATRIAL FIBRILLATION (IRAF)}

To study the effects of the transient shortening of the atrial refractory period after termination of AF in remodeled atria, we analyzed the AFCL during the first phase of immediate recurrences of AF. In Fig 7 an example is given of an immediate reinitiation of AF. 4 seconds after spontaneous termination of a $5 \mathrm{~min}$ episode of AF. A single premature stimulus was applied with a coupling interval as short as $46 \mathrm{~ms}$. This very early premature stimulus restarted AF. Interestingly, at the beginning of IRAF, the AF cycle length was markedly shortened $(65 \mathrm{~ms})$ to prolong again during the first $5-6$ seconds of the recurrence of $\mathrm{AF}$.

In the 8 remodeled atria ( $48 \mathrm{~h}$ of $\mathrm{AF}$ ) the median $\mathrm{AFCL}$ during the 5 -min paroxysms of AF was $107 \pm 9 \mathrm{~ms}\left(5^{\mathrm{k}}\right.$ percentile: $\left.90 \pm 12 \mathrm{~ms}\right)$. The AERP measured during entrainment of AF was $89 \pm 9 \mathrm{~ms}$. Immediately after termination of $\mathrm{AF}(5 \pm 3 \mathrm{sec})$, the AERP during sinus rhythm was as short as $57 \pm 10 \mathrm{~ms}(-36 \%, \mathrm{p}<0.01)$. Also, the AFCL during the first second of IRAF was significantly shorter $(66 \pm 6 \mathrm{~ms}, p<0.01)$. However, already after 6 seconds. AFCL had returned to its baseline value $(104 \pm 23 \mathrm{~ms}, \mathrm{p}=0.46)$. This observation strongly supports the transient shortening of the atrial refractory period immediately after termination of $\mathrm{AF}$. 


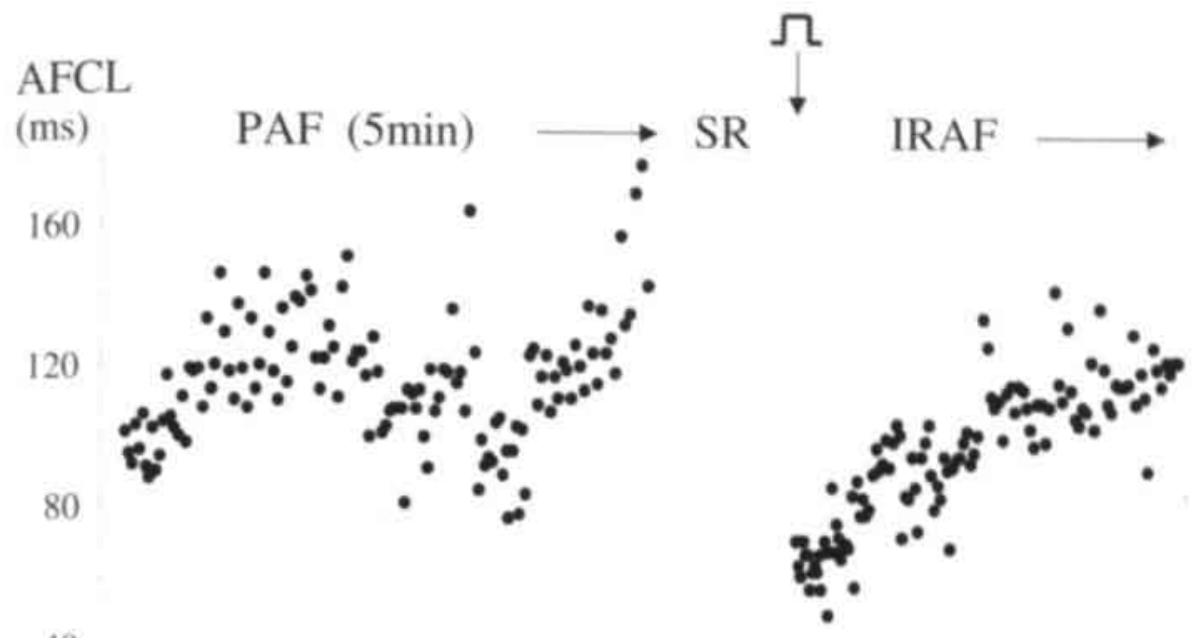

40

$\begin{array}{lll}-16 & -12 & -8 \\ \text { Paroxysmal AF }\end{array}$

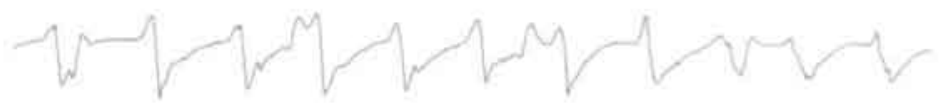

AFCL:

$99 \mathrm{~ms}$

Spontaneous Cardioversion

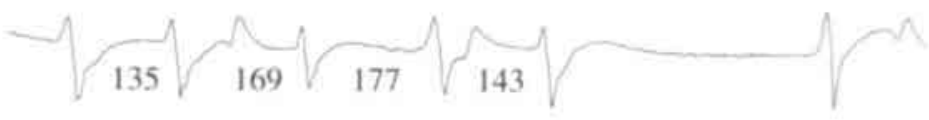

SR

Immediate Recurrence

Time (seconds)

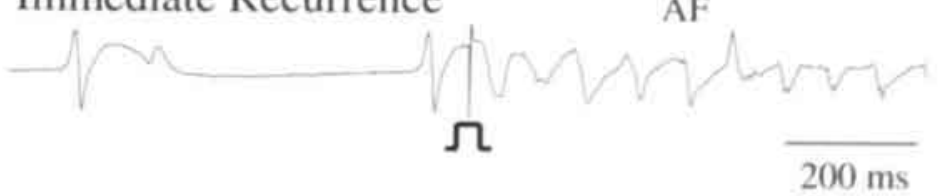

AFCL:

$65 \mathrm{~ms}$

Figure 7. Four seconds after spontaneous termination of a 5 min pamxysm of $A F$, an imenediate merurrence of $A F$ was induced by a single early premature stimulus. The median AFCL. during the preceding AF pamoxm wax $99 m$ s, with a 5 th perrentile of $80 \mathrm{~ms}$. Spontaneous termination of AF was preceded by a spontaneous progressive prolongation of $A F C L$ to $180 \mathrm{~ms}$. Immediately after rrinitiation of AF (IRAF) the AFCL was very short $(65 \mathrm{~ms})$ indic ating a shortened atrial refractory period. During the first 5.6 seronds of IRAF the AFCL. progressively pmilonged to is baseline value. 


\section{Discussion}

\section{IMMEDIATE RECURRENCE OF AF}

Immediate recurrences of AF can occur both after internal (27\%) and external (26\%) electrical defibrillation. ${ }^{1.51}$-1s The time between successful cardioversion and immediate recurrence varies between $8 \pm 5$ seconds (range 2-20) and 16 17 seconds (range 2-55). ${ }^{21}$ All IRAF's are triggered by premature ectopic beats, the coupling interval ranging between 310 and $580 \mathrm{~ms}(418 \pm 79)$. Ectopic beats with a coupling interval longer than $600 \mathrm{~ms}$ never lead to recurrence of AF. Immediate recurrences of AF may be caused by an increase in triggers (enhanced atrial ectopy) or a vulnerable substrate for initiation of reentry during the first minutes of sinus rhythm after cardioversion.

\section{A SUPERVULNERABLE SUBSTRATE FOR REENTRY IMMEDIATELY AFTER TERMINATION OF AF}

In the present study we evaluated the electrophysiological substrate immediately after termination of $\mathrm{AF}$ in the caprine model. The main findings were the following: (1) During the first minutes after spontaneous termination of AF, both in normal and remodeled atria, a transient shortening of atrial refractoriness occurred. (2) These changes were associated with a transient depression of atrial conduction velocity, resulting in a marked temporal shortening of the atrial wavelength directly after termination of AF. (3) In remodeled atria, due to the cumulative effects of $\mathrm{AF}$-induced electrical remodeling and immediate post-cardioversion changes, the AERP and wavelength could become as short as $58 \mathrm{~ms}$ and $7.1 \mathrm{~cm}$ respectively. (4) In remodeled atria, during the first minute of sinus rhythm, the window of inducibility of AF by single premature beats was markedly widened.

These observations imply that directly after termination of atrial fibrillation a highly vulnerable substrate for initiation of reentry exists. ${ }^{100}$ Especially after cardioversion of AF lasting longer than 24 hours, the cumulative effects of electrical remodeling and the immediate post-AF changes will result in a "supervulnerable phase" during the first minutes of sinus rhythm. During this supervulnerable phase, both early and later premature beats can be expected to initiate immediate recurrences of $\mathrm{AF}$.

However for immediate re-initiation of AF, the spontaneous occurrence of atrial triggers is at least as important as a vulnerable substrate for reentry. This is illustrated by the fact that due to the absence of atrial ectopy, in our goat model not a single case of spontaneous IRAF was observed. 


\section{ATRIAL REFRACTORINESS}

It is already known for a long time that the refractory period adapts to acute changes in cycle length. ${ }^{1521}$ Both experimental and clinical studies have shown that at increasing heart rates the atrial refractory period becomes progressively shortened (physiological rate adaptation). ${ }^{16.17 .162}$ Although the duration of the refractory period is predominantly determined by the preceding cycle length. ${ }^{10}$ after a marked change in heart rate, it may take up to several hundred beats before a new steady-state has been reached. ${ }^{2 *}$ As in the studies by Daoud et al. " and Yu et al., ${ }^{2}$ we observed that in normal atria, after cardioversion of AF it takes about 5 minutes for the refractory period to adapt to the slower sinus rhythm. The duration of the atrial refractory period is largely determined by the duration of the plateau phase of the action potential, carried predominantly by the calcium current. Calcium overload, resulting from the high rate during $\mathrm{AF}$, causes inactivation of the L-type calcium channels (calcium-induced inactivation) which. in combination with the decreased gradient of $\mathrm{Ca}^{*}$. will reduce the magnitude and duration of calcium inflow and shorten the plateau phase of the action potential. ${ }^{\infty n}$ After conversion to sinus rhythm, it may take several minutes for the $\mathrm{Na} / \mathrm{Ca}$ exchanger and the ATP. driven active $\mathrm{Ca}^{*+}$ transport to lower the cytoplasmic $\mathrm{Ca}^{*}$ concentration. The gradual reduction of the calcium-induced inactivation of calcium-current will result in a progressive prolongation of the action potential.

The observed acute post-cardioversion shortening of atrial refractoriness in electrically remodeled atria was quite unexpected. As shown by several studies, ts the physiological rate adaptation of the atrial refractory period is lost after long-lasting AF due to a reduction of the L-type calcium current. ${ }^{1-n}$ In the presence of a flat rate adaptation curve we expected no effect anymore of changes in heart rate on the atrial refractory period. At this moment one can only speculate about the mechanisms underlying the transient shortening of the action potential after cardioversion of remodeled atria. Changes in neurohumoral balance do not seem to play a major role since sinus rate after cardioversion was equal to the rate before the paroxysm of AF. During a sudden change in heart rate various metabolic alterations occur like changes in intra-and extracellular ion concentrations, ion pump activity. phosphorylation of ion channels, intracellular acidosis, etc, ${ }^{22}$ It is yet unclear whether the increase in metabolic demand during AF may lead to atrial ischemia."

\section{ATRIAL CONDUCTION VELOCITY}

Although it is well known that at high heart rates atrial conduction velocity is decreased, ${ }^{i s} 12$ in the present study is the first to measure atrial conduction velocity after transition from AF to sinus rhythm. Immediately after termination of AF conduction velocity was $10 \%$ slower than during normal sinus rhythm. After cardioversion atrial 
conduction velocity was restored quickly within 1-2 minutes. The slowing of atrial conduction after AF is probably due to an increase in intracellular sodium and extracellular potassium concentration due to the high atrial rate during $\mathrm{AF}{ }^{\text {mis }}$. The associated decrease in membrane resting potential and driving force for sodium ions will lower the upstroke velocity of the atrial action potential and consequently lower the conduction velocity of the first sinus beats. In addition, a high intracellular $\mathrm{Ca}^{* *}$ concentration after conversion of AF may lead to a decrease in electrical coupling of the atrial myocardium and a slowing of conduction of the atrial impulse. ${ }^{10}$ It may take 1-2 minutes before the normal intracellular sodium and calcium concentrations are restored and a new metabolic steady-state is reached.

\section{POSSIBLE CLINICAL RELEVANCE}

In previous studies in the goat we measured steady-state changes in atrial refractoriness induced by prolonged episodes of maintained AF? It was found that atrial fibrillation itself induced a progressive shortening of the atrial refractory period from about 140 to less than $80 \mathrm{~ms}$ (electrical remodeling). This shortening of the action potential has been shown to be due to a down regulation of the L-type calcium current (altered gene expression)." "In the present study the transient changes were studied occurring immediately after termination of AF. During the first minutes of sinus rhythm an additional shortening of atrial refractoriness occurred, resulting in a refractory period transiently shorter than $50 \mathrm{~ms}$. The transient post cardioversion shortening of refractoriness should not be confused with AF-induced electrical remodeling. " This is clearly illustrated by the markedly different time course of recovery of the immediate post-AF shortening (minutes) compared to electrical remodeling (days).'

Recurrence of atrial fibrillation during the first days after electrical cardioversion has been ascribed to fibrillation-induced electrical remodeling of the atria. The high incidence of immediate recurrences of AF (during the first minutes) can be explained by the additional transient shortening of RP described in the present study (supervulnerable phase). On the other hand, together with electrical remodeling, the supervulnerable phase may also play an important role in the persistence of AF. In patients with chronic $\mathrm{AF}$, it has been shown that AF still terminates spontaneously but that AF recurs within seconds (immediate re-initiation).

It still has to be shown whether prevention of post-AF shortening of refractoriness by antiarrhythmic drugs might reduce the incidence of immediate and early recurrences." On the other hand, the postcardioversion shortening of atrial refractoriness might also be prevented by preventing the sudden change in atrial rate after cardioversion of AF. Decremental rapid post-AF pacing might prevent the incidence of IRAF, not only by overdrive suppression of atrial ectopy, but also by preventing the immediate post-AF shortening of AERP. 


\section{LIMITATIONS}

In the present study, the supervulnerable phase was evaluated after spontaneous termination of AF. In case of direct-current cardioversion the electrical shock may cause transient electrophysiological changes. Thus, after electrical cardioversion, the substrate for reentry and the vulnerable phase may be different than after spontaneous cardioversion of AF. Also we do not know whether the supervulnerable phase would be the same after $\mathrm{AF}$ of $>48$ hours of duration. During chronic AF other changes (like a decrease of connexin 40, an increase in size of the atrial myocytes, loss of sarcomeres, dedifferentiation, atrial dilatation etc.) might alter the immediate post-AF vulnerability. Another limitation is that we could not study the incidence of spontaneous IRAF since the goat did not show any atrial ectopy. Because of this our study does not provide information about the important question whether immediately after cardioversion atrial triggers might occur more frequently or whether atrial ectopic beats are more premature. 
Table 1. Atrial Electrophysiology Immediately After Termination of AF.

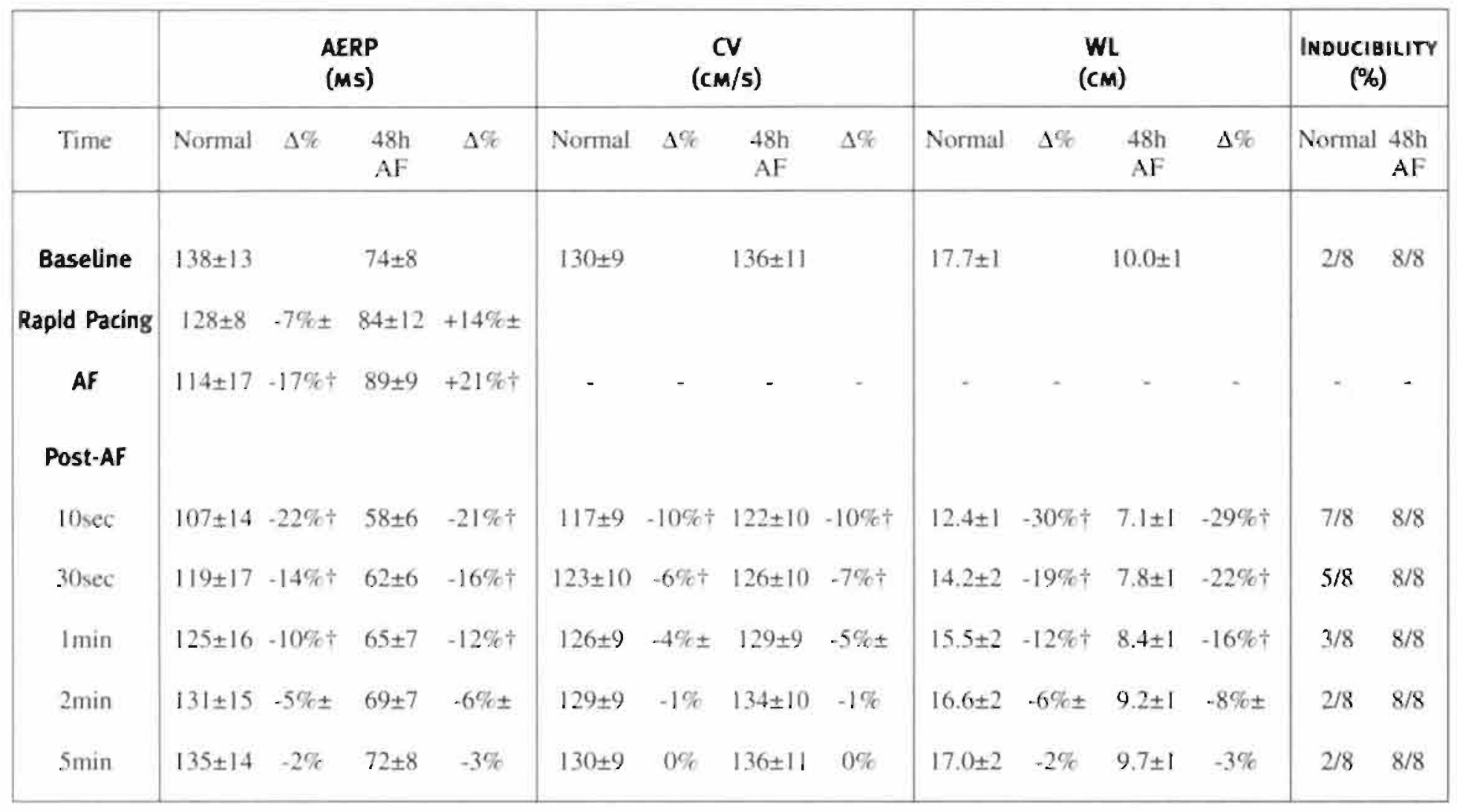


Table 2. Atrial Vulnerability immediately after Conversion of AF.

\begin{tabular}{|c|c|c|c|}
\hline & \multicolumn{3}{|c|}{ AFTER 48 HOURS OF AF (REMODELING) } \\
\hline & Wl-AF (ms) & LLI-AF (ms) & ULI-AF (ms) \\
\hline Baseline & $90 \pm 15$ & $74 \pm 12$ & $167 \pm 11$ \\
\hline Post-AF & $109 \pm 22$ & $57 \pm 10$ & $168 \pm 19$ \\
\hline$\Delta \%$ & $\begin{array}{c}+20 \% \\
(p<0.05)\end{array}$ & $\begin{array}{c}-23 \% \\
(p<0.01)\end{array}$ & $\begin{array}{c}1 \% \\
\text { (n.s.) }\end{array}$ \\
\hline
\end{tabular}

WI-AF: window of inducibility of AF: LLI-AF: lower limit of inducibility of AF: ULI-AF: upper limit of inducibility of AF 


\section{References}

1. Wellens HJ, Lau CP, Luderitz B, Akhtar M, Waldo AL, Camm AJ. Timmermans C, Tse HF, Jung W, Jordaens L, Ayers G, for the METRIX Investigators. Atrioverter: an implantable device for the treatment of atrial fibrillation. Circulation, 1998:98:1651-1656.

2. Timmermans C, Rodriguez LM. Smeets JLRM. Wellens HJ, Immediate reinitiation of atrial fibrillation following internal atrial defibrillation. J Cardiovasc Electrophysiol. 1998; 9:122-128.

3. Sra J, Biehl M, Blanck Z, Dhala A, Jazayeri MR, Deshpande S, Akhtar M. Spontaneous reinitiation of atrial fibrillation following transvenous atrial defibrillation. PACE. 1998:21:1105-1110.

4. Lau CP. Tse HF. Ayers GM. Defibrillation-guided radiofrequency ablation of atrial fibrillation secondary to an atrial focus. J Am Coll Cardiol, 1999:33:1217-1226.

5. Haissaguerre M, Jais P. Shah DC, Arentz T, Kalusche D. Takahashi A, Garrigue S. Hocini M. Peng JT. Clementy J. Catheter ablation of chronic atrial fibrillation targeting the reinitiating triggers. J Candiovase Electrophysiol, 2000:11(1):2-10.

6. Hoffmann E. Janko S, Steinbeck G. Edvardsson N. Camm J. for the AFT study group. Onset scenarios of paroxysmal atrial fibrillation using new diagnostic pacemaker functions (abstract). PACE, 2000, 23(partII): 656 .

7. Wijffels MCEF, Kirchoff CJHJ, Dorland R, Allessie MA. Atrial fibrillation begets atrial fibrillation: a study in awake chronically instrumented goats. Circulation. 1995:92:1954-1968.

8. Garratt CJ. Duytschaever M. Killian M. Dorland R. Mast F. Allessic MA. Repetitive electrical remodeling by paroxysms of atrial fibrillation in the goat: no cumulative effect on inducibility or stability of atrial fibrillation. J Candiovasc Electrophysiol, 1999:10:1101-1108.

9. Duytschaever M, Mast F, Killian M. Blaauw Y, Wijffels M. Allessie MA. Methods for determining the refractory period and excitable gap during persistent atrial fibrillation in the goat. Circulation. 2001:104:957,962.

10. Wiener $\mathrm{N}$. Rosenblueth $\mathrm{A}$. The mathematical formulation of the problem of conduction of impulses in a network of connected excitable elements, specifically in cardiac muscle. Arch Inst Candiol Mex. 1946;16:205-265.

11. Baker BM. Botteron GW. Smith JM. Low-energy internal cardioversion for atrial fibrillation resistant to external cardioversion. J Candiovase Electrophysiol, 1995:6:44-47.

12. Schmitt C. Alt E. Plewan A. Ammer R. Leibig M. Karch M, Schomig A. Low energy intracardiac cardioversion after failed conventional external cardioversion of atrial fibrillation. I Am Coll Cantiol, 1996:28:994-999.

13. Saksena S. Prakash A. Atrial defibrillation: Techniques and clinical results. In Saksena S, Luderitz. B. eds Intenentional Electmophvsiologv: A Textbook. Second edition. Futura Publishing Company, Armonk NY, 1996, pp.509.520.

14. Bianconi L. Mennuni M, Lukic V. Castro A. Chieffi M. Santini M. Effects of oral propafenone administration before electrical cardioversion of chronic atral fibrillation: a placebo-controlled study. J Am Coll Candiol. 1996:28:700-706.

15. Yu WC. Lin YK. Thi CT, Tsai CF. Hsieh MH. Chen CC, Hsu TL, Ding YA. Chang MS, Chen SA. 
Early recurrence of atrial fibrillation after external cardioversion. PACE, 1999:22:1614-1619.

16. Smeets JLRM. Allessie MA, Lammers WJEP, Bonke FIM. Hollen SJ. The wavelength of the cardiac impulse and reentrant arhythmias in isolated rabbit atrium. The role of heart rate, autonomic transmitters, temperature and potassium. Cinc Res, 1986:58:96-108.

17. Rensma PL. Allessie MA, Lammers WJEP. Bonke FMM, Schalij M. Length of excitation wave and susceptibility to reentrant atrial arrhythmias in normal conscious dogs. Cinc Res. 1988;62:395-410.

18. Daoud EG. Bogun F. Goyal R. Harvey M. Man KC. Strickberger SA, Morady F. Effect of atrial fibrillation on atrial refractoriness in humans. Cinculation, 1996:94:1600-1606.

19. Mendez C, Grunzit CC, Moe GK. Influence of cycle length upon refractory period of auricles, ventricles and AV node in the dog. Am J Phvsiol. 1956:184:287.

20. Denes P. Delon W. Dhingra R. Pietras RJ. Rosen KM. The effects of cycle length on cardiac refractory periods in man. Circulation, 1974;49:32-41.

21. Goodman DJ. Rossen RM, Rider AK. Harrison DC. The effect of cycle length on cardiac refractory periods in the denervated human heart. Am Heart J. 1976:91:332-338.

22. Janse MJ. Van der Steen, van Dam RT, Durrer D. Refractory period of the dog's ventricular myocardium following sudden changes in frequency. Circ Res, 1969:24:251-262.

23. Carmeliet E. Repolarization and frequency in cardiac cells. $J$ Physiol (Paris), 1977;73;903-923.

24. Olsson SB. Broman H. Hellstrom C. Talwar KK, Volkmann R. Adaptation of human atrial muscle repolarization after high rate stimulation. Cardiovase Res, 1984:19:7-14.

25. Yu WC. Chen SA, Lee SH. Tai CT. Feng AN. Kuo BIT. Ding YA. Chang MS, Tachycardia-induced change of atrial refractory period in humans: rate dependency and effects of antiarrhythmic drugs. Circulation. 1998:97:2331-2337.

26. Li GR, Nattel S. Properties of human atrial $\ell_{\mathrm{Ca}}$ at physiological temperatures and relevance to action potential. Am J Physiol, 1997:272:H227-H235.

27. Courtemanche M. Ramirez RJ, Nattel S, Ionic mechanisms underlying human atrial action potential properties: insights from a mathematical model. Am J Physiol. 1998:275: H301-321.

28. Attuel P. Childers RW. Cauchemez B. Poveda J, Mugica J. Coumel P. Failure in the rate adaptation of the atrial refractory period: its relationship to vulnerability. Int J Cardiol, 1982:2:179-197.

29. Franz MR, Karasik PL, Li C, Moubarak J. Chavez M. Electrical remodeling of the human atrium: similar effects in patients with chronic atrial fibrillation and atrial flutter. I Am Coll Candiol. 1997:30:1785-1792.

30. Yu WC, Tai CT, Tsai CF, Hsieh MH. Chen CC, Ding YA, Chang MS. Chen SA. Reversal of atrial electrical remodeling following cardioversion of long-standing atrial fibrillation in man. Candiovasc Res, 1999:42:470-476.

31. Yue L, Feng J. Gaspo R. Li GR, Wang Z. Nattel S. Ionic remodeling underlying action potential changes in a canine model of atrial fibrillation. Cinc Res, 1997:81:512-525.

32. Van Wagoner DR. Pond AL. Lamorgese M, Rossie SS, McCarthy PM. Nerbonne JM. Atrial L-type $\mathrm{Ca}^{2+}$ currents and human atrial fibrillation. Cir Res, 1999;85:428-436.

33. Bosch RF, Zeng X. Grammer JB, Popovic K. Mewis C. Kuhlkamp V. Jonic mechanisms of electrical remodeling in human atrial fibrillation. Candiovasc Res, 1999:44:121-131.

34. Katz AM. T Wave "memory": possible causal relationship to stress-induced changes in cardiac ion channels? J Cardiovasc Electrophysiol, 1992:3:150-159. 
35. White CW. Kerber RE. Weiss HR. Marcus ML. The effects of atrial fibrillation on atrial pressure-volume and flow relationships. Cinc Res, 1982:51:205-215.

36. Plumb VJ. Karp RB, James TN, Waldo AL. Atrial excitability and conduction during rapid atrial pacing. Circulation, 1981;63:1140-1141.

37. Leistad E, Verburg E, Christensen G. Cytosolic calcium overload, not atrial ischemia, accounts for post-fibrillation atrial dysfunction (abstract). Circulation, 1994;90:492.

38. Rubart M. Dowell J, Ziad I. Zipes DP. $\left[\mathrm{K}^{-}\right]^{j}$ Accumulation in the acutely fibrillating canine atrium (abstract). PACE, 1999;22:744.

39. Bredikis J. Bukauskas F, Veteikis R. Decreased intercellular coupling after prolonged rapid stimulation in rabbit atrial muscle. Circ Res, 1981:49:815-820.

40. Tieleman RG, Van Gelder IC, Crijns HJ, de Kam PJ, van den Berg MP. Haaksma J, Van der Woude HJ, Allessie MA. Early recurrences of atrial fibrillation after electrical cardioversion: a result of fibrillation-induced electrical remodeling of the atria? J Am Coll Candiol, 1998;31:167-173.

41. Van Noord T, Van Gelder IC, Crijns HJ. Pericardioversion dofetilide does not suppress immediate and subacute recurrences of persistent atrial fibrillation. Circulation. 2001:104:E57. 


\title{
Chapter 5
}

\section{Is there an Optimal Pacing Site to Prevent Atrial Fibrillation?}

\author{
An experimental study \\ in the chronically instrumented goat.
}

Mattias Duytschaever, MD; Peter Danse, MD; Sabine Eysbouts, MD;

Maurits Allessie, MD, PhD

I Cardiovasc Electrophysiol, 2002; I3:(december issue). 


\section{Abstract}

Background: Atrial pacing is able to reduce the number of recurrences of atrial fibrillation (AF). It is unclear to what extent this effect is determined by the site(s) of pacing.

Methods: In 6 electrically remodeled goats ( $24 \mathrm{~h} \mathrm{AF}$ ), the window of inducibility of AF (WI-AF) was determined by applying premature stimuli (S1-S2) at the right (RA) or left (LA) atrium (baseline values). Determination of WI-AF at RA and LA was repeated during preventive pacing at 4 sites: RA, LA, Bachmann's Bundle (BB) and RA+LA (Bi-atrial). Mapping was used to elucidate the mechanisms of prevention of $\mathrm{AF}$.

Results: At baseline, WI-AF was $49 \pm 9 \mathrm{~ms}$ at RA and $45 \pm 17 \mathrm{~ms}$ at LA. Initiation of AF was associated with conduction block of the premature beat at $\mathrm{BB}$. Preventive pacing at BB markedly shortened WI-AF at RA $(25 \pm 11 \mathrm{~ms})$ and $\mathrm{LA}(17 \pm 8 \mathrm{~ms}, \mathrm{p}<0.01)$. Pacing at RA only shortened WI-AF at LA $(23 \pm 9 \mathrm{~ms}, \mathrm{p}<0.01)$, whereas pacing at LA only shortened WI-AF at RA ( $23 \pm 1 \mathrm{Ims}, \mathrm{p}<0,01)$. Bi-atrial pacing failed to shorten WI-AF both at RA and LA. Prevention of AF by pacing was due to prolongation of the premature interval at BB.

Conclusions: In the caprine model of AF, Bachmann's Bundle is a critical area of conduction of premature beats and initiation of AF. Pacing at BB can prevent but not completely abolish the initiation of AF by single premature beats (shortening of the window of inducibility). Prevention of AF by pacing is based on prolongation of the premature interval at BB thus preventing conduction block and reentry. The optimal site for preventive pacing is close to the area of block and remote from the origin of premature beats.

Key-words: Fibrillation-Electrophysiology-Pacing.

\section{Condensed abstract}

In the goat model of atrial fibrillation (AF), we compared the effect of different sites of preventive atrial pacing on the window of inducibility of AF by right and left atrial premature beats. Initiation of AF was due to critical conduction of the premature impulse at Bachmann's bundle. The optimal site of preventive pacing was close to the area of block and remote from the origin of premature beats. Preventive pacing was based on pre-excitation of the critical area of conduction. 


\section{Introduction}

Atrial pacing has been shown to reduce the number of paroxysms of AF in patients with sinus node dysfunction. ${ }^{1.5}$ Daubert et al. demonstrated that bi-atrial pacing reduced the likelihood of atrial flutter and fibrillation in patients with advanced inter-atrial conduction delay.' Saksena et al. showed that both single-and dual-site pacing of the right atrium markedly prolonged the arrhythmia-free interval. ${ }^{45}$ Recently, several studies have shown that after coronary artery surgery the incidence of AF is markedly reduced by atrial pacing. ${ }^{\circ T}$ The mechanisms of prevention of AF by atrial pacing are not clear."10 Especially it is still uncertain to what extent the location and number of pacing sites can improve the efficacy of prevention. ${ }^{+7, *}, \mathrm{is}$

Atrial pacing might prevent AF by inhibiting the triggers of AF due to prevention of bradycardia or suppression of atrial premature beats. ' In the present study we investigated the mechanisms by which atrial pacing can attenuate the substrate of initiation of AF by atrial premature beats. It was found that atrial pacing can reduce the window of inducibility of AF. The degree of this anti-arrhythmic effect was largely dependent on the pacing site relative to the site of origin of the premature beat and the area of intra-atrial conduction block.

\section{Methods}

\section{GOAT MODEL OF ATRIAL FIBRILLATION}

Six goats weighing between 40 and $58 \mathrm{~kg}(48 \pm 7)$ were used for this study. Animal handling was carried out according to the European Directive for animal research. After sedation with Nesdonal, the animals were anaesthetized by halothane and a mixture of $\mathrm{O}_{2}$ and $\mathrm{N}_{2} \mathrm{O}$. Two rectangular plaques $(3 \times 2.5 \mathrm{~cm}, 30$ electrodes, inter-electrode distance $4 \mathrm{~mm}$ ) were sutured on the free wall of the RA and LA. A strip of $6 \times 1 \mathrm{~cm}$. containing 23 electrodes (inter-electrode distance $6-10 \mathrm{~mm}$ ) was pulled through the space between the aortic root and Bachmann's bundle $(\mathrm{BB})$ and sutured to the tips of the atrial appendages (Fig. 1). The electrode leads were tunneled to the neck and exteriorized by three 30-pin connectors. After the goats had recovered from surgery (2-3 weeks) they were connected to a data acquisition system recording all unipolar atrial electrograms simultaneously (gain 300: bandwidth $1-500 \mathrm{~Hz}$ ). Local activation times were determined automatically by an algorithm detecting the maximal negative slope of the electrograms. Isochrones were drawn manually at $10 \mathrm{~ms}$ intervals. Atrial pacing was performed using a stimulator generating biphasic stimuli of $2 \mathrm{~ms}$. In the present study, AF was maintained for 24 hours by a fibrillation pacemaker. ${ }^{n z}$ 


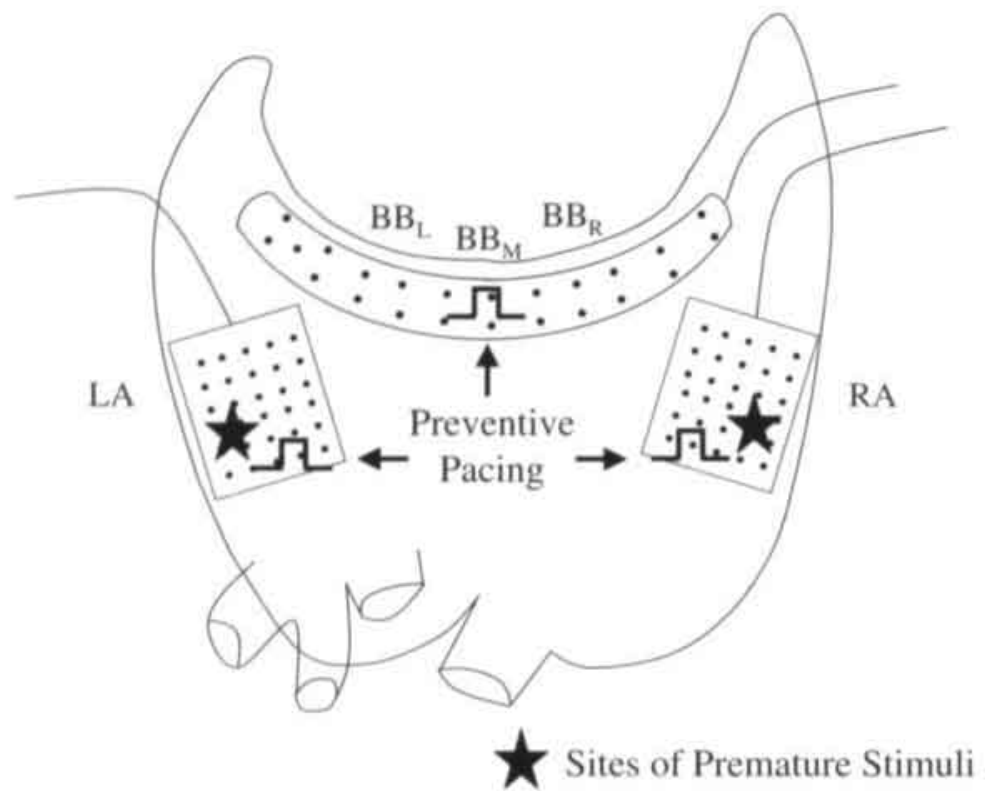

Figure 1. Localisation of epicardial electondes. Preventive pacing was performed at the right and left atrium and the middle portion of Bachmann's bundle. Premature stimuli were elicited at RA or IA.

\section{ELECTROPHYSIOLOGICAL MEASUREMENTS}

After 24h of AF, programmed electrical stimulation (S1-S2) was performed both at RA and LA to determine the window of inducibility of AF (WI-AF) at baseline (Fig.1). During regular pacing (S1-S1:400ms), premature stimuli (S1-S2, 4x threshold) were interpolated, starting with a coupling interval of $250 \mathrm{~ms}$. Each coupling interval was applied 3 times before it was decremented in steps of $5 \mathrm{~ms}$. The upper limit of inducibility (ULI-AF) was determined as the longest coupling interval (S1-S2) inducing AF $(>1 \mathrm{sec})$, whereas the lower limit (LLI-AF) was taken as the shortest SI-S2 interval that still induced AF, WI-AF was defined as the time window between the longest and shortest $\mathrm{S} 1-\mathrm{S} 2$ coupling interval inducing AF. The atrial effective refractory period (AERP) was determined at 5 sites: $\mathrm{RA}, \mathrm{BB}_{\text {math }}, \mathrm{BB}_{\operatorname{mat}}, \mathrm{BB}_{\mathrm{ken}}$ and $\mathrm{LA}$. During regular pacing ( $\mathrm{S}$ ) S1:400ms), premature stimuli (S1-S2, $4 \mathrm{x}$ threshold) were interpolated, starting well within the expected refractory period. After every $8^{\mathrm{m}} \mathrm{basic}$ interval, the coupling interval was incremented in steps of $2 \mathrm{~ms}$. The longest $\mathrm{S} 1$-S2 interval that failed to capture the atrium was taken as AERP. 


\section{PREVENTIVE ATRIAL PACING PROTOCOL}

In each goat, the effects of different sites of atrial pacing on WI-AF were determined in random order. Pacing (S1-S1:400ms) was performed at 4 sites: RA, LA, BB mit $_{\text {and }}$ RA+LA (Fig.1). During preventive pacing, single premature stimuli were applied at RA and L.A. A stimulator was used which also recorded a bipolar atrial electrogram at the site of stimulation (Medtronic SP3111). The degree of prematurity was varied by changing the coupling interval relative to the preceding bipolar electrogram (A1-S2 interval). Starting with a coupling interval of $250 \mathrm{~ms}$, the AI-S2 interval was decremented in steps of $5 \mathrm{~ms}$. Each interval was repeated 3 times. WI-AF was defined as the time window between the longest and shortest A1-S2 coupling interval inducing AF.

\section{STATISTICAL. ANALYSIS}

Data are presented as mean \pm SD. Statistical analysis was performed by the paired Student's t test. WI-AF during preventive pacing (A1-S2) was compared to WI-AF at baseline ( $\mathrm{S} 1-\mathrm{S} 2$ ). A p-value of less than 0.05 was considered as statistically significant.

\section{Results}

\section{INITIATION OF AF BY SINGLE PREMATURE BEATS}

A representative example of WI-AF after $24 \mathrm{~h}$ of AF is shown in Fig.2. Due to AFinduced electrical remodeling. AERP was $94 \mathrm{~ms}$. Single premature stimuli with coupling intervals between 96 and 150ms all induced AF (WI-AF:54ms). In Table 1, WI-AF values at baseline are given for 6 goats. LLI-AF, determined by the AERP, was $101 \pm 6 \mathrm{~ms}$ at RA and $108 \pm 10 \mathrm{~ms}$ at LA. ULI-AF was similar in both atria $(150 \pm 6 \mathrm{~ms}$ and $152 \pm 9 \mathrm{~ms})$. Thus, at baseline WI-AF at RA (S1-S2) was $49 \pm 9 \mathrm{~ms}$ and $45 \pm 17 \mathrm{~ms}$ at LA. Measurement of WI-AF was highly reproducible and varied less than $<5 \mathrm{~ms}$ during a time period of 4 hours. All premature coupling intervals in this window invariably induced AF (no gap). Initiation of AF by single premature stimuli was found to be associated with critical conduction at Bachmann's bundle. In Fig.3, a representative example is given (S1-S2 at $\mathrm{RA}: 150 \mathrm{~ms})$. Unipolar electrograms recorded at RA, BB sum, $\mathrm{BB}_{\text {mil. }} \mathrm{BB}_{\text {ent }}$ and $\mathrm{LA}$ are shown together with activation maps of BB, RA and LA. During regular pacing ( $\mathrm{S} 1$ ) the wavefront propagated uniformly from RA along BB to LA. During the premature beat (S2), the unipolar electrogram at $\mathrm{BB}_{\text {mid }}$ became fragmented and of low amplitude. 


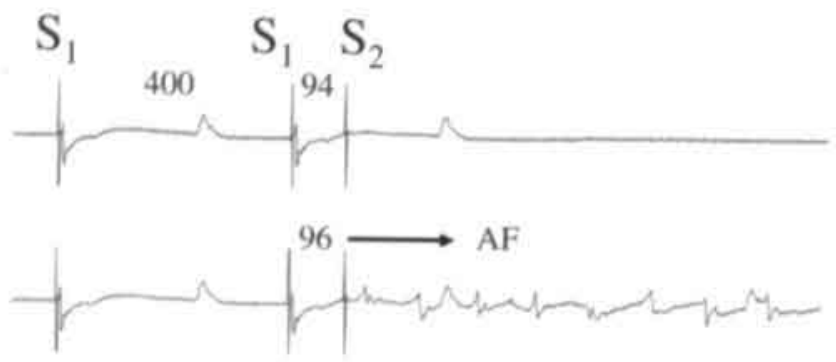

\section{AERP}

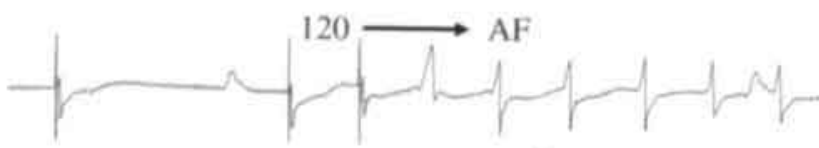

Window of Inducibility of AF (54ms)
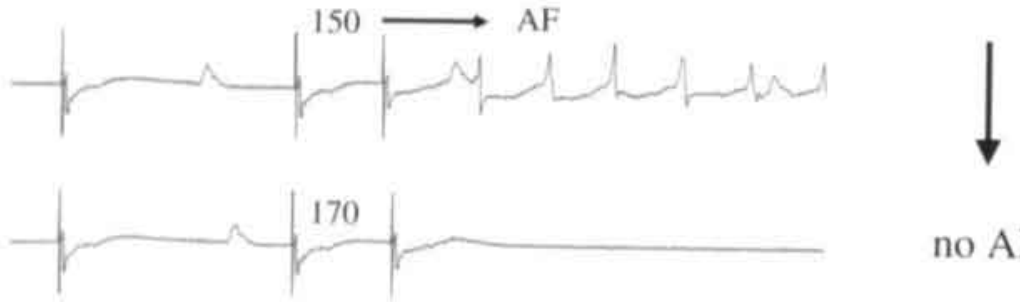

no $\mathrm{AF}$

Figure 2. After 24 h of electrical remodeling. AF was induced by single premature stimuli with compling intervals between 96 and $150 \mathrm{~ms}$ ( WI-AF at baseline: $54 \mathrm{~ms}$ ).

Initiation of AF by a Single Premature Stimulus

(S1-S2 at RA)
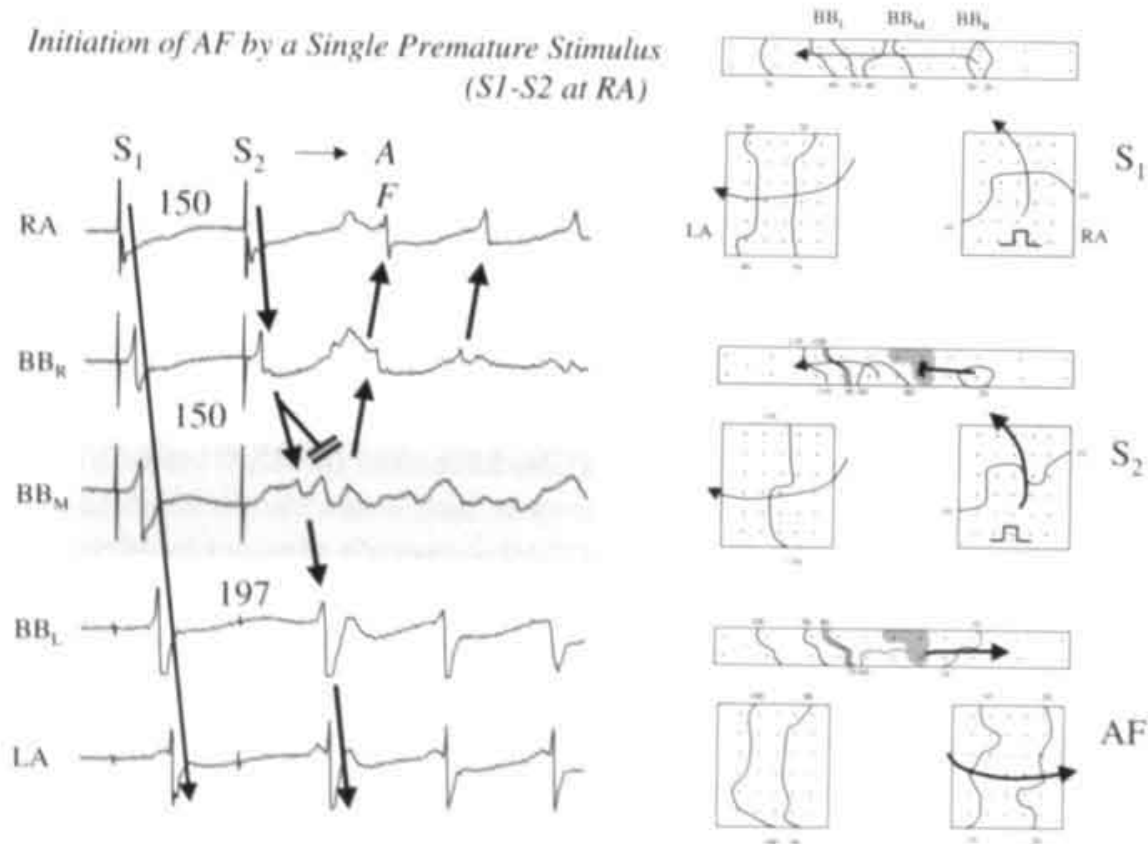

Figure 3. Initiation of AF by a single premature stimulus $(S /-S 2: 150$ ms). Unipoiar ciectrograms at $R A$, the right, middle and left part of BB and $L A$ are shown together with the activation maps during initiation of $A F$. 
From the activation map it can be seen that $\mathrm{BB}_{\mathrm{an}}$ was activated after a considerable delay (A1-A2 interval at $\mathrm{BB}_{\text {leth }}: 197 \mathrm{~ms}$ ). During the first beat of $\mathrm{AF}$, the earliest activation occurred at $\mathrm{BB}_{\text {nyt }}$ proximal to area of fragmented potentials. The combination of lowvoltage potentials at $\mathrm{BB}_{\mathrm{m}}$ and early re-excitation of $\mathrm{BB}_{\text {nitu }}$ strongly suggests that $\mathrm{AF}$ was initiated by block and reentry in Bachmann's bundle. However, the activation maps can not distinguish between micro-reentry within BB and macro-reentry involving the interatrial septum.

\section{ELECTROPHYSIOLOGICAL PROPERTIES OF BACHMANN'S BUNDLE}

In all goats, complete conduction curves along BB were determined during S1-S2 stimulation at RA and LA. In Fig.4, the average A1-A2 intervals along BB are given for 6 goats during S1-S2 pacing at RA. At long coupling intervals (S1-S2:250-180ms), premature beats conducted normally along BB. However, at S1-S2 intervals $<180 \mathrm{~ms}$, a progressive conduction delay along $\mathrm{BB}$ became apparent $\left(\mathrm{A} 1-\mathrm{A} 2_{\text {mann }}>\mathrm{A} 1-\mathrm{A} 2_{\text {masda }}\right.$ $\mathrm{p}<0.05$ ). At coupling intervals shorter than $158 \pm 16 \mathrm{~ms}$, the electrogram at $\mathrm{BB}_{\text {mad }}$ became fragmented and of low amplitude and all premature stimuli were associated with markedly prolonged $\mathrm{A} 1-\mathrm{A} 2$ intervals at $\mathrm{BB}_{\mathrm{len}}\left(\mathrm{p}<0.01\right.$ compared to $\left.\mathrm{BB}_{\text {rigta }}\right)$. Conduction delay at RA (prolongation of $\mathrm{A} 1-\mathrm{A} 2_{\text {senght }}$ ) only became apparent at S1-S2 intervals shorter than $120 \mathrm{~ms}$. The events during premature stimulation at LA were almost an exact mirror image of pacing at RA (not shown).

Critical conduction at BB seemed to be due to a longer AERP at BB mid. In Fig.4 (right panel) we plotted representative tracings of the shortest S1-S2 intervals at RA, BB aptur $\mathrm{BB}_{\operatorname{mid}}, \mathrm{BB}_{\text {iet }}$ and $\mathrm{LA}$ resulting in a propagated atrial response, Clearly, at $\mathrm{BB}_{\operatorname{mid}} \mathrm{AERP}$ was markedly longer than AERP at other sites. For all goats, the average AERP at BB mat was $163 \pm 15 \mathrm{~ms}$. significantly longer $(\mathrm{p}<0.05)$ than in the right and left part of $B B$ (117 \pm 14 and $115 \pm 22 \mathrm{~ms})$ or RA (101 $\pm 6 \mathrm{~ms})$ and LA $(108 \pm 10 \mathrm{~ms})$. 
86 | Chapter 5

Conduction Curves along Bachmannis bundle

$\mathrm{A} 1-\mathrm{A} 2$ at $\mathrm{BB}(\mathrm{ms})$

240

220

200

180

160

140

120

100

(SI-S2 at RA)
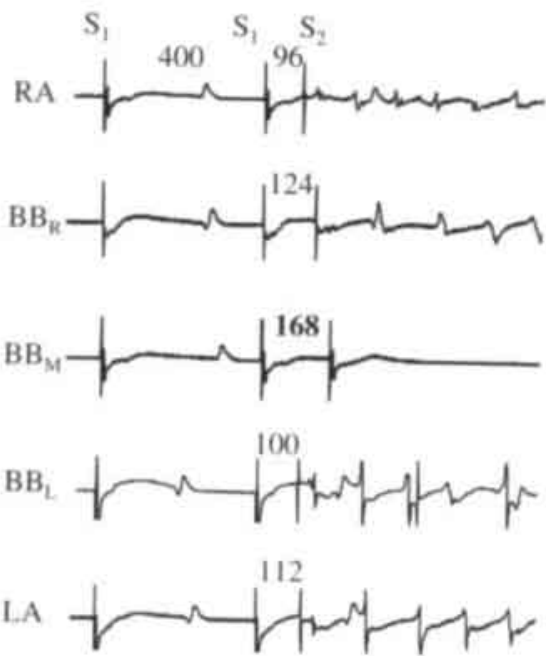

SI-S2 at RA (ms)

Figure 4, Left panel: conduction curies along BB during $S 1.52$ pacing at $R A$ ( $n=6)$. At S1.S2 intervals shorter tham $158 \pm 10 m s$, the electmgram at BBmid became fragmented and of low-woltage. In the right panel the marked spatial dispersion in AERP was illustruted 


\section{EFFECT OF PREVENTIVE ATRIAL PACING ON THE WINDOW OF INDUCIBILITY OF AF}

In Fig.5, representative tracings are shown of the effects of preventive pacing on the inducibility of AF by right and left premature stimuli (A1-S2:150ms). Without preventive pacing a premature beat with an $\mathrm{S} 1-\mathrm{S} 2$ interval of $150 \mathrm{~ms}$ invariably had induced $\mathrm{AF}$.

Preventive

Pacing at RA
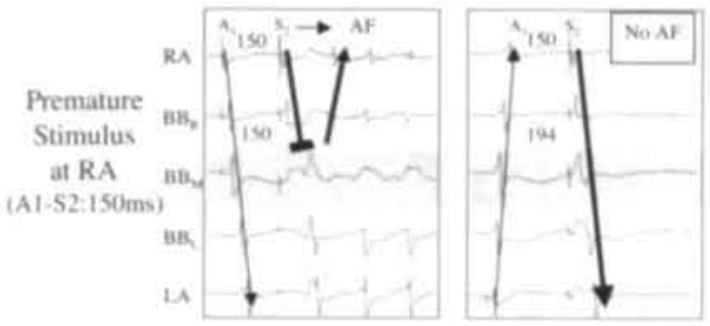

Preventive

Pacing at LA

Preventive Bi-

Atrial Pacing
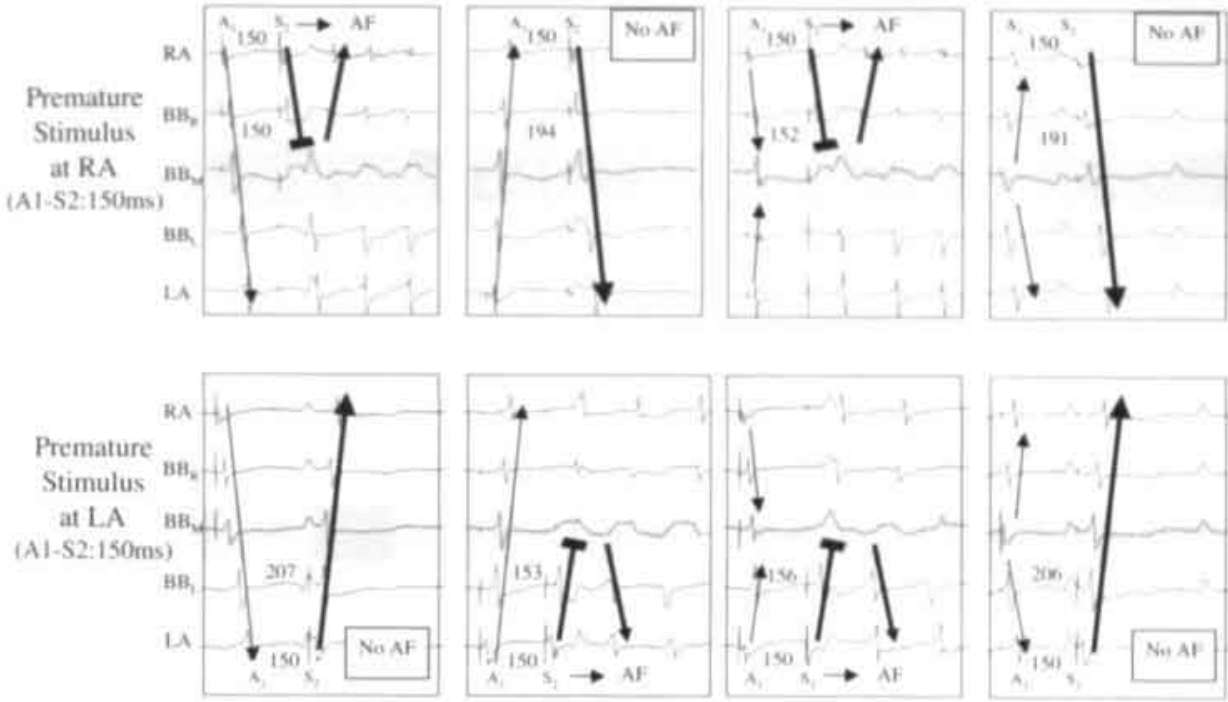

Preventive Pacing at BB

Figure 5, Representative tracings of the effects of preventive pacing at different sites in case of right and leff atrial premature stimuli (Al-S2:150ms),

During preventive pacing. AF was prevented in 4 specific situations, In case of premature stimuli at RA. preventive pacing at LA and BB were both effective. During premature stimulation at LA, in contrast preventive pacing at RA and $\mathrm{BB}$ were effective. In Fig.6. the effects of preventive pacing on WI-AF are given for all goats $(n=6)$. Without preventive pacing WI-AF was $49 \pm 9 \mathrm{~ms}$ at RA, and $45 \pm 17 \mathrm{~ms}$ at LA (Table 1). Preventive pacing at RA was not effective against premature stimuli at RA (WI-AF:55 \pm 11 ms. $\mathrm{p}=0.17$ ). On the other hand it significantly shortened WI-AF by premature stimuli at LA $(23 \pm 9 \mathrm{~ms}, \mathrm{p}<0.01)$. This was due to a marked lowering of ULI-AF from $152 \pm 9 \mathrm{~ms}$ to $122 \pm 14 \mathrm{~ms}(\mathrm{p}<0.01)$. In neither case preventive pacing affected the lower limit of inducibility (AERP) and the same degree of prematurity was achieved during all modalities of preventive pacing. Preventive pacing at LA showed the opposite effect. Now, initiation of AF by premature stimuli originating in the RA was reduced (WI-AF:23 11 ms, $\mathrm{p}<0.01$ ), whereas it had no effect on induction of AF by premature stimuli at LA (WI$A F: 52 \pm 10 \mathrm{~ms}, \mathrm{p}=0.35$ ). Again the shortening of WI-AF was due to a lowering of ULI-AF 
(from $150 \pm 6 \mathrm{~ms}$ to $125 \pm 9 \mathrm{~ms}, \mathrm{p}<0.01$ ). Preventive bi-atrial pacing failed to shorten WIAF both in case of premature stimuli delivered at RA $(56 \pm 12 \mathrm{~ms}, \mathrm{p}=0.69)$ and LA $(54 \pm 8 \mathrm{~ms}, \mathrm{p}=0.13)$. Pacing at $\mathrm{BB}$ exerted the largest preventive effect and shortened the window of inducibility to $25 \pm 11 \mathrm{~ms}(\mathrm{RA})$ and $17 \pm 8 \mathrm{~ms}$ (LA, $\mathrm{p}<0.01$ ). Again this protective effect was due to lowering of LLI-AF to $123 \pm 15 \mathrm{~ms}$ and $119 \pm 8 \mathrm{~ms}(\mathrm{p}<0.01)$.

Preventive Pacing at RA

WI-AF (ms)
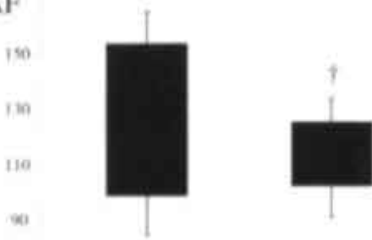

Premature

Premature

Stimulus at RA Stimulus at L.A

Preventive Bi-Atrial Pacing

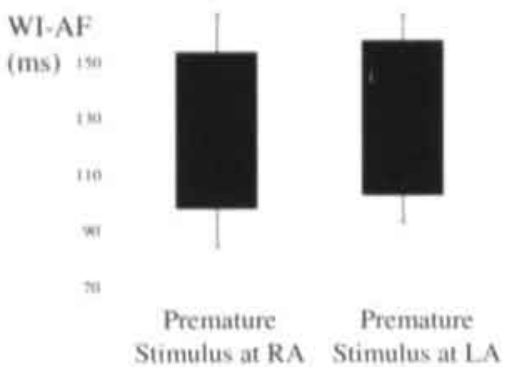

Preventive Pacing at LA
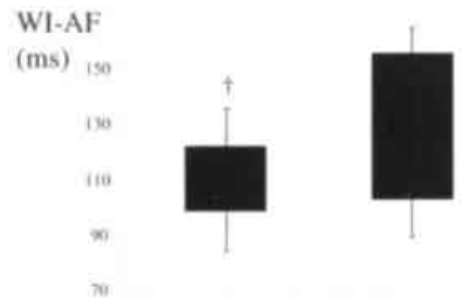

Premature Premature Stimulus at RA Stimulus at LA

Preventive Pacing at BB

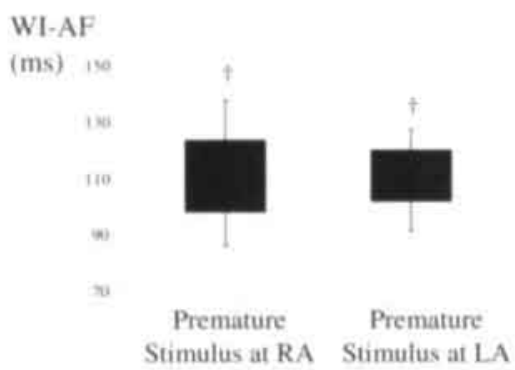

Figure a. Effects of prrventwe pacing on the window of inducibility of AF during premature stimuli at RA and $L A(n=6)$. Pacing at BB relucrd WI-AF both in case of $R A$ and LA premature stimuli. Bi-atrial pacing fid not shorten WI-AF in either case.

\section{MECHANISMS OF PREVENTIVE PACING}

In all cases, the preventive effect of pacing was due to prevention of critical conduction of premature beats at BB. This is clearly illustrated in Fig.5. In cases in which pacing failed to prevent $\mathrm{AF}$, the premature stimulus was blocked at $\mathrm{BB}_{\operatorname{mid}}$ (fragmented. low-voltage potentials associated with early proximal re-excitation). When pacing prevented induction of $\mathrm{AF}$, the premature impulse conducted normally along $\mathrm{BB}_{\operatorname{mid}}$ (high-amplitude negative deflections). The prevention of conduction block of premature beats could be explained by marked prolongation of the premature interval at $\mathrm{BB}_{\operatorname{mis}}$. When $\mathrm{AF}$ was prevented $A 1-A 2$ at $B B_{\max }$ was longer than $191 \mathrm{~ms}$ compared to $<156 \mathrm{~ms}$ when pacing failed to prevent $\mathrm{AF}$. 

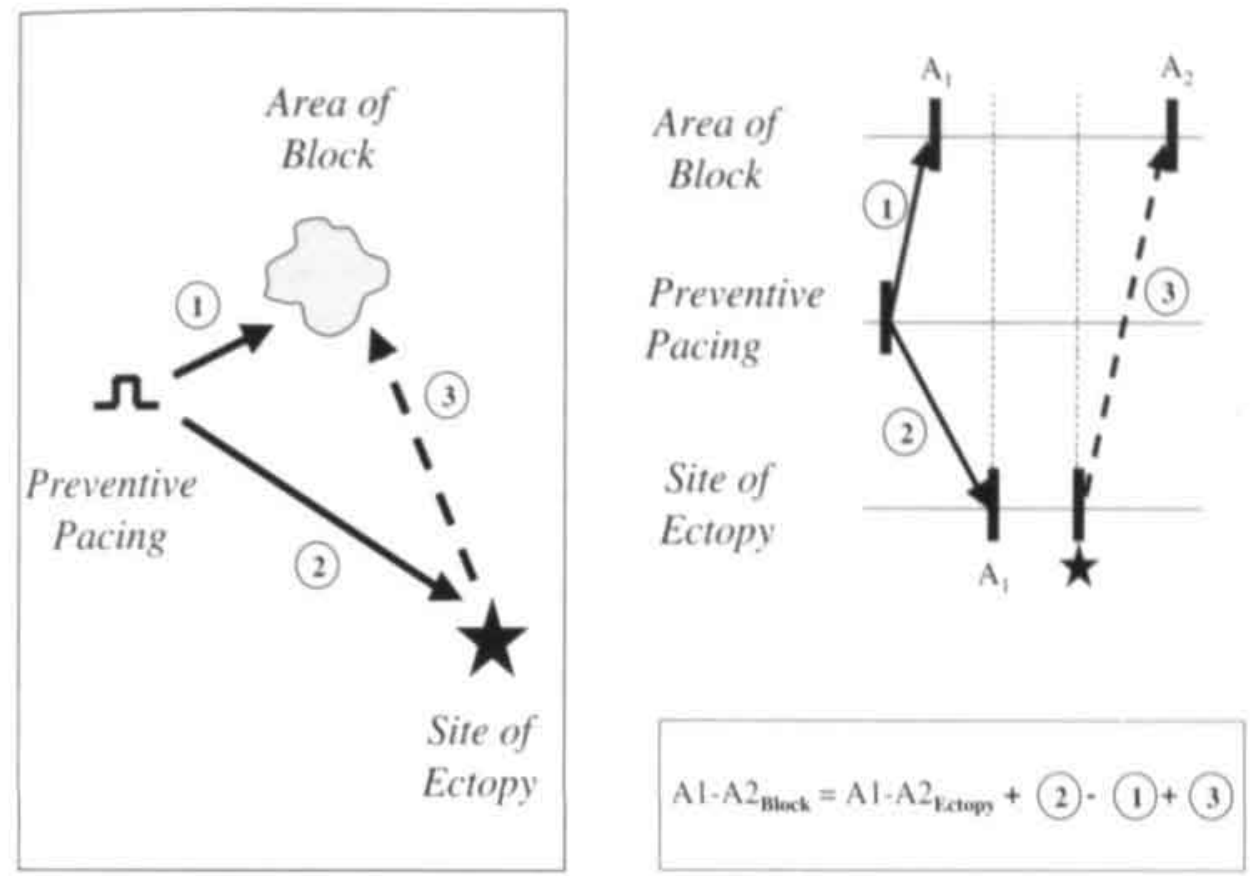

Figure 7, Diagrammatic explanation of the prevention of initiation of AF by atrial pacing. Left: the spatial relation. ship befween the site of preventive pacing. the site of ectepy and the area of critical conduction. $j$ Conduction time (CT) benween site of pacing and area of block, $\mathrm{CT}$ befween site of pacing and sife of ectopy. $I \mathrm{CT}$ benveen site of ectopy and area of bleck. Right: the premature interval at the area of block (Al-A2Block) is determmed by the sum of the prematurity at the site of ectopy $(A / \cdot A 2 E$ itopy $)+C 7 k \cdot C T j+C 7$.

In Fig.7 the mechanisms of preventive atrial pacing are illustrated schematically. Prolongation of the premature interval at the area of block by preventive pacing is due to pre-excitation of the area of block relative to the site of ectopy (left panel). As illustrated in the right panel, the prematurity at the area of block $\left(\mathrm{A} 1-\mathrm{A} 2_{\mathrm{ina}}\right)$ is determined by the sum of the prematurity at the site of ectopy + the conduction time from the site of preventive pacing to the site of ectopy (2) - the conduction time from the site of pacing to the area of block (1) + the conduction time of the premature beat to the area of block (3). In Table 2, these conduction times and the resulting prolongation of the premature interval at the area of block are given for all goats. Preventive pacing at RA only prolonged the premature interval of left ectopic beats (by $48 \pm 14 \mathrm{~ms}$ ), whereas preventive pacing at LA only prolonged the prematurity at BB during right ectopy (by $39 \pm 6 \mathrm{~ms}$ ). Preventive bi-atrial pacing did not prolong the premature intervals of either right or left ectopic beats. Preventive pacing at $\mathrm{BB}$, prolonged the premature interval of both right and left premature stimuli (by $38 \pm 8 \mathrm{~ms}$ and $50 \pm 15 \mathrm{~ms}$, respectively) because in this case the area of block was always pre-excited relative to the site of ectopy. 


\section{Discussion}

\section{SHORTENING OF THE WINDOW OF INDUCIBILITY BY PREVENTIVE ATRIAL. PACING}

The main findings of the present study in the caprine model of AF show that: (1) Bachmann's bundle is an area of critical conduction of premature beats. The fragmented low-voltage potentials recorded at BB can be the result of non-uniform anisotropy, slow discontinuous conduction, longitudinal dissociation or conduction block. The combination of low-voltage potentials together with early re-excitation proximal to this area strongly suggest that initiation of $\mathrm{AF}$ was due to conduction block and reentry at $\mathrm{BB}$. Critical conduction of premature impulses along $\mathrm{BB}$ can be explained by a considerable longer refractory period at the mid-portion of BB. (2) Atrial pacing can prevent but not completely abolish the initiation of AF by single premature beats. The shortening of the window of inducibility was due to prevention of AF by late premature beats. Atrial pacing could not prevent the induction of AF by very early premature beats. (3) In neither case pacing affected the atrial effective refractory period and the same degree of prematurity was achieved during all modalities of preventive pacing. (4) The mechanism of prevention of $\mathrm{AF}$ is a prolongation of the premature interval at the area of critical conduction (Bachmann's bundle). During atrial pacing, the premature interval at the area of

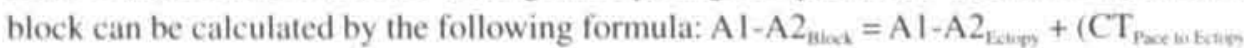

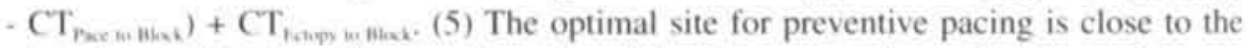
critical area of block and remote from the origin of premature beats. In this case the area of block is maximally pre-excited relative to the site of ectopy. Other pacing sites remote from the area of block may be as effective as long as the area of block is equally preexcited. Bi-atrial pacing can be less effective than single-site pacing when one of the pacing sites is close to the origin of premature beats.

\section{IS THERE AN OPTIMAL PACING SITE TO PREVENT ATRIAL FIBRILLATION?}

The present findings suggest that Bachmann's bundle (area of critical conduction) may be an effective pacing site for preventive atrial pacing. This finding is in agreement with a recent clinical study by Bailin et al. showing that in patients with paroxysmal AF pacing at Bachmann's bundle had an incremental benefit (compared to right atrial pacing) in the prevention of chronic AF." However, it should be emphasized that our caprine model of AF does not emulate the more complex substrate of different types of human AF. Several differences have to be taken into consideration comparing our experimental 
findings to preventive pacing in human AF. First of all, the substrate for initiation of AF might be very different in patients compared to normal, electrically remodeled caprine atria. Although also in patients the atrial septum, including the ostium of the coronary sinus and Bachmann's bundle. seems to be a preferential site for intra-atrial conduction delays. ${ }^{1+13}$ abundant patho-anatomical changes may occur in the atrial myocardium as a result of ageing, atrial dilatation and coronary artery disease. ${ }^{15 \times 0}$ In such diseased atria, other areas may act as critical sites of conduction block and reentry. In addition, the triggers of human AF may be different from the single premature stimuli applied in our experimental study. Although also in humans single premature beats have been shown to initiate $\mathrm{AF},{ }^{21}: 2$ other onset-mechanisms like multiple premature beats, focal atrial tachycardia and atrial flutter may trigger AF as well. In these cases, the efficacy and mechanism of preventive pacing may be different from the mechanisms shown in our experimental study. Finally, the beneficial effect of the observed shortening of the window of inducibility by atrial pacing may be rather limited. Since in patients with AF the window of inducibility may be wide, ${ }^{2}$ a reduction by 30 to $40 \mathrm{~ms}$ as found in our study may exert only a negligible effect. In such case choosing an optimal site for preventive pacing might have only a minor effect on recurrences of $\mathrm{AF}$.

Nevertheless, although our observations can not provide guidelines for preventive pacing in humans they may help to gain insights into the basic mechanism(s) of prevention of AF. Our findings imply that the optimal site for preventive pacing depends on the site of origin of atrial premature beats and the location of areas of critical conduction. The best pacing site may differ from case to case and therefore should be determined on an individual basis. Characterization of the nature of triggers of AF and localization of areas of critical conduction delay, may help to define the optimal site for preventive pacing.

\section{SINGLE-SITE VERSUS MULTI-SITE PACING}

Single-site pacing at the right atrium was found to reduce recurrences of $\mathrm{AF}$ in patients with sinus node dysfunction. ${ }^{12}$ 's According to our data, this might not only be due to prevention of bradycardia-dependent triggers but also by lowering the chance of initiation of AF by atrial premature beats. In our study. pacing at the right atrium was effective in preventing AF induced by left atrial premature beats. Since in the majority of patients with paroxysmal AF the atrial ectopic beats originate from the pulmonary veins. ${ }^{14}$ " the efficacy of right atrial preventive pacing in these cases might be explained by the mechanisms as proposed in our experimental study. Clinical studies on the additional benefit of bi-atrial pacing are controversial. " of bi-atrial pacing on recurrent atrial arrhythmias in patients with advanced inter-atrial conduction delay.' After coronary artery surgery, bi-atrial pacing was found to be more as well as less effective than right atrial pacing." "Like in our experimental study, in one clinical study, bi-atrial pacing was found to be less effective than single-site pacing in 
preventing AF by premature stimuli. ${ }^{34}$ Saksena et al. reported a beneficial effect of dualsite pacing in the right atrium. Pacing both at the ostium of the coronary sinus and the high right lateral atrium, prolonged the arrhythmia-free interval more than pacing at the right atrium or coronary sinus alone ( $195 \pm 96$ days vs $143 \pm 110$ days). ${ }^{3}$ These clinical studies are not necessarily conflicting with our experimental findings. In case of an optimal single pacing site multi-site pacing could be of limited value, whereas in case of a more complex atrial substrate with multiple areas of conduction delay, multisite pacing might be better than single site pacing. On the other hand, multi-site (or dual-site) pacing may also have favorable hemodynamic effects explaining their incremental benefit in the prevention of $\mathrm{AF}^{23}$

\section{Limitations}

The limited epicardial mapping, does not allow complete reconstruction of all the complex interactions between ectopic premature beats and the different pacing modes to prevent initiation of AF. Because of the absence of endocardial recordings the 3-D structure of the atria was not taken into account.

Another limitation our study is that we did not study the effects of preventive atrial pacing on initiation of AF by spontaneous atrial premature beats (which are virtually absent in the goat) and multiple atrial premature beats. 
Table 1. Window of Inducibility of Af by Single Premature Beats (Baseline Values).

\begin{tabular}{|c|c|c|c|c|c|c|}
\hline Goals & $S 1-S 2$ al $R A$ & $\mathrm{~S} 1-\mathrm{S} 2$ at LA & $\mathrm{S} 1-\mathrm{S} 2$ at RA & $\mathrm{S} 1-\mathrm{S} 2$ at LA & $\mathrm{S} 1-\mathrm{S} 2$ at RA & S1-S2 at LA \\
\hline 2 & 104 & 122 & 150 & 145 & 46 & 23 \\
\hline 3 & 92 & 96 & $1+4$ & 164 & 52 & 68 \\
\hline 4 & 96 & 111 & 150 & 140 & 54 & 29 \\
\hline 6 & 105 & 97 & 150 & 155 & 45 & 58 \\
\hline Mean & $101 \mathrm{~ms}$ & $108 \mathrm{~ms}$ & $150 \mathrm{~ms}$ & $152 \mathrm{~ms}$ & $49 \mathrm{~ms}$ & $45 \mathrm{~ms}$ \\
\hline SD & \pm 6 & \pm 10 & \pm 6 & \pm 9 & \pm 9 & \pm 17 \\
\hline
\end{tabular}


Table 2. Prolongation of the Premature Interval at the Area of Block (Bachmann's bundle) during Preventive Pacing (6 goats).

\begin{tabular}{|c|c|c|c|c|c|c|c|c|}
\hline & \multicolumn{2}{|c|}{$\begin{array}{l}\text { Paeventive Pacing } \\
\text { at RA }\end{array}$} & \multicolumn{2}{|c|}{$\begin{array}{c}\text { Preventive Pacing } \\
\text { at LA }\end{array}$} & \multicolumn{2}{|c|}{$\begin{array}{c}\text { Preventive Bi-Arrial } \\
\text { Pacing }\end{array}$} & \multicolumn{2}{|c|}{$\begin{array}{c}\text { Preventive Pacing } \\
\text { at BB }\end{array}$} \\
\hline & $\begin{array}{l}\text { Premature } \\
\text { Stim. at RA }\end{array}$ & $\begin{array}{l}\text { Premature } \\
\text { Stim. at LA }\end{array}$ & $\begin{array}{l}\text { Premature } \\
\text { Stim. at RA. }\end{array}$ & $\begin{array}{l}\text { Premature } \\
\text { Stim. at LA }\end{array}$ & $\begin{array}{l}\text { Premature } \\
\text { Stim. at RA }\end{array}$ & $\begin{array}{l}\text { Premature } \\
\text { Stim. at LA }\end{array}$ & $\begin{array}{l}\text { Premature } \\
\text { Stim. at RA }\end{array}$ & $\begin{array}{l}\text { Premature } \\
\text { Stim. at LA }\end{array}$ \\
\hline$O 1 \mathrm{CT}_{\text {Pace wind }}$ & $25 \pm 4$ & $66 \pm 10$ & $57 \pm 9$ & $33 \pm 13$ & $25 \pm 4$ & $33 \pm 13$ & $17 \pm 3$ & $20 \pm 6$ \\
\hline $2 \mathrm{CT}_{\text {Paec nut turn }}$ & $2 \pm 1$ & $83 \pm 7$ & $75 \pm 4$ & $6 \pm 3$ & $2 \pm 1$ & $5 \pm 4$ & $36 \pm 10$ & $41 \pm 10$ \\
\hline $3 \mathrm{CT}_{\text {farom w whe }}$ & $24 \pm 4$ & $31 \pm 12$ & $21 \pm 1$ & $29 \pm 13$ & $25 \pm 4$ & $30 \pm 14$ & $21 \pm 1$ & $30 \pm 12$ \\
\hline $\begin{array}{l}\text { Prolongation of } \\
\text { the Premature }\end{array}$ & & $48 \mathrm{~ms}$ & $39 \mathrm{~ms}$ & $2 \mathrm{mis}$ & $3 \mathrm{~ms}$ & $2 \mathrm{~ms}$ & $40 \mathrm{~ms}$ & $50 \mathrm{~ms}$ \\
\hline Interval at BB & \pm 1 & \pm 14 & \pm 6 & \pm 3 & \pm 2 & \pm 3 & \pm 9 & \pm 16 \\
\hline
\end{tabular}




\section{References}

1. Andersen HR, Nielsen JC. Thomsen PEB et al. Long-term follow-up of patients from a randomized trial of atrial versus ventricular pacing for sick sinus syndrome. Lancet, 1997:350:1210-1216.

2. Coumel P. Friocourt P, Mugica $J$ et al. Long-term prevention of vagal arrhythmias by atrial pacing at 90/minute: experience with 6 cases. Pacing Clin Electrophysiol, 1983,6:552-560.

3. Daubert C. Gras D, Berder V et al. Permanent atrial resynchronization by synchronous biatrial pacing in the prevention of atrial flutter associated with high degree interatrial block (French). Anch Mal Coeur Vaiss, 1994:87(Suppl):1535-1546.

4. Saksena S, Prakash A, Hill M et al. Prevention of recurrent atrial fibrillation with chronic dual-site right atrial pacing. I Am Coll Candiol. 1996:28:687-694.

5. Delfaut $P$, Saksena S, Praksah A et al, Long-term outcome of patients with drug-refractory atrial flutter and fibrillation after single- and dual-site right atrial pacing for arrhythmia prevention. $J \mathrm{Am}$ Coll Candiol. 1998:32:1900-1908.

6. Daoud EG, Dabir R, Archambeau M et al. Randomized, double-blind trial of simultaneous right and left atrial epicardial pacing for prevention of post-open heart surgery atrial fibrillation. Cinculation, 2000:102:761-765.

7. Greenberg MD. Katz NM. Iuliano $S$ et al. Atrial pacing for the prevention of atrial fibrillation after cardiovascular surgery. J Am Coll Cardiol, 2000:35:1416-1422.

8. Murgatroyd FD, Nitzsche R. Slade AKB et al. for the Chorus Multicentre Study Group. A new pacing algorithm for overdrive suppression of atrial fibrillation. Pacing Clin Electrophysiol. 1994:17:1966-1973.

9. Yu WC. Chen SA. Tai CT et al. Effects of different atrial pacing modes on atrial electrophysiology. Implicating the mechanism of biatrial pacing in prevention of atrial fibrillation. Cinculation, 1997:96:2992-2996.

10. Prakash A, Delfaut P, Krol RB et al, Regional right and left atrial activation pattems during singleand dual-site atrial pacing in patients with atrial fibrillation. Am J Cardiol. 1998:82:1197-I204.

11. Wijfels MCEF, Kirchoff CJHJ, Dorland R et al. Atrial fibrillation begets atrial fibrillation: a study in awake chronically instrumented goats. Circulation, 1995:92:1954-1968.

12. Garratt CJ. Duytschaever M. Killian M et al. Repetitive electrical remodeling by paroxysms of atrial fibrillation in the goat: no cumulative effect on inducibility or stability of atrial fibrillation. J Candiovasc Electrophys, 1999:10:1101-1108.

13. Bailin SJ. Adler SW. Giudici MC. Prevention of chronic atrial fibrillation by pacing in the region of Bachmann's bundle: results of a multicenter randomized trial. $J$ Cardiovasc Electrophys, 2001: 12: $912-917$.

14. Chen SA. Hsich MH. Tai CT et al. Initiation of atrial fibrillation by ectopic beats originating from the pulmonary veins. Electrophysiological characteristics, pharmacological responses and effects of radiofrequency ablation. Circulation, 1999:100:1879-1886.

15. Cosio FG. Palacios J. Vidal JM et al. Electrophysiologic studies in atrial fibrillation: slow conduction of premature impulses: a possible manifestation of the background for reentry. Am J Cardiol, 1983: $51: 122-128$. 
16. Saksena S, Giorgberidze I, Mehra R et al. Electrophysiology and endocardial mapping of induced atrial fibrillation in patients with spontaneous atrial fibrillation. Am J Cardiol. 1999:83:187-193.

17. Papageorgiou P. Monahan K, Boyle NG et al. Site-dependent intra-atrial conduction delay: relationship to initiation of atrial fibrillation. Circulation, 1996:94:384-389.

18. Papageorgiou $\mathrm{P}$, Anselme F, Kirchoff $\mathrm{CJHJ}$ et al. Coronary sinus pacing prevents induction of atrial fibrillation. Circulation, 1997:96:1893-1898.

19. Davies MJ, Pomerance A. Pathology of atrial fibrillation in man. Br Heart J, 1972:34:520-525.

20. Thijssen VL. Ausma J, Liu GS et al. Structural changes of atrial myocardium during chronic atrial fibrillation. Candiovasc Pathol, 2000;9:17-28.

21. Hoffmann E, Janko S. Steinbeck G et al. for the AFT study group. Onset scenarios of paroxysmal atrial fibrillation using new diagnostic pacemaker functions (abstract). Pacing Clin Electrophysiol, 2000,23(partII): 656.

22. Tieleman RG, Van Gelder IC, Crijns HJ et al. Early recurrences of atrial fibrillation after electrical cardioversion: a result of fibrillation-induced electrical remodeling of the atria? $\mathrm{J} \mathrm{Am}$ Coll Cardiol, 1998:31:167-173.

23. Haissaguerre M. Jais P. Shah DC et al. Spontaneous initiation of atrial fibrillation by ectopic beats originating in the pulmonary veins. $N$ Eng J Med, 1998:339:659-666.

24. Yu WC. Tsai CF. Hsieh MH et al. Prevention of the initiation of atrial fibrillation: mechanism and efficacy of different atrial pacing modes. Pacing Clin Electrophysiol, 2000:23:373-379.

25. Prakash A. Saksena S, Ziegler $\mathrm{P}$ et al. Dual site atrial pacing for prevention of atrial fibrillation (DAPPAF) trial: Echocardiographic evaluation of atrial and ventricular function during a randomized trial of support, high right atrial and dual site right atrial pacing (abstract). PACE 2001; 24:553. 


\section{Chapter 6}

\section{Pro-fibrillatory Effects of Verapamil but not of Digoxin in the Goat Model of Atrial Fibrillation.}

Mattias F, Duytschaever, MD; Clifford J. Garratt, MD:

Maurits A Allessie. MD. PhD

J Cardiovasc Electrophysiol, 2000:11:1375-1385. 


\section{Abstract}

Background: Verapamil (V) and digoxin (D) have been shown to modulate tachycardiainduced atrial electrical remodeling. The goal of the present study was to determine the direct effects of $\mathrm{V}$ and $\mathrm{D}$ on $\mathrm{AF}$, before and after electrical remodeling.

Methods and Results: In 6 goats we measured the cycle length (AFCL) and duration of AF (DurAF) of 50 consecutive induced paroxysms, before $(t=0)$ and after $24 \mathrm{~h}(\mathrm{t}=24)$ of electrical remodeling. During $A F$ conduction velocity $\left(\mathrm{CV}_{\mathrm{AF}}\right)$, refractory period $\left(\mathrm{RP}_{\mathrm{AP}}\right)$ and the type of AF (I-II-III) were determined. V was administered by a loading dose of $0.1 \mathrm{mg} / \mathrm{kg}$, followed by a continuous (2-hour) infusion of $5 \mu \mathrm{g} / \mathrm{kg} / \mathrm{min}$. D was given intravenously as a single bolus of $0.02 \mathrm{mg} / \mathrm{kg}$. At $\mathrm{t}=0$ and $\mathrm{t}=24$, D and $\mathrm{V}$ caused a significant slowing of the ventricular rate of $>40 \%$. D had no effect on DurAF, AFCL, CV or $\mathrm{RP}_{\mathrm{A}}$. Infusion of $\mathrm{V}$ had a direct pro-arrhythmic effect. Both at $\mathrm{t}=0$ and $\mathrm{t}=24, \mathrm{AFCL}$. and $\mathrm{RP}_{\mathrm{A}}$ were shortened by about $15 \%$. During acute $\mathrm{AF}, \mathrm{V}$ prolonged the average duration of AF-paroxysms from 7 to 16 seconds. After 24 hours of AF, the proarrhythmic effect was much stronger. Shortly after start of the infusion $(6 \pm 2 \mathrm{~min}) \mathrm{V}$ converted paroxysmal into sustained $\mathrm{AF}$. As long as $\mathrm{V}$ infusion was maintained, in all goats $\mathrm{AF}$ no longer terminated. This effect was associated with an increase in AF-fragmentation from type 1 to type II-III.

Conclusions: Verapamil shortens AFCL and $\mathrm{RP}_{N F}$ in the presence and absence of electrical remodeling. After 24 hours it exerted a marked proarrhythmic effect and converted paroxysmal (type-I) into sustained (type-III) AF. In contrast, digoxin had no effect on rate or stability of $\mathrm{AF}$.

Key Words: Atrial fibrillation- Electrical Remodeling- Verapamil- Digoxin- Proarrhythmia. 


\section{List of Abbreviations}

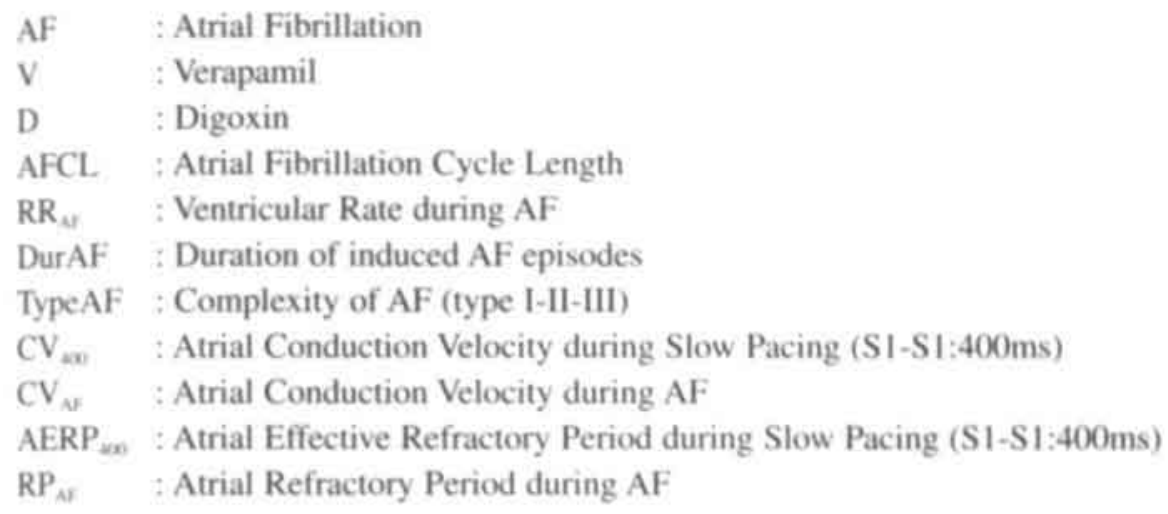

\section{Introduction}

Digoxin and verapamil are commonly used to control the ventricular rate during atrial

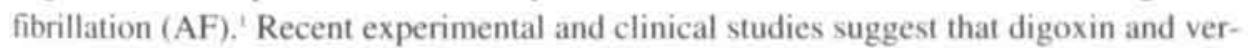
apamil might influence the natural course of $\mathrm{AF}^{2+}$ Tieleman et al. demonstrated that verapamil attenuated the tachycardia-induced shortening of atrial refractoriness (electrical remodeling). In contrast, digoxin had no detectable effect on remodeling, but slightly delayed its recovery (reverse electrical remodeling).' Clinically, there are indications that patients treated with calcium lowering drugs have fewer relapses of AF after electrical cardioversion, whereas digoxin may increase the likelihood of recurrences. ${ }^{4}$

However, little is known about the direct effects of digoxin and verapamil on the electrophysiological properties of the atria and on the characteristics of atrial fibrillation. The goal of the present study was to compare the effects of both drugs on the refractory period and conduction velocity during $\mathrm{AF}$ and to determine the pro-and antiarrhythmic effects on rate and duration of AF. To investigate whether AF-induced electrical remodeling affected the action of digoxin and verapamil, they were administered both during acute $\mathrm{AF}$ (no remodeling) and after 24 hours of $\mathrm{AF}$ (remodeling). 


\section{Methods}

\section{THE GOAT MODEL OF ATRIAL FIBRILLATION}

Six goats weighing between 42 and $74 \mathrm{~kg}(56 \pm 12)$ were used for this study. Animal handling was carried out according to the Dutch Law and the European Directive for protection of vertebral animals. Anesthesia was induced by intravenous administration of Nesdonal $(15 \mathrm{mg} / \mathrm{kg})$ and maintained by ventilation with halothane $(1-2 \%)$ and a mixture of $\mathrm{O}_{2}$ and $\mathrm{N}_{2} \mathrm{O}$. The chest was opened through a left intercostal thoracotomy. Three teflon felt plaques, each containing 23-30 silver electrodes, were sutured to the atrial epicardium (Fig1). Two oval-shaped plaques $(3.5 \times 2.5 \mathrm{~cm}, 30$ electrodes, inter-electrode distance $4 \mathrm{~mm}$ ) were sutured on the free wall of the right (RA) and left atrium (LA). One strip of $6 \times 1 \mathrm{~cm}$, containing 23 electrodes (inter-electrode distance 6-10 $\mathrm{mm}$ ), was pulled through the sinus between the atria and the aortic root and sutured to the atrial appendages. A plaque containing 4 electrodes was sutured on the free wall of the left ventricle (LV). A silver plate was left under the skin of the thorax to serve as indifferent electrode. The electrode leads were tunneled subcutaneously to the neck and exteriorized by three 30 pin connectors (Lemosa $($ ). Post-operatively the animals received buprenorfine (Temgesic@) for 2-4 days. Experiments were started 3-4 weeks after surgery.
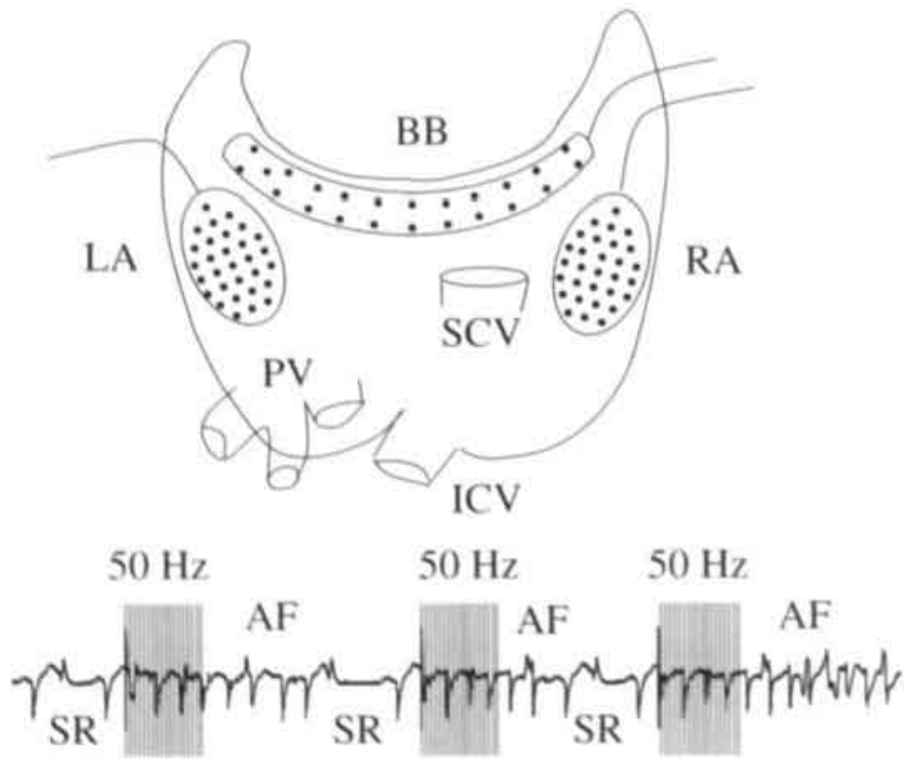

Figure 1. Lacalizarion of chronicallv implanted clectrodes. Two plaques, containing 30 clectndes were suturnd on the frre wall of the atria. One strip with 23 electrodes was positioned alone Bachmann's twandle. In the lonser panel the fibrillation pacemaker is illostruated. Ar soen as sinus rhvthm is detected. a $50 \mathrm{~Hz}$ burst was deliverred wo indace AF. In this cuample (no rmovleling) anty short cpisodes of AF nere indacind. 


\section{EXPERIMENTAL PROTOCOL}

The effects of verapamil and digoxin were measured both before and after electrical remodeling by 24 hours of AF. AF was maintained by a fibrillation pacemaker. This custom-made computer program automatically delivered a 1-second burst of stimuli $(50 \mathrm{~Hz}, 4 x$ diastolic threshold) to a pair of atrial electrodes as soon as sinus rhythm was detected (Figl). By these automatic bursts of stimuli. AF could be maintained continuously during 24 hours as has been previously described.'

First the effects of verapamil were studied both during normal sinus rhythm (no remodeling) and after 24 hours of AF. Then digoxin was administered both before and after AFinduced electrical remodeling. Between all 4 experiments the goats were left in sinus hythm for at least one week. During this period the atria recovered completely from earlier remodeling and drug administration. ${ }^{\circ}$ Before each drug a baseline study was performed. First, during regular pacing $\left(\mathrm{S}_{1} \mathrm{~S}_{1}: 400 \mathrm{~ms}\right)$ the left atrial effective refractory period ( $\left.A E R P_{n \infty}\right)$ and conduction velocity along Bachmann's bundle $\left(\mathrm{CV}_{\mathrm{us}}\right)$ were measured. The double row of electrodes on Bachmann's bundle was used to verify propagation parallel to the electrodes. Cycle length and duration of AF were measured during 50 consecutively induced episodes of AF. The mean AFCL and RR-interval were determined from 100 consecutive AF and RR cycles from unipolar left atrial and ventricular electrograms. Verapamil was administered by a loading dose of $0.1 \mathrm{mg} / \mathrm{kg}$. followed by a continuous (2-hour) infusion of $5 \mu \mathrm{g} / \mathrm{kg} / \mathrm{min}$. Digoxin was given intravenously as a single bolus of $0.02 \mathrm{mg} / \mathrm{kg}$. These dosages were chosen, based on previous studies in the goat : ' and because they prolonged the average RR-interval during AF to a similar extent $( \pm 45 \%)$. Immediately after drug administration, repeated induction of AF was continued for a period of 2 hours. The mean AFCL and RR interval were measured every 15 minutes after start of the infusion. whereas the duration of the paroxysms of AF was monitored continuously for a period of 2 hours. After 1 and 2 hours of drug administration, the atrial refractory period and conduction velocity were measured during regular pacing with an interval of $400 \mathrm{~ms}$.

\section{ELECTROPHYSIOLOGY OF AF}

The type of atrial fibrillation (type ${ }_{A F}$ ), the conduction velocity and the refractory period during AF were measured after 1 and 2 hours of drug infusion. To determine the type of AF (1-II-III) fibrillation maps were recorded from the free wall of the left and right atrium. Time windows of 4 seconds were analyzed excluding the first and last seconds of AF. The software used for mapping (custom-made) included an algorithm for automatic detection of the intrinsic negative deflections of unipolar electrograms and interactive editing of local activation times. Isochrones were drawn manually at 5-ms intervals. Type I AF was defined by broad single wavefronts propagating without apparent 
conduction delay. Type II AF was characterized either by the presence of two wavelets or by lines of intra-atrial conduction block. During type III. multiple wavelets were present under the mapping array which continuously changed their size and position. During a 4 second-sample of $\mathrm{AF}$ ( 25 to $40 \mathrm{AF}$ cycles) beat to beat variations in $\mathrm{AF}$ pattern were observed. The degree of disorganization during AF was determined by calculating the percentage of beats with a type II or III pattern.

To measure the atrial conduction velocity during AF, the fibrillation maps were triangulated and the local conduction vectors calculated from the activation times at the corners (Fig 2). When neighboring electrodes were activated almost simultaneously (either by collision or by epicardial breakthrough of fibrillation waves) high virtual conduction velocities were measured. Values of more than $140 \mathrm{~cm} / \mathrm{sec}$ were discarded from analysis. The $\mathrm{CV}_{A}$, histogram, obtained in this way, contained about 700-900 data points. The median value was taken as an index of conduction velocity during AF.

Activation map

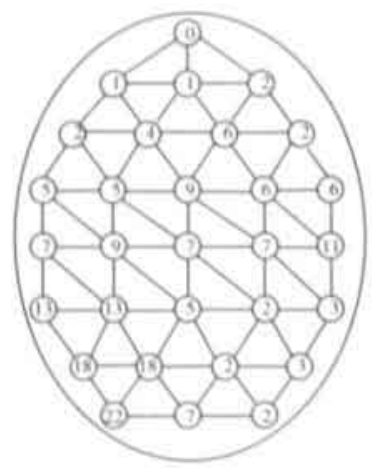

Vector map

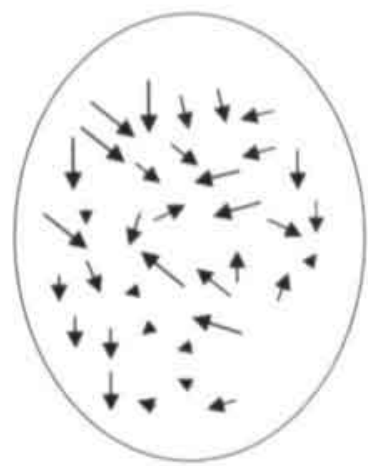

\section{Velocity Histogram}

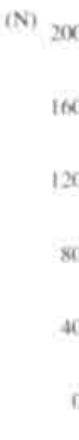

Figure 2. Measurement of intra atrial conduction velocity during AF. After triangulation of the fibrillation map fleffi local conduction irctors were calculated from the activation times at the corners (midalle). All local conduction veloc. ities < $140 \mathrm{~cm} / \mathrm{s}$ wre collected in a velocify histogram (right). The median conduction velocity was taken as the conduction velesity during At.

The refractory period during $\mathrm{AF}$ was measured during regional entrainment of the free wall of the left atrium with a pacing interval equal to the median AFCL (Fig 3). A pair of electrodes in the center of the mapping array was selected for stimulation whereas local capture was verified at a neighboring electrode $4 \mathrm{~mm}$ from the pacing site. Capture was defined by the absence of R-waves and a short and constant latency between stimuli and response. After 8 entrained beats, single premature stimuli were applied starting well within the refractory period. In the upper panel of Fig 3, a premature stimulus with a coupling interval of $112 \mathrm{~ms}$ did not capture the atrium. The post-stimulus electrogram appeared after a long latency and exhibited a clear R-wave. Failure of capture was confirmed by the activation map, showing a fibrillation wave propagating from left to right under the pacing electrode. A coupling interval of $116 \mathrm{~ms}$ (lower panel. Fig 3 ) resulted in 
local capture. The activation map showed radial spread from the pacing site at the center of the mapping array and the neighboring electrogram exhibited a similar response as during the previous entrainment of AF. The shortest coupling interval that captured the atrium during AF was not constant. When stimuli with the same coupling interval were applied repeatedly, capture sometimes occurred and sometimes not. This shows that. instead of deterministic, the $\mathrm{RP}_{\mathrm{AF}}$ is a probabilistic measurement. Therefore each coupling interval was repeated 10 times before it was incremented by 2 ms. Because we were interested in the largest possible excitable gap during AF, the refractory period during AF was taken as the shortest coupling interval that resulted in $20 \%$ of capture ( 2 of 10 attempts).
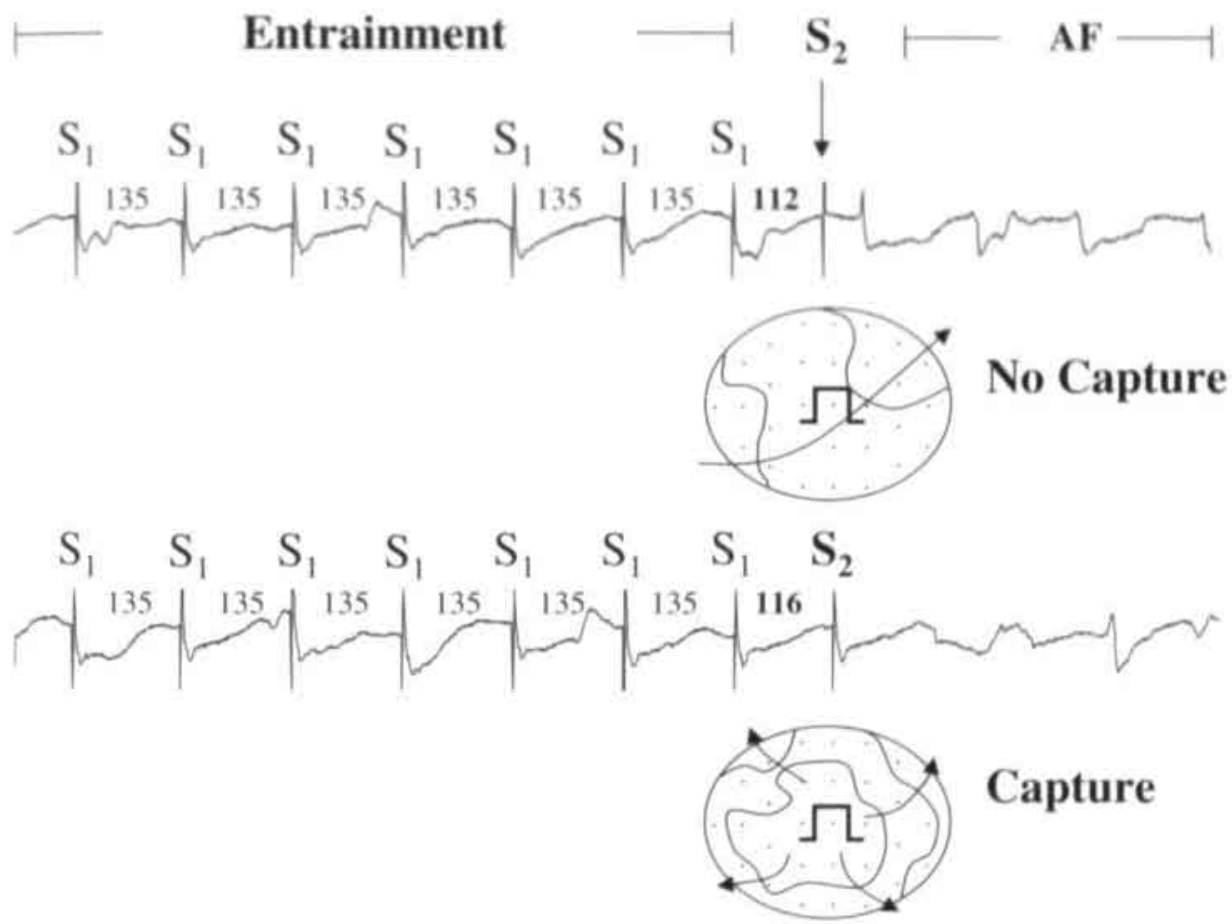

Figure 3. Measurement of the atrial refracton period during entrainment of AF. The atrium was pared at the median $A F C L$ at the center of the mapping area. The electrogram recorded $4 \mathrm{~mm}$ from the pacing site, showed local entrainment of AF. A premature stimulus with a coupling intenul of $112 \mathrm{~ms}$ failed to capture the atrium (upper panel). The lower panet shows that a coupling interval of $116 \mathrm{~ms}$ resulted in radial spread of activation from the pacing site (capture).

\section{STATISTICAL ANALYSIS}

Data are presented as mean $\pm \mathrm{SD}$. In case the data were not normally distributed the median value and its range are given. Statistical analysis was performed by the paired Student's t test or the Wilcoxon matched pairs signed ranks test. A p-value of less than 0.05 was considered as statistically significant. 


\section{Results}

\section{EFFECTS OF DIGOXIN AND VERAPAMIL ON ATRIAL RATE AND STABILITY DURING AF}

A representative example of the effects of digoxin and verapamil on $R R$ interval and $\mathrm{AFCL}$ is given in Fig 4. During acute AF (no remodeling) the average RR interval was $573 \pm 104 \mathrm{~ms}$ and the mean AFCL $164 \pm 11 \mathrm{~ms}$. Digoxin progressively slowed the ventricular rate during the first 15 minutes after administration of the single bolus. Then, during 2 hours, the average RR interval remained constant $(908 \pm 315 \mathrm{~ms})$. AFCL remained unchanged $(164 \pm 13 \mathrm{~ms})$. Verapamil equally prolonged the RR interval to $849 \pm 365 \mathrm{~ms}$. However, in contrast to digoxin, the AFCL was shortened to $138 \pm 12 \mathrm{~ms}$. After 24 hours of $\mathrm{AF}$, the RR interval was unchanged $(630 \pm 84 \mathrm{~ms})$, while the AFCL had shortened to $132 \pm 12 \mathrm{~ms}$ (atrial electrical remodeling). Again digoxin prolonged the RR interval $(927 \pm 319 \mathrm{~ms})$, but left the AFCL unchanged $(130 \pm 9 \mathrm{~ms})$. Infusion of verapamil prolonged the RR interval to $908 \pm 355 \mathrm{~ms}$ and again shortened AFCL. As a result of the combination of electrical remodeling and verapamil, the AFCL became as short as $109 \pm 15 \mathrm{~ms}$ (lower right panel).

\section{Acute AF}

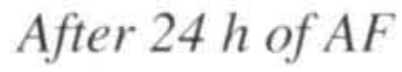

Control

RR
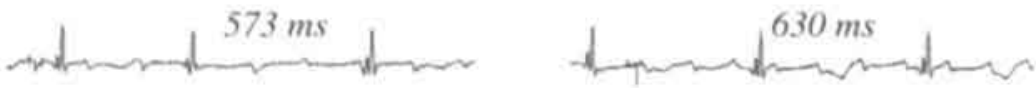

$\mathrm{AFCL}$
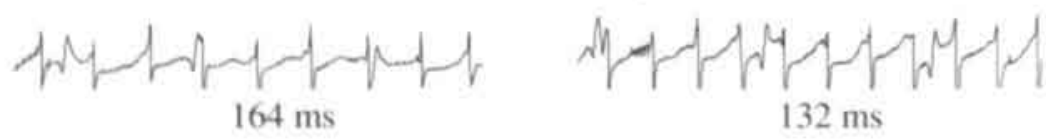

$132 \mathrm{~ms}$

Digoxin

RR

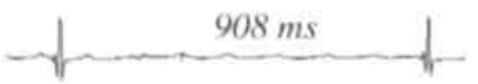

$\mathrm{AFCl}$
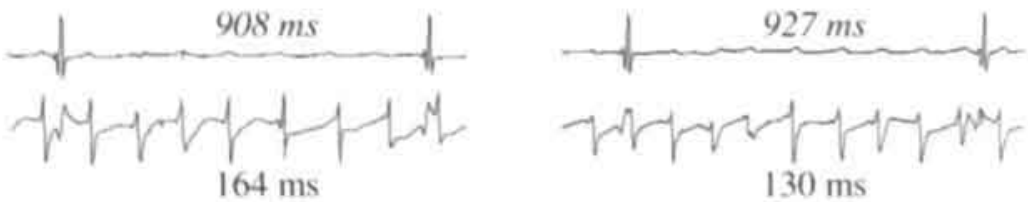

Verapamil

RR
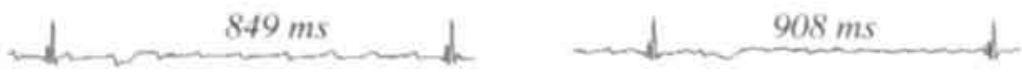

$\mathrm{AFCl}$
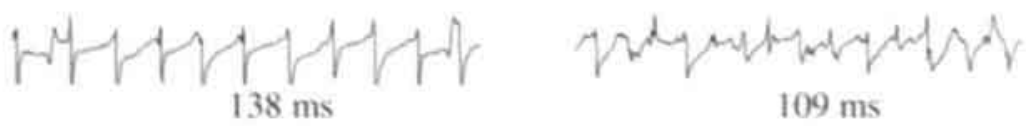

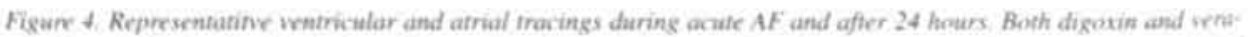

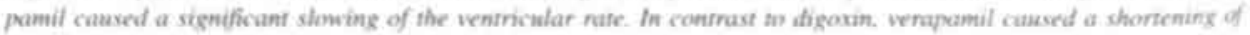
the fibrillation interval. both in acute AF and after 24 hours. 
The effect on the duration of AF is illustrated in Fig 5. In the non-remodeled state (acute AF) the AF paroxysms were short lasting (median 6 seconds, range 2-24). Digoxin had no effect on the duration of the AF episodes, whereas verapamil (lower panel) slightly prolonged the AF paroxysms (median 15 seconds, range 2-72 sec). After 24 hours of electrical remodeling, the AF paroxysms lasted longer with a median duration of 54 seconds (range 8-230 sec). Again digoxin did not alter the duration of AF. Verapamil now had a dramatic effect on the stability of AF. During the first 5 minutes after start of the infusion. AF was still self-terminating (7 episodes). However, the $8^{\circ}$ paroxysm of $\mathrm{AF}$, induced after 5 minutes, no longer terminated and persisted as long as verapamil was given ( 2 hours).

\section{Acute AF}

\section{Control}

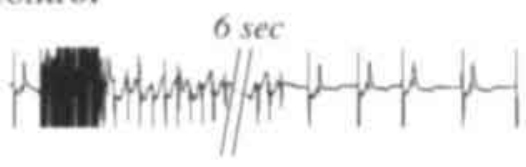

Digoxin

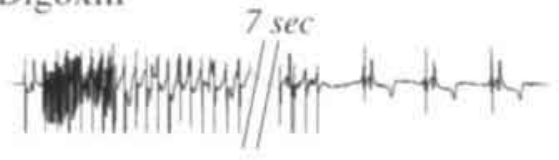

Verapamil

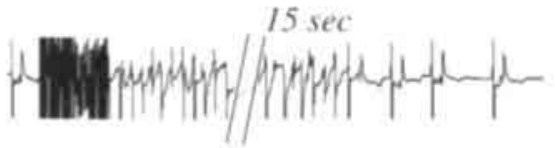

\section{After 24 of $A F$}
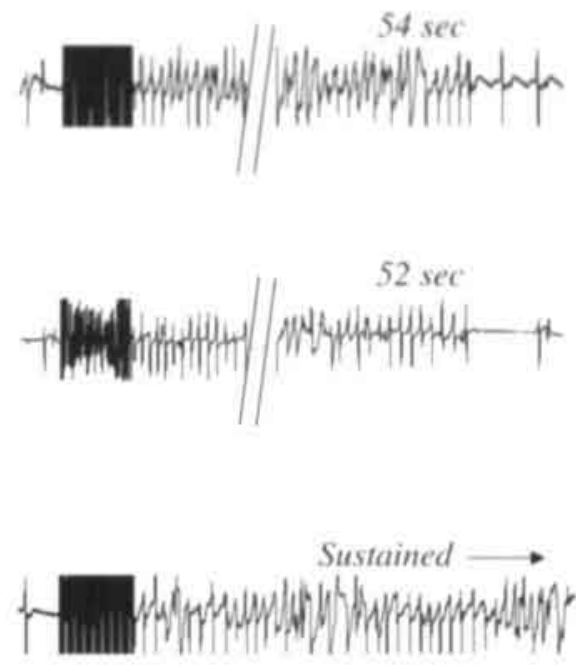

Figure 5. Effects of digoxin and verupamil on the stability of AF, Acute AF was short-lived and veropamil caused only a slight increase in its duration. After 24 hours, the atrial substrate was changed and AF pamxysms now lasted appoximately one minute. Although digoxin did not affect AF stability verapamil made Af sustained.

Analysis of fibrillation maps showed no effect of digoxin on the degree of fragmentation. either during acute AF or after 24 hours of electrical remodeling. However, administration of verapamil increased the fragmentation of the fibrillation waves in the remodeled atria (24h AF). In Fig 6 an example is given. Before verapamil was given (upper panel), the AFCL was $119 \pm 11 \mathrm{~ms}$. The majority of the electrograms consisted of single high-amplitude complexes, separated by isoelectrical segments. The fibrillation maps revealed single broad wavefronts propagating without much conduction delay (type I). Only incidentally dissociation by a line of functional conduction block was observed (type II). Administration of verapamil accelerated AF (AFCL 99ms) and the fibrillation electrograms became more fragmented and lower in amplitude. The fibrillation maps 
now showed a more complex activation pattern. Often multiple wavelets were seen separated by lines of functional conduction block (type II and III).

\section{Control (after 24 h of $A F)$}

AFCL

$119 \mathrm{~ms}$
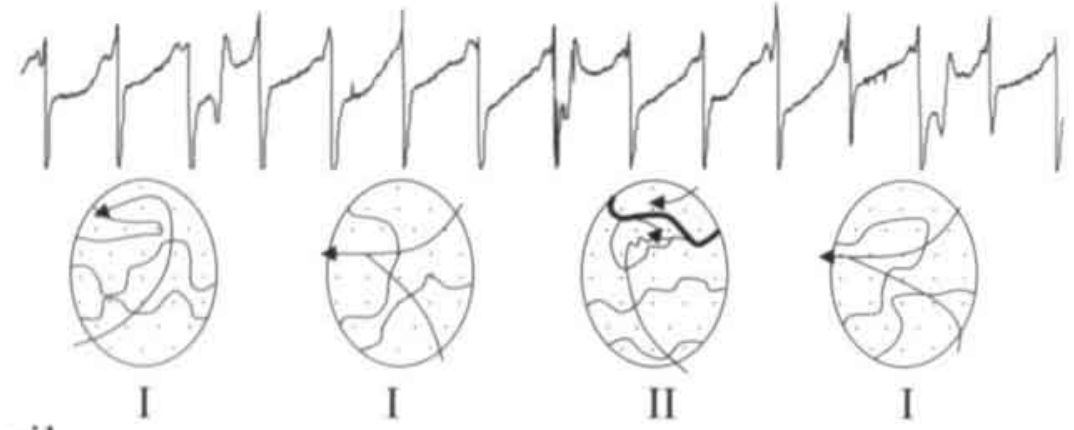

\section{Verapamil}

$\mathrm{AFCL}$

$99 \mathrm{~ms}$
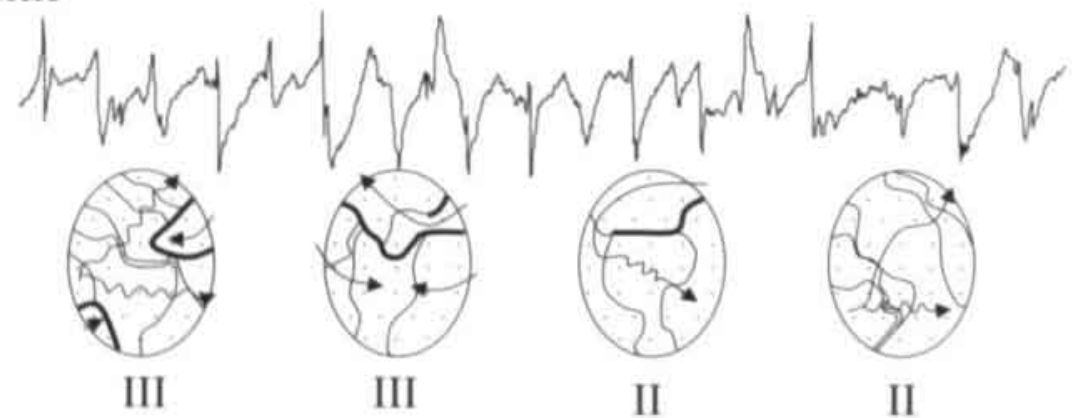

Figure 0. Increased fragmentation of AF by verapamil. Compared to control the AFCL was shortened and the fibril. lation electrognams were mere fragmented and lewer in amplitude. The fibrillation maps showrd a more comples fope of activation (type $\mid 1-I I I)$

In Fig 7 and Table I the effects of digoxin and verapamil on the characteristics of AF are given for all six goats. Both during acute AF and after 24 hours, digoxin and verapamil caused a similar prolongation of the RR interval by $>40 \%$. In all goats, administration of digoxin progressively slowed the ventricular rate during the first 15 minutes, after which the average RR interval remained constant for 2 hours. Digoxin had no effect on $\mathrm{AFCL}$, neither during acute $\mathrm{AF}$ ( $151 \pm 17$ versus $151 \pm 15 \mathrm{~ms})$ nor after 24 hours of $\mathrm{AF}$ $(115 \pm 12$ versus $116 \pm 13 \mathrm{~ms})$. In contrast, verapamil clearly accelerated the rate of AF. In non-remodeled atria. AFCL shortened from $152 \pm 15$ to $129 \pm 9 \mathrm{~ms}(-15 \%)$ and in remodeled atria from $121 \pm 10$ to $102 \pm 8 \mathrm{~ms}(-16 \%)$. The duration of $\mathrm{AF}$ was not influenced by digoxin. neither before nor after remodeling. Verapamil prolonged the duration of AF The median duration of paroxysms of acute AF was prolonged from 7 to 16 seconds $(p=0.06)$. After AF of 24 h duration, the effect of verapamil on the stability of AF was more pronounced. Only during the first $6 \pm 2$ minutes of verapamil infusion. AF was still self-terminating. Then, verapamil converted paroxysmal into sustained atrial fibrillation 
in all 6 goats and as long as verapamil infusion was maintained ( 2 hours), AF no longer terminated.

Whereas the degree of fragmentation of AF was not affected by digoxin, the effects of verapamil were largely determined by the degree of electrical remodeling. During acute AF verapamil had no effect on the complexity of AF. However, after 24 hours of AF. induced electrical remodeling, verapamil shifted AF from type I to type II-III. The percentage of type $\mathrm{II}+\mathrm{III}$ beats after administration of verapamil was $96 \pm 6 \%$ compared to $25 \pm 11 \%$ at baseline $(\mathrm{p}<0.01)$.
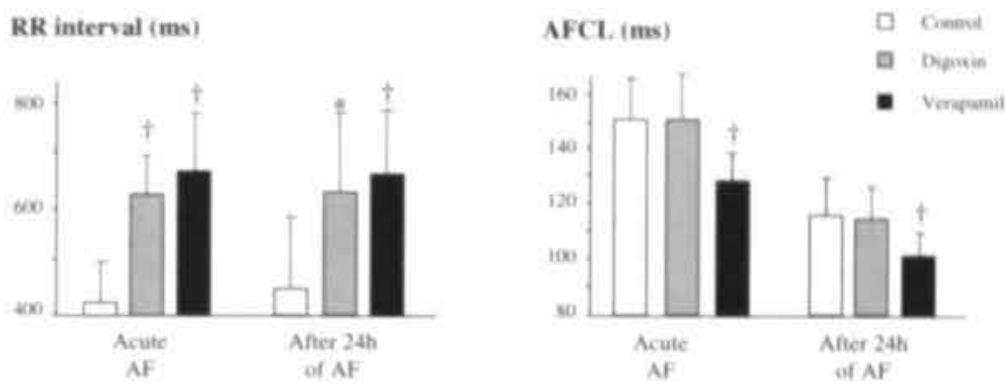

DurAF (min)

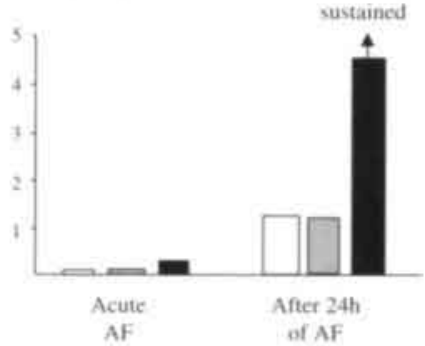

Type II+III (\%)

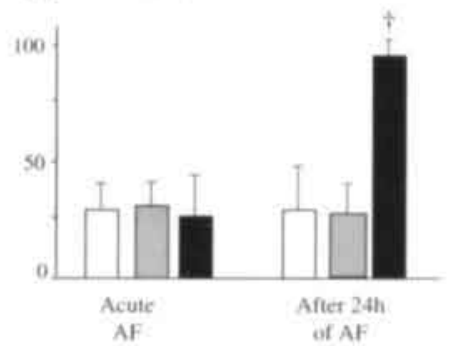

Figure 7. Effects of verapamil and digoxin on acute and 24-h.AF in 6 goats. Verapamil had a similar effect on RR. interval as digoxin. but preferentially shortened AFCL and inereased the stability of AF. The degree of fragmentation. plotted as the percentage of type $\|+I I I$ beats, also increased by verapamil $(* p<0,05,+p<0,01)$

\section{EFFECTS OF DIGOXIN AND VERAPAMIL ON ATRIAL REFRACTORY PERIOD AND CONDUCTION VELOCITY}

Both digoxin and verapamil had no effect on atrial conduction during slow pacing either before or after AF-induced electrical remodeling. Conduction during AF was also not changed by digoxin (acute AF: $75 \pm 15$ versus $76 \pm 12 \mathrm{~cm} / \mathrm{s}: 24 \mathrm{~h}$ of $\mathrm{AF}: 74 \pm 8$ versus $74 \pm 10 \mathrm{~cm} / \mathrm{s}$ ) (Table 1). The effects of verapamil on conduction during AF are illustrated in the $\mathrm{CV}_{\mathrm{AF}}$ histograms given Fig 8. During acute AF, verapamil had no effect on the $\mathrm{CV}_{\mathrm{AF}}$ histogram. However, after 24 hours of $\mathrm{AF}$, the histogram was clearly skewed to the 
left, indicating an increase in the incidence of intra-atrial conduction block. The contribution of local conduction velocities of $<20 \mathrm{~cm} / \mathrm{s}$ increased from 0 to $12 \%$ and the percentage of $\mathrm{CV}_{\mathrm{AF}}$ between 20 and $40 \mathrm{~cm} / \mathrm{s}$ increased from 4 to $18 \%$. As a result the median $\mathrm{CV}_{\mathrm{Ar}}$ decreased from 80 to $60 \mathrm{~cm} / \mathrm{s}$. In Table 1 the effects of digoxin and verapamil on $\mathrm{CV}_{\mathrm{AF}}$ both during acute $\mathrm{AF}$ and $24 \mathrm{~h}$ of $\mathrm{AF}$ are given for all six goats.

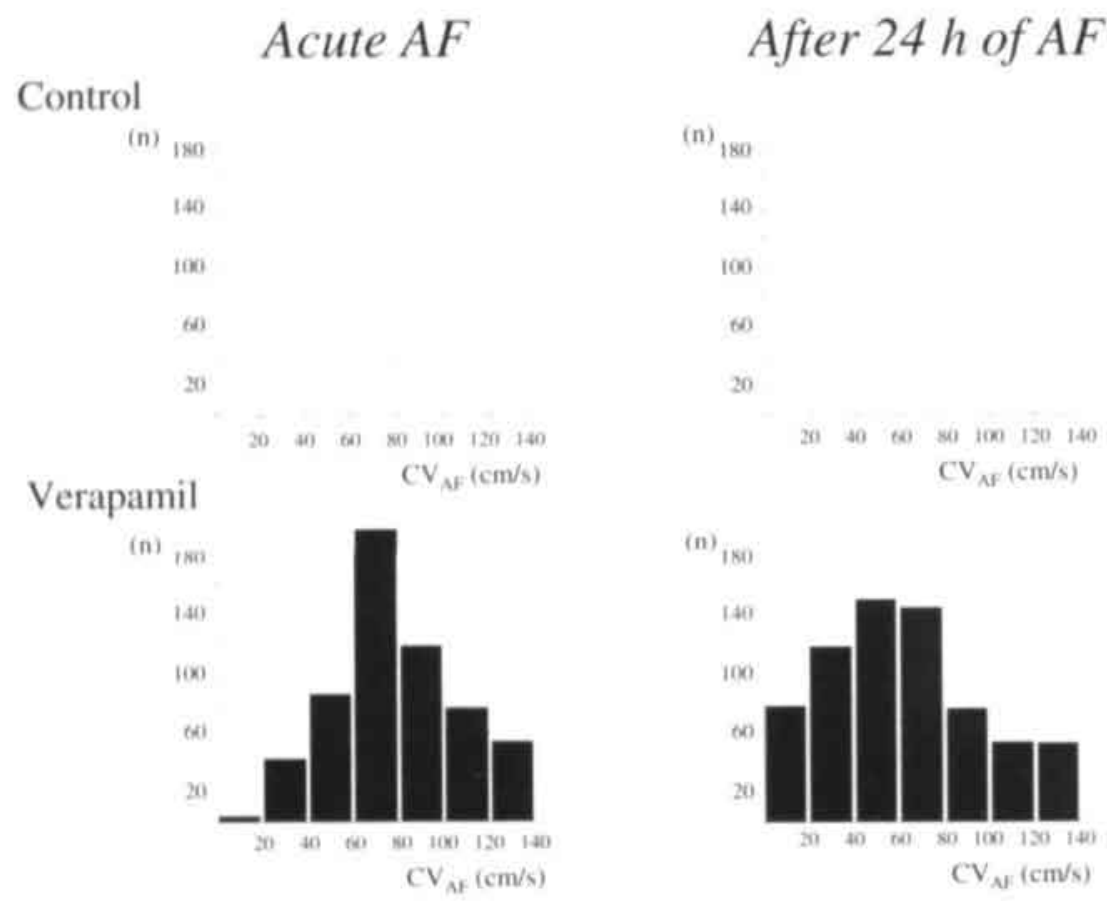

Figure $X$. Cinduction velesiry histograms during AF both before and after verupamil. In acute AF. ver. apamil had no effect on arrial conduction during AF. After 24 hours, verapamil shewed the histogram to the lefi, indicuting a higher incidence of slow conduction and conduction block.

The atrial refractory period, both during slow pacing and atrial fibrillation was not affected by digoxin (Table 1). During slow pacing in non-remodeled atria also verapamil had no significant effect on atrial refractoriness ( $157 \pm 19$ versus $152 \pm 19 \mathrm{~ms})$. Because in remodeled atria verapamil resulted in persistent $\mathrm{AF}$, the $\mathrm{AERP}_{+\infty 0}$ could not no longer be determined. The shortening of the AFCL by verapamil was paralleled by a shortening of the atrial refractory period during AF. In Fig 9, an example of the shortening of RP $\mathrm{N}_{\mathrm{F}}$ by verapamil is shown. During control, the shortest coupling interval that captured the atrium during entrainment of AF was $116 \mathrm{~ms}$ (upper panel). Verapamil accelerated $\mathrm{AF}$ to a median AFCL of $108 \pm 15 \mathrm{~ms}$. During regional entrainment of AF with a pacing interval of $108 \mathrm{~ms}$, the shortest coupling interval which captured the atria was now $94 \mathrm{~ms}$ (lower panel). In Table I the average results were listed. During acute AF, RP st shortened from $130 \pm 14$ to $113 \pm 11 \mathrm{~ms}(-13 \%, \mathrm{p}<0.01)$. After 24 hours of $\mathrm{AF}$, verapamil shortened the $\mathrm{RP}_{\mathrm{A}}$ from $106 \pm 7$ to $90 \pm 6 \mathrm{~ms}(-16 \%, \mathrm{p}<0.01)$. 


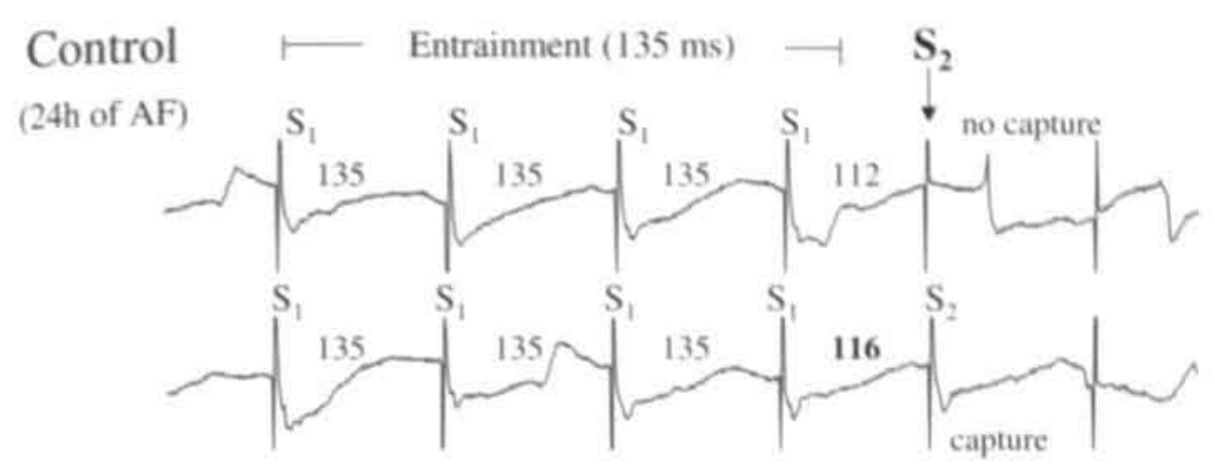

\section{Verapamil}

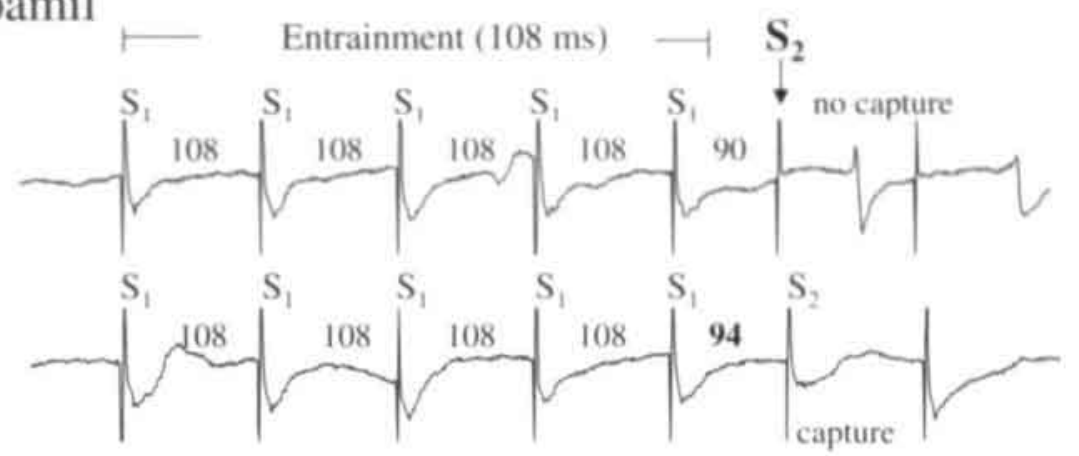

Figure 9. Verapamit-induced shortening of the atrial refractory period during AF. The unipolar electmgram was reconted 4 mm from the pacing site. Verapamil shortened the RPAF from $116 \mathrm{~ms}$ to $94 \mathrm{~ms}$.

\section{Discussion}

Both experimental and clinical studies have suggested that digoxin and verapamil might alter the natural course of atrial fibrillation by modulating tachycardia-induced electrical remodeling. 2*." AF-induced electrical remodeling was first described by Wijffels et al. as a progressive shortening of the atrial refractory period during the first days of $\mathrm{AF}$.' Two years later Yue et al. showed that the shortening of the action potential was due to downregulation of the L-type calcium current.' It is believed that this process of electrical remodeling is mediated by intracellular calcium overload resulting from the extremely high atrial rate. ${ }^{10}$

Initially, experimental and clinical studies demonstrated that verapamil could attenuate tachycardia-induced electrical remodeling. ${ }^{21}$ Patients treated with intracellular calcium lowering drugs experience fewer relapses of AF after electrical cardioversion. ${ }^{4}$ However. more recently it has been shown that long-term tachycardia-induced shortening of atrial refractoriness can not be prevented by verapamil. ${ }^{.7}$

Digoxin, which increases intracellular calcium content. had no significant effect on the 
time course of electrical remodeling, but delayed its recovery (reverse electrical remodeling). Clinically, there are indications that digoxin might increase the likelihood of recurrence of $\mathrm{AF}^{*}$

\section{DIGOXIN}

Clinical studies on the effects of digoxin on the stability of AF are controversial. Some authors suggested that digoxin might cardiovert recent onset AF, " whereas others reported that digoxin prolonged the duration of paroxysmal $\mathrm{AF},{ }^{\prime 4}$ In isolated human atrial tissue it has been shown that ouabaine shortens the atrial action potential due to its parasympathetic effect. "Rawles et al. hypothesized that this might increase the atrial rate of $\mathrm{AF}^{\text {ia }}$ In the present study, we showed that ( 1 ) intravenous administration of digoxin $(0.02$ $\mathrm{mg} / \mathrm{kg}$ ) had no effect on atrial fibrillation cycle length, degree of dissociation of AF waves or atrial electrophysiology during $\mathrm{AF}$, neither in the non-remodeled and remodeled atria; (2) digoxin had no effect on the duration of electrically induced AF episodes. Even in the

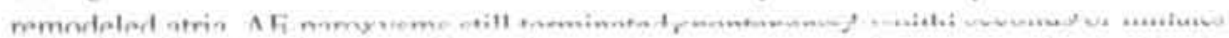
during digoxin administration. These data are in agreement with recent randomized studies demonstrating that digitalization of patients with recent onset AF does not increase the likelihood of restoration of sinus rhythm. ${ }^{\text {ind }}$ Obviously. intravenous administration of digoxin does not exert much parasympathetic effect on the atrial myocardium. The lack of effects of digoxin on AF could not be due to inadequate plasma levels or insufficient time to reach its maximal effect because. in all goats, after 15 minutes of digoxin administration a maximal prolongation of the RR-interval $(>40 \%)$ was observed. The early onset of prolongation of the RR-interval is in agreement with the clinical study by Powell et al. in which a maximal effect on atrio-ventricular conduction was already reached $10-$ 20 minutes after intravenous administration of digoxin (1 $\mathrm{mg}) . "$

\section{PRO-FIBRILLATORY EFFECT OF VERAPAMIL}

Both experimental ${ }^{10}$ and clinical ${ }^{*}$ studies have shown that verapamil enhances the maintenance of electrically induced AF episodes. However, in non-remodeled atria this pro-fibrillatory effect was only moderate. In patients verapamil prolonged the duration of electrically induced AF from 5 to $39 \mathrm{~min}$, but all paroxysms were still self-terminating." Friedman et al. suggested that the verapamil-induced increase in catecholamines ${ }^{10}{ }^{3}$ promoted the maintenance of AF but they could not identify the electrophysiological mechanism by which this occurred. In vitro, calcium antagonists cause a decrease in the action potential duration due to shortening of the calcium dependent plateau of the action potential. However, clinical studies showed no effects of verapamil on the atrial refractory peri- 
od during slow pacing $\left(\mathrm{S}_{1} \mathrm{~S}_{1}: 500-700 \mathrm{~ms}\right) .{ }^{234}$ Only limited data are available on the effects of verapamil at high atrial rates."

In the present study we showed that (1) the direct pro-arrhythmic effect of verapamil was based upon an increase in the atrial rate during AF due to a shortening of the refractory period at AF rates, both in the presence and absence of electrical remodeling but that (2) the pro-fibrillatory effect of verapamil on stability of AF was markedly enhanced by electrical remodeling. In non-remodeled atria, the pro-fibrillatory effect of verapamil was negligible and resulted in a non-significant prolongation of the average duration of AF from 7 to 16 seconds. In contrast, in electrically remodeled atria, verapamil converted paroxysmal into sustained atrial fibrillation, shortly after start of the infusion. As long as verapamil infusion was maintained ( 2 hours). AF no longer terminated.

Also in the present study there was no effect of verapamil on atrial refractoriness during slow pacing. The preferential shortening of the refractory period during high atrial rates might be due to a rate-dependent block of the L-type calcium channels. Due to their low lipid solubility, phenylalkylamines (verapamil) access their intracellular binding site predominantly via the open channel and because these compounds are charged they unbind slowly from their receptor. Therefore verapamil exhibits a marked use-dependent block. Since during AF the excitable gap comprises not more than $20-25 \%$ of the cycle length. the L-type calcium channels are in the open state more than $75 \%$ of the time. This might explain the preferential shortening of the atrial refractory period by verapamil during $\mathrm{AF}$. An alternative explanation is that shortening of the atrial refractory period at high rates is mediated by the neurohumoral effects of verapamil. In a canine model of AF, sympathetic stimulation shortened the atrial refractory period especially at high atrial rates, resulting in a shortening of the AFCL by $12 \%$. This resulted in a slight prolongation of AF duration similar to the pro-fibrillatory effect of verapamil in the non-remodeled atria of the goat. In the present study we demonstrated that the effect of verapamil on AF stability strongly depended on the degree of electrical remodeling. It is very likely that the profibrillatory effects of electrical remodeling and of verapamil both are based upon a shortening of the atrial refractory period. This will shorten the pathlength and increase the number of atrial fibrillation waves. The resulting increase in the average number of intra-atrial circuits could explain the increased stability of $\mathrm{AF}^{\mathrm{X}}$ However, since the atrial refractory period (and circuit size) have to be shortened below a critical value. 'only after the additive effect of electrical remodeling and verapamil. fibrillation became sustained. This is supported by the observation that only in the remodeled atria, verapamil resulted in a marked increase in the fragmentation of the atrial activation during AF.

It is unclear whether verapamil would also shorten the $\mathrm{RP}_{\mathrm{A}}$ in chronic $\mathrm{AF}$, since Yue et al. ' reported a significant reduction in the L-type calcium current after 6 weeks of rapid atrial pacing. In addition, after long-standing AF, structural changes may occur which could alter the effects of verapamil on atrial electrophysiology. A recent study by Ramanna $\mathrm{et}$ al. reported that also in patients with chronic AF verapamil increases the atrial rate during AF ${ }^{>}$This implies that also after long-term electrical remodeling ( $>24 \mathrm{~h} \mathrm{AF}$ ), verapamil could shorten the refractory period during $\mathrm{AF}$. 


\section{CLINICAL IMPLICATIONS}

The choice of drugs for rate control of AF might not only be determined by the efficacy of regulating the ventricular rate but also by their possible effects on atrial fibrillation itself. This is emphasized by our present study in which digoxin and verapamil exerted a similar effect on the RR interval but different effects on rate and stability of AF. In patients with paroxysmal $\mathrm{AF}$, the proarrhythmic effect of verapamil might prolong the duration of AF paroxysms. When an episode of AF has proceeded long enough for electrical remodeling to occur, rate control by verapamil might even reduce the likelihood of spontaneous termination of AF. Furthermore, the acceleration of atrial rate might also reduce the efficacy of chemical cardioversion.

\section{LIMITATIONS OF THE STUDY}

The question whether the observed pro-fibrillatory effect of verapamil is mediated through an increase in sympathetic tone remains unanswered. The occurrence of severe bradycardia in the goat by the combination of verapamil and beta-blockade precluded experimental evaluation of this hypothesis. Furthermore. the direct effect of verapamil as described in this paper is clinically relevant, since also in patients verapamil is preferably administered in the absence of beta-blockade.

The different experiments were not performed in a random order. However, sufficient time was allowed between experiments for complete washout of the previously administered drug or complete recovery from electrical remodeling (reversed remodeling). In addition, serum levels of digoxin and verapamil were not measured. However, the sig. nificant slowing of the ventricular rate during $\mathrm{AF}(>40 \%)$ by verapamil and digoxin implied adequate serum levels of both drugs.

Since, even after prolonged periods of AF, the goat does not get spontaneous paroxysms of $\mathrm{AF}$, it is unknown whether digoxin or verapamil would affect the triggers for initiation of AF. Also it remains to be seen how these drugs affect AF of longer than 24 h duration. However. preliminary reports suggest that also in patients with chronic AF, verapamil increases the atrial rate during $\mathrm{AF}^{2}$

\section{Acknowledgments}

Dr. Duytschaever is a Research Assistant for the Fund of Scientific Research-Flanders (Belgium). 
Table \&, Effect of digoxin and verapamil on acute and 24-hours AF.

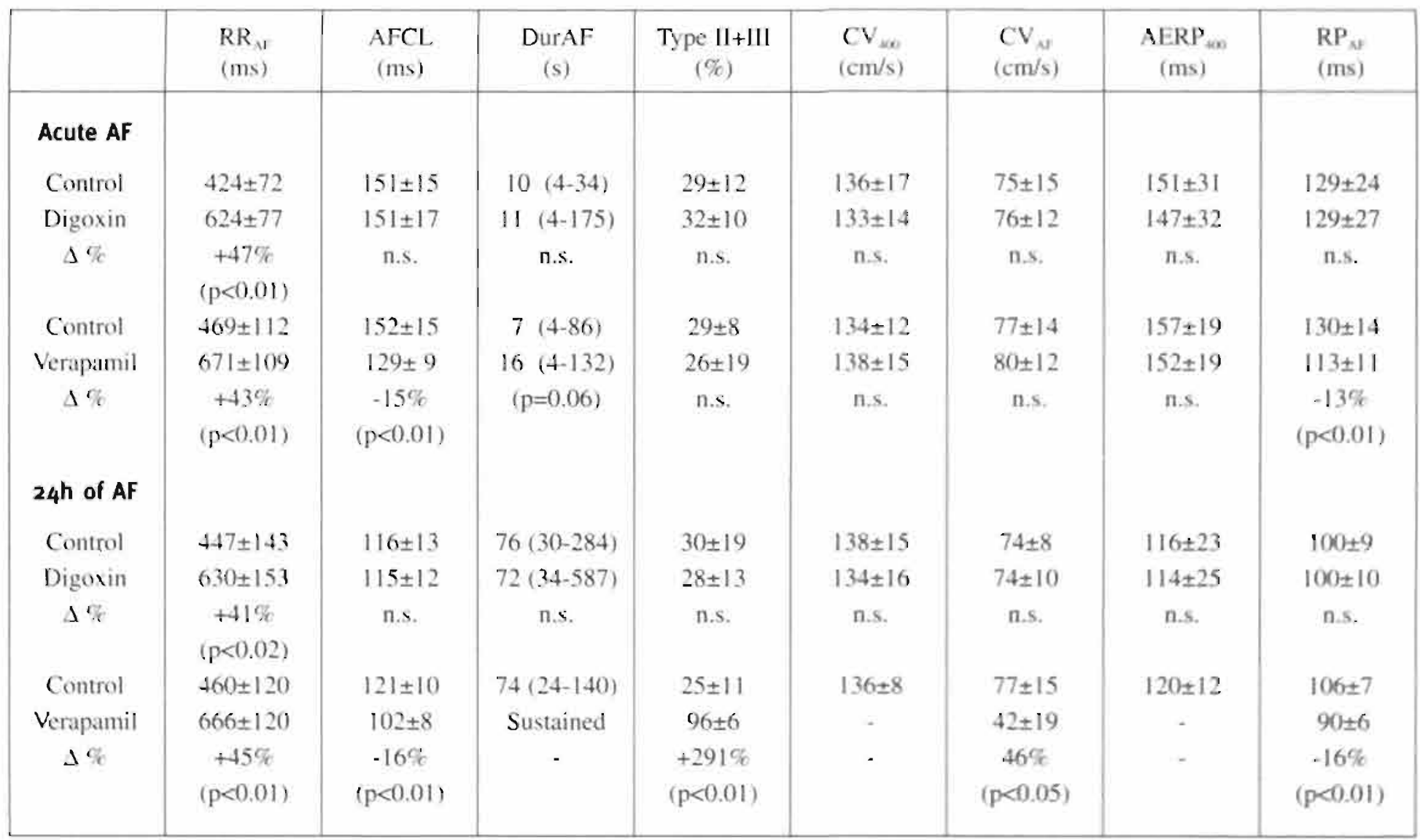




\section{References}

1. Prystowsky EN, Benson DW, Fuster V. Hart RG, Kay N, Myerburg RJ, Naccarelli GV, Wyse DG. Management of patients with atrial fibrillation. Circulation, 1996;93:1262-1277.

2. Tieleman RG, De Langen CDJ, Van Gelder IC, De Kam PJ, Grandjean J, Bel KJ. Wijffels MCEF, Allessie MA. Crijns HJGM. Verapamil reduces tachycardia-induced electrical remodeling of the atria. Circulation, 1997:95:1945-1953.

3. Tieleman RG, Blauw Y, Van Gelder IC. De Langen CDJ, De Kam PJ, Grandjean J, Patberg KW. Bel KJ. Allessie MA, Crijns HJGM. Digoxin delays the recovery from atrial electrical remodeling in the goat. Circulation, 1999:100:1836-1842,

4. Tieleman RG, Van Gelder IC, Crijns HJ, de Kam PJ, van den Berg MP, Haaksma J, Van der Woude HJ. Allessic MA. Early recurrences of atrial fibrillation after electrical cardioversion: a result of fibrillation-induced electrical remodeling of the atria? J Am Coll Cardiol, 1998:31:167-173.

5. Wijffels MCEF, Kirchoff CJHJ, Dorland R. Allessie MA. Atrial fibrillation begets atrial fibrillation: a study in awake chronically instrumented goats. Circulation, 1995;92:1954-1968.

6. Garrall CJ, Duytschaever M, Killian M. Dorland R, Mast F. Allessie MA. Repetitive electrical

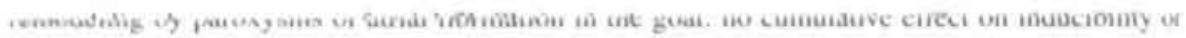
stability of atrial fibrillation. J Candiovasc Electrophys, 1999;10:1101-1108.

7. Konings KTS, Kirchoff CJHJ, Smeets JRLM. Wellens HJJ. Penn OC. Allessie MA. High density mapping of electrically induced atrial fibrillation in man. Cinculation, 1994:89:1665-80.

8. Yue L. Feng J, Gaspo R. Li GR. Wang Z. Nattel S. Fonic remodeling underlying action potential changes in a canine model of atrial fibrillation. Circ Res. 1997:81:512-525.

9. Morillo CA. Klein GJ, Jones DL. Guiraudon CM. Chronic rapid atrial pacing: stuctural, functional, and electrophysiological characteristics of a new model of sustained atrial fibrillation. Cinculation.1995:91:1588-1595.

10. Goctte A. Honeycutt C. Langberg JJ. Electrical remodeling in atrial fibrillation. Time course and mechanisms, Cirvulation, 1996:94:2968-2974.

11. Daoud EG, Knight BP. Weiss R, Bahu M. Paladino W, Goyal R. Man KC, Strickberger SA. Morady $F$. Effect of verapamil and procainamide on atrial fibrillation-induced electrical remodeling in humans, Cinculation, 1997:96:1542-1550.

12. Lee SH, Yu WC. Cheng JJ. Hung CR, Ding YA, Chang MS, Chen SA. Effect of verapamil on longterm tachycardia-induced atrial electrical remodeling. Cinculation. 2000;101:200-206.

13. Weiner P. Bassan MM. Jarchovsky J. Jusim S. Plavnick L. Clinical coune of acute atrial fibrillation treated with rapid digitalization. Am Heart J, 1983:105:223-227.

14. Rawles JM. Metcalfe MJ. Jennings $K$. Time of occurrence, duration and ventricular rate of paroxysmal atrial fibrillation: the effect of digoxin. Br Heart J. 1990;63:225-227.

15. Hordof AJ. Spotnitz A. Mary RL. Edie RN. Rosen MR. The cellular electrophysiologic effects of digitalis on human atrial fibers. Cinculation, 1978:57:223-229.

16. Falk RH, Knowlton AA. Bernard SA. Gotlieb NE, Battinelli NJ. Digoxin for converting recentonset atrial fibrillation to sinus rhythm. Ann Intern Med, 1987:106:503-506.

17. Jordaens L. Trouerbach J, Calle P, Tavernier R, Derycke E. Vertongen P. Bergez B, Vandekerckhowe 
Y. Comversion of atrial fibrillation to sinus thythm and rate control by digoxin in comparison to placebo. Eur Heart J. 1997:18:643-648.

18. Powell AC. Horowitz JD. Hasin Y, Syrjanen ML. Horomidis S, Louis WJ, Acute myocandial uptake of digoxin in humans: correlation with hemodynamic and electrocardiographic effects. $J$ Am Coll Candiol, 1990;15:1238-1247.

19. Friedman HS, Rodney E, Sinha B, Sharafkhaneh A, Wattanasuwan N, Win M, Mallipeddi D, Sinha A, Hussain A, Dai CP. Verapamil prolongs atrial fibrillation by evoking an intense sympathetic neurohumoral effect. J Imestig Med, 1999:47:293-303.

20. Shenasa M. Kus T. Fromer M. LeBlanc RA. Dubuc M. Nadeau R. Effect of intravenous and oral calcium antagonists (diltiazem and verapamil) on sustenance of atrial fibrillation. Am J Cantiol, 1988:62:403-407.

21. Grossman E. Messerli FH. Effect of calcium antagonists on sympathetic activity. Eur Heart J, 1998:19::27-31.

22. Li GR. Nattel $S$. Properties of human atrial $I_{\mathrm{C}}$ at physiological temperatures and relevance to action potential. Am J Physiol, 1997:272:H227-H235.

23. Singh BN, Hecht HS. Hademanee K. Chew CYC. Electrophysiologic and hemodynamic effects of slow-channel blocking drugs. Prog Candiovasc Dis, 1982:25:103-132.

24. Rinkenberger RL. Prystowski EN. Heger JJ. Troup PJ. Jackmann WM, Zipes DP. Effects of intravenous and chronic oral verapamil administration in patients with supraventricular tachyarrhythmias. Cinculation, 1980;62:996-1010.

25. Kumagai K. Matsuo K. Ono M. Yamanouchi Y, Moroe K. Hamasaki N. Arakawa K. Effects of verapamil on electrophysiological properties in paroxysmal atrial fibrillation. PACE, 1993:16: 309-316.

26. Glossmann H. Striessnig J. Molecular properties of calcium channels. Rev Physiol Biochem Pharmacol, 1990:114:1-104.

27. Liu L. Nattel S. Differing sympathetic and vagal effects on atrial fibrillation in dogs: role of refractoriness heterogeneity, Am J Physiol, 1997:273:H805-H816.

28. Allessie MA, Bonke FIM. Schopman FJG: Circus movement in rabbit atrial muscle as a mechanism of tachycardia. III. The "leading circle" concept: a new model of circus movement in cardiac tissue without the involvement of an anatomical obstacle. Cinc Res, 1977:41:9-18.

29. Ramanna H, Elvan A, Hauer RN, Wittkampf FH, de Bakker JM, van Capelle FJ. Wever EF, Robles de Medina EO. Verapamil causes increase in dispersion and shortening of refractoriness in human chronic atrial fibrillation (abstract). PACE, 1998;21(PartII):802. 



\section{Chapter 7}

\section{Methods for Determining the Refractory Period and Excitable Gap during Persistent Atrial Fibrillation in the Goat.}

Mattias Duytschaever. MD: Frans Mast. PhD; Matthijs Killian, PhD, Yuri Blaauw, MD, Maurits Wijffels, MD. PhD: Maurits Allessie, MD. PhD 


\section{Abstract}

Background: Recently, the temporal excitable gap during atrial fibrillation (AF) has been identified as a vulnerable parameter for cardioversion of AF. In this study, we evaluated 5 methods to measure the refractory $\left(\mathrm{RP}_{\mathrm{A}}\right)$ and excitable period $\left(\mathrm{EP}_{\mathrm{AF}}\right)$ during persistent AF.

Methods and Results: In 11 goats, instrumented with 83 epicardial atrial electrodes, persistent AF (43 \pm 34 days) was induced with a median-AFCL of $98 \pm 14 \mathrm{~ms}$. To measure $\mathrm{RP}_{\mathrm{AF}}$. premature stimuli were applied to the center of the electrode array on the right or left atrium. The $R_{A}$ measured by mapping of premature stimuli was $70 \pm 12 \mathrm{~ms}$ (gold standard). The $\mathrm{RP}_{A}$ determined during entrainment of $A F$ was $77 \pm 17 \mathrm{~ms}\left(\mathrm{R}^{2}: 0.88\right.$. $\mathrm{p}<0.01$ ). Statistical analysis of the effects of synchronized stimuli (each coupling interval: $100 \mathrm{x}$ ) on the AFCL histogram yielded an $\mathrm{RP}_{\mathrm{AF}}$ of $70 \pm 13 \mathrm{~ms}\left(\mathrm{R}^{2}: 0.94, \mathrm{p}<0.01\right)$. A further simplification was to apply slow fixed-rate pacing $(1-\mathrm{Hz})$ during $\mathrm{AF}$. For each stimulus (n:250-500) the paced AFCL was plotted against its coupling interval and capture was determined by statistical shortening of the AFCL (RPA $: 71 \pm 17 \mathrm{~ms}, \mathrm{R}_{\mathrm{A}}: 0.84$. $\mathrm{p}<0.01)$. The $5^{* t}$ percentile of the $A F C L$ histogram as an index of $R_{A r}$ was $77 \pm 12 \mathrm{~ms}$ $\left(R^{\mp}: 0.90, p<0.01\right)$.

Conclusions: During persistent $\mathrm{AF}$ with an AFCL of $98 \pm 14 \mathrm{~ms}$, the $\mathrm{RP}_{\mathrm{AF}}$ determined by mapping of synchronized premature stimuli (gold standard) was $70 \pm 12 \mathrm{~ms}$, with an excitable period of $28 \pm 8 \mathrm{~ms}$. Although the indirect methods to measure $\mathrm{RP}_{\mathrm{A}}$ all correlated well with the gold standard. slow fixed-rate pacing seems the most attractive technique because of the ease of acquiring the data and the clear graphic result.

Key Words: Atrial fibrillation: Refractory Period; Excitable Gap.

\section{Condensed Abstract}

Methods to assess the refractory or excitable period during AF so far have been limited to monophasic action potential recordings or extensive pace-mapping protocols. In the present study we evaluated 5 different methods to measure the $\mathrm{RP}_{\mathrm{N}}$ in the chronically instrumented goat. During persistent AF with an AFCL of $98 \pm 14 \mathrm{~ms}$, the RP $\mathrm{P}_{\mathrm{H}}$ determined by mapping of synchronized premature stimuli (gold standard) was $70 \pm 12 \mathrm{~ms}$. with an excitable period of $28 \pm 8 \mathrm{~ms}$. The results of the other methods all correlated well with the gold standard (activation maps). 


\section{Introduction}

Recently it has been suggested that the temporal excitable gap during AF is a critical determinant for perpetuation and termination of $\mathrm{AF}^{1-7}$ In the presence of a short excitable gap fibrillation waves are more likely to die out by encountering refractory tissue. On the other hand, a short excitable gap may also promote the formation of new wavelets due to an increase in the likelihood of intra-atrial conduction block. So far, determination of the excitable gap during AF has been limited to the recording of monophasic action potentials. ${ }^{-}$Recently, $\mathrm{RP}_{A X}$ has been measured directly by programmed electrical stimulation. ${ }^{2 \cdot 3}$ Cardioversion by class I drugs was found to be associated with a 2-3 fold widening of the temporal excitable gap.

The aim of the present study was to develop clinical tools for the measurement of the refractory period and temporal excitable gap during persistent AF. Five methods were evaluated in a goat model of persistent AF using mapping as gold standard.

\section{Methods}

The goat model of AF was described previously." In eleven goats $(51 \pm 8 \mathrm{~kg})$ two plaques $(3.5 \times 2.5 \mathrm{~cm}, 30$ electrodes, distance $4 \mathrm{~mm})$ were sutured to the free wall of the right (RA) and left atrium (LA). One strip $(6 \times 1 \mathrm{~cm}, 23$ electrodes, distance 6-10 mm) was pulled along Bachmann's bundle and sutured to both atrial appendages. The leads were tunnelled subcutaneously to the neck and exteriorized by three 30 -pin connectors. A subcutaneous silver plate served as indifferent electrode. After recovery from surgery. persistent AF was produced by a fibrillation pacemaker." After amplification $(300 \mathrm{x})$ and filtering $(1-500 \mathrm{~Hz})$ all unipolar atrial electrograms were stored on tape. Local activation times were determined automatically by a custom-made algorithm detecting the maximal negative slope of the fibrillation electrograms. The goats were studied after $43 \pm 34$ days of AF at a median AFCL of $98 \pm 14 \mathrm{~ms}$. A central pair of electrodes on RA $(n=7)$ or LA $(n=4)$ was used for stimulation. Biphasic stimuli of $2 \mathrm{~ms}$ were generated by a constant current stimulator equipped with an amplifier recording a bipolar electrogram from the pacing electrodes (Medtronic SP3111). The minimal current required for regional entrainment of AF was taken as the threshold for stimulation.? 


\section{METHODS TO MEASURE THE REFRACTORY PERIOD DURING AF}

In Fig. I the five methods to measure $\mathrm{RP}_{\mathrm{AF}}$ are illustrated. Mapping was used as the gold standard. Single premature stimuli of 4 xthreshold were synchronized to the fibrillation waves at the pacing site. Capture was verified by activation maps around the pacing site. In case of capture the atrium was activated in a radial fashion from the site of pacing.

A second method to measure $\mathrm{RP}_{\mathrm{AF}}$ is to apply premature stimuli during regional entrainment of AF with an interval equal to the median-AFCL. The S1-S2 interval was changed in steps of $2 \mathrm{~ms}$. Capture was determined by the latency and morphology of an electrogram recorded $4 \mathrm{~mm}$ from the pacing site. In case of capture, the premature electrogram showed a similar morphology and latency as during entrainment. The longest S1-S2 interval that failed to capture the atria was taken as the RP during entrainment of AF.

A third method to measure $\mathrm{RP}_{A}$ is to determine the statistical effect of synchronized premature stimuli on the AFCL-histogram. Each coupling interval was repeated 100 times. The shortest coupling interval resulting in a statistically significant difference in AFCL-histogram was taken as the $\mathrm{RP}_{\mathrm{AF}}$ (Wilcoxon two-sample test).

A fourth method to determine $\mathrm{RP}_{A}$ is to pace the fibrillating atria at a slow fixed-rate $(1-\mathrm{Hz})$. Because of the irregularity of $\mathrm{AF}$, slow pacing actually results in a series of randomly applied premature stimuli. A computer algorithm was used to determine the coupling interval at the pacing site (AF-S) and the associated AFCL at a neighboring electrogram. At least 250 consecutive stimuli were analyzed. The shortest coupling inter$\mathrm{val}$ (classes of $5 \mathrm{~ms}$ ) resulting in a significant shortening of AFCL (Kolmogorov-Smimov one-sample test) was defined as the $\mathrm{RP}_{\mathrm{AF}}$. Since this method was developed during evaluation of the other techniques, it was applied only in the last 6 of 11 goats.

A fifth method to estimate $\mathrm{RP}_{\mathrm{A}}$ is to determine the $5^{\text {tp}}$ percentile of the AFCL-histogram. constructed from at least 100 consecutive AF cycles from a unipolar RA or LA electrogram.

\section{THE EXCITABLE GAP DURING AF}

The term "excitable gap" refers both to the excitable tissue between fibrillation waves (spatial EG) and the time window of excitability during the AF interval (temporal EG). We used the term excitable period $\left(\mathrm{EP}_{A Y}\right)$ to indicate the temporal excitable gap. With all 5 methods. EP $P_{A}$ can be calculated as the difference between the median-AFCL and $\mathrm{RP}_{\mathrm{AF}}$. During fixed-rate pacing. $\mathrm{EP}_{\mathrm{AF}}$ could be directly measured from the histogram of the interval between the stimulus and the first response (S-AF). Whereas during subthreshold pacing the S-AF intervals were equally distributed. pacing at 4 xthreshold caused a gap in the S-AF histogram. The longest S-AF interval occurring less frequently than expected $(95 \%$-confidence interval) was taken as the EP 
Mapping
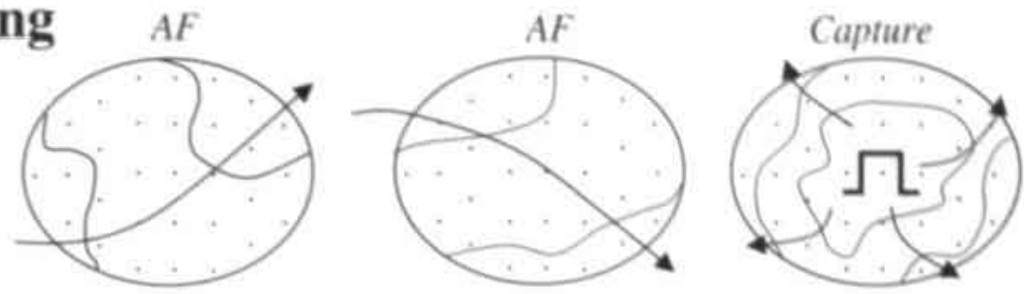

\section{Entrainment}

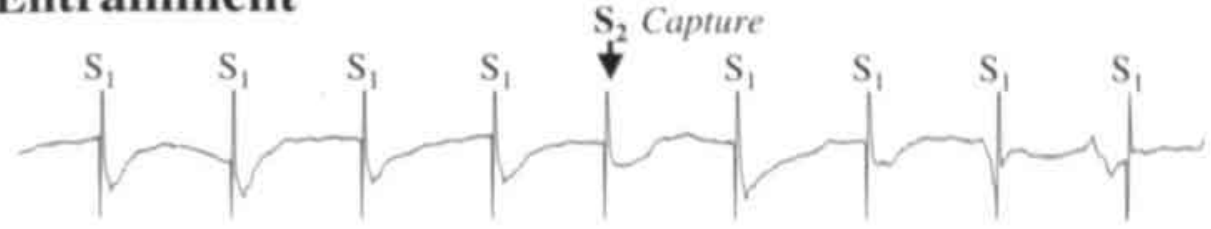

\section{Synchronized Stimuli}

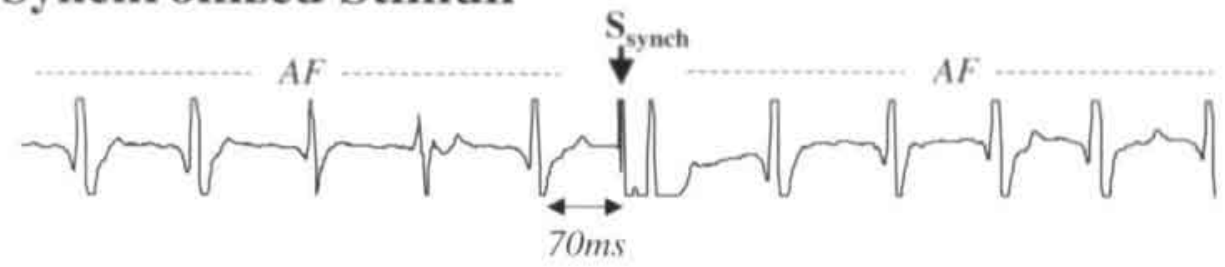

\section{Fixed Rate Pacing}

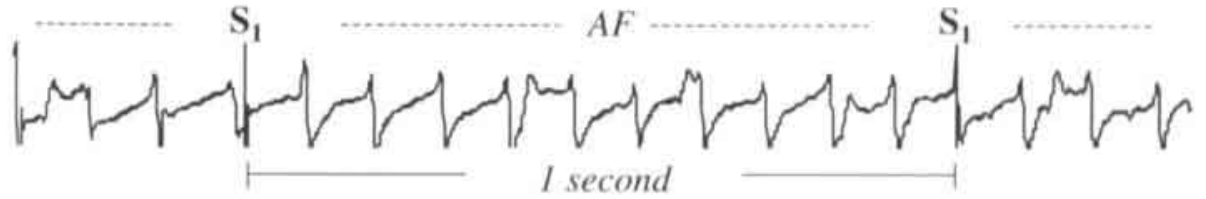

p5 AFCL

20

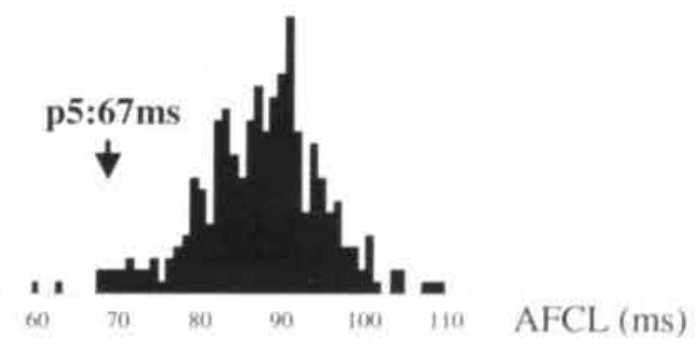

Figure 1. Five methods to determine RPAF (1) mapping of premature stimuli during AF, 2) premature stimult (ST,S2) during entrainment of $A F,(3)$ statistical analysis of the effect of synchmoized premature stimuli $(n: 100)$, (4) fixed-rate pacing ( $\mathrm{HHz}$ ) during $\mathrm{AF}$ resulting in randomly applied premature stimuli, (s) the sthpercentile of the $\mathrm{AFCl}$. 


\section{Results}

\section{MAPPING OF THE REFRACTORY PERIOD DURING AF}

In Fig.2 an example is given of the $\mathrm{RP}_{\mathrm{AF}}$ determined by mapping. In the upper panel, a stimulus was applied $70 \mathrm{~ms}$ after the pacing site was activated. The activation map shows that the stimulus did not capture the atrium. A stimulus with a slightly longer interval of $75 \mathrm{~ms}$ (lower panel) resulted in capture as evidenced by radial spread of activation from the pacing site. However, when stimuli with the same coupling interval were repeated $20 \mathrm{x}$, sometimes capture occurred and sometimes not. In Fig.3 we plotted the percentage of capture at different coupling intervals. At short coupling intervals $(<65 \mathrm{~ms})$ the atrium was never captured. Prolonging the interval from 65 to $90 \mathrm{~ms}$ resulted in a progressive increase in the probability of capture. A coupling interval longer than $90 \mathrm{~ms}$ resulted in $100 \%$ capture. The $\mathrm{S}$-shaped curve shows that the $\mathrm{RP}_{\mathrm{AF}}$ is not a deterministic but a probabilistic variable. We arbitrarily defined the $\mathrm{RP}_{\mathrm{AF}}$ as the shortest coupling interval that captured the atrium at least $20 \%$ of the times. This value represents the shortest of a wider range of refractory periods during $\mathrm{AF}$. In all goats the $\mathrm{RP}_{\mathrm{Ar}}$ measured in this way was $70 \pm 12 \mathrm{~ms}$. The temporal variation in $\mathrm{RP}_{A F}(5 \%$ to $95 \%$-capture $)$ was $19 \pm 4 \mathrm{~ms}$.

No Capture

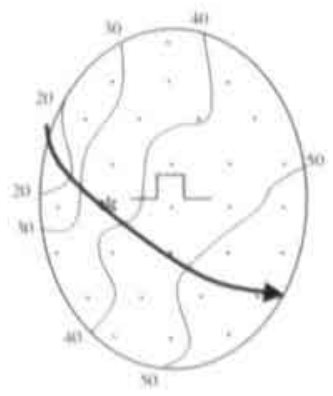

Capture

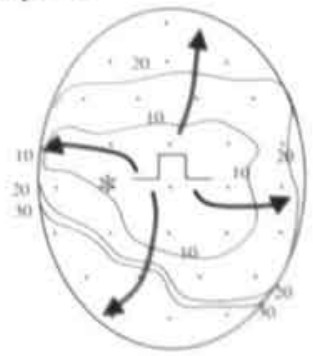

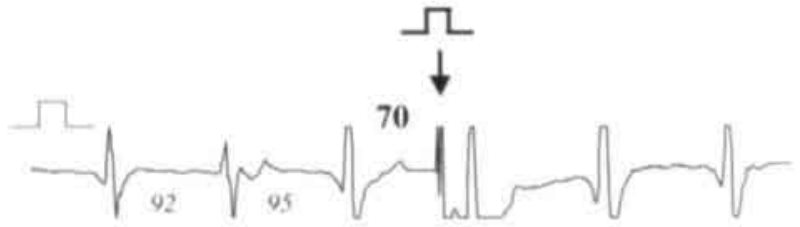

$*$

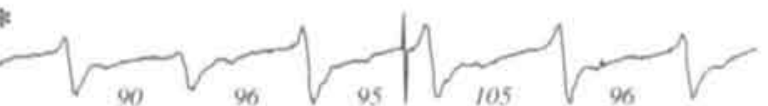

पil
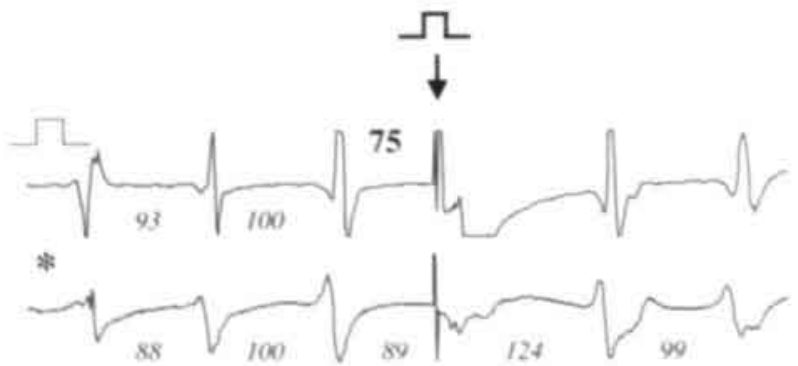

Fisure 2. A moncicntative ctample of caphure by a single symohninized stimulus. The electrograms were mconled at the pacing site (bipolari and a neighboring electrode tunipolari. 


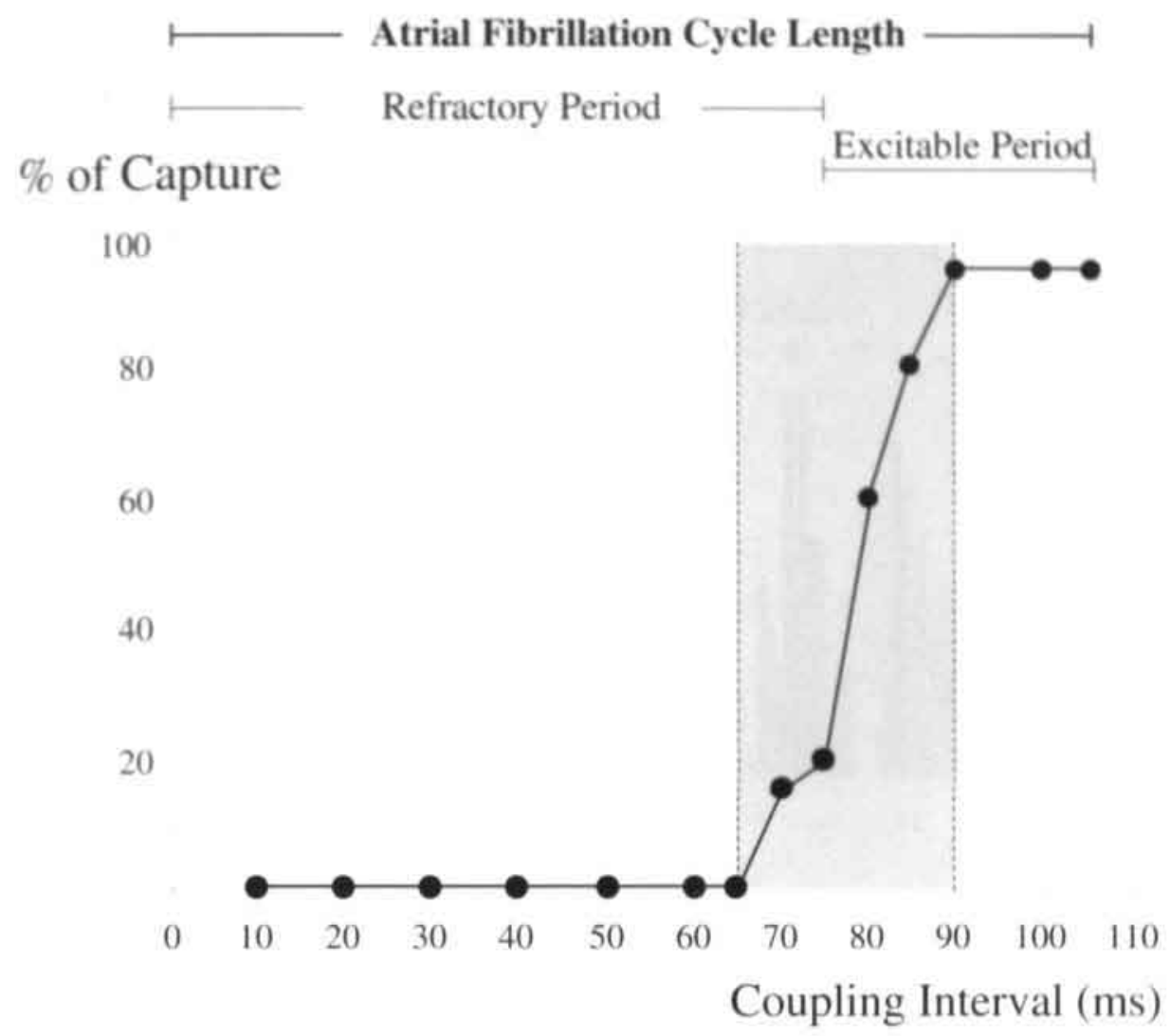

Figure 3. Probability of capture of AF by premature stimuli. The $S$-shaped curve shows the temporal variation in $R P A F$.

\section{REFRACTORY PERIOD DURING ENTRAINMENT OF AF}

An example of the RP during entrainment of AF is shown in Fig.4. Entrainment was performed at the LA with an SI-SI interval of $110 \mathrm{~ms}$ (median-AFCL:113ms). The unipolar electrogram recorded next to the pacing site shows 8 entrained beats followed by a single premature stimulus (S2). During entrainment, the activation maps revealed radial spread of activation. An S2 stimulus of $90 \mathrm{~ms}$ did not capture the atrium, whereas an S2 stimulus with a coupling interval of $92 \mathrm{~ms}$ did capture the atrium (radial spread). For determination of the $\mathrm{RP}_{\mathrm{AF}}$, capture was verified by the morphology of the unipolar electrogram next to the pacing site. In case of no capture, the electrogram showed a clear Rwave and a variable time interval between the stimulus and the next activation. In case of capture by the premature stimulus the latency and electrogram morphology were similar as during entrainment of $\mathrm{AF}$ (no R-wave). The RP during entrainment, defined as the longest S1-S2 interval that did not capture the atrium, was $77 \pm 17 \mathrm{~ms}$ ( 6 goats). 

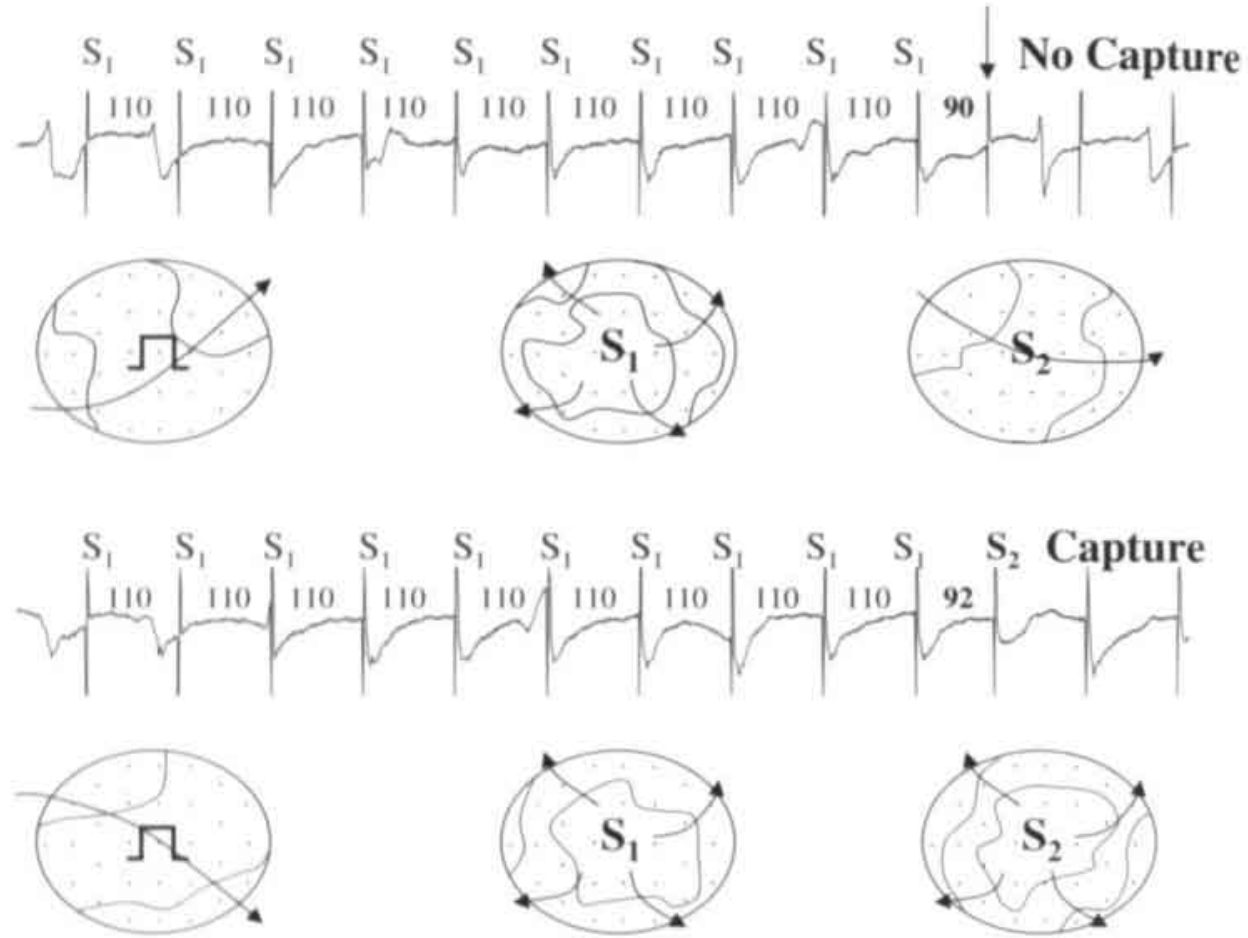

Figur 4 Measurement of RP daring entrainment of AF. The electrogram was meonled 4 mm from the pacing site. A prematur stimulus with a coupling interval of $90 \mathrm{~ms}$ dut not capture the atrium, whercas an $\mathbf{S} / .52$ interval of $92 \mathrm{~ms}$ coptared the atra ino $R$-waw; short latency).

\section{MEASUREMENT OF THE RP ${ }_{\text {AF }}$ BY SYNCHRONIZED STIMULI}

The response to synchronized stimuli was determined statistically by applying a premature stimulus 100 times. For each coupling interval a histogram of the paced-AFCL was reconstructed from a neighboring electrogram. In Fig.5 an example is given of a premature stimulus with a coupling interval of $50 \mathrm{~ms}$. The control-AFCL histogram (sampled one second before each premature stimulus) shows a normal distribution with a medianAFCL of $80 \mathrm{~ms}$. In contrast, the paced-AFCL histogram showed a bimodal distribution. Due to capture, $39 \%$ of the AF-cycles were now shorter than $60 \mathrm{~ms}$. The Wilcoxon twosample test revealed a significant difference between the two histograms $(p<0.05)$. Premature stimuli with a coupling interval of $<50 \mathrm{~ms}$ did not result in statistically different AFCl-histograms. In II goats, the $\mathrm{RP}_{A E}$ measured by the shortest coupling interval yielding a statistically different AFCL was $70 \pm 13 \mathrm{~ms}$. This value represents the shortest of a range of refractory periods during $\mathrm{AF}$. 


\section{No Stimuli \\ Median AFCL: $80 \mathrm{~ms}$}

(n)

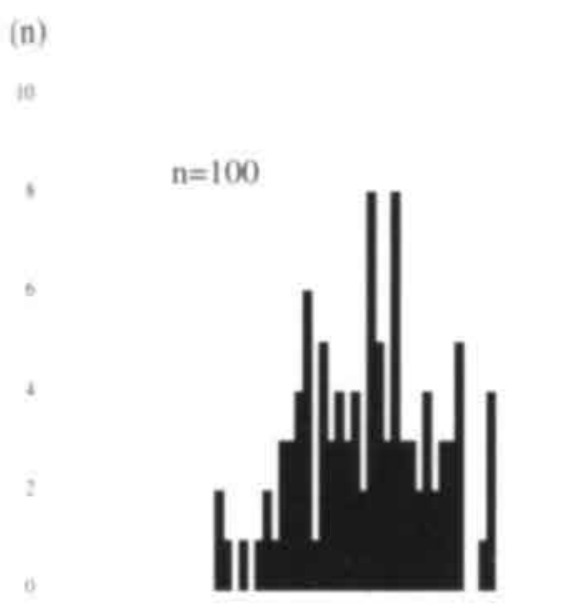

40

Spontaneous AFCL (ms)

\section{Premature Stimuli \\ Coupling interval: $\mathbf{5 0 m s}$}

(n)

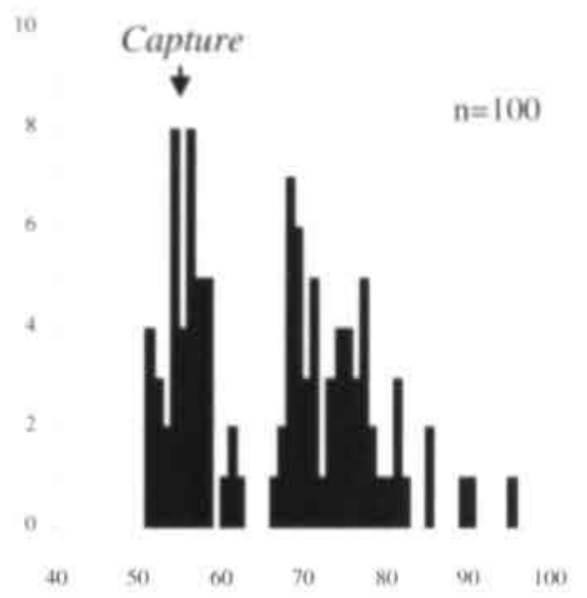

Paced AFCL (ms)

Figure 5. Determination of RPAF by statistical analysis of the paced-AFCL histogram close to the pacing site. During admustration of premature stimuli with a coupling interval of $50 \mathrm{~ms}$ (n:-100) the histogram showed a shift to the left due to capture of part of the stimuli.

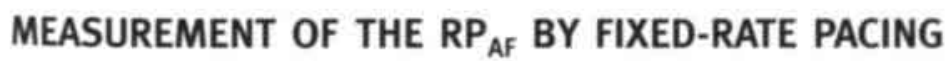

An alternative way to determine $\mathrm{RP}_{\mathrm{Af}}$ is to stimulate the fibrillating atria at a slow fixedrate of $1 \mathrm{~Hz}$, resulting in a series of randomly applied premature stimuli. In Fig.6 the AFCL at an electrode close to the pacing site is plotted for all coupling intervals during 4 minutes of fixed-rate pacing ( $n: 240$ ). Two populations of data points can be clearly distinguished. At shorter coupling intervals AFCL shows the normal variation (median: $88 \mathrm{~ms}$ ). At longer coupling intervals the normal variation in AFCL was lost and, due to capture, the paced-AFCL was now determined by the coupling interval of the stimulus. At intermediate coupling intervals $(48-69 \mathrm{~ms})$ only part of the stimuli captured the atrium, illustrating the temporal variation in $\mathrm{RP}_{\mathrm{AF}}$ (grey column). In all goats the range of temporal variation of the $\mathrm{RP}_{\mathrm{AF}}$ was $24 \pm 7 \mathrm{~ms}$. The shortest coupling interval producing a significant shortening of AFCL, as determined by the Kolmogorov-Smirnov test, was $71 \pm 17 \mathrm{~ms}$. This method was applied only in the last 6 of 11 goats since it was developed during evaluation of the other techniques in the first 5 goats. 


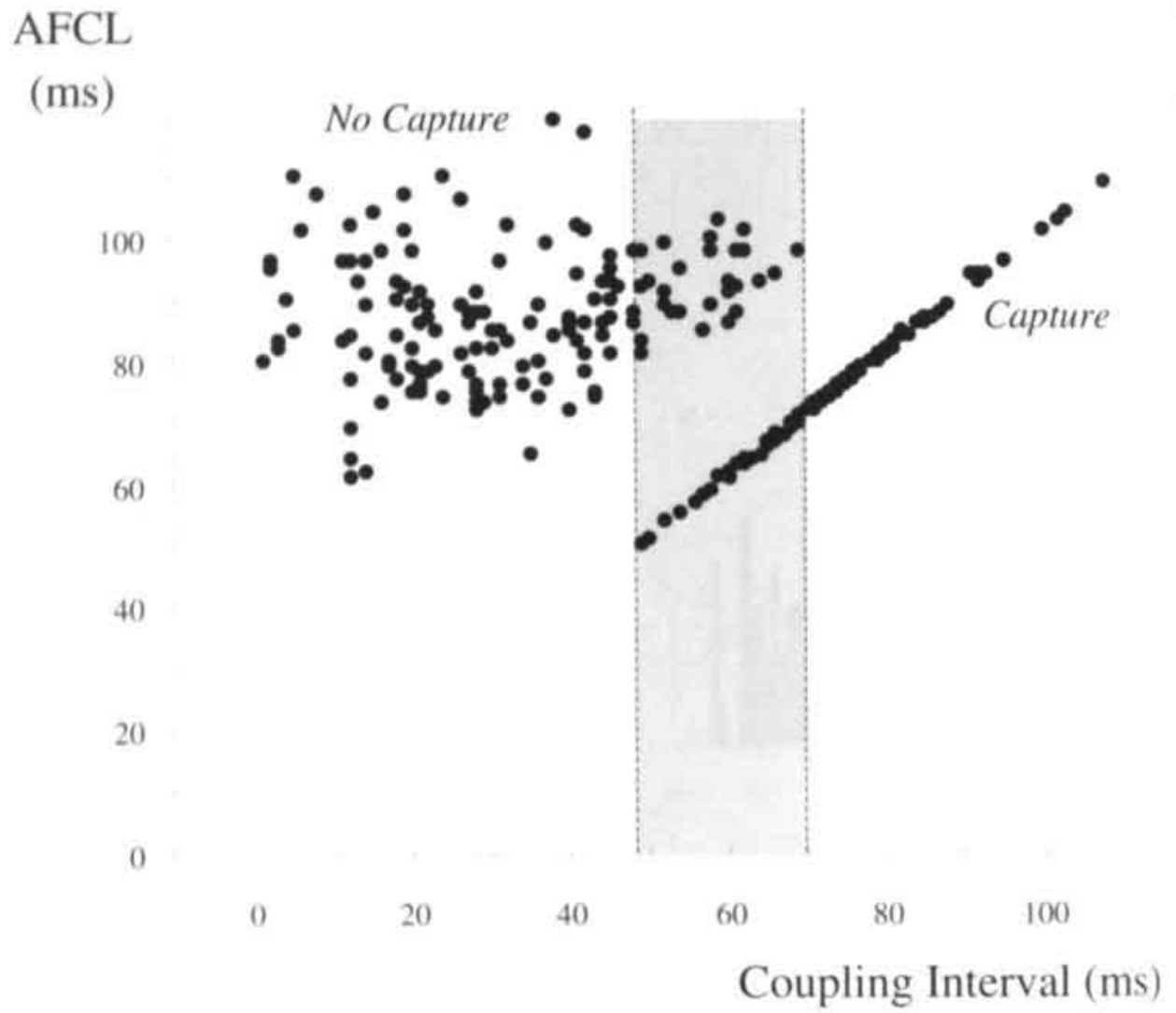

Figure 6. Determination of the RPAF by slow ficd-rate pacing (IH:). During 250 consecutive stimuli the paced $A F C L$ is plottrel asainst its coupling interval. The grey column indicates the range of refractory periods during $A F$

Using fixed-rate pacing, $\mathrm{EP}_{N}$ can be directly visualised (Fig.7). During 16-17 minutes of $1 \mathrm{~Hz}$ pacing all post-stimulus intervals $(\mathrm{n}: 1000)$ were plotted in a histogram. During sub-threshold pacing the S-AF intervals were equally distributed with a mean incidence of $10.7 \pm 2.9$ ( $95 \%$-confidence interval between 4.9 and 16.5 ). When stimulus strength was set at 4 xthreshold, the S-AF intervals were no longer equally distributed. Now, a high incidence ( $\mathrm{n}: 368$ ) of shor $\mathrm{S}-\mathrm{AF}$ intervals was observed representing the latency between stimulus and response during capture. At the same time, the incidence of S-AF intervals between 5 and $30 \mathrm{~ms}$ markedly decreased. These intervals disappeared because they were shortened by capture of the premature stimuli. The distribution of S-AF intervals longer than $35 \mathrm{~ms}$ did not change during pacing. The upper limit of the excitable period was determined by the longest $\mathrm{S}$-AF interval occurring less frequently than the $95 \%$-confidence interval. In 6 goats, EP ${ }_{A}$ measured in this way was $27 \pm 4 \mathrm{~ms}$. This valuc represents the longest of a range of excitable periods during AF. Due to variation in AFCL and $\mathrm{RP}_{A F}$, during many cycles $\mathrm{EP}_{A}$ will actually be shorter. This is illustrated in Fig. 7 by the atrial responses still occurring during the measured excitable period. 


\section{Sub-threshold}

n)

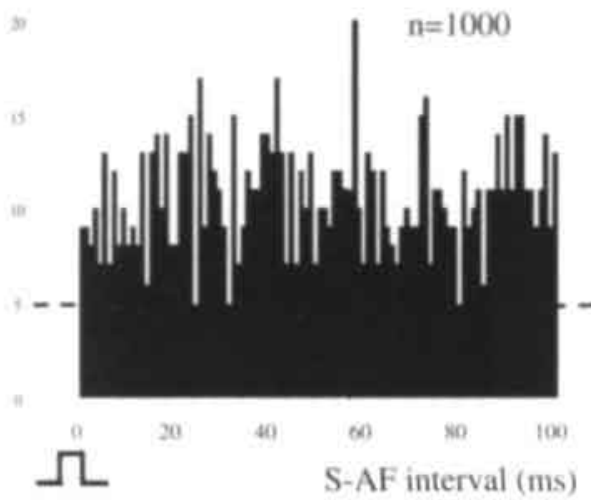

\section{Supra-threshold}

\section{Capture}

(n)

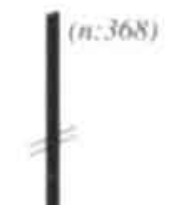

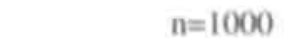

19
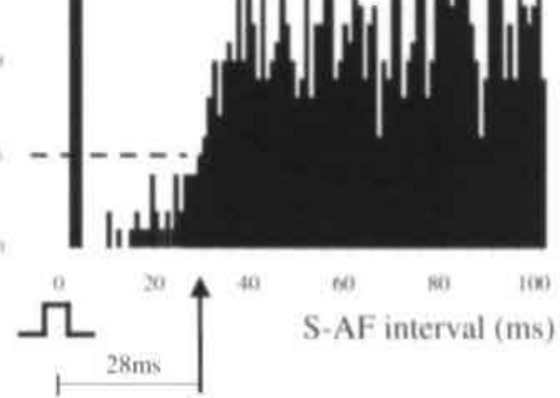

Excitable Period

Figure 7. Determination of the excitable period during AF by fised-rate pacing. The horizontal dotted line represents the $95 \%$-confidence limit of the incidence of the $S$-AF intervals during sub-threshold pacing.

\section{THE P5-AFCL VALUE AS AN INDEX OF THE RP ${ }_{\text {AF }}$}

In 11 goats the median AFCL measured at RA or LA was $98 \pm 14 \mathrm{~ms}$. The $95^{\text {th }}$ and $5^{\text {th }}$ percentile of the AFCL were $120 \pm 16$ and $77 \pm 12 \mathrm{~ms}$. The p5-value was used as andex of $\mathrm{RP}_{A \mathrm{f}}$. This is based on the assumption that the shortest AF cycle lengths have no or only a very short excitable period.

\section{COMPARISON OF THE DIFFERENT MEASUREMENTS OF THE RP ${ }_{\text {AF }}$}

In Table 1 the values of $\mathrm{RP}_{\mathrm{AF}}$ as obtained by the 5 methods are listed for all goats. The $\mathrm{RP}_{A F}$ measured by mapping is considered as gold standard. All methods yielded an $\mathrm{RP}_{A F}$ between 70 and $80 \mathrm{~ms}$. During entrainment the RP was $4 \pm 5 \mathrm{~ms}$ longer than the RP $\mathrm{P}_{\mathrm{N}}$ determined by mapping $(77 \pm 17$ vs $73 \pm 15 \mathrm{~ms}, \mathrm{p}=0.12)$. The correlation between the values obtained by entrainment and mapping was 0.88 ( $<<0.01)$. The $R_{A F}$ determined by synchronized stimuli yielded the same values as obtained by mapping $(70 \pm 13$ vs $70 \pm 12$; 
$\left.\mathrm{R}^{2}: 0.94 ; \mathrm{p}<0.01\right)$. The $\mathrm{RP}_{\mathrm{AF}}$ measured by fixed-rate pacing also gave a similar result $\left(71 \pm 17\right.$ vs $\left.73 \pm 15 \mathrm{~ms} ; \mathrm{R}^{2}: 0.84 ; \mathrm{p}<0.01\right)$. The $5^{\mathrm{m}}$ percentile of the AFCL-histogram was $7 \pm 4 \mathrm{~ms}$ longer than $\mathrm{RP}_{\mathrm{AF}}$ measured by mapping $(77 \pm 12$ versus $70 \pm 12 \mathrm{~ms} \mathrm{p}<0.05)$ with a correlation coefficient of $0.90(\mathrm{p}<0.01)$. Although the study was not designed to compare measurements in RA and $\mathrm{LA}, \mathrm{AFCL}$ and $\mathrm{RP}_{\mathrm{A}}$ were consistently longer and showed more variation in the RA ( $p: 0.33-0.47)$.

\section{Discussion}

\section{THE REFRACTORY PERIOD DURING ATRIAL FIBRILLATION}

In the present study it was shown that the refractory period during AF exhibits a considerable temporal variation. Measurement of $R P_{A,}$ by mapping or fixed-rate pacing revealed a time window of $20-25 \mathrm{~ms}$ during which premature stimuli sometimes captured the atrium and sometimes not (Fig.3 and 6). This probabilistic nature of $\mathrm{RP}_{\mathrm{A}}$ is probably due to beat-10-beat variations in AFCL and direction of propagation. Also fragmentation of fibrillation waves and electrotonic modulation of the action potential by dissociated neighboring wavelets may cause temporal variation in $\mathrm{RP}_{\mathrm{A}}$." The $\mathrm{RP}_{\mathrm{Ar}}$ measured by mapping was defined as the coupling interval resulting in $>20 \%$ capture. Also the other methods determined the "shortest" refractory period during AF. The values obtained by the 5 methods ranged between $70 \pm 12$ and $77 \pm 17 \mathrm{~ms}(70-80 \%$ of median$\mathrm{AFCl}$.). Although these measurements of the refractory period ignore the existing temporal variation, they may be useful to explore the effects of changes in RPA on perpetuation and termination of $\mathrm{AF}$. In addition, they might be of value to evaluate the spatial variation in refractory periods during $\mathrm{AF}$. The observed greater variability in AFCL and $R P_{4}$ in the right atrium may be associated with a more complex geometry, allowing 3D propagation during $\mathrm{AF}^{10}$

\section{COMPARISON OF DIFFERENT TECHNIQUES TO MEASURE RP ${ }_{\text {AF }}$}

The different methods to measure $\mathrm{RP}_{\mathrm{A}}$ all have certain advantages and disadvantages (Table 2). Mapping of premature stimuli is the most reliable technique and can be regarded as gold standard. However, due to its complexity and invasive nature, it can only be used under exceptional circumstances. Measurement of the refractory period during entrainment of $\mathrm{AF}$ has the advantage that it uses the conventional extrastimulus tech- 
nique (S1-S2) and that it can also be applied during paroxysmal $\mathrm{AF}$. The somewhat longer values obtained during entrainment are probably due to electrotonic prolongation of the action potential at the pacing site, ${ }^{*}$ On the other hand, entrainment of AF is not always feasible during type III AF."' Statistical comparison of the AFCL-histogram during synchronized premature stimuli is a highly objective way to determine the RP $P_{A F}$. However, it is a rather complex technique requiring specific expertise. The easiest way to pace the atria during AF is slow fixed-rate pacing. The required equipment is limited to a standard pacemaker, a multipolar catheter and software for data-analysis. The data acquisition time is about 15 minutes during which no intervention of the electrophysiologist is needed. This method produces a clear graphic output from which both $R_{\mathrm{A}}$ and $E P_{A S}$ can be directly read out. It was applied only in the last 6 of 11 goats because the technique was developed in the first 5 goats. Although the p5-AFCL is even more simple, its reliability is questionable. During administration of class I drugs, the RPA became considerably shorter than the p5-AFCL. ${ }^{2}$

\section{THE EXCITABLE PERIOD DURING ATRIAL FIBRILLATION}

In the present study $\mathrm{EP}_{\mathrm{AF}}$. calculated as the difference between AFCL $(98 \pm 14 \mathrm{~ms})$ and $\mathrm{RP}_{\mathrm{AF}}(70 \pm 12 \mathrm{~ms})$, was $28 \pm 8 \mathrm{~ms}$. The $\mathrm{EP}_{\mathrm{AF}}$ measured directly during fixed-rate pacing was $27 \pm 4 \mathrm{~ms}$ (Fig.7). However, also $\mathrm{EP}_{\mathrm{AF}}$ must show a considerable temporal variation. In our experiments the p5 and p95-AFCL were $77 \pm 12$ and $120 \pm 16 \mathrm{~ms}$. This variation in AFCL $(43 \pm 8 \mathrm{~ms})$ can not completely be explained by the variability in $\mathrm{RP}_{\mathrm{At}}$ (19 $\pm 4 \mathrm{~ms})$. This implies that at short AF cycles the excitable period may become as short as $7 \mathrm{~ms}$, whereas during long cycles the excitable period might be as long as $50 \mathrm{~ms}$. This beat-to-beat variability in $\mathrm{EP}_{\mathrm{AF}}$ may play a role in perpetuation of $\mathrm{AF}$.

The excitable period during AF might be explained by the different types of reentry during $\mathrm{AF}^{\prime}$ In case an impulse circulates around an anatomic obstacle, EP $\mathrm{P}_{\mathrm{Ar}}$ is determined by the difference between the conduction time around the obstacle and the refractory period within the reentrant circuit. ${ }^{14}$ In case of functional reentry, $E P_{A}$ is caused by the curvature of the circulating wavefront at pivot points. Due to the high curvature, the excitatory current generated by the turning wavefront may not be enough to make a rapid $180^{\circ}$ turn $^{13}{ }^{12}$ and the resulting conduction delay creates an excitable period in the returning limb of the turning wavefront." In addition, when functional reentrant circuits are drifting through the myocardium, the excitable gap will be shortened or lengthened by the Doppler effect. ${ }^{10,30}$ In case of random reentry an excitable period will arise at areas remote from the site of reentry due to the anterograde and retrograde conduction time to the site of reentry.' On the other hand, the excitable period will be shortened by epicardial breakthrough of wavefronts propagating in one of the pectinate muscles. ${ }^{10}$ The resulting short-circuit of epicardial reentry may play an important role in perpetuation of $\mathrm{AF}$, not only because of the 3-D nature 
of the reentrant process but also by narrowing its excitable gap.

Recently we suggested that $\mathrm{EP}_{\mathrm{A} F}$ might be a critical determinant for termination of $\mathrm{AF}$. Cardioversion of persistent AF by class I drugs was associated with a dose-dependent widening of $\mathrm{EP}_{\mathrm{AF}}{ }^{2}$ We speculated that widening of the $\mathrm{EP}_{\mathrm{AF}}$ decreases the number of head-tail interactions between fibrillation waves, resulting in less dissociation and a higher degree of organization of the multiple wavelets. Cardioversion of AF would occur if multiple wavelets would fuse into a single wavefront whose circulating pathway is ultimately interrupted. However, the possibility that under other circumstances cardioversion of AF might be due to closure of the excitable period can not be excluded. Measurement of $\mathrm{RP}_{\mathrm{A}}$ and $\mathrm{EP}_{\mathrm{AF}}$ during pharmacological cardioversion of $\mathrm{AF}$ using the methods developed in the present study, may further elucidate the significance of the excitable period for termination of $\mathrm{AF}$.

\section{Limitations}

In the present study epicardial mapping was used to determine $\mathrm{RP}_{\mathrm{AF}}$. Since no endocardial recordings were made, the three-dimensional structure of the atrial wall, which might play a role in the activation during $\mathrm{AF}$, ${ }^{10}$ was not taken into account. Also, the study was not designed to determine differences in $A F C L$. RP $P_{A F}$ and $E P_{A F}$ at different atrial sites. Variation in atrial architecture and underlying geometric discontinuities may cause spatial variability in the RP and EP during AF. Future clinical studies measuring $\mathrm{RP}_{\mathrm{AF}}$ with the use of a catheter will be needed to elucidate differences between RA and LA. Another limitation is that measurements of $\mathrm{RP}_{A}$ were not compared with monophasic action potential recordings. Therefore it remains unknown whether the $\mathrm{EP}_{\mathrm{AF}}$ is due to a diastolic interval between the successive action potentials during fibrillation. Since in the present study $\mathrm{RP}_{\mathrm{AF}}$ was measured by chronically implanted epicardial electrodes. clinical application of these methods must await validation using multipolar endocardial catheters. 
Table 1. RP, values obtained by different Methods.

\begin{tabular}{|c|c|c|c|c|c|c|c|}
\hline \multirow[t]{2}{*}{ Goal } & \multirow[t]{2}{*}{ Sitc } & \multirow[t]{2}{*}{$\begin{array}{l}\mathrm{AFCl} \\
\text { (median) }\end{array}$} & \multicolumn{5}{|c|}{$\begin{array}{c}\text { Refractory Period during AF } \\
\text { (ms) }\end{array}$} \\
\hline & & & Mapping & Entrainment & $\begin{array}{l}\text { Synchronized } \\
\text { Stimuli }\end{array}$ & $\begin{array}{l}\text { Fixed-Rale } \\
\text { Pacing }\end{array}$ & p5AFCL. \\
\hline 1 & $\mathrm{RA}$ & 105 & 75 & . & 80 & - & 82 \\
\hline 2 & RA & 107 & 70 & - & 70 & - & 79 \\
\hline 3 & LA & 88 & 55 & - & 55 & - & 64 \\
\hline 4 & $\mathrm{RA}$ & 88 & 65 & - & 65 & - & 70 \\
\hline 5 & LA & 93 & 70 & - & 70 & . & 74 \\
\hline 6 & LA & 86 & 65 & 72 & 65 & 68 & 69 \\
\hline 7 & $\mathrm{RA}$ & 90 & 70 & 66 & 70 & 58 & 72 \\
\hline 8 & RA & 127 & 95 & 100 & 100 & 98 & 104 \\
\hline$\varphi$ & LA & 103 & 75 & 74 & 70 & 68 & 88 \\
\hline 10 & RA & 113 & 80 & 90 & 75 & 83 & 85 \\
\hline 11 & RA & 80 & 50 & 58 & 50 & 53 & 64 \\
\hline Mean & & 98 & $70(73)$ & (77) & 70 & (71) & 77 \\
\hline SD & & 14 & $12(15)$ & $(17)$ & 13 & $(17)$ & 12 \\
\hline $\mathrm{R} 2$ & & & & $0.88 *$ & $0.94^{*}$ & $0.84 *$ & $0.90^{*}$ \\
\hline
\end{tabular}

Numbers between brackets indicate mean and standard deviation of goats $6-11:{ }^{*} p<0.01$.

R2. correlation of the RPAF measured by the different techniques compared to mapping. 
Table 1. Comparison of Different Techniques to measure the RP

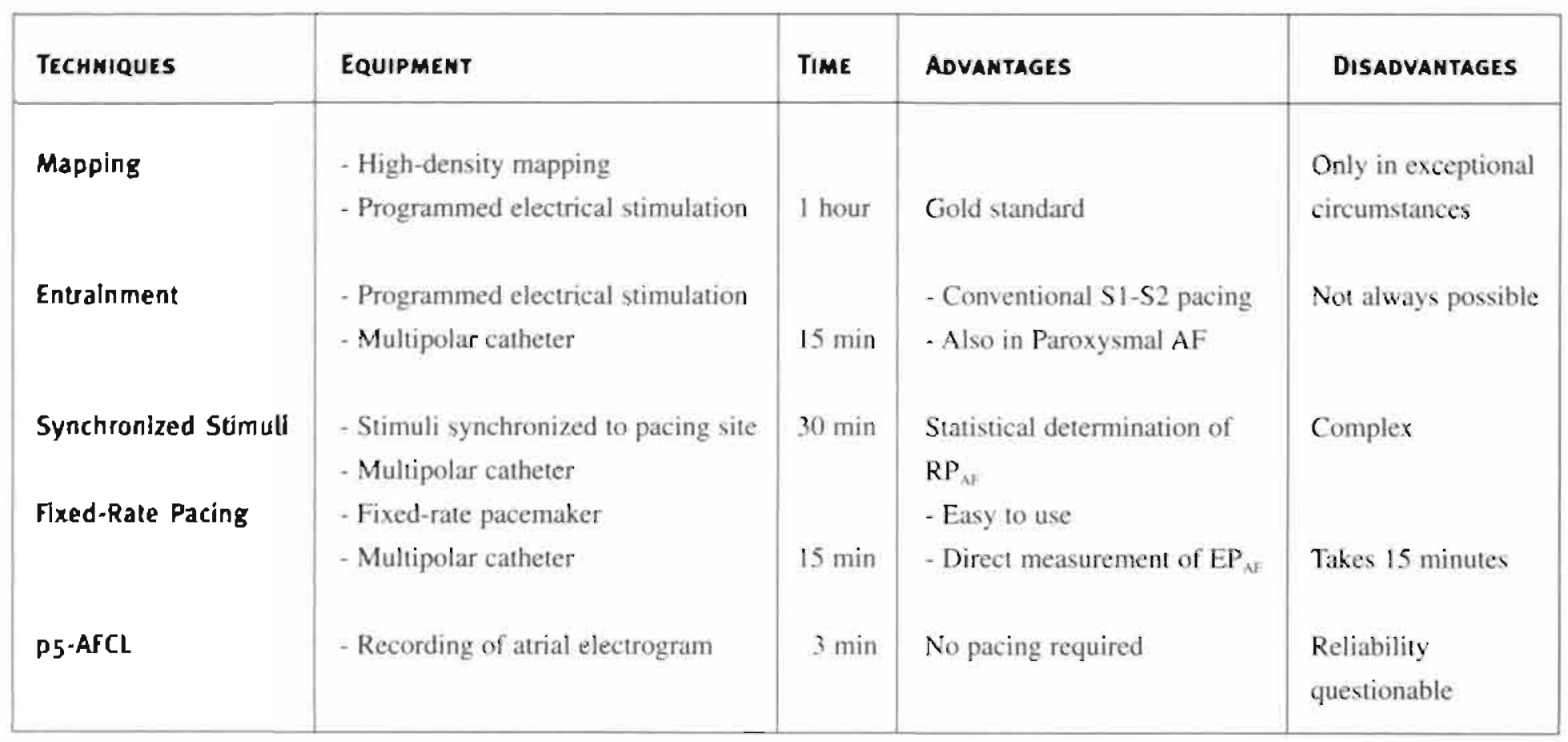




\section{References}

I. Allessie MA, Konings KTS, Kirchof CJHJ, et al. Electrophysiologic mechanisms of perpetuation of atrial fibrillation. Am J Cardiol, 1996:77:10A-23A.

2. Wijffels MCEF. Dorland R. Mast F, et al. Widening of the excitable gap during pharmacological cardioversion of atrial fibrillation in the goat. The effects of cibenzoline, hydroquinidine, flecainide and $d$-sotalol. Circulation, 2000:102:260-267.

3. Franz MR. The role of monophasic action potential recording in atrial fibrillation. In: Olsson SB. Allessie MA. Campbell RW, eds. Atrial fibrillation: mechanisms and therapeutic strategies. Armonk. NY: Futura publishing Co Inc. 1994:109-125.

4. Stambler BS, Wood MA, Ellenbogen KA. Antiarrhythmic actions of intravenous ibutilide compared with procainamide during human atrial flutter and fibrillation. Electrophysiological determinants of enhanced conversion efficacy. Cinculation. 1997;96:4298-4306.

5. Shinagawa $\mathrm{K}$, Mitamura $\mathrm{H}$, Takeshita $\mathrm{A}$, et al. Determination of nefractory periods and conduction velocity during atrial fibrillation using atrial capture in dogs: Direct assessment of the wavelength and its modulation by a sodium channel blocker pilsicainide.JACC, 2000:35:246-253.

6. Wijffels MCEF, Kirchof CJHJ. Dorland R, et al. Atrial fibrillation begets atrial fibrillation: A study in awake chronically instrumented goats. Circulation, 1995:92:1954-1968.

7. Kirchof CJHJ. Chorro F. Scheffer GJ, et al. Regional entrainment of atrial fibrillation studied by high-resolution mapping in open-chest dogs. Circulation. 1993:88:736-749.

8. Spach MS, Dolber PC, Heidlage JF. Interaction of inhomogeneities of repolarization with anisotropic propagation in dog atria. A mechanism for both preventing and initiating reentry. Circ Res, 1989;65:1612-1631.

9. Davidenko JM. Delmar M, Beaumont J, et al. Electrotonic inhibition and active facilitation of excitability in ventricular muscle. J Cardiovasc Electrophysiol, 1994;5:945-960.

10. Gray RA. Pertsov AM, Jalife J. Incomplete reentry and epicardial breakthrough patterns during atrial fibrillation in the sheep heart. Circulation. 1996:94:2649-2661.

11. Daoud EG, Pariseau B. Niebauer M, et al. Response to type 1 atrial fibrillation to atrial pacing in humans. Circulation, 1996:94:1036-1040.

12. Pandozi C, Bianconi L, Villani M, et al. Local capture by atrial pacing in spontaneous chronic atrial fibrillation. Cinculation, 1997:95:2416-2422.

13. Capucci A. Ravelli F. Nollo G. et al. Capture window in human atrial fibrillation. Evidence of an excitable gap. J Cardiovasc Electrophysiol, 1999:10:319-327.

14. Allessie MA. Bonke FIM. Schopman FJG. Circus movement in rabbit atrial muscle as a mechanism of tachycardia. III. The "leading circle" concept: a new model of circus movement in cardiac tissue without the involvement of an anatomical obstacle. Circ Res, 1977:41:9-18.

15. Spach MS, Miller WT, Dolber PC, et al. The functional role of structural complexities in the propagation of depolarization in the atrium of the dog. Cardiac conduction disturbances due to discontinuities of effective axial resistivity. Circ Res. 1982:50:175-191.

16. Fast VG, Kleber AG. Role of wavefront curvature in propagation of cardiac impulse. Cardiovasc Rex. 1997:33:258-271. 
134 | Chapter 7

17. Girouard SD. Pastore JM, Laurita KR, et al. Optical mapping in a new guinea pig model of ventricular tachycardia reveals mechanisms for multiple wavelengths in a single reentrant circuit. Circulation, 1996;93:603-113.

18. Danse P, Garrat C, Mast F, et al. Preferential depression of conduction around a pivot point in rabbit ventricular myocardium by potassium and flecainide. J Cardiovasc Electrophysiol, 2000;11:262-273.

19. Davidenko JM, Pertsov AV, Salomonsz R, et al. Stationary and drifting spiral waves of excitation in isolated cardiac muscle. Nature, 1992:355:349-351.

20. Ikeda T. Uchida T. Hough D. et al. Mechanism of spontaneous termination of functional reentry in isolated canine right atrium. Evidence for the presence of an excitable but nonexcited core. Circulation, 1996:94:1962-1973. 
Chapter 8

\section{General Discussion}

New Perspectives for Atrial Fibrillation. 


\section{Introduction}

In recent years the interest in $\mathrm{AF}$ has increased explosively. One explanation might be that the successful treatment of other arrhythmias has shifted the attention of cardiologists to the remaining challenges in arrhythmia management. Also an increased awareness of the considerable morbidity and mortality associated with AF has caused a more aggressive attitude towards attempts to restore normal sinus rhythm (rhythm versus rate control). ${ }^{1.5}$ Finally, the discovery that 'AF begets AF' has emphasized that accepting atrial fibrillation to persist, may lead to irreversible atrial remodeling and a progressive inability to treat the arrhythmia. ${ }^{6+}$ These considerations have boosted the development of both pharmacological and non-pharmacological therapies for treatment of atrial fibrillation." Current non-pharmacological treatments of AF encompass atrial surgery, linear and focal RF ablation. single and dual site preventive pacing, and the implantable atrial defibrillator. However, despite all these efforts, present-day treatment of AF can still be characterized as 'doing our best without knowing what is wrong'. To develop a more effective strategy for treatment of AF, one needs to know the underlying pathophysiological mechanisms in a given individual patient. ${ }^{n}$ In this respect, one has to realize that the diagnosis of atrial fibrillation is merely a description of a certain electrocardiographic pattern which can be generated by different pathophysiological mechanisms.

\section{Triggers, Initiators and Perpetuators}

Three different 'players' are involved in the electropathology of atrial fibrillation: triggers, initiators and perpetuators (Fig. 1). Atrial fibrillation can be triggered by single premature stimuli originating from the crista terminalis, ostium of the coronary sinus, interatrial septum and atrial free wall. ${ }^{212}$ Also other onset-mechanisms like multiple premature beats, focal atrial tachycardia, atrial flutter and AV nodal tachycardia can start AF.

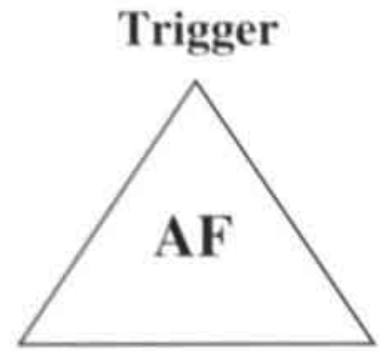

Figure 1. The pathophvsiological riad of AF The "players" imwlied in the electropathology of $A F$ include miesers that elicit the arrhyth. mia and a sutstrute for initiation and perpetaation of intru-atrial erentn. 
Recent pioneering work by Haissaguerre et al. showed that in patients with frequent paroxysms of AF the vast majority of AF episodes $(95 \%)$ were due to ectopic foci in the wall of the puimonary veins." This was confirmed and strengthened by other investigators and led to the introduction of radiofrequency catheter ablation of these pulmonary vein foci. ${ }^{152}$ However, if one believes that atrial fibrillation is due to a reentrant mechanism, apart from the trigger also a substrate for initiation of atrial reentry is required (initiator). Initiators are thought to consist of areas of prolonged atrial refractoriness, depressed or delayed conduction and/or a short atrial wavelength. ${ }^{\mathrm{s}} \mathrm{s}$ Also factors such as local wavefront curvature and sink-source mismatch may be relevant for initiation of $\mathrm{AF}^{\times *}$ The area where atrial reentry occurs and $\mathrm{AF}$ is actually initiated may be located remote from the trigger site. In normal atria AF is short-lasting and is expected to terminate spontaneously within minutes. A variety of different abnormalities in the atria may act as perpetuators. " Persistence of AF can result from atrial dilatation, electrical contractile and structural remodeling. pro-fibrillatory effects of drugs and pathoanatomical changes like apoptosis, fibrosis and fatty degeneration. ${ }^{-1}$ 13.4 Knowledge about how AF is initiated and perpetuated in a single patient could help in chosing between the different treatment options. It is quite feasable that different underlying mechanisms of AF require different therapies (Fig.2). Such a differential diagnosis of the underlying pathophysiological mechanisms (trigger-initiator-perpetuator) would imply a clinical history, echocardiography, Holter monitoring, autonomic and invasive electrophysiological testing. Although in many cases the underlying pathophysiology will be multifactorial, in some patients a dominant pathophysiological mechanism might be involved. Presently available catheters and sophisticated mapping systems allow detailed analysis of the atrial electrophysiological substrate of AF, which might be useful to choose the best treatment in individual cases."

\section{Trigger Initiator Perpetuator}
AAR Drugs
$+$
Atrial Surgery
Focal Ablation
Linear Ablation
+t+
Preventive Pacing

Figure 2. Different underlying mechanisms of AF require different treatment strategies, In patients with "trigkered" AF. focal ablation of premature beats or discharging foci may eradicate atrial arrhythmia. Supprestion of atrial arrhythmia may also be accomplished by atrial-based preventive pacing or antiarrhythmic drugs. In patients with a manifest "initiator", ablation or pacing at the culprit area of critical conduction might prevent recurrence of AF. In patients with a marked substrate for self-perpetuation of $A F$. reducing atrial size by atrial surgery or linear ablation mav help to terminate and provent $A F$. 


\section{The Initiatior as Target for Non Pharmacological Treatment of AF}

Most cases of AF are self-perpetuating and after a short time become independent of the trigger site. It is widely accepted that atrial fibrillation is maintained by single or multiple reentrant wavefronts. In a caprine model of AF we recently evaluated the substrate for initiation of atrial reentry by single premature beats. ${ }^{*}$ Premature beats and initiation of $\mathrm{AF}$ were found to be associated with critical conduction delay at Bachmann's bundle. Also during rapid left atrial pacing, AF initiated remote from the rapidly firing focus, ${ }^{\text {n }}$ The preferential conduction delay and fragmented low-voltage potentials recorded at the mid-portion of Bachmann's bundle can result from non-uniform anisotropy, slow discontinuous conduction, longitudinal dissociation or conduction block. ${ }^{\star 5 \times 19}$ In the goat. critical conduction along Bachmann's bundle might be explained by the considerably longer refractory period measured at the mid-portion of BB. There is evidence that also in human atria the inter-atrial septum plays a role in the genesis of AF. In several studies it was found to have a longer atrial refractory period and be an area of preferential conduction delay of premature beats. ${ }^{21,20,0+1}$ In patients with rheumatic heart disease the earliest activity during induced AF was located near the inter-atrial septum (ostium of the coronary sinus). ${ }^{42}$ It seems quite likely that due to ageing, atrial dilatation, fibrosis, etc... also other areas than the inter-atrial septum may become an 'initiator' of $\mathrm{AF}^{+3.4}$ Localisation of areas of critical conduction delay and fragmentation and site(s) of earliest activation during onset of AF might provide a new target for modification of the substrate of AF by RF ablation in patients. Because of their anisotropic properties and strategic position. Bachmann's bundle and the inter-atrial septum are an attractive target for radiofrequency ablation. ${ }^{450}$ In a canine model of sterile pericarditis. Kumagai et al. showed that ablation of $\mathrm{BB}$ successfully terminated and prevented $\mathrm{AF}^{\text {ts }}$ In another canine study Tondo et al. showed that ablation of the mid-part of the inter-atrial septum significantly reduced the likelihood of initiation of $\mathrm{AF}^{*}{ }^{*}$ In the caprine model of AF we showed that the site of initiation of AF might also be an optimal site for preventive pacing. Pacing at the mid-portion of Bachmann's bundle significantly shortened the window of inducibility of AF by single premature beats, originating either from the right or the left atrium." These experimental findings suggest that Bachmann's bundle (area of critical conduction) may be an effective pacing site for preventive pacing. In patients with recurrent AF. Padeletti et al. showed that atrial septal pacing was successful in reducing the recurrences of AF $(65 \%$ in sinus rhythm after 17 months). 's Similarly, Bailin et al. showed that in patients with paroxysmal AF, pacing at Bachmann's bundle had an incremental benefit compared to right atrial pacing. ${ }^{16}$ 


\section{Need for New Antiarrhythmic Drugs}

Despite the success of non-pharmacological approaches, drug therapy will remain the mainstay in the management of atrial fibrillation in the general population." macological approaches, although eagerly welcomed by cardiac arrhythmologists and industry, are expensive, time-consuming and limited to a small subset of the general population." In Fig. 3 we plotted the estimated number of patients with atrial fibrillation in Belgium, according to age-related prevalence of $\mathrm{AF}^{\circ}$. The total number of people with AF is estimated to be 121.000 . Of this population, $85 \%$ or actually 102.000 patients are older than 65 years. In these elderly, the underlying pathophysiology of AF is expected to be multifactorial and AF is likely to recur or persist even after treatment of the initial "culprit" mechanism. Most likely in these patients antiarrhythmic drugs will be needed in an effort to attain the goal of arrhythmia management (reduction of AF burden and prevention of symptoms, cerebral embolism and aggravation of heart failure).

Population with $\mathrm{AF}$ $\vdash$ Non-pharmacologic -1

\section{Pharmacological}

Treatment

25.000

20.000

15.000

10.000

5.000

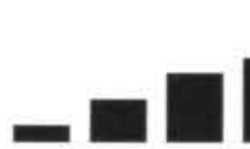

1

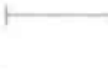

Treatinent

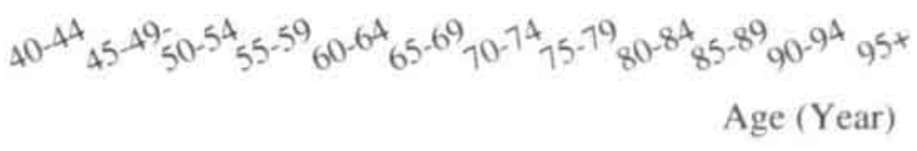

\footnotetext{
Figure 3. Age-related distribution of patients with AF in Belgium. The vast majority of people with AF (85\%) are older than 65 years. In these patients pharmacological treatment will be needed in an effort to attain the goal of arrhythmia management. Beyond finding effective treatment in patients with Af (secondary prevention) it should be possible to present $A F$ in high-risk patients (primary prevention).
} 
Until now, antiarrhythmic drugs have been limited and far from ideal.' In the search for the ideal drug the aim should be for superior efficacy, low risk of proarrhythmia, few adverse events, no serious interactions and appropriate pharmacokinetics. New drugs like ibutilide, dofetilide and azimilide might offer additional benefit in cardioverting AF." However, better ion channel-targeted drugs aimed at suppression of atrial foci or prolongation of atrial refractoriness at slow heart rates may become equally important. Also it must be better understood how antiarrhythmic drugs terminate AF (widening of the excitable gap) and why they ultimately loose their efficacy for cardioversion of AF":-s" The progressive inability of drugs to terminate AF might be due to an increase in stability of the arrhythmia. $"$ and/or a progressive loss of efficacy of antiarrhythmic drugs by electrical remodeling." Also it remains to be seen whether antiarrhythmic drugs restoring the shortened action potential in remodeled atria (such as $\mathrm{I}_{\mathrm{Ca}} \mathrm{L}$ agonists) are able to promote restoration and maintenance of sinus rhythm in patients with atrial fibrillation." ${ }^{4-45}$

\section{Primary Prevention of AF}

Since atrial fibrillation is widespread and associated with significant morbidity and mortality, prevention seems essential in managing AF (Fig.3). Beyond finding effective pharmacological and non-pharmacological treatments for patients with atrial fibrillation (secondary prevention), it should be possible to prevent the arrhythmia in high-risk patients (primary prevention). To focus on means for prevention necessitates considering both clinical and pathophysiological factors. The Cardiovascular Health Study and the Framingham study have shown that some of the clinical risk factors for AF (e.g. systolic blood pressure. blood glucose and valvular heart disease) are subject to control. ${ }^{2}$ The most common clinical settings for AF are hypertension and congestive heart failure." Identification and aggressive management of these clinical risk factors may play an important part in the primary prevention of AF. For instance, administration of angiotensin-converting enzyme inhibitors is expected to reduce the incidence of atrial fibrillation in patients with congestive heart failure. ${ }^{\text {so }}$ Primary prevention strategies should also focus on the prevention of the electropathological factors of AF (trigger. initiator and perpetuator). ${ }^{30}$ The inter-atrial septum (initiator) seems an attractive target for radiofrequency ablation in high-risk patients. Also the development of a substrate for self-perpetuation of AF, the point of no return. must be forestalled. The latter may be accomplished by prevention of electrical remodeling, by either early cardioversion of AF (implantable atrial defibrillator) or administration of antiarthythmic drugs (calcium blockade). ${ }^{n+1}$ On the other hand, therapies aimed at the prevention of fibrosis, atrial distension or age-related structural and electrical changes may offer incremental benefit. 
Interest in atrial fibrillation is growing at an impressive rate and tools are becoming available to study the electrophysiologic mechanisms responsible for human atrial fibrillation. These tools could be the basis for the development of better pharmacologic and nonpharmacologic ways for primary and secondary prevention of atrial fibrillation. Patients already benefit substantially from these efforts. However, treatment of AF will remain a challenge and it seems likely that a few years more will be required before the "vicious circle" of AF is cut short." 


\section{References}

1. Benjamin E, Levy D, Vazíri SM, D'Agostino RB, Belanger AJ. Wolf PA. Independent risk factors for atrial fibrillation in a population-based cohort: the Framingham Heart study. $J$ Am Med IAssoc, 1994:271:840-844.

2. Benjamin E. Wolf PA, D'Agostino RB. Silbershatz H, Kannel WB. Levy D. Impact of atrial fibrillation on the risk of death: the Framingham Heart study. Circulation, 1998;98: 946-952.

3. Braunwald E. Shattuck lecture-cardiovascular medicine at the turn of the millenium: triumphs, concerns and opportunities. N Engl J Med, 1997:337:1360-1369.

4. Scheinman MM. Atrial fibrillation and congestive heart failure: the intersection of two common diseases (editorial). Circulation, 1998:98:941-942.

5. Wolf PA, Abbott RD, Kannel WB. Atrial fibrillation as an independent risk factor for stroke: the Framingham study. Stroke. 1991:22:983-988.

6. Wijffels MCEF, Kirchoff CJHJ. Dorland R, et al. Atrial fibrillation begets atrial fibrillation: a study in awake chronically instrumented goats. Circulation, 1995:92:1954-1968.

7. Garratt CJ. Duytschaever M, Killian M, et al. Repetitive electrical remodeling by paroxysms of atriat fibrillation in the goat: no cumulative effect on inducibility or stability of atrial fibrillation. J Candiovase Electrophysiol, 1999;10:1101-1108.

8. Prystowski EN, Benson DW. Fuster V. et al. Management of patients with atrial fibrillation. Cinculation. 1996:93:1262-1277.

9. Hohnloser SH. Yi-Gang Li. Drug treatment of atrial fibrillation: what have we learned? Curnent Opinion Candiol, 1997:12:24-32.

10. Cardiac Arrhythmia Suppression Trial (CAST) Investigators. Preliminary report: Effect of encainide and flecainide on mortaility in a randomized trial of arrhythmia suppression after myocardial infarction. $N$ Engl J Med, 1989:321:406-412.

11. Flaker GC, Blackshear JL, McBride R, Kronmal RA, Halperin JL, Hart RG. Antiarthythmic drug therapy and cardiac mortality in atrial fibrillation. The Stroke Prevention in Atrial Fibrillation Investigators. I Am Coll Cardiol, 1992;20:527-532.

12. Camm AJ. Clinical differences between the newer antiarrhythmic agents. Eunopace Supplements. 2000, $1: \mathrm{Cl} 16 \cdot \mathrm{C} 22$

13. Haissaguerre M, Jais P. Shah DC, et al. Spontaneous initiation of atrial fibrillation by ectopic beats originating in the pulmonary veins. $N$ Eng $J$ Med, 1998;339:659-666.

14. Pappone C, Oreto G. Rosiano S. et al. Atrial electroanatomic remodeling after circumferential radiofrequency pulmonary vein ablation: efficacy of an anatomic approach in a lange cohor of patients with atrial fibrillation. Cinculation, 2001:104:2539-2544.

15. Padeletti L. Porciani M. Michelucci et al. Prevention of shon term reversible chronic atrial fibrillation by permanent pacing at the triangle of Koch. J Inten. Cand Electmphysiol, 2000;4-575-583.

16. Bailin SJ. Adler SW, Gudici MC. Prevention of chronic atrial fibrillation by pacing in the region of Bachmann's bundle: results of a multicenter randomized trial. J Candienase Electrophys. 2001. 12: 912.917.

17. Wellens HJ. Lau CP. Luderitz B. Akhtar M. Waldo AL. Camm AJ. Timmermans C. Tse HF, Jung 
W, Jordaens L. Ayers G, for the METRIX Investigators. Atrioverter: an implantable device for the treatment of atrial fibrillation. Cinculation. 1998:98:1651-1656.

18. Cox J, Boineau J, Schuessler R, et al. A review of surgery for atrial fibrillation. I Candiowasc Electrophysiol. 1991;2:541-561.

19. Scheinman M. Morady F. Nonpharmacological approaches to atrial fibrillation. Cinculation, 2001;103:2120-2125.

20. Allessie MA. Boyden PA. Camm AJ, et al. Pathophysiology and prevention of atrial fibrillation. Circulation, 200I:103:769-777.

21. Hoffmann E, Janko $S$. Steinbeck $G$ et al, for the AFT study group. Onset scenarios of paroxysmal atrial fibrillation using new diagnostic pacemaker functions (abstract). Pacing Clin Electmphysiol, 2000, 23(partll): 656 .

22. Waktare J, Hnatkova K. Sopher S, et al. The role of atrial ectopics in initiating paroxysmal atrial fibrillation. Eur Heart J, 2001:22:333-339.

23. Chen SA. Hsieh MH. Tai TC et al. Initiation of atrial fibrillation by ectopic beats originating from the pulmonary veins: electophysiological characteristics, pharmacological responses, and effects of radiofrequency ablation. Circulation. 1999:100:1879-1886.

24. Hassaguerre M. Jais P, Shah DC, et al. Catheter ablation of chronic atrial fibrillation targeting the reinitiating triggers. J Cardiovasc Electrophysiol, 2000:11(1):2-10.

25. Jais P, Haissaguerre M. Shah DC, Chouairi S, Gencel L. Hocini M, Clementy J. A focal source of atrial fibrillation treated by discrete radiofrequency ablation. Circulation. 1997:95: 572-576.

26. Wang J, Liu L. Feng J, et al. Regional and functional factors determining induction and maintenance of atrial fibrillation in dogs. Am J Physiol. 1996:273:H148-HI58.

27. Fareh S. Villemaire C. Nattel S. Importance of refractoriness heterogeneity in the enhanced vulnerability to atrial fibrillation induction caused by tachycardia-induced atrial electrical remodeling. Cinculation, 1998:98:2202-2209.

28. Cosio FG, Palacios J, Vidal JM, et al. Electrophysiologic studies in atrial fibrillation: slow conduc. tion of premature impulses: a possible manifestation of the background for reentry. Am I Cardiol, 1983: 51:122-128.

29. Fast VG, Kleber AG. Role of wavefront curvature in propagation of cardiac impulse. Cardiovasc Res. 1997:33:258-271.

30. Danse $P$, Garratt $C$. Mast F, et al. Preferential depression of conduction around a pivot point in rabbit ventricular myocardium by potassium and flecainide. I Cardiovasc Electrophysiol, 2000:11:262-273.

31. Allessie MA, Konings KTS. Kirchof CJHJ, et al. Electrophysiologic mechanisms of perpetuation of atrial fibrillation. Am J Cardiol, 1996:77:10A-23A.

32. Ausma J. Wijffels M, van Eys G. et al. Dedifferentiation of atrial cardiomyocytes as a result of chronic atrial fibrillation. Am J Pathol. 1997:151:985-997.

33. Duytschaever MF, Allessie MA. Pro-fibrillatory Effects of Verapamil but Not of Digoxin in a Goat Model of Atrial Fibrillation. J Cardiovasc Electmphysiol. 2000, 11:1375-1385.

34. Duytschaever MF. Danse P. Allessie MA. Supervulnerable phase immediately after termination of atrial fibrillation, J Cardiovasc Electrophysiol, 2002, 13:267-275.

35. Duytschaever MF, Mast F, Killian M, Blaauw Y, et al. Methods to Determine the Refractory Period 
and Excitable Gap during Atrial Fibrillation. An Experimental Study in the Chronically Instrumented Goat. Circulation. 2001. 104: 957-962.

36. Duytschaever MF, Danse P. Eysbouts S, et al. The Window of Inducibility of Atrial Fibrillation is Determined by Critical Conduction Block within Bachmann's Bundle. Pacing Clin Electrophysiol, 1999:22: 880 (abstract).

37. Duytschaever MF. Allessic MA. Mechanisms of initiation of AF: implications for non-pharmacological treatment. Candiology International, 2002.

38. Ogawa S. Dreifus L. Osmick M. Longitudinal dissociation of Bachmann's bundie as a mechanism of paroxysmal supraventricular tachycardia, Am J Cardiol, 1977:40:915-922.

39. Dolber P, Spach M. Structure of canine Bachmann's bundle related to propagation of excitation. Am J Physiol, 1989:257:H1446-H1457.

40. Papageorgiou P, Monahan K. Boyle NG et al. Site-dependent intra-atrial conduction delay: relationship to initiation of atrial fibrillation. Circulation. 1996:94:384-389.

41. Papageorgiou P, Anselme F, Kirchoff CJHJ et al. Coronary sinus pacing prevents induction of atrial fibrillation. Circulation. 1997:96:1893-1898.

42. Nair M, Shah P, Batra R. Kumar M. Mohan J, Kaul U. Arora R. Chronic atrial fibrillation in patients with rheumatic heart disease. Mapping and radiofrequency ablation of flutter circuits seen at initiation after cardioversion. Circulation, 2001:104:802-809.

43. Davies MJ. Pomerance A. Pathology of atrial fibrillation in man. Br Heart J. 1972:34:520-525.

44. Thijssen VL. Ausma J. Liu GS et al. Structural changes of atrial myocardium during chronic atrial fibrillation. Candiovase Pathol, 2000;9:17-28.

45. Kumagai K. Uno K, Khrestian et al. Single site radiofrequency catheter ablation of atrial fibrillation: studies guided by simultaneous multisite mapping in the canine sterile pericarditis model. J Am Coll Cardiol, 2000:36:917-923,

46. Tondo C, Scherlag BJ, Otomo K, et al. Critical atrial site for ablation of pacing-induced atrial fibrillation in the normal dog heart. J Candiovasc Electrophysiol. 1997:8:1255-1265.

47. Duytschaever MF. Danse P. Allessie MA. Is there an optimal atrial pacing site to prevent atrial fibrillation? Pacing Clin Electrophysiol, 1999; 22:777 (abstract).

48. Camm AJ. Clinical differences between the newer antiarthythmic agents. Europace Supplements, 2000:1:C16-C22.

49. Fuster V. Ryden L. ACC/AHAVESC Guidelines for the management of patients with atrial fibrillation: executive summary. $J$ Am Coll Cardiol, 2001:38:1231-1265.

50. Feinberg WM. Blackshear JL. Laupacis A, et al. Prevalence, age distribution and gender of patients with atrial fibrillation: analysis and implications. Arch Intern Med. 1995:155:469-473.

51. Garratt C, Duytschaever MF, Allessie MA. Effect of atrial electrical Remodeling on pharmacological cardioversion of atrial fibrillation: a study in the chronically instrumented goat model. Candiovasc Research, 2002 (submitted).

52. Wijffels MCEF, Dorland R, Mast F, et al. Widening of the excitable gap during pharmacological cardioversion of atrial fibrillation in the goat. The effects of cibenzoline, hydroquinidine, flecainide and d-sotalol. Circulation. 2000;102:260-267.

53. Duytschaever MF. Wijffels M. Allessie MA. Effect of AF-induced electrical remodeling on class Ic and III drug action: loss of class II effect by atrial fibrillation. Pucing Clin Electrophysiol, 2000:23:564. 
54. Yue L. Feng J. Gaspo R, et al. lonic remodeling underlying action potential changes in a canine model of atrial fibrillation. Circ Res, 1997;81:512-525.

55. Van Wagoner DRV, Pond AL. McCarthy PM, et al.. Outward K+ current densities and Kv1.5 expression are reduced in chronic human atrial fibrillation. Cir Res, 1997:80:772-781.

56. Van Noord T. Van Gelder I. Tieleman R. et al. The verapamil versus digoxin cartioversion trial: a randomized study on the role of calcium lowering for maintenance of sinus thythm after cardioversion of persistent atrial fibrillation. J Candiovass Electmphysiol, 2001:12:766-769.

57. Scheimman MM. Atrial fibriliation and congestive heart failure: the intersection of two common diseases (editorial). Circulation, 1998;98:941-942.

58. Pedersen OD, Bagger $\mathrm{H}$. Kober L, et al. Trandolapril reduces the incidence of atrial fibrillation after acute myocandial infarction in patients with left ventricular dysfunction. Circulation, 1999; 100:376-380.

59. Nakashima H. Kumagai $\mathrm{K}$, Urata $\mathrm{H}$, et al. Angiotensin II antagonist prevents electrical remodeling in atrial fibrillation. Cinculation, 2000:101:2612-2617.

60. Danshi Li, Melnyk P. Feng J, et al. Effects of experimental heart failure on atrial cellular and ionic electrophysiology. Circulation, 2000:101:2631-2638.

61. Timmermans C. Levy S. Ayers GM et al. Spontaneous episodes of atrial fibrillation after implan. tation of the Metrix Atrioverter: observations on treated and nontreated episodes. I Am Coll Cardiol. 2000:35:1428-1433.

62. Tieleman RG, De Langen CDJ, Van Gelder IC, et al, Verapamil reduces tachycardia-induced electrical remodeling of the atria. Circulation, 1997:95:1945-1953.

63. Lee SH, Yu WC. Cheng JJ, et al. Effect of verapamil on long-term tachycardia-induced atrial electrical remodeling. Circulation, 2000;101:200-206.

64. Wellens HJJ. Atrial fibrillation - the last big hurdle in treating supraventricular tachycardia. Circulation. 1994:331:944-945.

65. Allessie MA. Atrial electrophysiologic remodeling: another vicious circle? I Cardiovase Electrophysiol, 1998:9:1378-1393. 



\section{Summary}

In the present thesis, we studied in the caprine model of AF, the role of AF-induced electrical remodeling in the management of atrial fibrillation.

In Chapter 1 the background to the present study is given. In recent years the interest in AF has increased explosively. Especially the increased awareness of the considerable prevalence, morbidity and mortality associated with AF has shifted the attention of cardiologists to the oldest arrhythmia (atrial fibrillation: the oldest arrhythmia-the newest disease). The renewed interest in AF has boosted the development of both pharmacological and non-pharmacological therapies for treatment of atrial fibrillation. However, despite all these efforts, present-day treatment of AF can still be characterized as "doing our best without knowing what is wrong". To develop a more effective strategy for treatment of $\mathrm{AF}$, one needs to study the underlying pathophysiological mechanisms of AF. Or, as Thomas Lewis laconically suggested in 1902. "The notion of a patient continuing to live with an auricle incapable of contraction is a somewhat novel idea...it seems necessary to devote a little study to the condition. "

In Chapter 2 we described the cumulative effect of repeated paroxysms of AF on inducibility and stability of AF in the goat. Two days of sinus rhythm were found to be enough to recover completely from AF-induced electrical remodeling by 5 days of atrial fibrillation. Also we observed no cumulative effect of repeated 5 day paroxysms of AF on inducibility and stability. These findings highlight the importance of atrial refractoriness as a potential target for antiarrhythmic strategies aimed at inhibiting the self-perpetuation of $\mathrm{AF}$.

In Chapter 3 we studied the effect of AF-induced electrical remodeling on atrial vulnerability by single atrial premature beats. In the goat, 2 days of atrial fibrillation was associated with a marked widening of the window of inducibility of AF by single premature beats. Enhanced vulnerability in remodeled atria was due to a higher likelihood of reentry in the presence of critical conduction at Bachmann's bundle. These findings suggest that, during the first days of after cardioversion of human AF, both early and late premature beats can initiate early recurrences of $\mathrm{AF}$. In patients, measurement of the window of inducibility might be useful to predict likelihood of recurrence of AF and to evaluate the efficacy of new treatment strategies.

In Chapter 4 we described the transient changes in atrial electrophysiology immedi- 
ately after spontaneous termination of atrial fibrillation. In the goat, during the first 2 minutes of sinus rhythm after spontaneous termination of AF there was a transient decrease in both atrial refractory period and conduction velocity. In remodeled atria. the cumulative effect of electrical remodeling and this short-term changes created an ultra-short atrial wavelength after termination of AF. In patients, immediate re-initiation of AF (IRAF) can be explained by this transient supervulnerable phase. However for immediate re-initiation of $\mathrm{AF}$, the spontaneous occurrence of atrial triggers is at least as important as a vulnerable substrate for reentry.

In Chapter $\mathbf{5}$ we determined the effects of different atrial pacing sites on the inducibility of AF by both right and left single atrial premature beats. It was found that, in remodeled atria, preventive atrial pacing markedly could reduce the window of inducibility of AF by single premature beats. The optimal site for preventive pacing was found to be at Bachmann's bundle, close to the area of critical conduction delay. Also in patients, the inter-atrial septum (Bachmann's bundle) might play a critical role in the genesis of AF. Pacing at Bachmann's bundle might be optimal pacing to prevent AF by both right and left atrial premature beats. Multi-site pacing seems of limited additional value.

In Chapter 6 the effects of both digoxin and verapamil were evaluated on the duration and electrophysiological properties of paroxysmal atrial fibrillation. In the goat, verapamil but not digoxin exerted a direct pro-fibrillatory effect on paroxysmal $\mathrm{AF}$. Especially in remodeled atria, intravenous administration of verapamil converted paroxysmal into persistent $\mathrm{AF}$. This pro-fibrillatory effect of verapamil was due to shortening of atrial refractoriness at high AF rates (rate-dependent shortening of AERP). These findings suggest that in patients with paroxysmal AF, administration of verapamil might reduce the likelihood of spontaneous termination of the atrial arrhythmia. In contrast, digoxin is expected to reduce ventricular rate during AF without any effect on atrial electrophysiology during $\mathrm{AF}$.

In Chapter 7 we described five methods to determine the refractory and excitable period during chronic AF. During persistent AF with an AFCL of $98 \pm 14 \mathrm{~ms}$, the RPA determined by mapping of synchronized premature stimuli (gold standard) was $70 \pm 12 \mathrm{~ms}$. with an excitable period of $28 \pm 8 \mathrm{~ms}$. Although the indirect methods to measure $R P_{\text {N }}$ all correlated well with the gold standard, slow fixed-rate pacing seemed the most attractive technique because of the ease of acquiring the data and the clear graphic result. 
Finally, in the last chapter of this thesis (Chapter 8) the possible implications were discussed. To develop a more effective strategy for treatment of AF one needs to know the underlying pathophysiological mechanisms of AF. Three different "players" are involved in the electropathology of AF: triggers, initiators and perpetuators. Although in many cases the underlying pathophysiology will be multifactorial (e.g. elderly), in some patients a dominant pathophysiological mechanism might prevail. It is quite feasible that different underlying mechanisms of AF require different therapies (differential treatment of AF). 



\section{Nawoord}

Het werd me al duidelijk tijdens mijn eerste jaar opleiding inwendige geneeskunde. Ik zou "wetenschappelijk onderzoek" gaan doen. Het waarom is moeilijk uit te leggen, maar ik denk dat vooral het gevoel primeerde dat ik iets moest bewijzen. meer nog tegenover mezelf dan tegenover anderen. Sommige mensen noemen het ambitie.

Dus zei ik op een dag tegen Isabelle: "Belleke, ik zou voor een jaartje naar Maastricht kunnen, voor onderzoek in de electrofysiologie, ... het is een buitenkans", We woonden toen nog in de Patijntjestraat te Gent en waren pas een jaar getrouwd. Liefste Belle, je wist toen al beter en je vermoeden werd bevestigd toen ik uiteindelijk er nog drie jaar langer bleef voor het vervolledigen van een doctoraat. Steeds heb je me gesteund in mijn keuze, ook al was ik de godganse weken in Maastricht en liep ik ook in de weekends hoofdzakelijk te piekeren. Het was niet altijd even gemakkelijk voor jou, maar dankzij je zin voor realiteit en je enorme relativeringsvermogen, is het ons gelukt deze ommeweg te "overleven". Belleke, je mag er van op aan, ik blijf nu thuis en alle liefde en aandacht die je nog tegoed hebt. krijg je dubbel en dik terug. Het electrofysiologisch centrum te Maastricht, onder leiding van Professor Maurits Allessie, was een weldoordachte carrière keuze. Het betrof een groot experimenteel centrum, zeg maar het Mekka van de electrofysiologie van de lage landen. Maar al vlug werd het me duidelijk dat dit geen normaal laboratorium was. Het was vreemd dat ik, opgegroeid in een hiërarchisch feodaal stelsel, de "Professor" kon aanspreken met Maurits...ik deed het dan ook heel stil tussen twee kuchjes in. Beste Maurits, ik kan je niet genoeg bedanken voor de vele uren die we samen zaten, je enorme niveau van begeleiding en je creativiteit. Velen waren bang van je, tussen ons klikıe het altijd. Ook Thea wil ik van harte bedanken, want de vele uren te Waalren en Frankrijk zitten niet in het normale takenpakket van de vrouw van een promotor. Beste Maurits, ik denk dat jij een belangrijke invloed gehad hebt en zult hebben op mijn verdere leven. Dus als ik jou naam nu wat luider en duidelijker uitspreek is het enerzijds omdat ik zelfzekerder ben geworden maar anderzijds ook omdat ik heel fier ben dat ik je ken. Het thuisfront was minstens even belangrijk voor mij. Mijn familie heeft me altijd gesteund. Beste Moe, Va, Tine, Rudi, Hilde, Christof, Maarten, Caroline, Anneke, Koen, Filip, Isabelle, Mama en Pappa, voor jullie was het waarschijnlijk niet altijd even duidelijk waarom ik niet normaal mijn opleiding cardiologie kon afmaken. Het vertelt iets vlotter als je tegen nieuwsgierige mensen kan zeggen "hij zit in zijn laatste jaar opleiding cardiologie" eerder dan "we weten het niet goed, iets met geiten en fibrilleren". Vaak waren jullie evenzeer met mijn toekomst begaan als ikzelf. Maar ik mag je gerust stellen, ik sta nu in de kliniek. en er zijn weinig verschillen tussen de (electrofysiologie van de) geit en de mens. Deze laatste zin volledig in deze context weliswaar.

Gedurende een werkweek. reed ik twee keer per week op en af tussen Gent en Maastricht. In de vroege ochtend, sliep ik op verlaten parkings langsheen de autostra- 
de. In den beginne was het, als "kleine Belg" tussen de Nederlanders, niet altijd even eenvoudig. Maar vooral de laatste jaren heerste er op het werk een gezellige sfeer en drukte, Peter, Sabine, Frits, Jan, Frans, Jannie, Ullie, Cliff , Marcus, Shan, Paolo, Claire, Theo, Ruuth, Leo, Natascha, Olivier, Bodo, Maurits aan jullie allen bewaar ik de beste herinneringen. Peter en Sabine waren ervan bij het beginne bij. Met Peter besprak ik de toekomst in de cardiologie die steeds zover afleek omdat de grote hindernis van het proefschrift ons het zicht belemmerde. Bientje was onze troost, ze is verstanding en realistisch en ze zorgde voor onze gemoedsrust door gewoon zich zelf te blijven. Jan. speciaal voor jou nog een dankwoord, want zonder jou was dit gewoonweg niet gelukt en was er geen proefschrift.

Ondertussen werkte ik op woensdag op de afdeling ritmologie te Gent onder leiding van Professor Jordaens. Beste Luc - je werkt nu ook in Nederland dus de voornaam mag - jij bent het die me in de beginne gemotiveerd hebt naar Maastricht te gaan. Jij was de "trigger" en zoals je weet is dit een conditio sine qua voor elk permanent proces. $\mathrm{Na}$ je verhuis naar Rotterdam, verloren we elkaar uit het oog maar niet uit het hart. Ondertussen was ik nog steeds welkom op het $10^{\text {se }}$ in het UZ Gent, nu geleid door Rene Tavernier. Bedankt Rene, voor je realistische kijk op mijn onderzoekswerk en je rustige en secure manier van opleiding. Ook de anderen van het $10^{\text {te }}$ wil ik bedanken, Karlien, Thea, Veerle, Etienne, Bert en Rudy. Het gebeurt niet vaak dat je op éćn dienst, zoveel aangename en hulpvaardige mensen samen aantreft.

Ook mijn vrienden wil ik bedanken, want zoals de meeste weten draag ik ze allen hoog in het vaandel. Tijdens mijn doctoraatsjaren, brachten we de meeste tijd door aan Zee. bij Jeroen \& Isabelle en Bruno \& Sylvie. Vooral Peentje - tevens een collega doctorandus - wil ik bedanken. Ze heeft tot vervelens toe geluisterd naar verhalen betreffende mijn werk, maar ook en vooral als het eens niet over het werk ging, vond ik bij haar een luisterend oor. Ook Sylvie wil ik bedanken voor haar aanstekelijk enthousiasme en haar niet aflatende vraag of ik niets nieuws had uitgevonden die voorbij week. Hier sluit ik af. Wellicht heb ik er velen niet bedankt, maar het was dan ook een nawoord en geen dankwoord. Ik laat de geitjes, parkings, manuscripten en zenuwachtige congressen achter me en blijf nu lekker thuis, bij Belleke en Charles. 


\section{Curriculum Vitae}

31 december 1970 Geboren te Gent.

$1982-1988$

Latijn-Griekse Humaniora, St.-Barbara college Gent, Grote Onderscheiding.

1988-1995

Opleiding Geneeskunde, Rijksuniversiteit Gent, Grootste onderscheiding.

$1995-1996$

Opleiding Interne Geneeskunde.

1996-2000

Wetenschappelijk onderzoek, Fysiologie, CARIM. Rijksuniversiteit Limburg. 



\section{Publications}

\section{PAPERS}

Duytschaever MF. Haerynck F, Tavernier R, et al. Factors Influencing Long Term Persistence of Sinus Rhythm After a First Electrical Cardioversion for Atrial Fibrillation. Pacing Clin Electrophysiol, 1998;21 (II);284-287.

Garratt CJ, Duytschaever MF, Killian M, et al. Repetitive Electrical Remodeling by Paroxysms of Atrial Fibrillation in the Goat: No Cumulative Effect on Inducibility or Stability of Atrial Fibrillation. J Cardiovasc Electrophysiol, 1999:10:1101-1108.

Duytschaever MF, Allessie MA. Pro-fibrillatory Effects of Verapamil but Not of Digoxin in a Goat Model of Atrial Fibrillation. J Cardiovasc Electrophysiol, 2000, 11:1375-1385.

Van Loon G, Tavernier R, Duytschaever MF, et al. Pacing-induced Sustained Atrial Fibrillation in a Pony. Can J Vet Research, 2000;64:254-258.

Duytschaever MF. Mast F, Killian M et al. Methods to Determine the Refractory Period and Excitable Gap during Atrial Fibrillation. An Experimental Study in the Chronically Instrumented Goat. Circulation, 2001, 104: 957-962.

Duytschaever MF, Danse P, Allessie MA. The Supervulnerable Phase Immediately after Termination of AF, J Cardiovasc Electrophysiol, 2002, 13:267-275.

Duytschaever MF, Allessie MA. Mechanisms of Initiation of AF: Implications for Nonpharmacological Treatment. Cardiology International, 2002:S1-S6.

Garratt C, Duytschaever MF. Allessie MA. Effect of Atrial Electrical Remodeling on Pharmacological Cardioversion of Atrial Fibrillation: a Study in the Chronically Instrumented Goat Model. (submitted). 
Hobbs J, Duytschaever MF, Todd M, et al. Net effect of Profibrillatory and Antiremodeling Actions of Verapamil in the Conscious Goat Model of Atrial Fibrillation. (submitted).

Duytschaever MF. Danse P. Eijsbouts P, et al. Is there an Optimal Pacing Site to Prevent Atrial Fibrillation? An experimental study in the chronically instrumented goat. J Cardiovasc Electrophysiol, 2002;13:(december issue).

Duytschaever MF, Dierickx C. Tavernier R. Variable atrio-ventricular block during atrial flutter: what is the mechanism ? J Cardiovasc Electrophysiol, 2002:13:950-951.

Van Loon G. Duytschaever MF. Tavernier R, et al. An Equine Model of Chronic Atrial Fibrillation: Methodology. The Veterinary Journal, 2002;164:142-150. 


\section{ABSTRACTS}

Duytschaever MF, Danse P. Eysbouts S. Allessie MA. The Presence of a Supervulnerable Period Immediately after Conversion of Atrial Fibrillation. Pacing Clin Electrophysiol, 1999:22:707 (abstract).

Duytschaever MF. Danse P. Allessie MA. Is there an Optimal Atrial Pacing Site to Prevent Atrial Fibrillation? Pacing Clin Electrophysiol, 1999; 22:777 (abstract).

Danse P. Duytschaever MF. Kelderman P. Allessie MA. Mapping and Resel Characteristics of Anatomical Reentry in Healed Myocardial Infraction in the Rabbit. Pacing Clin Electrophysiol, 1999:22;834 (abstract).

Duytschaever MF. Danse P, Eysbouts S, et al. The Window of Inducibility of Atrial Fibrillation is Determined by Critical Conduction Block within Bachmann's Bundle, Pacing Clin Electrophysiol, 1999;22: 880 (abstract).

Duytschaever MF. Wijffels M. Allessie MA. Effect of AF-induced Electrical Remodeling on Class Ic and III drug action: Loss of Class III effect by Atrial Fibrillation. Pacing Clin Electrophysiol, 2000;23: 564 (abstract).

Duytschaever MF, Danse P, Allessie MA. Is there an Optimal Atrial Pacing Site to Prevent Atrial Fibrillation by Ectopic Beats Originating in the Left Atrium. Pacing Clin Electrophysiol, 2000:23: 708 (abstract).

Danse P, Duytschaever MF, Allessie M. Pleiomorphism of Reentrant Ventricular Tachycardia in Rabbit Hearts with a Healed Myocardial Infarction. Pacing Clin Electrophysiol. 2000:23: 728 (abstract).

Duytschaever MF, Danse P, Eijsbouts S, Allessie MA. Widening of the Window of Inducibility of Atrial Fibrillation by Electrical Remodeling. Pacing Clin Electrophysiol. 2000;23: 730 (abstract).

Ausma J, Duytschaever MF, Wijffels M, Borgers M, Allessie MA. Loss of efficacy of 
$15^{8} \mid$ Pubucanons

cardioversion by class Ic drugs after long term atrial fibrillation in the goat. Eur Heart J, 2000, 543 (abstract).

Ausma J, Duytschaever MF, Majidi M. Allessie MA. Increase in threshold for pharmacological cardioversion in the course of chronic AF in the goat. Pacing Clin Electrophysiol, 2001:24:599 (abstract). 

